\title{
Secularism, Assimilation and the Crisis of Multiculturalism
}

French Modernist Legacies

YOLANDE JANSEN

\section{A M S T.ER D A U.NIVERStTy PRESS}

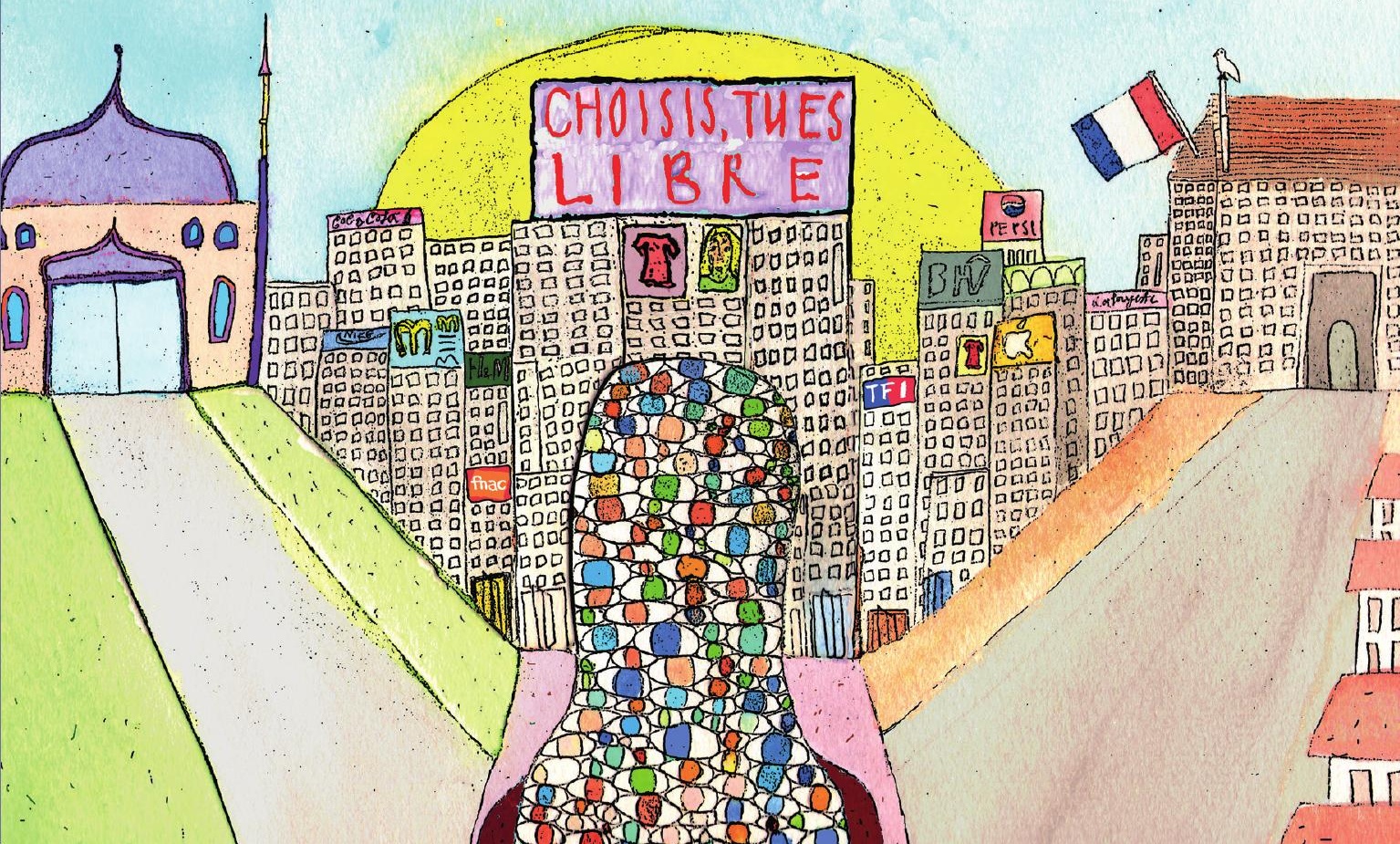


Secularism, Assimilation and the Crisis of Multiculturalism 


\section{IMISCOE}

International Migration, Integration and Social Cohesion in Europe

The IMIsCOE Research Network unites researchers from some 30 istitutes specialising in studies of international migration, integration and social cohesion in Europe. What began in 2004 as a Network of Excellence sponsored by the Sixth Framework Programme of the European Commission became, as of April 2009, an independent self-funding endeavour. IMISCOE promotes integrated, multidisciplinary and globally comparative research led by scholars from various branches of the economic and social sciences, the humanities and law. The network furthers existing studies and pioneers new scholarship on migration and migrant integration. Encouraging innovative lines of inquiry key to European policymaking and governance is also a priority.

The Imiscoe-Amsterdam University Press Series makes the network's findings and results available to researchers, policymakers and practitioners, the media and other interested stakeholders. High-quality manuscripts are evaluated by external peer reviews and the Imiscoe Editorial Committee. The committee comprises the following members:

Tiziana Caponio, Department of Political Studies, University of Turin / Forum for International and European Research on Immigration (FIERI), Turin, Italy

Michael Collyer, Sussex Centre for Migration Research (scmr), University of Sussex, United Kingdom

Rosita Fibbi, Swiss Forum for Migration and Population Studies (SFM), University of Neuchâtel, Switzerland / Institute of Social Sciences, University of Lausanne

Agata Górny, Centre of Migration Research (сMR) / Faculty of Economic Sciences, University of Warsaw, Poland

Albert Kraler, International Centre for Migration Policy Development (ICMPD), Vienna, Austria

Jorge Malheiros, Centre of Geographical Studies (CEG), University of Lisbon, Portugal

Marco Martiniello, National Fund for Scientific Research (FNRS), Brussels / Center for Ethnic and Migration Studies (CEDEM), University of Liège, Belgium

Eva Østergaard-Nielsen, Department of Political Science, Autonomous University of Barcelona, Spain

Marlou Schrover, Institute for History, Leiden University, The Netherlands

Patrick Simon, National Demographic Institute (INED), Paris, France

Imiscoe Policy Briefs and more information on the network can be found at WWW.IMISCOE.org. 


\title{
Secularism, Assimilation and the Crisis of Multiculturalism
}

\author{
French Modernist Legacies
}

Yolande Jansen

IMISCOE Research

Amsterdam University Press 
Front cover art: Eva Meijer

Colour editing front cover image: Daphne Rosenthal and Wouter van Riessen Back cover image: 'Choisis, tu es libre', cartoon by Auguste Roubille for L'Assiette au Beurre, 1904

Cover design: Studio Jan de Boer BNO, Amsterdam

Layout: Trees Vulto DTP and book production, Schalkwijk

Amsterdam University Press English-language titles are distributed in the us and Canada by the University of Chicago Press.

ISBN 9789089645968

e-ISBN 9789048522132 (pdf)

e-ISBN 9789048522149 (ePub)

NUR 610

(C) Yolande Jansen / Amsterdam University Press, Amsterdam 2013

All rights reserved. Without limiting the rights under copyright reserved above, no part of this book may be reproduced, stored in or introduced into a retrieval system, or transmitted, in any form or by any means (electronic, mechanical, photocopying, recording or otherwise) without the written permission of both the copyright owners and the authors of the book. 


\section{Table of contents}

$\begin{array}{ll}\text { Acknowledgements } & 9\end{array}$

1 Introduction

The crisis of multiculturalism, new assimilationism

and secularism 13

1.1 Contours of the book 13

1.2 Zigzagging between assimilation and multiculturalism 20

1.3 Where the secularism-religion framework comes in:

A bifurcation within multiculturalism $\quad 38$

1.4 The paradoxes of Jewish assimilation in France and the prism of In Search of Lost Time $\quad 46$

1.5 Outline of the chapters $\quad 51$

1.6 Disciplinary note $\quad 55$

2 Assimilation in the French sociology of incorporation from a multicultural perspective $\quad 59$

2.1 Why reintroduce assimilation? 59

2.2 Gérard Noiriel: Writing the history of power in the context of migration 61

2.3 A multicultural perspective: 'I been in the right place, but it must have $\begin{array}{ll}\text { been the wrong time' } & 73\end{array}$

3 The liberal sociology of assimilation and citizenship and its transnationalist alternatives

3.1 A sociological debate about assimilation and its normative implications for multiculturalism

3.2 Critique of postnationalism, multiculturalism and integration $\quad 84$

3.3 The alternatives proposed by the 'liberal assimilationists' 90

3.4 Complications for a diagnosis: 'On their turf' 96

$\begin{array}{ll}3.5 \text { Alternatives } & 102\end{array}$

$\begin{array}{ll}3.6 & \text { Against the new discourses of assimilation } \\ \end{array}$

\section{TRANSIT I}

Proust as a witness of assimilation in 19th-century France 
4 Alfred Bloch's personal integration test at the threshold of his friend's home

4.1 'And what's the name of this friend of yours who is coming this evening?' 137

4.2 The Revolution's conditions of Emancipation 140

4.3 Bloch coping with paradox $\quad 151$

4.4 Partiality, perspectivism and assimilation $\quad 155$

\section{Stuck in a revolving door}

Cultural memory, assimilation and secularisation $\quad 165$

5.1 Assimilation, metaphor and cultural memory 165

5.2 Hannah Arendt reads Proust; from Judaism to Jewishness 176

5.3 'The Christians at the surface'; Zygmunt Bauman and the $\begin{array}{ll}\text { paradoxes of assimilation } & 179\end{array}$

5.4 'A consubstantial malaise of republican society' 184

\section{TRANSIT II}

Laïcité and assimilation in the Third Republic and today 195

6 Elements of a critique of the laïcité-religion framework 203

6.1 Towards a genealogy of the laïcité-religion framework 203

6.2 Laïcité and neo-Kantian liberalism 204

6.3 Kant at school; Durkheim and Buisson 212

6.4 Privileging Protestantism and the genealogy of the religious
sign with a French twist towards ordre public

7 Secularism, sociology and security 225

7.1 The sociology of secularisation, normative laïcité and multiculturalism 225

7.2 The Stasi report: Un rapport sans médiation 226

7.3 Secularism or democratic multiculturalism? $\quad 229$

7.4 Postmodern identity politics and security 236

\section{The highly precarious structure of assimilation}

Modernist philosophical schemes, memory and the Proustian narrative 253

8.1 The invention of tense pasts after assimilation 253

8.2 Adorno's and Benjamin's exchange about assimilation and the rejection of Swann

8.3 Public and private Dreyfusism 258

8.4 The social discipline of forgetting 265

$\begin{array}{ll}8.5 & \text { Forgetting and cultural memory } \\ & 268\end{array}$ 
9 Concluding remarks

9.1 Introduction

275

9.2 The assimilation of the French Jews as a memory for today

9.3 Getting stuck in a revolving door in the early 21st century

9.4 Problematising the laïcité-religion framework instead of defining a 'better' laïcité

9.5 Multicultural alternatives

Notes

Works cited

311

Index 



\section{Acknowledgements}

One of the things that kept me going while writing this book was the thought that it would one day be finished and I would be able to write the acknowledgments, in which I would finally give a place to the team that sustained me. A range of people and institutions made this study possible. First of all, I would like to thank the supervisors of my $\mathrm{PhD}$ dissertation, which formed the basis of this book: Ieme van der Poel and Veit Bader. I greatly benefited from Van der Poel's great knowledge of French studies and of the work of Marcel Proust in particular. Bader's enormous erudition both in sociology and in social and political philosophy, particularly his interest in multiculturalism and secularism, has been invaluable to me.

The time taken to write this book was made available to me thanks to the support of the Amsterdam School for Cultural Analysis (ASCA), the Netherlands Organisation for Scientific Research (NWO) and the Amsterdam Center for Globalisation Studies (ACGS).

I received helpful comments on my dissertation and on later articles which contributed to this book from many people. I especially thank Murat Aydemir, Rainer Bauboeck, John Bowen, Sudeep Dasgupta, René Gabriëls, Edward Hughes, Jo Labanyi, Irena Rosenthal, Elizabeth Shakman Hurd, Samia Touati, Markha Valenta, Hent de Vries and Marc de Wilde, and finally the anonymous readers from the IMIsCOE Editorial Committee.

At the University of Amsterdam, Karen Vintges, Ruth Sonderegger, Pieter Pekelharing, Robin Celikates, Marieke Borren, Karin de Boer, Beate Roessler, Eloe Kingma, Jantine van Gogh, Dorota Mokrosinska, Victor Kal, Noortje Marres, Marie-Aude Baronian and Stephan Besser were among my most inspiring colleagues.

I further thank my colleagues within the Nwo project The Sacred and the Secular: Genealogies of Self, State and Society in the Contemporary Islamic World: Michiel Leezenberg, Mariwan Kanie, Ruud Peters and Peter van der Veer enabled me to continue my research about secularity and Islam in the European context, and to broaden my view by taking into account a postcolonial perspective. Meeting Darius Rejali in the context of this project was a source of great inspiration. 
Over the last years, I had the opportunity to meet various specialists on secularism and laïcité, from whose comments during workshops and conferences I have greatly benefited. Among them I especially thank Anders Berg-Sørensen, Marcel Maussen, Valéry Amiraux, Sindre Bangstad, Nilüfer Göle, Markus Dressler, Alain Touraine, Jonas Jakobsen, Wim van de Donk, Hamit Bozarslan and Charles Taylor.

Esther Peeren and Marc Cooper, who copy-edited my book and Karina Hof and Michelle Luijben, who represented Imiscoe, helped me in many ways, far beyond the tasks allotted. Esther not only did a great job in correcting my English, but she also gave helpful comments, especially on the literary studies parts of the book. Karina Hof was supportive and patient especially during the period of time that IMISCOE had to wait for the book due to personal reasons of my own. Michelle Luijben replaced her and gave me good advice from the start. She helped me to enhance the readability of this book at the last stage before its publication. Annemarije Hagen meticulously assisted me with the references and the bibliography, and I owe her thanks as well. I also thank the anonymous referees for being careful and critical readers, the Imiscoe internal referee in particular. Finally, I thank the ACGS (Amsterdam Center for Globalisation Studies), AsCA (Amsterdam School for Cultural Analysis) and the Hendrik Muller's Vaderlandsch Fonds for generously funding the publication of this book.

This book draws on my dissertation Stuck in a Revolving Door: Secularism, Assimilation and Democratic Pluralism, which I defended at the University of Amsterdam, and on a number of articles: 'Secularism and Religious (In-)security: Reinterpreting the French Headscarf Debates' in Krisis: Journal for Contemporary Philosophy (2011); 'Secularism and Security: France, Islam, Europe' in Comparative Secularisms in a Global Age, edited by Linell Cady and Elizabeth Shakman Hurd; 'French Secularism in the Light of the History of the Politics of Assimilation', in Constellations: An International Journal for Critical and Democratic Theory (2009); 'Laïcité or the Politics of Republican Secularism' in Political Theologies: Public Religions in a Post-Secular World, edited by Hent de Vries and Lawrence Sullivan (2006); 'Laïcité in het licht van de geschiedenis van de Franse assimilatiepolitiek', in Geloven in het publieke domein: Verkenningen van een dubbele transformatie, edited by W.H.B.J. van de Donk, A.P. Jonkers, G.J. Kronjee and R.J.J.M. Plum (2006); and finally 'The Red Shoes: Walter Benjamin's Reading of Memory in Marcel Proust's À la recherche du temps perdu, in the Light of the Dreyfus Affair', in Journal of Romance Studies (2003). 
Atique Sultanpour was the first Afghan refugee I came to know through being a volunteer for VluchtelingenWerk Nederland. He became a good friend, like Mahbooba Menapal, whom I also met as a volunteer. We spent many hours, but not enough by far, discussing our lives and the political and historical circumstances that determined so much of theirs. Knowing Atique, Mahbooba and their families is an important source of inspiration for this book.

Most personally I thank my beloved sister Petra Jansen and my long-time friends Klaske de Jong, Jantien Smit, Sanne Verdam, Petra van Heteren and Carola Baller. I would have loved to thank my dear parents as well. They both suddenly died in 2010, having given their children all the love and support they needed, and so much more. I am also grateful to Huub van Baar, my long-time beloved partner, for my not having had to do this alone. We have been together since we were students. Both of us went through the process of writing a dissertation, turning it into a book, and writing journalistic and academic articles while trying to find academic jobs. Together we mourned the death of my parents. The only reasons we have not yet turned into pillars of salt at our computers are the two who have joined our lives to so infinitely enrich them, Johanna and Benjamin, in 2006. I dedicate this book to Johanna and Benjamin, together with Atique and Ferozah's children, Hamid, Elias, Sara and Angela. 



\section{CHAPTER 1}

\section{Introduction}

\section{The crisis of multiculturalism, new assimilationism and secularism}

\subsection{Contours of the book}

This book is the result of my reflections on the deepening crisis of multiculturalism that has been developing across the Euro-Atlantic region, in European countries in particular since the turn of the millennium. I critically evaluate multiculturalism's contemporary alternatives in terms of secularism, assimilation and (civic) integration, while also tracing the interconnections between these. I furthermore examine why these alternatives are problematic, not only from the standpoint of the migrants and minorities concerned, but also because these notions stem from, and will increasingly lead to, nationalist, Eurocentric and insufficiently democratic conceptions and practices of citizenship. This book, finally, sketches the contours of what could be considered fair and democratic conceptions of citizenship in multicultural societies, drawing from the debates on multiculturalism, secularism, assimilation and integration, while also trying to get beyond these complex and chameleonic concepts.

To explain the problems of the new assimilationism and its intersections with secularism, I scrutinise contemporary discourses on these concepts; but I also draw on a rereading of Marcel Proust's novel In Search of Lost Time (À la recherche du temps perdu), written between 1909 and 1922. Set in late 19th-century France, this novel narrates and criticises the ways in which schemes, ideas and practices concerning assimilation and secularisation became manifest in everyday relations between citizens of diverse religious and ethnic backgrounds. Proust's novel provides a unique perspective on the way that assimilation worked in practice over a long term, for Jewish citizens in particular. For political thinker Hannah Arendt, the novel also acts as a primary witness of the emergence of a specifically modern type of racism in the dynamics of assimilation. My reading of the novel explores this dynamic. The novel is relevant to today's questions about multi- 
culturalism, secularism and assimilation, and it provides hints of ways to perhaps address the dynamics of assimilationism as well.

Assimilation and secularism are related concepts that play a central role in the debates about minorities, migration and religion being held across Europe today. The frequent appeals to these two historically layered and interconnected concepts have marked a transformation in social, political and cultural scholarship, in public debates and in governmental policies. They have arisen in search of alternatives to multiculturalism, which itself is a concept that has been increasingly challenged from various positions.

In political discourses and public media, from as early as the 1990s, there has been increasingly vociferous criticism of multiculturalism, and much talk even of the 'death of multiculturalism'. By now, this 'death' has been proclaimed by prominent European politicians, among them Nicolas Sarkozy, David Cameron and Angela Merkel. Among progressive politicians, multiculturalism has not yet been buried, but it is definitely out of fashion. ${ }^{1}$

In rather complicated tandem with these developments, criticism of multiculturalism has arisen in academia as well. Criticism of dominant versions of multiculturalism has been based mainly on multiculturalism's alleged frequent recourse to reified or commodified concepts of culture or of social groups. A causal relationship has furthermore been suggested with neglect of socio-economic inequalities and exclusion, and even with racism or segregation, which may have been unintended but for that reason is all the more pernicious. Vertovec and Wessendorf (2010) give an elaborate account of the criticisms. I return to these in the next section.

Academic criticism has certainly not all been directly related to the new assimilationism in politics. However, some authors who were critical of multiculturalism have stressed the need to introduce new concepts of assimilation in order to remedy multiculturalism's more abstract conceptions of culture. For example, the anthropologist Gerd Baumann argued in 1999 that building a 'common civic culture' implies the need for a process of cultural convergence, which requires 'assimilation on the part of all, especially newcomers' (Baumann 1999: 14). Scholars of various backgrounds have adopted the image of a 'seismic shift' in European policies towards migrants, from the more multicultural policies of the 1990 os to policies oriented more towards integration and citizenship (Joppke 2004: 249, quoted by Phillips 2007: 4). Some of these scholars also subscribed to at least some of the ideas of assimilation and integration underlying these new policies, not least Joppke himself (see Joppke 2009). 
Like assimilation and integration, secularism is a strong competitor of multiculturalism. Since the late 1980s, when the Rushdie Affair arose in Britain and the first headscarf affairs occurred in France, it has become increasingly common to frame questions about the Muslim presence in Europe in terms of secularism or religion in the public sphere. This framing was initially supplementary to a framing in terms of integration, of citizenship, of the incorporation of ethnic or cultural minorities and of socio-economic emancipation or struggle. Increasingly, however, it has even superseded such framing.

The emergence of the secularism/religion framing occurred first in France, where headscarves, and more recently niqaabs and burqas, became contested objects due to their supposed transgression of the norms of laïcité, which is usually translated as 'French secularism' or 'laicism'. In French public debates, laïcité is often used in opposition to communautarisme, which is a non-technical term for multiculturalism in the broad sense of recognition of ethnic and religious boundaries in understandings and practices of citizenship. An implicit link between laïcité and (anti-)multiculturalism is therefore easy to trace. However, the focus on secularism implies that we are now talking about religion as a specific case for philosophies and policies of integration. We can also derive this from the fact that debates concerning the place of Muslims in France are often held in terms of debates about the position of Islam in France. These debates make frequent reference to the emergence of laïcité in the French Third Republic (1870-1914), when Republican laicism was struggling with the Catholic Church. Catholicism at the time was a religion with a quite different status, sociologically and historically, from Islam today. It was the religion of the large majority of French citizens and had a long history in France itself. Deploying the framework of laïcité to debate the position of religious minorities places religion in the foreground, with questions of postcolonial history, migration, racism and socio-economic position of secondary relevance.

A similar reframing of questions related to the presence of Muslims in terms of dilemmas concerning secularism and religion took place not only in France but gradually throughout Western Europe. This occurred in national contexts (e.g., in Denmark, the Netherlands, Belgium, Britain, Norway and Germany) and in Europe-wide public debates on websites such as 'Eurozine', 'Perlentaucher' and 'Sign and Sight'. ${ }^{2}$ In these public debates, secularism has become an increasingly central concept connected to a broadly-shared diagnosis of the present which goes more or less as follows: the most difficult and conflict-ridden questions in our Western multicultural societies, if not in 
the world at large, are related to religion, particularly since Islam has emerged as a public or, even more strictly, as a political force. Philosophies and policies in terms of multiculturalism have underestimated this dimension, which has only intensified. This became especially clear after 9/11 2001 and the rise of violent Islamism and Islamic terrorism worldwide. However, the direction of the conflicts was foreshadowed by the Rushdie Affair and the headscarf affairs in France.

In response to the events that have brought religious dimensions to the foreground of today's cultural diversity and especially of political conflict, and as an alternative to multiculturalism, public and academic debates have turned overwhelmingly to the question of how to deal with religion in the public sphere and with Islam specifically. In these contexts, secularism is invoked as a precondition of democracy, especially defence of the rights of women, children and sexual minorities.

Academics in the social sciences and political philosophy have increasingly concentrated on questions of secularism, post-secularism and religion. While in the late 2oth century, cultural diversity and minority formation became the focus of interpretations of social movements in the sociologies and philosophies of difference and recognition, during the past fifteen years, secular-religious boundaries became central in debates about societal and cultural conflict. This shift was facilitated within the context of political philosophy by the longstanding liberal tradition, which had frequently privileged religious conviction as a root cause of violence in Euro-American history. This tradition was reinvigorated after the Cold War, in particular in the debates about the major works of the American philosopher John Rawls concerning political liberalism. Its contemporary legacy can be traced in writings on post-secularism and the secular age (Taylor 2007).

The renewed focus on religion in political philosophy occurred in tandem with debates in the social sciences about whether secularisation is a necessary part of modernisation, and about what precisely we presuppose when we use the notion of religion, especially in a global context of postcolonial migration (Asad 1993, 2004; Casanova 1994, 2006; Bader 2007; Taylor 2007; Habermas 2008a, 2008b). By questioning how religion is thematised within political-theoretical and public debates, these debates have often reinforced the tendency to place religion and secularism as a focal point for the academic community as well.

With regard to the position of Muslims in Europe, the gradual reframing of multicultural questions in terms of religion in the public 
sphere could appear to be a more or less natural development. Many people with a Muslim background migrated over a generation ago. This may feed the expectation that we have entered a phase in which religion carries chiefly traces of former ethno-religious differences and postcolonial history, because it is relatively resilient in comparison to language and cultural memory during assimilative processes. Or, so the thought goes, for example, in Olivier Roy's (2005) analysis of global Islam, but also more generally in European discourses concerning migration, Muslims and Islam (see further Chapter 2 and 6 in this volume).

This book argues that to understand what happens within these processes of reframing today, it is important to grasp the complex relationship between assimilation, religion and secularism, not only in present-day discourses and practices, but also historically. I try to make plausible that a specific dimension of the place of Islam and of Muslims in Europe will escape us if we frame contemporary issues concerning the Muslim presence only or even mostly in terms of the relationship between secularism and religion in the public sphere. Within this framework, it may seem that the most pressing issues concerning the citizenship of Muslims in European countries can be understood in terms of how liberal democracies should deal with the claims of conservative, orthodox, non-liberal, illiberal and nationalist religious groups in the public sphere, and how these should be accommodated or not in liberal democracies.

The intimate and complicated historical relationship between secularism and assimilation teaches us that a focus on religious affiliations in the public sphere in a European multicultural context implies a multi-layered problem. Such a focus risks identification of the members of ethno-religious groups (or those identified as such by members of majorities) as 'others' who will ultimately never really belong to their adopted countries. This risk can be termed a 'paradox of assimilation'. I delve into this risk through my reading of In Search of Lost Time, in which I systematically connect this novel to the historical context of the 'paradoxes of assimilation', drawing secularism and assimilation together. I also present a literary and experience-oriented contribution to the exploration of alternatives by tracing how Proust's novel answers the paradoxes of assimilation.

Thus, this book develops a dual focus: on the multiculturalismassimilation-integration framework and on the secularism-religion framework. First of all, I undertake a critical analysis of the emergence of secularism, assimilation and, especially, the intersections between the two concepts and their related practices. This brings to 
light fundamental practical, epistemological and moral problems in the ways these concepts are being deployed in some European cultural, academic and political formations today. This is particularly so in the context of migration, but also more generally in the context of the position of ethnic and religious minorities, and even in the context of citizenship in general.

I think these problems are due, to a large extent, to insufficient reflection on the legacies of modern and modernist conceptual schemes and ideas about citizenship, religion and cultural difference. The largest part of this book is therefore dedicated to tracing an intertwined genealogy of the concepts of secularism and assimilation in relation to these conceptual schemes and images, particularly the way they emerged in 19th-century French Republicanism. I argue that contemporary discourses and politics concerning multicultural citizenship, especially those that advance secularism, assimilation or integration as their central concepts, are in many ways dependent on modernist conceptual dichotomies inherited from the 19th century.

Most centrally, these 19th-century dichotomies separate the citizen from the socially, ethnically, religiously and racially distinguished bourgeois or private individual. I argue that remembering the paradoxes of assimilation is useful in deconstructing the remaining traces of these underlying conceptual schemes. This is not because the schemes have not been critically scrutinised or even at least partly overcome in the course of the 2 oth century - hardly anyone today would defend the modernist dichotomies tout court. However, what I do try to trace is how they live on in conceptual and imaginary places where they are difficult to recognise, especially in today's debates about the status of Islam in France.

In the course of European modernity, it is not only exclusivist or racist doctrines that have contributed to the history of exclusion and marginalisation of minorities, ethno-religious ones in particular. Discourses and expectations about equal citizenship have done so as well. We do well to reconsider these histories before suggesting that assimilation or its contemporary equivalent 'civic integration' will do better than multiculturalism in producing societal peace, justice and democracy. The idea conveyed by the literature on the paradoxes of assimilation (introduced later in this chapter) is that the formation of racialised difference, in connection with practices of scrutiny and control, are results to be expected of the new integrationism.

A second and related objective of this book is to demonstrate that a critical exploration of multiculturalism's contemporary negatives in terms of secularism, assimilation and integration might take us a step 
further in imagining morally and practically defensible interpretations of multicultural citizenship in Europe today. This relates especially, perhaps, but not exclusively to the presence of Muslims and people with a Muslim background.

I hesitate to present this proposal in terms of a new interpretation of multiculturalism, and am wary of the idea of defending another 'ism' in a debate which has become overburdened with highly politicised and technocratic positions and definitions. Moreover, the allegedly segregationist, or at least reifying, effects of multiculturalism make me hesitant to adhere to the terminology of 'multiculturalism' in developing a position about cultural and religious diversity and the social and political inequalities that accompany this diversity. Therefore, I'd rather think of this book as one that strives to contribute to what has been called a 'multicultural sensibility' (Kivisto \& Faist 2007: 34-40). My contribution to this multicultural sensibility is to explore the role of cultural and intercultural memory and amnesia in cultural dynamics, and to ground a not-too-formal moral, cultural and religious pluralism in an understanding of that dynamic and its relational aspects.

Choosing to speak in terms of a 'multicultural sensibility' might also help to solve a problem concerning the methodological status of multiculturalism. Multiculturalism is among the most chameleonic contemporary socio-cultural-political concepts. In 2001, cultural theorist Stuart Hall complained that multiculturalism had 'come to reference a diffuse, indeed maddeningly spongy and imprecise discursive field: a train of false trails and misleading universals' (Hall 2001: 3). Yet the fact that multiculturalism (and other contested concepts) are not 'monochromatic' (Kivisto \& Faist 2007: 36) does not prevent them from having a set of associations, a sound, forming a sensibility, something to hope or strive for, or, conversely, to fear or reject. Thus, there are definitely contents to compare and evaluate. That is why I am sceptical about the idea that in the current age of transnationalism and globalisation we can easily go beyond the opposition of assimilation and multiculturalism, or happily replace 'multiculturalism' with 'interculturalism' (Kivisto 2005; Mogahed 2007; Rodriguez-Garcia 2010; Bouchard \& Taylor 2008; Taylor 2012).

As I discuss further later, the concepts of 'integration', of 'assimilation' and of 'secularism' are as contested as 'multiculturalism'. The fuzziness of all of the concepts that are central to this study led me to continually scrutinise the concepts themselves and their uses, rather than using them as analytical terms, or presenting them in terms of policy options that could be compared and evaluated, or in terms of normative or national models. 
Let me now first trace some connecting lines between the debates about assimilation, multiculturalism and secularism/religion as they have developed in recent decades. Doing so helps to explain how and why this book is further focused on the paradoxes of assimilation.

\subsection{Zigzagging between assimilation and multiculturalism}

MULTICULTURALISM AS A CRITIQUE OF ASSIMILATION AND ITS PARADOXES

In political theory, multiculturalism arose in the context of increasing criticism of the classical liberal philosophical notion of citizenship. In the course of the 1970 s and 1980s, some authors, and feminists were the first among them, argued that differences in cultural status inevitably affect the citizenship status of minorities. They also argued that this fact was structurally and conceptually repressed in liberal thought. This position was taken, for example, by Iris Marion Young (1990). The basic idea motivating multiculturalism then was that a neat separation between private and public, particular and universal, is impossible. Modern societies are much too layered and dense, and too penetrated by particularisms of all sorts, to be able to realise universality and neutrality at the level of citizenship. Therefore, so the thought went, more is needed than difference-blind citizenship to achieve material and actual equality. Indeed, pressure to assimilate, on the one hand, and forms of exclusion because of not being assimilated or 'civilised' enough, on the other, always play a role in modern societies.

Multiculturalism then was conceptualised in terms of a reflection on, and a complement to, modern, liberal or Republican conceptions of equal citizenship, especially with regard to minorities of gender, ethnicity, race, language, sexuality, age, ability and religion. Philosophers like Iris Marion Young, James Tully, Charles Taylor, Veit Bader, Melissa Williams, Judith Butler, Wendy Brown, Joseph Carens, Axel Honneth and Will Kymlicka argued that it is unjust and unnecessary to abide by institutional arrangements and mentalities that require assimilation from minorities, insofar as this means adaptation to 'models of normalcy' for citizenship based on the attributes of the 'able-bodied, heterosexual, white male'; an adaptation that is refused 'at the price of exclusion, marginalisation or silencing' - assuming, of course, that adaptation is an option at all (Kymlicka 2002: 327).

Because the goal of political theoretical multiculturalism is achieving equal citizenship and participation for all members of modern 
societies, Kymlicka (ibid.) calls this 'multiculturalism-as-citizenisation'. He situates multiculturalism as the third wave of human rights revolutions since World War II. These 'revolutions' have opposed undemocratic and illiberal relations worldwide. The first wave was formed by the decolonisation movements, the second wave by the antidiscrimination and anti-segregation civil rights movements around the early 196os. The third wave is formed by multiculturalism as a set of claims made by, or in the name of, diverse minorities against their marginalisation, exclusion or assimilation. Multiculturalists argue for what Iris Marion Young (1989) called 'differentiated citizenship', and specifically for forms of group-differentiated rights and policies such as affirmative action (Kymlicka 1995, 2002; see also Carens 2000). These claims complement the classical liberal notion of undifferentiated citizenship which is closely related to assimilation.

As far as assimilation itself is concerned, it is necessary to distinguish a few understandings of it. Assimilation, first, can be seen as a homogenising social process, in the course of which the members of minorities, or of out-groups, are more or less forced to fully shed their differences from a core group and, at the same time, acquire the cultural and civil competences of that core group. In the context of migration, this core group is usually but not necessarily a national majority, as in 'Americanisation', or, 'becoming Dutch' or 'French'. (This notion of assimilation is examined further in Chapter 2.)

A second understanding of assimilation is more liberal and democratic, because it isolates a private domain from pressure to assimilate. In this understanding, members of out-groups are allowed, or even encouraged, to act as citizens, or to 'pass into public life' (Alexander 2006: 421) on the condition that they privatise the differences which keep them from being members of the majority. Such a definition suggests that assimilation allows members of minorities to participate in the public sphere as citizens on a par with others after having acquired the civil competences necessary to do so, while maintaining or even cultivating their differences in private, if they wish. The idea that this form of assimilation is possible at all depends on the assumption of a workable and relevant private-public distinction. (This notion of assimilation is further discussed in Chapter 3.)

A last conception of assimilation is the one implicitly underlying liberal and Republican egalitarian philosophical understandings of citizenship. In these understandings, assimilation as a social process is seen as something prior to citizenship, which is made irrelevant by citizenship itself. In the liberal account, formal equal citizenship itself provides the guarantee that the cultural qualities and status of minori- 
ties are of no consequence for their participation in the public sphere and the state, which are defined as neutral - or, in the more critical versions, argued that they ought to be neutral.

To understand multiculturalism's relation to assimilation, which as a concept tends to drop out of political theoretical discourses, it helps to briefly look at how multiculturalism has been understood in a few sociological theories of modern society. Doing so also allows me to introduce a notion of multiculturalism as a critical practice, which has tended to be underdeveloped in Kymlicka's best-known normative and juridically-oriented understanding of multiculturalism.

Multiculturalism is related to sociological conceptions of citizenship which assume that there are more and less privileged groups in modern societies, and that there will always be dynamics between these groups which affect their status - as citizens and as persons. Such dynamics are usually understood in terms of 'incorporation', taken as a technical term for the societal dynamics through which subordinate or out-group members of a society become at least partly recognised as the equals of core-group members. It is important to note, however, that the terms 'incorporation', 'out-group' and 'core group' should not be taken literally. If we were to do so, this might lead to an understanding of modern societies as clearly bounded, and as themselves built up of clearly bounded groups into which persons can be incorporated, as in a body. Such an understanding of incorporation is problematic, both in view of the high degree of differentiation among modern societies, and in view of increasing transnationalism, as argued within the tradition of Weberian sociology and especially today within sociological systems theory (see, e.g., Bader 2007; Schinkel 2007). 'Incorporation' as a technical (but admittedly rather unhappy) term does not imply fixed boundaries between groups, and societies should not be imagined in terms of societal wholes. However, differentiation is required between relationally defined minorities and majorities within specific social contexts, especially within nation-states, because they are still very dominant, although this is not necessarily so. In other words, speaking of 'incorporation' implies that there are groups with more and less power at different levels of governance, but individuals can belong to several groups at the same time, and boundaries between groups are complex and often blurred, especially in contexts of transnational migration and globalisation (see Bauboeck 1998a; Modood 2007; Nederveen Pieterse 2007).

A power dynamic between minorities and majorities is intrinsic to the constitutional democracies that have emerged since the Enlightenment. Citizenship promises equality and solidarity, but in 
many cases these promises are not realised. Social movements then emerge to claim equality for those not-yet-fully-recognised, seeking to close the gap between out-group members and core group members. We observe such dynamics in the ongoing struggles to include the property-less, women, gays and lesbians, transgenders, transsexuals, migrants, and non-documented migrants as equal citizens and ultimately as equal persons within constitutional democracies (see also Rancière 2006).

With regard to migration, it is important to consider the particularities of specific political-historical contexts. They give cause for the founders of states and their descendants to stuff their definitions of civil competence with particular habits and characteristics, of race, language, religion, national origins, etc. These tend to become norms for people arriving later and to be considered as models for citizenship (Alexander 2006: 402-407; Guénif-Souillamas 2006; Schinkel \& Van Houdt 2010). These functional and historical particularities, argues Alexander (2001: 241), 'invade and distort the understanding of civil life - culturally, institutionally, psychologically, and in interactional practices in everyday life'. Modern (liberal or Republican) theories of citizenship tend to hide from view the power of inequalities resulting from these particularities because of the idea that they have (or should have) only private relevance, while civil spheres and states are - or at least should be - neutral.

Jeffrey Alexander (ibid.) argues that both assimilation (which he takes in the second, liberal understanding) and multiculturalism, as 'modes of incorporation', can be seen as attempts to realise a more profound equality than classical citizenship makes possible, and as means to close the gap between core group and out-group members. Multiculturalism is the most recent, the most experimental and by far the most demanding, while assimilation is by far the most common. They are usually intertwined in contemporary societies, and are not to be understood in terms of a historical progression from the one to the other (Alexander 2006). The main difference between multiculturalism and assimilation is that the latter tends to ask little from majorities and to expect the public adaptation of minorities to prevailing norms. Multiculturalism implies that dominant norms, rules, practices and hierarchies can be critically questioned, and that they can be transformed through the interaction between members of minority and majority groups.

Why, then, is there a need for multiculturalism, if assimilation has been a common and not too unsuccessful mode of incorporation? We already encountered the strong moral objections to assimi- 
lation in political theoretical debates. Multiculturalists ask whether it is just, from a liberal-democratic perspective, to impose on minorities degrees of acculturation and adaptation that are not required of majorities, and that are sometimes impossible to carry out. Yet, from a more sociological and historical standpoint, three other reasons to be critical of assimilation have developed which are at least as important as those reasons arising from the point of view of justice.

Firstly, in the 1960s and 1970s, assimilation was more or less abandoned for empirical reasons, after sociologists Nathan Glazer and Patrick Moynihan (1963) argued that the 'melting pot' - the widely used metaphor for the expected end-result of assimilation in mid2oth-century American sociology - just 'did not happen'? ${ }^{3}$ For these sociologists, assimilation implied cultural homogenisation and inclusion at the same time. Glazer and Moynihan's primary objection to assimilation was simply that we only have to look around to observe that full incorporation is not the end-result of nation-state formation. For them, this was an ambivalent observation: part of the reason why the melting pot did not happen was because black Americans were far from being allowed to assimilate, even after the civil rights movement had achieved its victories. This was a reason for Glazer to state, in 1997, 'we are all multiculturalists now'. That claim was founded on what we could call 'the fact of multiculturalism', as a variation of the Rawlsian 'fact of pluralism'. So for Glazer, being multiculturalist was not founded on a norm of what was ultimately desirable: it was at least partly a reaction to the undeniable reality of the continued exclusion of African Americans from the us mainstream. Note that speaking of 'multiculturalism' here is questionable, because, in the view of later authors, multiculturalism came to hide, or even legitimise, racism and segregation. This was surely one of the motives for the new assimilationists in the United States to fiercely criticise multiculturalism and return to assimilation or turn to integration (Anderson 2011; but see Merry 2013 for a critique).

The second more sociologically and historically oriented critique of assimilation concerns its moral paradox. As Alexander (2006) explains, processes of incorporation concern not only the formal and procedural guarantee of equal rights (of justice), but also the formation of public identities. The crux of assimilation is that - if everything goes well - people are allowed to become 'one of us'. But the price is that 'us' remains unchallenged. Although individual persons can gain access to the core group, the failure to challenge 'us' as a norm, and the representation of out-group qualities as negative, as qualities to be privatised at best, causes assimilation to reproduce negative stereotypes, 
and even to reinforce public-private boundaries between acceptable forms of civic behaviour and those habits and practices that one would do better to drop, repress or leave at home. This is where the first and second meanings of assimilation tend to intertwine, and opportunities for 'privatisation' tend to turn into pressures towards homogenisation. Therefore, from a multicultural perspective, the 'rules of the game' of assimilation should form part of the matter for critique. Majorities ('us') should be seen as possibly (and even probably) at least as much in need of transformation and critique as minority practices and identities, and not as a norm outside critical scrutiny. In this context, Alexander (ibid.: 457) calls multiculturalism 'a project of hope'.

This leads to the third objection to assimilation from a multicultural perspective, which is that assimilation is politically instable, and can become politically paradoxical. In societies with rather strong public spheres, assimilation can lead to more tolerant attitudes towards those who were formerly considered outsiders. Cultural differences may gradually come to be perceived as 'ethnic' instead of 'foreign' or race-related. Assimilation might lead to increasing intermarriage rates and other cross-group bonds. ${ }^{4}$ Here, the 'us' of the core group is still unchallenged, and equality remains unrealised, but differences enjoy more public space without having to pay the price of (renewed) exclusion.

In societies with less strong public spheres, or where public spheres are under strain, the hardening and fastening of differences under assimilation regimes, and negativity concerning what is different in the outsider groups from the core groups' qualities, can lead to more restrictive definitions of civil competence, and even to renewed exclusion of members of society (Alexander 2001: 245). This is how the moral paradox of assimilation can become a political one, where exclusionary mechanisms are actually reinforced by assimilationism. This political paradox of assimilation arises in unstable contexts where a minimum level of trust among citizens of diverse backgrounds is deteriorating or lacking (ibid.: 245). Such instability, and the ensuing reinforcement of assimilationism's exclusionary effects, formed the context of the paradoxes of assimilation experienced by European Jews in the course of the 19th and 2oth centuries, which this book specifically studies in the context of the French Third Republic.

The moral and political paradoxes of assimilation provide impetus for a multiculturalism which is not primarily interested in positive accounts of multicultural justice, but rather in deeper reflection on these paradoxes themselves, on the conditions for their emergence, 
and on their prevention. This is the line of reflection pursued in the current book. But first let us turn to criticisms of multiculturalism.

\section{CRITIQUe OF MULTICULTURALISM}

Most serious critics of multiculturalism since the 1980 os have argued that some dominant understandings of multiculturalism tend to work with problematic concepts of culture while being too focused on culture as well. According to a first strand in this critique, multiculturalism tends to work with closed or romantic concepts of 'culture' or 'identity'. It therefore fosters ideas and ideologies that legitimise, or even encourage, forms of separation or even enmity between populations. This supposed tendency was succinctly captured by Sen (2006: 157) as the idea that multiculturalism, in the abusive versions, threatens to turn into a 'plural monoculturalism'. Secondly, in the view of critics, multiculturalism tends to lose sight of the important questions of socio-economic equality and participation (Barry 2001). Thirdly, and very influentially, multiculturalism has been charged with privileging traditionalist or patriarchal mentalities at the expense of women, children and sexual minorities (Okin 1999).

From the angle of postcolonial cultural studies and cultural anthropology, multiculturalism has been argued to neglect the role played by syncretic cultural formations, rather than reified or commodified culture, in transforming inequalities instead of accepting or even conserving them (e.g., Gilroy 2004, 2006; Bhabha 1994). Homi Bhabha, Paul Gilroy and other postcolonial scholars argue that we should always read culture in the plural, as being flexible and dynamic, and always in interaction. Gilroy (2006: 669) criticises multiculturalism insofar as it is conceived as a 'mosaic plurality'. Liberal multiculturalism, he writes, tends to reify hybrid cultural formations in which ethnic, religious, economic and other differences may be complexly admixtured, conceiving of them as fixated cultural identities which need protection by the state. Therefore, 'difference gets contained within symmetrical or at least similarly-configured social and cultural units that are arranged, in spite of any hierarchy they might be made to compose, so that they form a national unit' (ibid.: 671). This is a legacy of conceptions of plural society that has its origins in colonial statecraft. It offers, Gilroy argues, 'a repudiation of post-colonial theory which has insisted on the primal significance of cultural conflict and its relation to political processes' (ibid.). He thus argues for a conception of 'multiculture' in terms of 'conviviality', and insists on the importance of an urban culture wherein social critique, syncretism and the traces 
of postcolonial history all play a role, and against the 'multiculturalism' that he considers to be central to political theory (Gilroy 2004: xi, 2006). 5

Anthropologist Talal Asad, commenting on the Rushdie Affair, added to this line of critique that British multiculturalism of the $1980 \mathrm{os}$ did not imply so much a commitment to cultural diversity but rather was a practical attempt to deal with problems in education and social services (for a recent similar interpretation, see Bowen 2011). While acknowledging that a notion of multiculturalism could be useful against assimilationism generally, Asad detected at the time of the Rushdie Affair an underlying assimilationism in the British rhetoric of multiculturalism, because of the emphasis placed on the need for 'common (and British) values' by politicians from all sides. He also took into account the earlier criticisms of multiculturalism expressed by radical left critics. They argued that multiculturalism hides racism by suggesting that the causes of urban riots and inequalities lie in the differences between 'cultures'. Asad (1993: 261) qualified this argument by reformulating the problem. Although differences should be taken more seriously than the radical left argument about racism could do, multiculturalism's problem is that it conceives of 'fundamentally different traditions' as being necessarily contradictory and therefore in need of regulation and coordination by the state. This interpretation tends to lead to normalising policies and to the freezing of differences.

Other critics targeted multiculturalism less as an idea, suggesting instead that multiculturalism takes a paradoxical turn where it as a general idea is combined with specific measures and policies to realise it. In the 1970 and 1980 s, multiculturalists argued for specific juridical measures, such as group rights and affirmative action. In reaction to those policies, the argument arose in the 1980s that recognising identities in law, and institutionalising them, tends to have the paradoxical side-effect of reifying identities that were themselves the result of inequalities (e.g., Brown 1995: 128-133, 2002: 422-423; Mookherjee 2010). Without rejecting special rights and identity politics, these authors contributed a line of reflection on the paradoxical effects of multicultural rights and policies. This remained, at least in their view, undertheorised in mainstream normative multiculturalism as it emerged in the late 20 th century.

Anne Phillips brought these arguments closer to political theory, for example, in her Multiculturalism Without Culture (2007). She argues for a multiculturalism that dispenses with reified notions of culture. She also demonstrates the tendency of writers on multiculturalism (supporters as well as critics) to 'exaggerate not only the unity 
and solidity of cultures but the intractability of value conflict as well, and to misrecognise highly contextual political dilemmas as if these reflected deep value disagreement' (ibid.: 8). Thus Phillips, like Gilroy, explicitly links critique of the concept of culture to much of the literature on multiculturalism and on value pluralism in political theory. The assumption that we should locate the most intractable political questions in deep value disagreement between different populations, cultures or peoples has gained currency within political theory as well, at least since the later work of John Rawls (Rawls 1993, 1999).

The critique summarised above was mostly directed against what Kymlicka calls the 'communitarian' and 'liberal' versions of multiculturalism. In his 2002 analysis of transformations of the concept of multiculturalism, he writes that both interpretations preceded a more relational account of multiculturalism. Communitarian multiculturalism was elaborated prominently in Bhiku Parekh's Rethinking Multiculturalism (2000), for example, and in Charles Taylor's (1994) work about the politics of recognition. They emphasise the value of culture, understood in terms of community and tradition, in contrast to the liberal emphasis on individual autonomy. Liberalism, they argue, is not an incontestable moral and universal framework for dealing with ethical and value pluralism, but is itself the bearer of a specific ethics (and ontology). They put forward the suggestion that ways of being other than 'being liberal' should be taken seriously. The communitarian version of multiculturalism has been criticised on various grounds, but the central argument tends to be that it was founded on an essentialising, culturalist concept of culture and is too close to cultural relativism.

In line with those critiques, Kymlicka (1995) criticised communitarian multiculturalism and developed instead what he calls 'liberal multiculturalism'. Kymlicka argues that the liberal concept of the individual requires the availability of a 'societal culture' as a context of choice. He rejects the opposition between either a liberalism concentrated on individual autonomy or a communitarianism concentrated on community and culture. This account of multiculturalism was much criticised. The concept of the 'societal culture' especially was seen as a legacy of the earlier, communitarian concept of culture, and as culturalist in itself. It was also argued that liberal multiculturalism privileges the claims of national minorities over ethnic and migrant ones, and that the boundaries between different kinds of minorities, let alone cultures, could not be as easily and succinctly drawn as liberal multiculturalism tends to suggest (Bauboeck 2002; Modood 2007). Moreover, especially from the side of poststructuralist and Marxist 
critics, it was argued that liberal multiculturalism tends to stand in the tradition of toleration, in which ultimately majorities and the states representing them remain in a position to give special rights to minorities on their own terms and conditions, and thus not really producing equality at all (Brown 2006; Mookherjee 2010; Žižek 2010; Povinelli 2011).

In response to the criticisms of liberal multiculturalism, Kymlicka (2002, 2010), in his latest normative definition of multiculturalism, gives it the relational form it had taken in earlier, more sociologically and social-movement-oriented understandings, reading multiculturalism as a response to power differences in the context of processes of nation-building (see also Chapter 3 in this volume). This redefinition brought the political philosophical defence of multiculturalism more into line with the strands in the social sciences and cultural studies discussed above.

However, even relational multiculturalism-as-citizenisation seems susceptible to the criticisms that were made of the earlier versions of multiculturalism. The boundaries between groups and nations in a global context have been blurred to such an extent that it may seem problematic to speak about nations, majorities and minorities at all. Or, in the baroque terms of Jan Nederveen Pieterse (2007), to characterise the global multiculture that we all inhabit:

In these times of transnational corporations, world products, world marketing, global brands, planetary social and professional networks, intercontinental pen pals, mail-order brides, and astronaut families, the old accounts of a world neatly compartmentalized in civilisations, religions, nations, states, and their forms of allegiance and belonging no longer fit. We have long entered the post-cubist phase of identity (ibid.: 3).

Nederveen Pieterse, in line with the earlier proponents of multiculture, criticises multiculturalism insofar as its conceptualisation is still dependent on older mono-cultural theories. Also, the majorities with which minorities have to bring their own positions into balance are less bounded, more internally diverse and more politically flexible than we tend to assume. If we take into account the idea of global multiculture, it could be argued that multiculturalism should be about the forms of 'interconnectedness between varied local cultures ... crisscrossing loyalties and overlapping jurisdictions' (ibid.: 2), not about relations between predefined social groups in terms of minorities and majorities (see also Schinkel \& Van Houdt 2010). 
The basic critique of multiculturalism remains that normative notions of multiculturalism tend to take culture (and notions of identity and minority) too readily as starting points of analysis. Even when multiculturalism-as-citizenisation acknowledges that cultures, minorities and identities are not given but constructed in interaction with political, economic and historical circumstances, it is questionable, from the perspective of this critique, whether this insight has been taken into account systematically enough. Multiculturalism-as-citizenisation also often refers to nation-states, majorities and minorities as quite separate, distinguishable, conceptual and practical unities, either going along or not with the imagined existence of specific, and rather static, identities. It seems important instead to reflect on the performative construction and formation of both minorities and majorities. Monika Mookherjee (2010) develops the concept of 'postcolonial multiculturalism' to further mediate between postcolonial cultural studies and normative multiculturalism on this issue.

In the French academic context, where multiculturalism has never been taken very seriously, similar critiques of multiculturalism have been formulated, though in a different language. These are articulated not so much in terms of a critique of a reified, or essentialised, concept of culture, but rather in terms of a misunderstanding of the practices and identities of French Muslims in terms of tradition. Critics oppose the idea that French Muslims' Islam, insofar as it exists at all, should be interpreted in terms of a culture passed on to a second generation. Concepts like bricolage (Touraine 1990) and Islam mondialisé (Roy 2005) were introduced to argue that rather the opposite was the case. In Touraine's view, persons who were actually fully integrated were experimenting with identities and knotting them together in much the same way as suggested by Gilroy's syncretic multiculture. Roy (2005) added that transnational Islam did offer young French Muslims new identities which were on a tense footing with French identity, but that this was not because the remainders of a culture were being preserved through the religious gateway. Instead, their religion itself was wholly the effect of global and mediated efforts towards the construction of a pure, 'de-culturalised' religion (see also Chapter 7 in this volume).

In preliminary conclusion, there has been a rather general outcome of the critiques of multiculturalism. That is, multiculturalism, while seeking to increase equality between majorities and minorities, through the ways in which it has been understood and institutionalised, has turned out to be a policy machine and public discourse with rather undesirable outcomes. Multiculturalism has created what it itself was struggling against: rigid differences between members of 
different groups, sometimes even enmity between them, and institutionalised categorisation and control of minorities leading to perpetuation of their unequal position (see also Lucassen 2005: 4).

In the course of the first decade of the 21st century, some participants in the debates started to talk about assimilation again - rather unexpectedly, because its moral credentials were low, especially in Europe. Others called for reinforced notions of integration and citizenship, of the nation and of civilisation. As already noted, yet others focused specifically on the relation between religion and secularism. This chapter turns to that new focus later. First it looks at how to interpret the return of assimilation in a context in which the academic community has become wary of using culture in a bounded sense, though bounded understandings of nations, identities, and public spheres have sprung up like mushrooms in public contexts over the last decade. The question pursued is how to evaluate the risk of a return of assimilationism's moral and political paradoxes in a context, ironically, of global multiculture.

THE RETURN OF ASSIMILATION

A revised concept of assimilation in the international sociology of migration took off in the United States in a debate sparked especially by influential books, one of which was Assimilation American Style by sociologist Peter Salins (1997) and another entitled Remaking the American Mainstream by Richard Alba and Victor Nee (2003). These authors argued for a reinvention of assimilation in the American context. Salins argued that assimilation had been misinterpreted by multiculturalists, and that assimilation mostly meant what the early American Chicago School sociologist Robert Park understood by it in the 1930s. Assimilation, according to Park, is 'the name given to the process or processes by which people of diverse racial origins and different cultural heritage, achieve a cultural solidarity sufficient at least to sustain a national existence' (quoted in Salins 1997b: 1).

Salins argued that assimilation requires a minimal solidarity with the United States and enables migrants to function in their country of arrival. Assimilation says nothing specifically about the need to adapt one's habits and practices to those of the mainstream, which was a different process, namely 'acculturation'. According to Salins, in the us historical context, and in contrast to the European one, assimilation had not required high degrees of acculturation from migrants. So it had also not required cultural homogenisation, certainly not full homogenisation. Salins here reiterated the old idea that assimilation in 
the United States was related to cosmopolitanism. In an idealistic, 19thcentury formulation of this idea, Carl Schurz, a German immigrant, saw the United States as 'a great colony of free humanity which has not old England but the world for its mother country' (quoted in Alexander 2006: 420). Assimilation merely required the will of migrants and minorities to function within society and their primary identification with the United States as a nation, colourful and culturally diverse as it was. But a second major condition for assimilation to succeed was that the majorities had to cooperate. It was they who had to give migrants chances and not distrust or exclude them. The majority's negative attitude was why the assimilation of black Americans had failed, according to Salins in tandem with Glazer. But Salins stressed that this was not due to their cultural differences, but because of racism.

Salins argued that the interpretation of assimilation as full homogenisation was partly caused by the unhappy metaphor of the melting pot, which suggested homogenisation. He argued that the metaphor was adopted too readily by assimilation's multiculturalist critics for them then to reject it. This, according to Salins, prevented them from seeing that a realistic view of American assimilation could teach us that it was a near ideal model for incorporation, navigating as it did between the segregation implicit in multiculturalism and the homogenisation policies that European countries had practised all along with regard to their migrants and minorities. Following that line of argument, Alba and Nee (2003) criticised multiculturalism as based, in their view, on a mistaken metaphor of the desirability of the co-existence of isolated social groups, or even ethnic islands. Salins plainly stated that multiculturalism ended up in an 'ethnic federalism' that 'at all times is an ideology of ethnic grievance and inevitably leads to and justifies ethnic conflict' (Salins 1997b: 1).

In the European context, a similar concept to 'assimilation American style' was introduced in a 2003 volume edited by Joppke and Morawska entitled Toward Assimilation and Citizenship: Immigrants in Liberal Nation-States. Few of the contributors opposed multicultural society or migration, rather the contrary, but they did criticise what they called 'official multiculturalism'. In their interpretation, this implied not just the flourishing of cultural diversity in the public sphere, but its institutionalisation and perpetuation at diverse policy and political levels. They blamed 'official multiculturalism' for institutionalising ethnic diversity from above and focusing too much on culture, while neglecting the socio-economic task of migration policies to offer migrants a place in society. For that reason they called 
for reintroduction of the concept of assimilation, also in the European context.

We need not worry, they argued, because assimilation has lost its old assimilationist tendencies and now functions within a liberal democratic framework and in an increasingly globalised world. Reintroducing assimilation was meant to contest only those naïve forms of multiculturalism that defended conservative, essentialised notions of culture, mostly in the service of patriarchal majorities within minorities, or of majorities wanting to exclude migrants because of their imagined irreparable difference. According to them, a transformed concept of assimilation does not designate the imposition of majority cultures on minorities, but rather indicates a direction in the processes of convergence, negotiation, adaptation and differentiation that inevitably take place in liberal democratic societies today. They suggested that a revised notion of assimilation could be of help in dealing with the problems caused by multiculturalism. In their view, such problems had contributed to produce an institutional context for culturalist approaches to minorities, flourishing fundamentalism and oppression of minorities within minorities, while at the same time neglecting socio-economic inequalities and the policies needed to counter them (Brubaker 2001; Joppke \& Morawska 2003). (I return to this argument in Chapter 3.)

In the French context it has been contested, however, whether we can have assimilation at all without its nationalist or, rather more broadly, its particularistic and even oppressive colonial sides. The Republican universalist notion of assimilation has long been thoroughly discredited as implicitly colonial and oppressive towards colonial subjects, migrants and internal minorities like the Bretons (Laborde 2008; Guénif-Souillamas 2006). As in other countries during the last decades of the 2oth century, French official discourse instead adopted the combined notions of 'integration' and 'cultural diversity'. However, for other reasons, in 1989 the French Marxist socio-historian Gérard Noiriel and his colleague Stéphane Beaud called for continued use of the concept of assimilation (Noiriel \& Beaud 1989; Noiriel 1996a, 1996b). Noiriel basically argued that a realistic understanding of the process of migrant incorporation into the modern nation-state must acknowledge the force of assimilation as a historical process. Like the liberal assimilatinonists, he strongly opposed policies of multiculturalism.

Interestingly, religion was not so much an issue in the early debates about the need to reintroduce the notion of assimilation. For Noiriel, writing in the late 1990s, political Islam implied an attempt towards creation of a political subject which was destined to remain powerless 
from the beginning, because religion was privatised in France to such an extent that Islam was not a useful identity at all for racialised 'beurs'. He thought this was an illusion that could only have arisen because there were no longer good ways for migrants and their children to organise as members of a class, together with other French citizens. In 2004, he and colleague Stéphane Beaud opposed the law prohibiting the wearing of headscarves at school, but did so on the grounds that it was stigmatising to the new 'pariahs de la République', a view they shared with many critics of that law from the left (Badiou 2006; Benbassa 2003; Geisser \& Zemouri 2007). These critics had always seen the discourse of secularism and of religious conflict as a distraction from what really mattered in politics, beginning with Pierre Bourdieu (1999) in his comments on the first protests against the headscarves at school, which he saw as the expression of a hidden, or barely hidden, opposition to the presence of Arabs in France.

The relatively low political relevance ascribed to religion among the new assimilationists was not exclusively French. Salins (1997: 2, my italics) wrote that 'the ethnic conflicts of Bosnia and Northern Ireland transcend religion and acculturation and would not disappear even in the fact of mass religious conversion'. In Salins' view, the virulence of these conflicts was due to the absence of assimilation in the sense of national solidarity, caused by a failed process of nation-state formation and not to a clash of religious values.

This teaches us how separate the intellectual trajectories of assimilation and secularism were in the first years of their strongly reinforced (re-)appearance, which took place more or less around the year 2000. At the same time, the new assimilationism and secularism were both formulated in terms of a critique of multiculturalism, and the participants in both debates agreed on the need to deconstruct the idea that religion could or should have relevance beyond the private domain.

\section{ASSIMILATION, INTEGRATION AND CIVIC INTEGRATION}

According to Joppke and Morawska (2003: 4), 'whoever uses the word "integration" wishes to say what is allegedly not meant by it, "assimilation".' They argued that in the 1970s and 1980s, integration was gradually adopted in most liberal countries because of assimilation's colonial and nationalist connotations. A liberal redefinition of assimilation instead of its replacement by integration or multiculturalism would have prevented abandonment of the legitimate, structural sides of assimilation, namely the 'socio-economic equalisation of the lifechances between immigrants and native population (in employment, 
income, education, etc.)'. Joppke and Morawska (ibid.) also criticised the use of the concept of integration because of its emphasis on the necessity of social cohesion and even unity, more so than assimilation. 'Integration' suggests the existence of an integrated society that can also disintegrate (Joppke \& Morawska 2003; see also Asad 2006 and Schinkel 2007).

In the course of the years, Joppke more or less abandoned this criticism of integration. In 2009, the target of his critique remained multiculturalism, but instead of contrasting it with assimilation, Joppke proposes integration. He calls 'integration' the intransitive process by which the migrant 'integrates', and he values this, although hesitatingly, as a positive thing. Yet in line with what Brubaker argued earlier, Joppke states that the end state of the process 'might be, perhaps even should be, assimilation', but then understood as the 'unintended consequence of a myriad of individual actions and choices' (Joppke 2009: 116, quoted in Brubaker 2001: 543).

It would thus seem no simple matter to distinguish integration from assimilation, especially since the contemporary understanding of assimilation has become more liberal. After all, moderate, liberal, anti-assimilationism was at the core of conceptions of multicultural integration when these were introduced in the late 2oth century as an alternative to assimilation, which tended to be understood as a more or less complete, compulsory and illiberal type of homogenisation. Why then concentrate on assimilation instead of on the - by now - more familiar integration?

Definitions of integration since the 1990s have often combined an emphasis on social cohesion with a specific form of anti-assimilationist multiculturalism, to convey an assurance of a space for minorities to preserve or protect their own culture. This is evident, for example, in the Dutch slogan 'integration with retention of identity' (integratie met behoud van eigen identiteit), as well as in the definition ascribed to integration by the French Haut Conseil de l'Intégration as early as 1991. The High Council defined intégration as follows: 'active participation in national society by varied and different elements while accepting the subsistence of cultural, social and moral specificities and accepting as truth that the whole enriches itself through this variety and complexity' (quoted in Kaltenbach \& Tribalat 2002: 36, my translation. See also Chapter 2 in the current volume).

Today, an anti-assimilationist element remains central in understandings of integration, as demonstrated by the 2007 definition of integration by the government-sponsored British Commission on 
Integration and Cohesion (COIC). Following a consultation of diverse stakeholders, the commission noted that many respondents

spontaneously include a level of concern to distinguish integration from assimilation, stressing the importance for true cohesion of accepting and celebrating - difference. Individual and group identities should not be endangered by the process of integration, but rather they should be enriched within both the incoming groups and the host nation. Cohesion implies a society in which differences of culture, race and faith are recognised and accommodated within an overall sense of identity, rather than a single identity, based on a uniform similarity (COIC 2007: 5, emphasis original).

What is noticeable about this recent British report is that, after years of criticism of the idea that we can preserve entire cultures, the definition of integration is still fashioned by the idea that cohesion implies that we accept differences and even celebrate them, while simultaneously offering no insight into precisely how these differences were caused, nor exactly how public they could become. Instead, the necessity of cohesion and integration is emphasised. There is even talk of an 'overall sense of identity', whatever that may imply in a context of global multiculture.

These definitions of integration seem to rely on the static concepts of multiculturalism and culture that have been so criticised: the nonassimilationist element in integration is mainly understood in terms of making it possible for people to retain or conserve their culture, or even identity. Moreover, in these definitions of integration, the central premise of multiculturalism as a critique of the rules of the game is missing. That would involve the possibility of putting up for discussion the nature of 'us', instead of focusing on questions of the accommodation of 'others' and their contribution to unity. It would involve critical scrutiny of the hierarchies of (relatively) old and new inhabitants. Or, more generally, of out-groups and in-groups. Thus, looking at present-day discourses about integration with one eye on assimilation criticisms, it is easy to recognise the remnants of assimilationism in currently influential definitions of integration.

Integration has to a certain extent been replaced by the new concept of assimilation proposed by liberal assimilationists. A dynamic relationship between the 'old' or 'different' and the 'new' is central to their concept of assimilation. That, at least, is progress and is the first reason why this volume focuses on the concept of assimilation and not integration. A second reason for concentrating on assimilation is 
that European countries, in spite of theoretical optimism regarding new forms of assimilation, have been turning back to the old, wellknown, homogenising forms of assimilationism. In European countries especially, some policies of civic integration can be understood in terms of old assimilation (Vasta 2007; Entzinger 2007; Joppke 2009). 'Civic integration' is a translation of the Dutch term 'inburgering', which was introduced in the late 1990s, and more or less simultaneously also in Denmark. It subsequently spread throughout Europe. The term denotes the practice of requiring newcomers to learn the national language and to familiarise themselves with the principles of liberal democracy in their specific national forms (see Joppke 2009; Bauboeck \& Joppke 2010). The question thus arises of whether, by suggesting from the start of someone's migration history that we, as Europeans, have established certain habits, norms and values that others can recognise and learn, we are not actually rehashing precisely the assimilationism in which not the 'we' but the 'they' is permanently the subject of discussion and scrutiny.

An important difference between civic integration and old forms of assimilation, according to proponents, is that the latter were explicitly nationalistic, while civic integration combines an emphasis on learning the national language with a cultural emphasis on allegedly 'European', even universal, secular and liberal democratic values. This brings civic integration more into line with the 'legitimate', liberal form of assimilation. The idea here is that people are not overtly required to declare that they agree in principle with these values. The question, however, is whether we can so easily distinguish universal values from homogenisation aimed at 'accidental' national forms of otherness. It has been suggested that the ways in which migrants are interrogated about their moral and political convictions sometimes actually constitutes a form of Gesinnungstests. This could hardly be called liberal, if that were to mean respect for freedom of conscience and religious expression, or to signal an attempt at cultural neutrality (see Spijkerboer 2007; Orgad 2010; Michalowski 2011). In any case, those born in Europe shall never be subject to interrogations about the extent of their integration. Thus, civic integration conveys the idea of conditional participation, in which evidence of a degree of civility is required that is never asked of people born in the host nation, creating a fundamental inequality (see also Carens 2012).

A comparable argument was powerfully confirmed in the context of France, where discourses and practices of integration, and integration tests in particular, have been criticised. Nacira Guénif-Souillamas (2006, paraphrased in Simon \& Sala Pala 2010: 95) argued that the 
tests are not about political citizenship, and they impose the adoption of norms that are more cultural than political. They are 'designed to defend the pre-eminence of norms and practices that are those of a silent but powerful majority that intends to impose its supremacy over the varied legacies and customs it does not recognise as its own' (ibid.).

We shall see that in the Proustian world of assimilation and the history of aristocratic status differentials between individuals is precisely this sort of test, but then applied in everyday life, assuring that the 'Others' remain permanently as 'other'. This is where the requirement to give evidence of one's integration may be paradoxical. This evidence should deliver an 'entry ticket' to European culture, as Heinrich Heine put it, but the entry ticket can be coupled with an 'exit visa', in the terms of Zygmunt Bauman (1988) in his analysis of one-and-ahalf century of experience with entry tickets for Jews in Europe (Heine quoted in Bauman 1988: 45). Max Silverman (2007), discussing the French Republican model, suggests that it is precisely such an initial but fundamental inequality between citizens and not-yet-full-citizens which has never been overcome in the French model, and which has forcefully re-emerged with the French rejection of the headscarf.

To gain more clarity regarding the connection between the new and the old concepts and practices of assimilation, we can look at assimilation's genealogy. However, let us first trace how some of the questions that tend to be framed in terms of dilemmas between multiculturalism and assimilation have been reframed over the last decade in terms of dilemmas between secularism and religion.

\subsection{Where the secularism-religion framework comes in: A bifurcation within multiculturalism}

In the course of the 1990s, the emergence of identity politics, the reification of culture and the ensuing claims of rigid differences between cultures were initially interpreted mostly in terms of (ethno-)nationalism and racism (e.g., Salins 1997a). However, increasingly, and in relation to 9/11 2001 and its aftermath, the causes of the echec of multiculturalism have been sought primarily in its hitting upon the hard stone of religion.

Sen (2006b: 2) expressed the problem as many people see it when he complained about the understanding of multiculturalism as 'giving priority to the dictates of traditional culture over everything else'. Not incidentally, Sen (ibid.) cited the example of Muslim Pakistani parents not allowing their child to marry outside their own group. It is not just 
traditionalism which is considered problematic, however, but also the extreme other side of the spectrum, where a political religion is constructed as a universalist, anti-traditionalist reply to liberal modernity, as in 'global Islam' (Roy 2005). While religion is the term generally used in contemporary debates, religious traditionalism, fanaticism, fundamentalism and religious identity politics are clearly considered most problematic.

Religion, then, is seen as problematic when it has legal, political and public tentacles, and these can be the result of either traditionalisms or of postmodern identity politics, or a combination of the two. These tentacles are often framed in terms of transgressions of the boundaries set by secularism. Many debates about religion and secularism have concentrated on the question of when exactly religious practices and claims transgress these boundaries. Moreover, while in principle all political and legal aspects of religion are at stake, in European contexts Islam has become the privileged example, if not the embodiment of a religion tending to transgress these boundaries. This idea is especially prolific in public discourses, but also in academic debates, with the number of examples from the context of Islam perhaps not entirely proportionate to their real share in the potentially contentious religious politics of Europe. ${ }^{6}$ In this regard, a discourse has arisen in which secularism is often seen as a more or less defining characteristic of Western societies with a deeply rooted history in Europe.

Yet it is important to note that secularism was more or less completely redrafted within the European context in the late 1980s. By the end of this decade, religion had more or less vanished from political arenas throughout Europe, to be replaced by political conflicts that could hardly be understood in terms of conflicts between secular and religious parties. Europe had known nearly a century of secular conflict during two world wars, the colonial wars and the Cold War. In and around the 1980s, even in France, which for centuries had known major conflicts concerning the relationship between Church and State, religion hardly stirred the political imagination or disturbed societal relations (Birnbaum 1998). All of this changed with the emergence of Islam on the geopolitical scene at the end of the Cold War (especially in the Afghan context) and after the Iranian Revolution and the Rushdie Affair. Debates in terms of secularism then quickly emerged.

The separation of Church and State, the neutrality of the state in regard to religion, religious freedom and understandings of secularisation in terms of the privatisation and decline of religion, are all at the heart of discourses about secularism. Interpretations of secularism, however, require further explanation and discussion of their practical 
application before they can be regarded as meaningful. For example, what precisely does 'separation of Church and State' mean? Even in France, which is known for its secularist model, based on a law enacted in 1905, there exist all sorts of administrative relationships between the Church and the State and between religions and the state. These have changed throughout history as well. To give just one example, contrary to what the law of 1905 prescribes and what general opinion thinks happens in practice, the French state does finance private religious schools and religious associations. It even finances the maintenance of core religious buildings such as the famous French cathedrals. Moreover, the French state has a long tradition of the gestion of religion, termed by John Bowen (2007b) as 'support and control' of religion. This implies accommodation of religion within the public sphere (see Roy 2005; Bowen 2007b; Bader 2007; Modood 2007). ${ }^{7}$

Accounts of conflicts concerning French secularism (i.e., laïcité), and especially of struggles concerning the wearing of headscarves in public spaces, and public schools in particular, corroborate the fact that matters are complicated. While some vociferous French secularist public intellectuals are still of the opinion that any public manifestation of religious affiliation transcends the prescriptions laid down by the concept of laïcité, this vision cannot be said to encompass the French 'model' of secularism, and it has received little institutional support from the beginning of the debates. As early as 1989, for example, the Conseil d'Etat argued that wearing a headscarf is a private matter for the person in question. The Conseil argued that laïcité encompasses protection of the freedom of conscience of the individual. Wearing the headscarf was regarded as problematic only when related to disturbances at school or pressure to convert to a different religion (prosélytisme). ${ }^{8}$

There is rather strong consensus among most researchers of laïcité that no French model of laïcité exists from which the headscarf law can be directly derived (see, among others, Bowen 2007a). Hence, no institutional framework settled the matter of the headscarf law. Rather, enactment of the law should be analysed in terms of an amalgam of institutional and cultural factors that is difficult to unravel and in which arguments and practices connected with security, racism and postcoloniality have also played a significant role. An analysis of this amalgam teaches us more about the specific relationship between Islam and laïcité in present-day French society than a 'model' of secularism that supposedly applies to church-state relationships more generally. 
This does not mean, of course, that religion and state in France - or elsewhere - are not separated at all. It does mean that we have to deal with varying forms of differentiation in different contexts. Political theorist Geoffrey Brahm Levey (2009: 14) spoke of a 'floating threshold' amid the legions of unsystematic relations between state and religion in diverse national and regional contexts.

On similar ground, political theorist and sociologist Veit Bader (2007) argued that insight into the diversity of religious governance is blurred rather than clarified by the use of a general term such as 'secularism', especially if 'secularism' is taken to mean 'strict separation' or if a sociological theory of secularisation is presupposed. Instead, differentiation and separation are terms that themselves should be distinguished (ibid.). Yet others have proposed qualifications of the concept of secularism itself. They suggest 'moderate secularism' (Tariq Modood), 'liberal secularism' (Jean Baubérot), laïcité ouverte (Pierre Tevanian), and 'laïcité bien entendue' (Charles Taylor at a conference in Istanbul in 2008), as opposed to, for example, 'exclusive', 'aggressive', 'strong', 'intolerant', 'statist' or 'malevolent' secularism (Bader 2010a provides an even longer list). This presents secularism as a complex notion that like other central political ideas, such as liberalism and democracy, acquires concrete form only in a specific cultural, historical and political context.

The context of European countries in the last decades of the 2oth century, when the reinvented secularism emerged, was that of a struggle for recognition by minorities, often understood in terms of 'multicultural struggles'. From the outset of the debates about secularism and religion, cross-references were made with discussions of multiculturalism. However, references to secularism have become increasingly independent of the multicultural focus on minority and majority relations, to focus on religion, and Islam in particular, as a specific problem.

In public discourses, secularism has increasingly been cast as a viable alternative to populist anti-Islamic discourses, without 'falling back' into multiculturalism. Even for left-wing politicians, secularism seems a good, even promising, option for dealing with Islam. ${ }^{9}$ For, so the theory goes, secularism does not encourage the visibility of Islam in Europe, as multiculturalism would do, therewith incurring populist and nationalist resentment. Neither does it involve the exclusion of Islam or even possibly anti-Muslim racism. Secularism means only that religions should be left alone by the state, provided that they respect others' freedom of belief and that their practices do not conflict with the constitutional rights established for each individual by liberal 
laws. The main difference with multiculturalism then, according to secularists, is that a secular society jettisons the idea that government should adopt a paternalistic role, in which conservative religious elites are seen as representatives of entire groups or even entire 'cultures'. Secularism might be a way to definitively shed the legacy of communitarian multiculturalism.

Liberal multiculturalism, until the late 1990s, also hardly seemed to contrast with secularism. It long exempted religion from multicultural questioning, as did other strands of liberalism. Most notably, Kymlicka's (2002) view has been that with regard to religion, the state should abide by the old liberal principle of 'benign neglect', and so remain difference-blind towards religion, while perceiving other differences. Yet Kymlicka (2010) has now recognised this as an untenable position, insofar as religions have their cultural, practical and public dimensions as much as other differences and need to be accommodated rather than privatised (in line with Bader 2007; Modood \& Meer 2008). These authors argue that secularism, when it is defined in terms of a strict separation of Church and State, is closely related to the classical liberal and Republican notions of difference-blind citizenship; it is actually just the religion-focused version of difference blindness.

Moreover, the singling out of religious or Islamic identifications as specifically problematic has led a number of authors to complain that Muslims have to answer to higher levels of distrust, bias and prejudice than do other minorities in liberal societies today. These authors think that religious minorities, and Muslim minorities in particular, should be included on a fully equal basis. They suggest that the secularist denial of the fact of actual accommodation of religion in the public sphere also leads to blindness to the cultural privileges of Christian traditions, which has led to a situation in which non-Christian traditions are definitely in an unequal position.

Added to this is the trend of anti-Muslim racism and Islamophobia which Muslims contend with in current European public spheres (Bader 2007; Modood 2007; Brahm Levey \& Modood 2009; Bangstad and Bunzl 2010; Shoohan \& Spielhaus 2010; Morey \& Yaqin 2011; Lentin \& Titley 2011; Göle 2011; Klug 2012). In sum, these authors signal a situation in which many minorities are more equal than Muslims in their right to be different:

[I]n Europe, Muslim immigrants confront, on the one hand, majority populations that are mainly secular and therefore suspicious of claims based on religion and its requirements and, on the other, societal institutions and national identities that remain anchored to an important 
extent in Christianity and do not make equal room for Islam (Foner \& Alba 2008: 374).

Kymlicka (2010) put forward the notion that, contrary to the declared death of multiculturalism, there is in fact no retreat of multiculturalism discernible in the global context. Rather, the opposite is found. Also, with regard to the broader European context, there is no question of a general return to classical liberal and Republican notions of difference-blind citizenship.

Instead, there is a specific problem with the post-immigration context in Europe, in reference to the position of Islam and of Muslims. In this respect, the two central conditions for multiculturalism have become increasingly unfulfilled, Kymlicka argues. These conditions are both about trust. For multiculturalism to work, there has to be a context of relative trust between minorities and majorities, both at the level of security and at the level of respect for human rights. With regard to the first level, as increasingly seen in recent decades, a context of securitisation with regard to Islam has arisen which undermines the minimum level of trust necessary for multicultural policies to have enough support among majority populations. The securitisation of Islam has been analysed by Cesari (2010), Foblets and Carlier (2010) and Edmunds (2011). These authors find exceptions being made to multicultural governance - and even to liberal democratic governance - towards Muslims in processes of securitisation under way in European countries. 'Securitisation' in general is understood as the framing of something, a person, or a group of persons, in terms of a risk to security (e.g., public security, public order or national security). Such a framing tends to lead to justifications of exceptions to normal, everyday governance (Huysmans 2006).

With regard to the second level of trust, that of human rights, Kymlicka (2010) argued that some practices by some Muslims have led people to think that at least some of their specific claims cannot be understood in terms of multiculturalism-as-citizenisation, because they are made in the name of patriarchy or illiberal ideology. So neither context of trust is fulfilled in the European context today. In Kymlicka's (ibid.: 45) rather straightforward terms, 'Muslims are often seen as both disloyal and illiberal', and both tendencies have undermined multiculturalism with regard to Muslims locally. ${ }^{10}$

So now we are back at the idea that there is something specific about Islam in Europe which prevents multicultural equality from being applicable, and thus to a gradual and almost unnoticed bifurcation within multiculturalism. This bifurcation has remained relatively 
unnoticed because of the increasing concentration on the position of Islam, and through the introduction of the secularism/religion framework in dealing with questions about the position of Islam in European countries.

We can contribute to multicultural answers to this state of affairs with regard to Islam in Europe in several ways. One way is by diversifying and historicising images of Islam and of Muslims and examining how Muslim practices and claims fit within secular and liberal frameworks. This avenue is one that has been extensively followed within the academic literature in recent decades (March 2009; Bowen 2010a; Bader 2011). Also, much has been written about the illiberal practices and beliefs which are often ascribed to Muslims. Multicultural reasoning is a way of dealing with the hard cases where the question of the compatibility of specific religious and cultural practices with liberal norms is at stake (Shachar 2001; Bader 2005a, 2007 and 2010b; Brahm Levey 2009).

Written histories of the Islamic world itself are important as well, especially the continuing criticisms of orientalist and culturalist frameworks. It seems necessary to rewrite the highly mediated narratives which pit bad, political Islam against good, secular, modern or moderate Islam, as if Islamic theories are pure ideologies or 'belief systems' instead of the outcome of centuries of global political interaction (see, e.g., Mamdani 2004; Asad 2006; Leezenberg 2008; Maussen, Bader \& Moors 2011). Significantly, considerable attention has been paid to the diversity of the reform movements within Islam itself (Abu Zayd 2006).

Furthermore, attention has been given to identity formation and identity blurring on the part of young people with a migrant and Islamic background in European contexts. Hybrid popular cultures are emerging that mock overly-zealous Islam, but also assimilationist practices such as the promotion of the 'right to insult'. According to contemporary anthropologists and sociologists such as Agnus Marsden (2005), Sindre Bangstad (2009), Jeanette Jouilli (2009), and Annelies Moors (2011), Islamic identities can be hybrid and simultaneously pious or orthodox, underlining the complexity of these notions themselves.

With regard to hybridity, however, we also run into a problem. When hybridity becomes not only an empirically established way of being for some Muslims but also a norm, with the assumption that a liberal way of experiencing religion should emerge, exclusion can be directed at those who fail to live up to the norm. It is directed not just at those who actually fail to live up to the norm but also at those who are 
perceived as not being hybrid, even if they actually are - for example, when they wear a headscarf. Therefore, if hybridity transmutes from a practice by some into a norm imposed on all, minorities, especially religious minorities, may have to constantly prove that they are hybrid enough to be accepted by majorities. This is an implicit endorsement of a cultural hierarchy that then inevitably keeps affecting practitioners' positions as Muslims, integrated though they may be. This problem is comparable to the one discussed earlier regarding integration as a norm and is analogous to the paradoxes of assimilation studied later in this volume (see also Modood \& Meer 2008; this volume Chapter 3).

This brings us to the necessity of looking not only at Islam or at Muslims, but also at the cultural and conceptual playing field on which Muslims have landed. The issue is not just that of Islam or Muslims, or even of policies for dealing with religious minorities, but actually the cultural embedding of present-day categories and practices. In order to overcome the impasse in which multiculturalism has ended up with respect to the position of Muslims and Islam in Europe, and in which integrationism, racism and a religion that is under pressure all play a part, a great deal of work needs to be done involving a history in which assimilationist and secularist ideas and images are intertwined. Such a history posits concepts and images of modernity, citizenship and secularity as a radical break with a past of traditionalism, religion and communitarianism. This history has led to expectations regarding ethnic and religious minorities in terms of premodern, religious people who have not yet been sufficiently 'citizenised' to participate as equals in the public sphere. We are required to show that present-day interpretations of Islam stand rooted in a modern European history in which combined ethnic and religious identity formation is already seen as problematic. We must further oppose the idea that this European past was one of old assimilation in the heyday of forcible nationstate formation, from which we can easily distinguish our globalising, multicultural and 'neo-assimilationist', or in any event liberal, present.

In this regard, I find myself in disagreement with Kymlicka's suggestion that there is no going back to the old liberal or Republican concept of difference-blind citizenship, and that only the present-day situation in regard to Islam is important in explaining the aversion to multiculturalism. It is in the ambivalent relationship between difference-blind citizenship and (nationalist) particularism that assimilationism has played a role in European countries, and continues to do so. Particularly important here is to look at France. It would be incorrect to say that France still has a paradigmatic status regarding freedom and equality in the Western world. However, the French response 
to the presence of Islam, and especially to issues concerning headscarves, is in another sense thoroughly paradigmatic: the amalgam of secularism, an ideology of difference-blind citizenship, and simultaneous processes of securitisation and racialisation constitutes a response, as also seen in other Western countries, to the present-day situation involving Islam.

The modernist conceptualisation of citizenship gained a hold on European history in post-revolutionary France, especially in the France of the Third Republic. At that time, experiments were conducted with equality and freedom in ways that were regarded as radical and new. Questions about the position of minorities were addressed as well, in particular, on integration, or assimilation, of the Jews. They were a minority with intermingled ethnic and religious characteristics, just as Muslims are today, and they stood at a point where their visible ethnic-religious difference seemed poised to either transform gradually into a (private) religious difference or to disappear entirely. Assimilation, however, did not happen. Instead, there emerged in the course of the 19th century reinforced, racialised forms of difference. Their emergence has been paradigmatic in the literature on the paradoxes of assimilation, to which the next section turns in more detail.

\subsection{The paradoxes of Jewish assimilation in France and the prism of In Search of Lost Time}

My intuition about the need to establish a more complete link between multiculturalism, assimilation and secularism was triggered by an observation about the European debates on secularism and assimilation, the French debates in particular. I noted that most contemporary debates about multiculturalism, secularism and integration made little or no reference to the ambivalent experience of Jewish assimilation in Europe after the French Revolution, especially in France itself up until World War I.

References to French Jewish history were not entirely absent. For example, the by now well-known report by the Stasi Commission on secularism (laïcité) advised the prohibition of 'conspicuous religious signs' (including headscarves) from public-sector schools and in public services. The commission made reference to the 'melting pot' and Franco-Judaism, both of which are crucially related to the history of assimilation. The commission viewed these as positive models for the secularisation of minority religions today. ${ }^{11}$ 
Yet, it is also important to bring contemporary debates about secularism into dialogue with what Zygmunt Bauman (1988) first called the 'paradoxes of Jewish assimilation'. ${ }^{12}$ Doing so might lead to a more critical scrutiny of today's French melting pot. Briefly, and in connection with our earlier discussion in this chapter, we might say that assimilation is paradoxical because the promise of assimilation, which implies full and equal citizenship for members of specific minorities on the condition of privatising their differences, is compromised, complicated and even contradicted by the structure of this condition itself. For instead of effacing differences or rendering them irrelevant, the very collectives and particularities that should be privatised are continuously remembered and reinforced, either consciously or unconsciously, through the effort to control access to the public sphere. In sum, assimilation tends to install a process that keeps wanting to efface a difference that is at the same time constantly affirmed. American political theorist Patchen Markell (2003: 146) formulated a trenchant analysis of Jewish assimilation when he said that the central paradox of assimilation is that the 'state must see at all times that each Jew has ceased to be Jewish'.

My reading of the work of Marcel Proust scrutinises this process of screening, noting that it is not reserved for the state. Rather, it becomes a habitual practice in many contacts between citizens of Jewish origin and their native French co-citizens.

Hannah Arendt (1979 [1948]) first analysed the paradoxes in Origins of Totalitarianism, already making Proust her chief witness of these paradoxes. She basically thought that the privatisation of Judaism did not lead to its disappearance, but instead, led to its racialisation. Thus, having a Jewish background came to be seen less as a collective characteristic, but more as an individual quality of the biological individual. Thus, after they had left all or most of the particularising and collective aspects of their religious culture behind, and had fully secularised and interiorised Judaism into what Arendt (ibid.) called 'Jewishness', they were confronted with the fact that this did not at all mean that being Jewish had lost its social or political relevance. That relevance had in fact increased in unexpected and quite undesirable ways that became manifest in the anti-Semitic Dreyfus Affair (1894-1906).

Very briefly summarised, the Dreyfus Affair unfolded as follows. In October 1894, Alfred Dreyfus, a captain in the French army, was accused of high treason; he was said to have procured military information for the Germans. His family was one of the many Jewish families that originated from Germany. They had lived near the border in Alsace for decades, and after emancipation gradually advanced 
socially and moved to Paris. From the beginning it was clear that the evidence on which the accusation of Dreyfus was based was unreliable, but it took five years for Dreyfus to be released from Devil's Island, where he was exiled and badly maltreated. Only after twelve years of struggle on the part of his family and an increasing number of socalled 'Dreyfusards' was his innocence finally established, in 1906.

The fact that Dreyfus was Jewish played an important role in the suspicions cast upon him. Dreyfus himself was convinced of this from the moment he was accused. The anti-Semitic press, headed by Édouard Drumont, revealed Dreyfus' Jewish identity on 1 November, before any details about the precise accusation were available (Burns 1991). Although Dreyfus was a fully secularised, assimilated Jew, very loyal to the French Republic, some people considered him a likely suspect of treason because of his multifaceted identity as a Frenchman and a Jew. Dreyfus himself considered this latter identity private and irrelevant to his functioning as a citizen of France.

Partly on the basis of her reading of In Search of Lost Time, Arendt (1979 [1948]) suggested that the Dreyfus Affair brought to light that Christian anti-Semitism had not been eradicated with the advent of modernity. It had been transformed instead: the crucial problem the Jews encountered was that their assimilation had led to new forms of particularisation and exclusion. Later authors have refined the analyses of the paradoxes of assimilation and of why they occurred so conspicuously in the context of French Judaism. Wendy Brown (2004: 5) extended the understanding of the process of racialisation through a reading of changing epistemological frameworks in 19th-century French thought. According to Brown (ibid.), 'becoming citizens' for the French Jews after the French Revolution should be seen in terms of a threefold process of 'decorporatisation' of the Jews as a collective, their incorporation (or assimilation) as citizens, and marking them as different.

Brown, like Arendt, considers the processes at work in 19th-century France as specific to that case. However, both also refer to the French Jewish experience in order to understand how easily modern processes of incorporation more generally can turn into those that have their own differentiating and even exclusionary effects. In that sense, to them, the French Jewish experience is an example of a general paradox in the modern idea and practices of citizenship.

The paradoxes of assimilation have also been explored by historians of French Judaism such as Shmuel Trigano, Pierre Birnbaum, Esther Benbassa, Max Silverman and Elizabeth Bellamy. These authors have systematically linked the paradoxes of Jewish assimilation with the 
position of religious, ethnic and racial minorities in today's France (and historically in the French Empire), and with the position of minorities in modernity more generally. French historian Pierre Birnbaum (2008) considers processes of what he calls 'disassimilation' as central to the Jewish experience in the Western context, and in Europe specifically. He uses disassimilation similarly to the way that I use 'paradoxes of assimilation'. Benbassa (2003) placed the analogy central in her book La France face à ses minorities: Les Juifs hier, les Musulmans aujourd'hui (France Facing Its Minorities: Yesterday the Jews, Today the Muslims). The link between Jews in the past and Muslims today is that these groups seem to acquire a paradigmatic status in defining a paradoxical relationship between the state, religion and individual citizens.

Such an argument brings us closer to the idea that assimilation as a strategy for incorporation tends to be paradoxical in general. Alexander (2001, 2006), as we saw in earlier, asserts that the screening of those who are assimilated by the majority implies a confirmation of the separation between what is private and what is public and an accentuation of the differences that are deemed undesirable in the public sphere. That was and still is the core of the moral and political paradoxes of assimilation.

In this sense, analysis of the paradoxes of assimilation with regard to the French Jews accentuates a problem contained within the concept of assimilation itself. This is not just specific to the situation of French Jews in post-revolutionary France. The situation then in France was merely more significant because so much value was attached to the promises of emancipation and equality of 1791. Thus the disappointment was great when anti-Semitism gripped France in the form of the Dreyfus Affair. The disastrous history that unfolded afterwards led to widespread sensitivity about the 'precarious assimilation' of the French Jews, to use the words of Walter Benjamin (1980 [1938]).

My reading of Proust's novel takes up and elaborates on this general analysis of the paradoxes of assimilation, while also showing that assimilation in practice is very complex. It implies a range of practices, images and concepts. This not only helps us to acquire an insight into the subjective and intersubjective ambivalences of assimilation, which may affect our evaluation of its political and moral merit for a contemporary debate. The literary character of Proust's work, particularly his deployment of intertextuality and metaphor, makes it possible to study the complicated social and political effects of the expectation of assimilation in a way that includes its effects on social imaginaries. This is a new approach to the paradoxes of assimilation, enabling us to scrutinise the emergence and deepening of such paradoxes over time and 
to examine their relations to expectations about secularisation and to processes of racialisation and culturalisation.

Therefore this book, in a sense, travels a different road from the more direct approach of analysing the paradoxes of assimilation in their most general form. With a reading of assimilation through the prism of Proust's novel, I veer off from general analyses, which detect in assimilation the fundamental paradox of modernity. My argument is not that there is a French semi-transhistorical, post-Revolutionary model of Republican integration that necessarily leads to these paradoxes, whereas a multicultural model would not. That would be a somewhat too static analysis. It will become clear that models, including the Republican one, contrast with actual practices, which tend to be rather muddled affairs. At the same time, however, models do impact on practices. My reading of the Proustian novel contributes insights into how profound, though sometimes unexpected, this impact can be.

My reading of In Search of Lost Time therefore focuses on its presentation, narration, rendering as ironic, performance and analysis of the oblique and long-term practical and discursive effects of the requirement to assimilate. Proust's novel provides a unique perspective on the way these expectations worked in the long run and in practice. Analysing the experience of assimilationism as invoked in Proust's novel is crucial to establish the 'history of the present' of ethno-religious diversity in France - and also in many respects more generally in Europe. Doing so helps us to gain insight not so much to ethnoreligious diversity itself, but to its construction through a modernist lens which is deployed without reflection on binary categorisations of citizen/foreigner, tradition/modernity and religion/secularity. It helps us to reflect on these categories as co-constitutive of each other and on how they are formed in the interaction between minorities and majorities, of citizens and yet-to-become-citizens, instead of preceding them. My reading also shows how these ideal-typical and stereotypical distinctions are undermined in the very plot of the novel. In this respect my reading of the novel does not focus on the experience of assimilation, but rather, provides a critical rebuttal of the modernistic framework within which current ideas about multiculturalism, assimilation, secularism and citizenship tend to be debated.

My reading of the narrative threads concerning the Dreyfus Affair makes clear that political conflict can easily undo forms of recognition among citizens which have been built up over considerable periods of time. This happens when conflicting parties require simple, binary forms of identification, and when it becomes less easy to adopt layered and complex identities. One central idea turns out to be that discourses 
about assimilation and integration can contribute to the questioning of loyalty, especially if historical circumstances encourage this. I argue that processes of securitisation with regard to Muslims taking place today can also be considered such a circumstance. Proust's work enables us to trace the experiences of those who were only just discovering what it means if the fundamental tenets of assimilation are not challenged when a context of conflict and security arises, even though these tenets had previously seemed to be working perfectly.

\subsection{Outline of the chapters}

Chapters 2 and 3 critically evaluate, from a multicultural perspective, the views of two prominent contemporary currents in socio-history and sociology. In the European context, these have called for the reintroduction of assimilation as an acceptable, even necessary, concept for understanding and normatively evaluating processes of incorporation. Chapter 2 discusses the path-breaking work on assimilation done by French historian of immigration Gérard Noiriel. Chapter 3 discusses the new assimilationism of sociologists Rogers Brubaker, Eva Morawska and Christian Joppke. These currents were already briefly introduced in this chapter.

Each of these two groups of scholars have their own ways of actively proposing their notions of assimilation as alternatives to multiculturalism in the European context. Because of the normative dimensions, their views deserve a reply from a multiculturalist perspective, which is usually oriented towards political theory rather than sociology and history. A central question is if and how both groups of scholars can take into account the idea that the rules of the game itself and the 'us' that defines these rules should also come under discussion in a democratic polity in notions of assimilation. This is, however, not meant to suggest that this choice provides an overview of the larger sociological debate on assimilation as it has especially been developing in the American sociological context in recent decades.

The views of the two groups of scholars are discussed in separate chapters because of a salient disagreement between them. Elaboration of that point of discord brings me to an introduction of my own critical reading of assimilation, and an explanation of why I focus on the paradoxes of assimilation in the French late 19th-century Republican context later in the book. Although Noiriel was mentioned as a precursor by the new assimilationists Brubaker, Joppke and Morawska, there is one crucial difference between them: Noiriel does not assume the lib- 
eral categories of liberty, freedom and autonomy for the private sphere, as Brubaker, Joppke and Morawska do. This makes their concept of assimilation justifiable from a liberal moral perspective. Instead, Noiriel stresses the inherently violent and illiberal aspects of assimilation as a social process, arguing that full and undivided citizenship can be the only just response to inevitable suffering. In that sense, Noiriel sticks to our first meaning of assimilation as homogenisation, while the liberal assimilationists are committed to the second meaning of assimilation, as adaptation to a majoritarian public sphere with a guarantee of private liberty.

A central query emerges from my comparison of the two groups of scholars' understandings of assimilation: Can liberal requirements for assimilation, which strive to leave habits and beliefs free and which only require adaptation to a central but limited, publicly-shared, moral, legal and political set of rules and values, ever be neatly separated from pressures to assimilate more comprehensively in the everyday context of European societies? Chapter 2 criticises Noiriel's ultimately dark and illiberal view of historically necessary homogenisation as the kernel of incorporation. It makes a case instead for a more multicultural standpoint, on both empirical and normative grounds. However, Chapter 3 argues against the new assimilationists' overly optimistic projection of the abstract theoretical opposition between assimilation as homogenisation and assimilation as free adaptation onto European history. They contrast pre-World War II assimilationism with the new liberal assimilation, and, analogously, pre-World War II ethnicised citizenship with contemporary de-ethnicised and dual citizenship. I argue instead that it is crucial to consider the memory of Europe's assimilationist past more seriously and less schematically, to consider it rather as a mirror instead of as a distant past.

Such a programme of memorial self-reflection is provided by scrutinising the vicissitudes and complexities of 19th-century assimilationist France as perceived and narrated by Marcel Proust. Transit I reflects on contemporary questions about assimilation, secularism and multiculturalism and how they can be responsibly addressed by drawing analogies, however carefully, with the pre-World War II history of the European Jews. This section also explains my methodology for analysing 19th-century assimilation via a contextualised reading of In Search of Lost Time, and situates my reading in relation to earlier interpretations of the position of the Jews in 19th-century France through readings of the novel.

Chapter 4 and 5 explore In Search of Lost Time's perspective on the history of Jewish assimilation in 19th-century France. Chapter 4 inter- 
prets the character Alfred Bloch's 'integration test' at the threshold of the home of the protagonist's family, describing how this can be read as a response to the French historical discourses of Emancipation and assimilation of the Jews. The chapter further examines the novel's suggestion that certain aspects of Judaism - practical, visible, partly public aspects - did not disappear as a result of its privatisation. Rather, these were transformed into cultural memories, inhabiting an unspeakable semi-private, semi-public sphere. In reply to the readings of assimilation discussed in Chapter 2 and 3, I focus on whether and where we can trace, even in the historical period usually connected to nationalist, homogenising and paradoxical assimilation, minimal spaces for Alexander's 'multiculturalism as a project of hope', thanks to the ways in which the novel interweaves various alternative and critical voices within assimilationism.

Chapter 5 further explores the Proust novel's narration of the role of cultural memories of difference in how assimilationist expectations work out in practice. Proust's literary techniques, particularly his metaphors, make such memories accessible. Such a reading of the Proust novel complicates French historian Théodore Reinach's (1901 [1884]) definition of Jewish assimilation. Reinach understood assimilation in terms of the decollectivising of ethnic-religious backgrounds into a secularised form, with only a privatised religious Judaism remaining. My reading of the Proustian metaphors makes plausible that it was precisely the attempt at privatisation and decollectivisation of religious belonging, in accordance with the aims of secularism, that led to new forms of collective identification in terms of memories of difference and to persistent 'evidence' that full assimilation was not yet complete. I compare my reading to Hannah Arendt's, Zygmunt Bauman's and Esther Benbassa's analyses of the paradoxes of assimilation while focusing on the role of modernist expectations about secularisation in the emergence of these paradoxes.

Transit II argues against seeking the legacy of modernist assimilationism and the accompanying secularism in explicit practices, policies or laws trying to render religion invisible - or even seeking it in attempts to ban religious arguments and symbols from the public sphere. These interpretations of laïcité are explicitly excluded from most recent French and international attempts at rethinking the concept. Rather, I argue that the problem lies in the modern dichotomous conceptual distinctions that are still being used to understand the relation between religious belonging (appartenance) and freedoms of the individual citizen (e.g., modernity versus tradition, religious communitarianism versus liberal autonomy, culture versus 'deculturalisation' 
and citizenship versus ethnicity), including their relation to the emergence of concerns for security and public order.

These hypotheses are corroborated in Chapter 6 and 7. Chapter 6 is a study of the philosophical background of laicism in the French Third Republic (1870-1914). Contemporary political philosophers dealing with the French headscarf laws have often argued that these laws have been the result of intransigent, theologising and moralising secularism inherited from the Third Republic. They argue for a more moderate or liberal laicism as an alternative (e.g., Maclure \& Taylor 2011). This chapter argues that we need to question instead the secularism-religion framework itself. To do so, I first trace the concept of the interiorisation of religion in the neo-Kantian ideology of laïcism in the Third Republic and reflect on one of the early Republican deconstructions of neo-Kantianism, that of French sociologist Émile Durkheim. This genealogy is cast in relation to Talal Asad's (2006) reading of the legacy of neo-Kantianism in contemporary secularism, which he relates to the emergence of the security framework in France. I argue for a more political-historical account of the secularist legacy and its relation to securitisation than Asad gives us. By navigating between readings of Maclure and Taylor and of Asad, the chapter reflects on what secularism does as a specific framework for understanding the position of religious and ethnic minorities, and of Muslims specifically, in today's French context.

Chapter 7 critically analyses the Stasi Commission's 2003 report from the perspective developed in Chapter $6 .{ }^{13}$ It argues that to answer contemporary questions concerning the deep chasms and inequalities that have emerged in the context of postcolonial migration, we must deconstruct the dichotomous opposition between laïcité and communautarisme, as well as the underlying opposition between freedom and belonging inherited from the French Enlightenment. The chapter then turns to a democratic critique of secularism in line with Bader's (2007) approach to the relation between democracy and secularism. The last step is interpretation of fragments from the work of the contemporary French Islamologists (islamologues) and scholars Gilles Kepel, Alain Touraine, Marcel Gauchet and Olivier Roy concerning the relation between religion, culture, security and politics in the public sphere. At crucial points in their analyses, they all share a modernist legacy with regard to their interpretation of modernity, secularity and religion, independent of their standpoints regarding the headscarves or laïcism. Yet, in order to develop an alternative framework we need, first, to pay systematic attention to the distribution of power and to minority-majority relations. Secondly, we must critically rethink the relation 
between religion and culture in the sociological concept of secularisation that underlies the political-philosophical concept of lä̈cité.

Chapter 8 returns to the paradoxes of assimilation and to how they are narrated in In Search of Lost Time. This chapter, in particular, comments on Walter Benjamin's reading of Proust and what Benjamin (1980 [1938]) called 'modern experience' and the 'precarious assimilation' of the European Jews. I interweave a commentary on Benjamin's reading with a tracing the novel's narrative of the gradual exclusion of the Jewish character Charles Swann from the Parisian salons where he had been at home for at least 20 years at the time of the Dreyfus Affair. The focus here is on the suddenness of the distrust of the Jews in that context, though this distrust is associated with the assimilationist expectations that preceded the Affair. In dialogue with Gilles Deleuze, Veit Bader and William Connolly, I present a reading of how individual memories are subtly moulded by their connections with the collectives to which they are affectively linked, particularly in times of deep cultural conflict such as the era of the Dreyfus Affair. The discussion simultaneously looks at what room is left for critical, alternative voices within the narrative itself.

The book's conclusion brings together thoughts on what multiculturalism we need if we want it to form an answer to the paradoxes of assimilation and secularism.

\subsection{Disciplinary note}

This book is the result of interdisciplinary work connecting sometimes surprisingly segregated disciplines, most notably political philosophy, social theory, the sociology and history of migration, French studies, and cultural and postcolonial studies. Its primary intention is philosophical, but not in the way philosophy is often understood today, in terms of constructing a normative theory. Rather, the philosophical aspiration of the book has an affinity with a firm although not too vociferous tradition in critical philosophy which aspires to philosophise in the manner of a 'critical activity' rather than in composing ideal theory. Such a conception of political philosophy was nicely formulated by Iris Marion Young (1990: 5), when she said that our sense of justice does not arise from looking, from the old metaphysical activity of 'theorein', but from listening, and reacting to the voices of those who are treated unjustly. According to Young (ibid.), this sensitivity to injustice does not end with the product of looking, observing and ordering, namely a theory. Rather, it leads to a heeding of calls, pleas 
and claims upon some people by others, and ending up, if everything goes well, in a normative reflection that is historically and socially contextualised.

James Tully (2002: 534) formulated a similar programme for critical philosophy as follows:

Rather, it [political philosophy as a critical activity] seeks to characterise the conditions of possibility of the problematic form of governance in a re-description (often in a new vocabulary) that transforms the selfunderstanding of those subject to it and struggling within it, enabling them to see its contingent conditions and the possibilities of governing themselves differently. Hence ... it is also a specific genre of critique or critical attitude.

In this book I radicalise both Tully's and Young's perspectives in a specific sense. Whereas they take a step back from normative theorising, they remain committed to a predominantly argumentative style, and to the idea that philosophy, as philosophy, has to re-describe, systematise or evaluate voices from outside, those that are heard either in social movements or perhaps in literary or other artistic works. The interdisciplinary challenge for my project was to merge philosophy more fully with extensive literary analysis and historical-sociological research, trying, however, to keep sight of a specific set of normative questions about freedom, justice and democracy that are systematically and consistently called for in contemporary political philosophy.

Beyond the recent critical social philosophies of, for example, Young and Tully, older critical philosophy had a tradition of literary and public engagement that is sorely missed today. The neo-liberal academy is a rather closed institution, in which it is difficult to resist pressures for specialisation and commodification. What barely flourishes there is the more literary-oriented, essayist side of earlier critical philosophy, based on an intuition shared with today's cultural studies. This is the intuition that literature, art and music can help us to analyse what early cultural studies theorist Raymond Williams (1961) called 'structures of feeling' of a specific period of time, while also helping us to better understand the present. Structures of feeling are 'present in almost all the novels we now read as literature, as well as in... popular fiction' (ibid.: 84). Works of culture can form 'social formations of a specific kind which may in turn be seen as the articulation of structures of feeling which as living processes are much more widely experienced' (ibid.: 133), and they give us entry points to those 'elements of social and material experience which may lie beyond, or be uncov- 
ered or imperfectly covered by, the elsewhere recognisable systematic elements' (ibid.). A method to uncover such structures of feeling has been called 'cultural analysis', insofar as it can be conceived as a selfreflexive interdisciplinary practice of interpreting cultural objects that considers the object under scrutiny as 'present, showing, arguing, and speaking' (Bal 1999: 7), and that tries to 'make the object speak back', to make the 'subject matter into subject, participating in the construction of theoretical views' (ibid.: 13).

My reading of Proust combines such a cultural-analytical approach with a rethinking of earlier interpretations of Proust's work by authors who have analysed Proust's novel as a testimony to the paradoxes of assimilation as broadly experienced by the European Jews at the time of the Dreyfus Affair. An innovative aspect of my reading is my situating the novel in the context of the 19th-century emergence of the intricacy of secularism and assimilationism. By reading Proust as a literary reflection of that intricacy, I allow the novel to participate in the current normative debate about multiculturalism and secularism, providing a deep, affective genealogy to the emergence of the paradoxes of assimilation and their connections to secularism.

Such a composite methodology, I will try to convince the reader, is one way to remain faithful to the legacy of critical Enlightenment thinking. But it does so in such a way as Michel Foucault proposed long before the Enlightenment became a central concept in a struggle for definitions about France's, and more generally Europe's, relation to secularism, assimilation, religion and multiculturalism:

[T] he thread which may connect us with the Enlightenment is not faithfulness to doctrinal elements but, rather, the permanent reactivation of an attitude - that is, of a philosophical ethos that could be described as a permanent critique of our historical era ... It even means precisely that one has to refuse everything that might present itself in the form of a simplistic and authoritarian alternative: you either accept the Enlightenment and remain within the tradition of its rationalism ... or else you criticise the Enlightenment and then try to escape from its principles of rationality (Foucault 1997 [1979]: 312-313).

This is a useful perspective in the present-day French context. But it is also valuable more generally in the current European context, in which public discourse is increasingly rife with arguments presenting the Enlightenment heritage as a fixed set of norms that we can be for or against by being 'pro' or 'anti' modern, particularist or universalist; religious or rational; worthy inheritors of 'radical Enlightenment' or 
somewhat rather cowardly, overly pragmatic defenders of a moderate Enlightenment that compromises with religion. In an attempt to contribute to a culturally and historically informed philosophical criticism, my focus is on what is happening in Europe today with respect to migration, multiculturalism and secularism, because fundamental issues from Europe's own history remain absent from these concepts and practices related to them. 


\section{Assimilation in the French sociology of incorporation from a multicultural perspective}

To depart from the present in order to deduce the past from it is a way to feed the history of the winners at the cost of the vanquished, the history of those who have left a trace of their passage at the cost of the invisible, of those without voice ... the large majority of foreigners who have immigrated to France in the past have not stayed. These tens of millions of people have given their opinion on 'the Republican model' through the only means of expression that the Republic has left to them: by fleeing to other, more hospitable regions - that is to say, by 'voting with their feet' (Noiriel 2002: 2, my translation).

\subsection{Why reintroduce assimilation?}

Assimilation is a rather unfriendly concept when used in a social context. In French, it generally means an act of the mind that considers (something) as similar (to something else). A relevant secondary meaning is the action of making (something) similar (to something else) by integration or absorption. This meaning has existed in physiology since 1495. Around 1840, the concept was related to social processes for the first time, as the act of assimilating persons and peoples; the process through which these persons, these peoples, assimilate (themselves). This connotation incorporates terms like 'Americanisation' and 'Frenchisation'. The older physiological connotation shines through in early politico-sociological discourse about assimilation. André Siegfried, for example, one of the first French political scientists to become occupied with immigration in the mid-2oth century, spoke of 'the assimilation of these immigrants, inserted into the American organism in massive doses' (quoted in Noiriel and Beaud 1989, my translation). ${ }^{1}$

Salman Rushdie's Satanic Verses (1989) provides a cruel and ironic summary of assimilation in the story of adolescent Indian Salahuddin Chamcha's arrival at an English boarding school. The first thing 
that we learn about Salahuddin's contacts with 'the English' is that his classmates giggle at his accent and exclude him from their secrets. Yet these exclusions only increase Salahuddin's determination to become English. He begins 'to act, to find masks that these fellows would recognise, paleface masks... until he fooled them into thinking he was okay, he was people-like-us' (Rushdie 1989: 44).

On one of Salahuddin's first days at boarding school, a kipper is served for breakfast. Salahuddin soon has a mouthful of bones, but nobody shows him how to eat the kipper. He must finish it before he is allowed to leave the table, which takes him 90 minutes. Finally, Salahuddin realises that he has been taught a lesson: 'England was a peculiar-tasting smoked fish full of spikes and bones, and nobody would ever tell him how to eat it' (ibid.: 44).

After a few years in England, Salahuddin has experienced culture as Zygmunt Bauman (1998: 344-345) described it in the context of his critique of assimilation: 'Is not contempt, that license to snub and despise and kill, what culture is about?' Salahuddin's response is to become, outwardly, a fish himself. His face is described as 'handsome in a somewhat sour, patrician fashion, with long, thick, downturned lips like those of a disgusted turbot, and thin eyebrows arching sharply over eyes that watched the world with a kind of alert contempt' (Rushdie 1989: 33).

The opening quote to this chapter, by Noiriel (1992: 86), makes clear that he does not idealise classical Republican ways of incorporating migrants. He understands assimilation as 'the social process that leads to the more or less forced homogenisation (linguistic, cultural, political) of the members of a group'. What leads a scholar as critical as Noiriel to argue for reintroducing a concept of assimilation? How should we interpret the relationship between the empirical and normative aspects of his understanding of the concept?

Noiriel's contribution to the debates about multiculturalism and assimilation can be read as a nuanced and empirically dense version of a French intellectual and sociological tradition in which elements of the Marxist and Republican traditions are simultaneously emphasised in interpreting the position of migrants in contemporary France. This is a tradition in which others also participate, including Pierre Bourdieu, Étienne Balibar, Alain Badiou and Olivier Roy. These authors consistently emphasise the importance of economic and urban exclusion, and the distortion by mainstream media of conflicts concerning migrants in terms of their cultural, Muslim or Arab backgrounds. They rejected the law on headscarves, but not primarily on the basis of arguments about religious liberty, nor based on multicultural arguments. Instead, 
they interpreted the law in terms of an exclusionary measure against a racialised class (Noiriel \& Beaud 2004; Geisser 2003; Balibar 2004, 2007; Badiou 2006). ${ }^{2}$

This chapter traces the development of Noiriel's analysis of the racialisation of assimilated youth in the 1990 os and early zooos. It examines how well argued and critical his analysis has been within the French context. However, it also anticipates an argument further developed in Chapter 3 and in the later chapters on laïcité. That is, Noiriel's interpretation of multiculturalism in terms of a differentialism imposed from above with only racialising effects mirrors the interpretation of multiculturalism in terms of a struggle for the conservation of culture. Yet this does injustice to the multiculturalism that we need in order to be able to criticise assimilationism and to conceptualise the contribution of social movements that make claims in multicultural or postcolonial terms. Towards that aim, this chapter first explains and then evaluates the relationship between the empirical and the normative aspects of Noiriel's use of the concept of assimilation, and his rejection of multiculturalism.

\subsection{Gérard Noiriel: Writing the history of power in the context of migration}

Noiriel developed his concept of assimilation by way of a larger project to trace the 'history of power' within the modern nation-state. He analysed the process of what he calls 'national assimilation' (Noiriel 1996a: 265) in order to understand 'how we can account for the success of dominant, national cultural norms in supplanting those local and immigrant cultures that were the wealth and diversity of French society' (ibid.). Hence, migration is a central issue in Noiriel's account of the history of power in the nation-state. His primary focus, however, was not on migrants as a special group, but rather on the ways migration has been involved in the 'social history of politics' in which other minorities (e.g., linguistic and regional) have also been central (Noiriel 2001: 41).

The fact that assimilation is the central concept of Noiriel's analysis of migration to France does not imply, as we have seen, that he defends the 'Republican model' of assimilation, for which France is well-known abroad, and which is often invoked as a counterexample to the politics of ethnicity and multiculturalism upheld in the Anglophone world. In actuality, however, as much as in many other European countries, the Republican model of assimilation, insofar as this 
implies a politics of national homogenisation, was officially rejected as a goal of French social politics from the 1980s onwards. The fact that Noiriel did not defend it is not exceptional, but in fact rather common. The idea of assimilation was replaced by 'philosophies of integration' (Favell 2001). 'Integration' was more in line with the terminology used in other European countries, and this convergence is not conveyed by the opposition of assimilation and multiculturalism. ${ }^{3} \mathrm{~A}$ brief sketch of these developments in France may help to situate Noiriel's concept of assimilation.

In the 1970s and 1980s, French intellectuals and politicians commonly held that the assimilation of earlier generations of immigrants and regional minorities had only taken place because it had been forced upon them in the same manner in which it had been forced upon entire populations within the colonies. Moreover, they asserted that assimilation should be rejected as a viable concept for immigration policies as well as for policies pertaining to regional languages. A preoccupation with respecting and preserving differences emerged among left-wing French politicians and also within the diverse French committees dealing with the incorporation of immigrants. ${ }^{4}$ In the policy advice of such committees, concepts like equality, solidarity, and social coherence, which appear to hark back to former French policies of national homogenisation, were nearly always surrounded and preceded by extensive declarations on the necessity of 'preserving' differences. In 1989, for example, the Commisariat Général du Plan stated the most important objective for social policies as the following:

to favour development of a dynamics of exchange that, while preserving the cultural specificities of the different components of society, contributes to the emergence of new social ties and establishes a social space that is sufficiently coherent (quoted in Kaltenbach \& Tribalat 2002: 35, my translation). ${ }^{5}$

In 1991, the Haut Conseil de l'Intégration once more defined integration:

[A set of policies that should] encourage active participation in national society by varied and different elements, while accepting the subsistence of cultural, social and moral specificities and accepting as truth that the whole enriches itself through this variety and complexity (quoted in Kaltenbach \& Tribalat 2002: 36 , my translation). ${ }^{6}$ 
Integration was presented as an alternative to assimilation. In order to explain the difference between the two, the committee emphasised the need for organised support for the 'subsistence' of immigrant cultures. Anticipating my impending argument about the French understanding of multiculturalism, I note that a perceived difficulty in mediating between cultural difference, on the one hand, and social coherence and equality, on the other, is at the centre of these debates about integration. This difficulty frequently leads to an understanding of multiculturalism as an ideology by which the state aids migrants in 'preserving differences' as opposed to an assimilationist ideology that aims merely to create social cohesion and stimulate social mobility and integration. I call this understanding of multiculturalism 'top-down differentialism', responding to a presupposed communautarisme from below. This understanding, which is by far the most common one in France, has inhibited more fruitful interpretations. ${ }^{7}$

One reason for the growing suspicion that differentialist integration might not be so ideal after all was the way the emphasis on difference was gradually usurped by the Front National over the course of the 1980 os and 1990s, in a manner quite shocking to those who, with the best of intentions, had advocated the right to difference. The Front National also called for the right to be different, but then only back in 'one's own country'. ${ }^{8}$ The respect for differences infused into political discourse seemed to lead to the belief that immigrants (and their children) 'are' different and that they should therefore never have left their countries of origin in the first place. This right-wing discourse took up the old discourses of inassimilability (inassimilabilité) that had stood at the basis of anti-immigration and xenophobic policies from the end of the 19th century onwards. Moreover, in the 1980 os and 1990s, the discourse surrounding the specific problems with immigrants from the Maghreb region increasingly began to present Islam as a factor causing their inassimilability (Noiriel 1996).

Such fears of inassimilability have a long history, and they kept resurfacing over the 2oth century, not just in extreme right-wing political parties. The origins of the discourse of an unbridgeable cultural distance is found in French 19th-century intellectual discourses, such as, for example, that of writer Maurice Barrès, historian Georges Vacher de Lapouge, and geographer Vidal de la Blache. Almost all categories of immigrants have at one time in French history been considered 'inassimilable': Germans who immigrated into the East of France before World War I; Polish, Armenian, Russian and East European Jewish immigrants in the interbellum period; and immigrants from North Africa after the 1960s. Discourses on inassimilability 
occur especially in the context of war and revolution: strong xenophobia existed against Germans after the 1870-1871 Franco-Prussian War; against Russians after the Russian Revolution; and against Maghrebis, especially Algerians, during the decolonisation of North Africa.

Theories of inassimilability did not remain the exclusive domain of the right or even of the extreme right. The left has contributed to them as well. Georges Mauco, migration expert of the Front Populaire - the left-wing united front against fascism in the 1930s - advised keeping the inassimilables out of the country: 'those who carry within them, in their customs and in their mind sets, tastes, passions, and the weight of ancient habits that contradict the profound orientation of our civilisation'. For this reason, Mauco considered Asians, Africans and the socalled 'levantins' (orientals) as 'undesirable' (quoted in Noiriel 2001: 39, my translation). Anti-Muslim and anti-Arab reactions after 9/11 2001 followed this trend (Guénif-Souillamas \& Macé 2004).

In the late 1980 os and early 1990s, it was not only right-wing politicians who spoke about immigration. Increasingly, socio-economic marginalisation and related problems within the French banlieues came to be explained in terms of the problematic integration of Arabs and Muslims. From the end of the 1980s onwards, a new current in sociology and political science, often explicitly referring to the heritage of Republicanism, started to problematise what it saw as the Americanisation of French politics, namely its increasing tendency towards communautarisme and identity politics. For example, Riva Kastoryano (1987, quoted in Noiriel 2001) wrote, 'the different regional, national, and ethnic ways of belonging on the part of the immigrant populations threaten the homogeneity of the nation-state', and 'the claims, whether identitarian or not, of religion threaten the cultural unity of the national space' (ibid.: 44, my translation and italics). Her worry was not a specific form of religion, but religion generally, which already announced the secularist framework. Moreover, from this quote we can surmise that it is ultimately the 'cultural unity of the nation-state' that worried Kastoryano, which closely connects secularism and nationalism in her discourse. Chapter 6 and 7 in this volume further discuss this worry about cultural unity as an important thread in the headscarf debates as well.

Noiriel developed his socio-historical concept of assimilation against these kinds of fears, which assume that the ethnically, religiously or regionally different backgrounds of migrant populations pose a threat to the coherence of the nation-state. These fears have produced mixed feelings, as remarked upon earlier, for many participants in French debates about the transition from assimilation to integra- 
tion. The debates on the headscarf affair testify to the fact that major social conflicts were increasingly explained in terms of their being produced by a too soft, ideologically and practically inappropriate philosophy of multicultural integration.

A main outcome of Noiriel's historical research is to demonstrate that fears of inassimilability have proven and continue to prove exaggerated, as well as being based on an inaccurate theory of (ethnic) belonging. However, Noiriel's concept of assimilation is not only an answer to xenophobia. It is also pitted against both the old Republican view of assimilation and the state-organised differentialism of the 1980s. At first, these appear to be each other's opposites. On the one hand, we have the 'republican view of the nation, [that] continually idealised the assimilation of successive waves of immigrants without inquiring about either the nature of that integration or its costs' (Noiriel 1996b: 162). Strong assimilationist policies were often called for in order to speed up this process. We find this view, for example, in the arguments of political scientist André Siegfried. He called in the 1950 s for a thorough 'de-racination' (e.g., by means of housing policies) and an accompanying advocacy of opportunities for integration among immigrants (quoted in Noiriel 2001: 38). On the other hand, we have the anti-assimilationist view that developed in the 1980s; a view that was once defended by Noiriel himself. However, according to him, the ideological differences expressed in these views are founded on the same error, namely their espousal of an overly political view of assimilation (Noiriel 1988: 263).

According to Noiriel, a historical reconstruction of the processes undergone by the various waves of immigrants to France and the United States shows that assimilation is something that is both endured and enacted by immigrants, more or less independent of the specific policies forced upon them. Assimilation, as such, forms part of the larger process of cultural homogenisation that accompanies the formation of the nation-state. We should recognise that assimilation is an inevitable process that migrants, and particularly their children, are destined to undergo, often at great psychological cost. This ought to be recognised by the receiving state and its majorities, and should be rewarded with unequivocal and full citizenship. Noiriel deployed his analysis of this underlying assimilation process to criticise what he sees as various myths about migration and the policies that have ensued from them. To explain his understanding of assimilation, he drew on the sociological theories of Émile Durkheim and Norbert Elias, on American sociology, and on empirical research conducted among immigrants in France. 


\section{Émile Durkheim, Norbert Elias ANd the CONCEPT OF 'NATIONAL ASSIMILATION'}

Noiriel's resistance to theories of the inassimilability of certain categories of immigrants is rooted in a long tradition within sociology founded by Durkheim. Durkheim's own theory of 'belonging' in modernity resulted from his struggle with right-wing French theories of national belonging. These stressed the ethnic ties of the French to either the Franks or the Gauls and presented the members of other ethnic groups as inassimilables, for a few generations at least, if not indefinitely. They excluded, therefore, people of different descent from the possibility of being loyal French citizens. Durkheim sought a way to refute these biologistic or geographistic theories without having to rely on the abstract contract theory of citizenship which the Republicans had taken from Rousseau at the beginning of the 19th century. Yet by the end of that century, it had proven insufficient for dealing with questions of belonging and loyalty (Noiriel 2001: 43).

From Durkheim, Noiriel adopted the idea that the modern nationstate profoundly shapes the ways in which individuals are related to each other and that this leads to a strong relativisation of the force of familial and ethnic ties. Durkheim thought that modern society, through the increasing importance of institutions like written language and law, had largely replaced the traditional 'mechanical' solidarity transmitted from parents or immediate (local) relatives to children with what he called 'organic solidarity'. In the modern state, earlier generations do not leave us their heritage by means of an immediate passing on of beliefs and practices. Rather, tradition is passed on largely through objective and material, institutional and collective forms. Hence, the materiality of the past is not denied, as in overly Republican understandings of collectivity in modern society, but the ways in which past forms are transmitted to individuals are reinterpreted. Heritage is no longer primarily ethnic, but becomes national. It is interiorised, partly unconsciously, by the children living with these past forms in their environments, and by the way public schools inculcate their pupils with these abstract ways of defining who belongs to the group, that is, the nation-state. This explains the enormous importance of schooling in Republican thought (ibid.).

Durkheim's theory was not developed in a politically neutral scientific climate. It was, at least partly, an attempt to argue, through solid theoretical argument, against the right-wing theories of what we could call 'mono-loyalty'. Durkheim, who was the son of an Alsatian rabbi, did not escape being questioned about his own loyalty. The insolence 
of these suspicions becomes clear when we read in La Libre Parole from 1916 that Durkheim is described as 'a German with a false nose who represents the war department, agents of which are swarming all over France'. Somewhat later, Senator Gaudin de Vilaine asked the committee charged with the reconsideration of permits for foreign residents to examine the situation of the 'French people of foreign descent like $\mathrm{Mr}$ Durkheim, a professor at our Sorbonne who, as has been confirmed, perhaps represents the (German) war ministry' (quoted in Noiriel \& Béaud 1991: 86, my translation).

Although it is probably exaggerated to suggest, as the French sociologist Jean-Claude Chamboredon did in 1984, that Durkheim's work can be read as 'a meditation on the correct way to be an assimilated Jew in contemporary France' (quoted in Noiriel and Beaud 1991: 69, my translation), this historical context explains Durkheim's sensitivity to the fallacies of ethnicity and to the inadequacy of purely Republican answers to right-wing ideas, a sensitivity that he shares with Marcel Proust. ${ }^{9}$

Durkheim's understanding of the changed role of cultural heritage in modern society contributed to undermine theories of the inassimilability of ethnic or ethno-religious 'others' held by the French right. Elias made it possible to understand the concept of assimilation in the context of a historical analysis of the social psychology of modern society. According to him, from the Renaissance onwards the monopolisation of taxes and public force by central authorities resulted in the pacification of society and the gradual development of 'civilisation'. In court society, codes of proper conduct were elaborated which spread through society as a whole as the result of a mutual assimilation process between the aristocracy and bourgeoisie. The aristocracy incorporated bourgeois elements and adopted some of their values; conversely, the bourgeoisie assimilated aristocratic culture, which, after the Revolution, spread across the rest of society. France experienced particularly strong mutual cultural assimilation processes between nobility and bourgeoisie (and subsequently also the popular classes). Over their course, external prohibitions and rules were increasingly internalised by individuals who acquired a place in increasingly long chains of interdependence, where people could start to move from one social circle to another. In Noiriel's view, this did not happen without conflict, but in the end led to homogenisation:

The relations of necessity by which people were conflictually united, given the weight of norms and the cruelty of social judgements, forced them to control their urges, to 'interiorise' good manners; consciously at first, 
and increasingly unconsciously from one generation to the next, through reflexes acquired in the early stages of childhood (Noiriel 1996a: 268).

Due to the force of this historical process, an education as a French person or subject came to profoundly influence individual behaviour, to the point of affecting people's body language and their affective, unconscious life. This provides a deep explanation of how the nation, with its hierarchical systems and heritage, forms us. It also helps us to understand assimilation at a level beyond the conscious adoption of dominant cultural values but also with the partly unconscious and largely uncontrollable wish to be recognised as 'one of them' at a deeper level.

\section{IMMIGRANT ASSIMILATION}

The framework provided by Durkheim's and Elias's theories of assimilation processes at work in modern society results in three theoretical starting points for Noiriel's understanding of immigrant assimilation. First, assimilation is something that immigrants, their children, and long-time residents share. Although immigrant assimilation is a process marked by some peculiarities, it shares many characteristics with the assimilation of any single individual or resident group into national society. Understanding the process in this way enables us to analyse the primary 'coexistence' between the French and immigrants, which helps, according to Noiriel (1996a: 269), 'transcend the litanies on "cultural differences" and the ambiguities of "ethnicity". Second, this framework makes clear that assimilation should be understood as operating both ways. It changes all of the groups involved, while making us recognise that there exist dominant norms and subaltern norms. Such an understanding ascribes a measure of agency to those in nondominant positions, without idealising this agency and neglecting the force of unequal power relations. Third, this framework can help us to understand the depth of experiences of national belonging, without reverting to naturalising explanations in terms of race, culture or national character. It explains the constitutive factors of these experiences in terms of history alone.

The particularities of the assimilation process relating to immigrants lead Noiriel to strictly distinguish between what assimilation means for immigrants and what it means for their children. Immigrants themselves did not go through the internalisation process of the social hierarchies of French society at a young age. Hence, the process is by no means as effective as it is in those who do grow up in 
France. Immigrants may or may not try to actively assimilate as much as possible. But the full force of the psychological process of assimilation does not touch them in the same way as it does their children. This is a reason for Noiriel's great reluctance towards assimilationism aimed at first-generation migrants and for his emphasis on the importance of recognising migrants' memories within the historiography of the nation-state. For first-generation migrants, problems of uprootedness and social isolation are aggravated by an assimilationism that includes, for example, the refusal to understand immigrants' desire to live in neighbourhoods with people of the same ethnic background.

On this point, Noiriel argues, we might learn from the early American sociologists of assimilation, who were not as assimilationist as we might think. He and Stéphane Beaud refer to sociological research conducted in the 1920 s by the Chicago School of Sociology (Robert Park and Henry Miller, William Thomas and Florian Znaniecki). These sociologists understood that it is important for migrants to have a collective life among those whose cultural background they share. This is not because they want to remain a separate group, but because only this makes their ultimate integration into larger society possible. Social bonds mediating between the individual and society are necessary. A second view that Noiriel adopts from the Chicago School is that conflicts between minority cultures and the larger society do not block assimilation; instead, they increase self-consciousness among minorities, which in turn conditions the possibility of integration (Noiriel \& Beaud 1991).

Noiriel criticises the Republic's amnesia and repression of immigrants' histories. Due to the Republican image of the immigrant as either a (future) citizen or a foreigner, French public memory and official history have rarely shown any interest in the history of immigration or in the origins of immigrants. Historiography should be opened up to the memory of immigration and should fully acknowledge immigrants' contributions to the wealth of the country (see as well Noiriel 2007). Attempts to release the historiography of France from its national orientation in a more fundamental sense are central to French postcolonial studies today (see, e.g., Thomas 2007; Swamy \& Durmelat 2012).

For the children of immigrants the situation is entirely different, according to Noiriel. They grow up in the new country. In the early years, there is potential for conflict between the values and habits transmitted by the parents and those that children are confronted with outside of their own home. The norms from outside are those of the dominant group, which often rejects the culture of the parents. 
This may cause inner conflict, since children (and adolescents) have a strong tendency to identify with dominant norms. Noiriel quotes narratives of French immigrants' children about their wish to be recognised as belonging to the dominant group. One of these stories, for example, is told by an architect of North African origin and French nationality, who tells of his dramatic experiences when he and others like him 'discovered our difference from other children':

[We] became aware of the way in which the other children saw our parents. And since that image was often negative, we rejected our own parents and tried to make friends with the other kids. These problems continued throughout our school years, culminating at around 14 or 15 years of age, in adolescence, a time that for me felt something like insanity (quoted in Noiriel 1996b: 170).

Accounts of these inner conflicts led Noiriel to think that the wish to be accepted by the dominant group is interiorised unconsciously and involuntarily. This 'appropriation of a dominant culture' is the most structural understanding of assimilation (Noiriel 1996b: 171). Here, assimilation is not a matter of pedagogy or attitude. Noiriel suggests that stigmatisation due to 'not being like the others' may constitute an important factor of assimilation: by interiorising the disavowing gaze of the other from one's early years onwards, individuals develop modes of behaviour designed to prove their belonging to the dominant majority. This is expressed in the story told by Rushdie's narrator in the anecdote opening this chapter.

The emotional price that individuals pay for assimilation, particularly members of the second generation, brings to mind, according to Noiriel, the 'odiousness' of all political measures or suggestions, even those made with good intentions, that promote the idea that members of the second generation are not like the others (Noiriel \& Beaud 1991: 277). This is where the debate on multiculturalism starts. According to Noiriel, things began to go in the wrong direction in the 1980s and 1990 s when, together with the rise of anti-racism, ethnicity came into focus as the location of the perceived specific problems with migrants from the Maghreb region. This was the time, Noiriel (1996b: 167) argues, that culturalism arose, which isolated culture from its concrete context and suggested that immigrants and their children could retain practically complete cultures, even though this is in fact impossible under the conditions both of the uprootedness of the first generation and of the deep assimilation of the second. ${ }^{10}$ 


\section{CRITIQUE OF 'ETHNICITY’ AND MULTICULTURALISM}

In Noiriel's view, the widely perceived specific problems surrounding the integration of persons of North African origin around the year 2000 were not caused by any specificity of this group, but by the changes in policies and perceptions with regard to immigration in general. ${ }^{11}$ In the late 1980s, immigrants from the Maghreb region had largely been divided into two groups. One group had experienced social emancipation and often developed into elites representing those less integrated. The other group was formed by individuals who had experienced social degradation, mostly because of the social effects of the perception of Arabs as a problem. This polarisation was caused by the fact that unemployment and social problems were less and less explained in socio-economic terms and attention was being focused more on the problems of the so-called 'second generation'. A combination of factors contributed to this new emphasis on immigrants' children, who came to be stigmatised as beurs, or people from North Africa. Main factors were the introduction of the social category of 'the youth'; the visibility that big urbanisation projects lent to the youth; the rise of media attention for immigration as a fundamental problem within society; the installation of the welfare state; the introduction of welfare workers specialised in migration; and finally, the loss of power of the workers' movement.

The importance of migrants' integration into French society spurred the investment of substantial resources in their emancipation; and the most privileged among them profited from this investment. But the perception of immigration as a problem, in particular with regard to 'Arabs', encouraged the stereotyping of children of North African origin as members of a problematic group, which is an important cause of contemporary racism. Those who have not achieved socially successful trajectories, for example, because of unemployment, are confined to the category that defines them as beurs, even if they are 'perfectly assimilated' (Noiriel 1996: 178). This has resulted in a major social problem of combined discrimination and marginalisation:

Continuously redirected to their ethnic origins, to a religion which the majority among them do not practice, to international political issues which concern them no more than the other French people, they are victims of a segregation that is not juridical but administrative, economic, social and cultural (Noiriel 2002: 5, my translation). 
The children of North African immigrants who came to France who in fact were invited to come at a time of great economic prosperity - are virtually all members of the working class. But they have learned to explain their problems in terms of racism rather than in terms of exploitation or unemployment. Moreover, Islam, as an ethno-religious identity marker, has come to be considered as a primary resource for the possibility of revolt, merely because its political invocation is an 'available vocabulary' (Noiriel 1996b: 178).

However, as Noiriel (1992a) argued, involvement in Islam for political reasons only weakens the position of immigrants' children, because defining oneself in ethnic or religious terms in a country as secularised and disenchanted as France has a much less powerful political meaning than defining oneself in terms of (social professional) class. And, we might add, this is the case even when doing so may intimidate or impress people (see also Benbassa 2007; Balibar 2007). According to Noiriel (2002), the resulting lack of a concrete political organisation of the unemployed 'working' class, which would channel dissidence and lead to integration, tends to turn today's popular uprisings against inequality into auto-destructive violence against vulnerable members of their own group. A similar view of political Islam is widely shared among the French left. For example, we find a similar argument in Balibar's (2007) comments on the 2006 riots in the French banlieues and in Badiou's (2006) comments about the headscarf law. Like Noiriel, they stress the weakness of political Islam in the French context, as it functions as a not-too-effective assertion of collective identity while the real problems are class-related.

Following this line of reasoning, Noiriel and Beaud (2004) explain the Republic's troubles with the headscarf in terms of racialisation and ethnicisation. Right-wing France, interested in presenting immigration as a problem, has succeeded in setting the agenda also of those considering themselves Republicans, by generalising the fear that France may become a country separated between different ethnic communities. All serious sociological research, Noiriel and Beaud (ibid.) argue, demonstrates that no immigrant community has ever posed a real threat to any Western nation-state (this is in line with Kymlicka 1995 and several multiculturalists). However, the fear that this will happen results in insufficient efforts made where they are really necessary, namely, in the area of social mobility. The different kinds of policies that stress ethno-cultural difference instead of economic and social inequality and segregation, even policies like affirmative action, can only increase the long-term effects of racialisation and marginalisation (Noiriel \& Beaud 2004). 


\subsection{A multicultural perspective: 'I been in the right place, but it must have been the wrong time'12}

Apart from the rejection of affirmative action, explicit normative judgements hardly appear in Noiriel's historical analysis of migration to France. Instead, he uses his socio-historical concept of assimilation to debunk what he perceives as the myths underlying overly political and normative views of assimilation. Yet we have seen that Noiriel opposes right-wing arguments of inassimilability, Republican assimilationism, and a culturalism cast in terms of ethnicity also with regard to the so-called 'second generation'. This implies that his analysis of assimilation does have normative implications, and I problematise some of these in the following.

Noiriel's historical analysis of the assimilation of immigrants within a larger context of the processes of assimilation occurring in all nation-states (and perhaps particularly in France), provides convincing arguments against fears of the inassimilability of immigrants. Moreover, it is a powerful antidote against the contemporary version of that fear, which suggests the likelihood of spontaneous immigrant culturalism or communautarisme, causing them either to stubbornly stick to old-time cultural practices without flexibility or adaptation, or to actively construct an 'otherness' that threatens the coherence of the nation-state. Recognising the force of assimilation as a social process may convince Europeans to adopt a less restrictive admission policy for migrants, since its current restrictiveness is at least partly caused by an unnecessary fear that migrants will not assimilate - or integrate, for that matter. Lastly, the historical-sociological understanding of assimilation may reinforce opposition to current citizen integration tests. This is not only from a normative perspective - for example, in terms of whether they are liberal or not - but also with regard to the question of whether such tests are unrealistic and fall back into the overly political understanding of integration (or assimilation) of the first generation of political scientists occupied with immigration from the Republican tradition.

However, Noiriel may have drawn too abstract and too general conclusions from his analysis, conclusions which remain indebted to the Republican tradition that idealised full assimilation. In general, therefore, I agree with Jerôme Vidal (2007), who diligently established a relation between the French sociological culture of functionalism connecting Durkheim, Bourdieu and Noiriel and a tendency to easily reject minority cultural, social and political movements in terms of particularisms, especially when they get critical, such as the movement 
of the Indigènes de la République. My central concern is with Noiriel's suggestion that his analysis of immigrant assimilation should lead us to reject nearly all immigrant claims in terms of ethnicity, as well as to a rather general rejection of 'culturalism'. Though as a historian, he only comments on those forms of 'culturalism' that actually occurred in France, drawing no conclusions about multiculturalism or pluralism in general, Noiriel's interpretation of the assimilation process implies that all kinds of references to ethnicity or claims of culture can be based only on a faulty theory of ethnic belonging - with the exception of claims based on actual cultural memory, made by first-generation immigrants. In his interpretation, multiculturalism only leads, and has led, to social conflicts based on illusionary identifications. It therefore risks undermining the social position of the weakest groups among the descendants of immigrants.

A problematisation of the normative implications of Noiriel's analysis need not, in the first place, be based on a normative standpoint. Instead, it can stem from a questioning of the suggested necessary course of the assimilation process. Is the assimilation process undergone by members of the second generation necessarily as violent and as 'perfect' as Noiriel suggests, leading to the profound desire for recognition he supposes? If this were the case, it implies that the identityformative structures of the nation-state and the social psychology of majority-minority relations are indeed so strong and unidirectional as to lead to an autonomous process that renders state policies, normative standpoints and migrants' agency practically irrelevant. I argue that this is not necessarily the case and critique the suggestion that pluralism and multiculturalism can only be ideological and lead to racialisation. Taking a normative perspective, I ask how we can design policies and institutions that do not take for granted one specific outcome and interpretation of incorporation.

Noiriel presents the relation between ethnicity and assimilation as an 'either/or' opposition with regard to the second generation. For first-generation migrants, Noiriel recognises a certain, albeit always interrupted, continuity between the established habits and ways of perceiving things learned by migrants in their original cultural contexts and those they practise in France. For them, it is impossible to entirely shed the traces of the country of origin. Once arrived in France, migrants may have more or less pronounced wishes to remember and continue - or to forget and shed - their cultural background. Hence, they do have some agency in deciding the speed and extent of their assimilation. 
Yet while this diminishes the Republican ideal of full assimilation for the first generation, it returns for the second generation, in Noiriel's explanation, this time in a naturalised form. Noiriel allocates little agency to second-generation migrants in relation to the assimilation process. Members of the second generation assimilate in a manner that is partly voluntary but, under pressure of the violent gaze of the majority and the institutional structure of the nation-state, perhaps even more involuntarily. Talking about the passively experienced perfect assimilation of second-generation Maghreb immigrants, Noiriel suggests that any claims they might make in terms of culture or ethnicity can only be interpreted as inscriptions onto the then-available vocabulary of French multicultural discourse. This precludes any actual experience of the self as a (partial) member of a specific ethnic or religious group that goes beyond the mere result of a discriminated social position or a political motive. Further, it perhaps also deprives migrants' children of opportunities to group themselves and act collectively to improve their situation by presenting themselves as members of a disadvantaged minority instead of only as members of a racialised class. ${ }^{13}$

Noiriel presents a well-documented long-term analysis of the thoroughness of the process of assimilation in general at a time of strong nation-state formation, particularly in France. Yet under the institutional force of the French nation-state and under the pressure of a violently assimilationist majority, it is quite implausible that full assimilation for the second generation of migrants is the only possible interpretation of the process. This is particularly true in the context of the last decades of the 2oth century or the first decades of the twenty-first.

Understanding assimilation as a structural process that occurs as detached from politics and migrants' agency results in a disregard of aspects of cultural transmission that fall at least partly within the control of migrants. Among these are, classically, the transmission of language and religion, but also the memory of having been colonised, discriminated against and even persecuted on the basis of membership of a specific ethnic group. This is certainly not just the case for the second generation of migrants, but also for other minorities such as Roma and Sinti and Jews (Birnbaum 2008). Their claims for forms of cultural difference and agency are not merely private, accidental and illusory, nor are they necessarily only effects of multicultural politics and therefore insufficiently substantial to counter the structural process of full assimilation. ${ }^{14}$

A less deterministic perspective permits us to see that both for second-generation immigrants individually and for the process of incor- 
poration in general, there are other possible outcomes, depending on specific contexts, within the French nation-state. Incorporation processes, however asymmetrical, are open-ended, involving multiple actors. Assimilation does not happen to migrants, and particularly to their children, independent of state policies and the agency of the people concerned. What migrants themselves want and do, both individually and collectively, is a relevant factor in determining the shape, tempo and end result of the process, and this is not necessarily the same for everyone or for every group. Whether migrants and minorities assimilate - and the speed with which they do so - depends on numerous factors: the resources and authority they possess; whether they live in concentrated districts or dispersed among other ethnic groups; the power balances between minorities, majorities and the state; the wants of spiritual or actual elites and whether they are politically astute enough to realise their goals. Opportunities that members of minorities see for integrating into the majority also play an important role (Alba \& Nee 2003; Lucassen 2005; Kymlicka 1995, 2007).

With regard to the members of the second generation, different kinds of reactions are possible, even if we acknowledge the force of nation-state formation and of the discriminatory gaze and attitudes of assimilatory majorities. This force does not imply that everyone reacts to these experiences in the way Noiriel seems to assume, namely by aspiring to recognition as 'one of us' by the dominant group. It cannot be said that this is the essential result of the process and that identifications with ethnicity (or with religion) are only attempts to hide the disillusionment of failed recognition. Claims of culture can have other sources than frustration or mere political usefulness. Moreover, people play with their imposed identities and make them useful to their specific social situation.

Let me draw attention here to what Rushdie's narrator adds to his description of the old turbot cited at the beginning of this chapter. This man 'had constructed his face and voice with care', the story goes, and migrants' 'false descriptions of themselves' are made 'to counter the falsehoods invented about us, concealing for reasons of security our secret selves' (Rushdie 1989: 49). Is nothing left of these secret selves in the second generation? The immense literature within the humanities (and cultural studies in particular) on hybridity, mimicry, translation and performativity, and on what it means to be 'the same but not quite' (Bhabha 1994) offers a more promising avenue for understanding the subtleties of agency within a context of inequality than the assumption of full assimilation (ibid., see also, e.g., Butler 1997; Gilroy 2006). ${ }^{15}$ 
But let us return to Noiriel's notion that historical evidence teaches us that whatever perspective we may take, long-term analyses of the process lead to the conclusion that immigrants in France have almost all fully assimilated, if not within two then at least within three generations. This situation has changed over the course of the last decades under the influence of the politics of multicultural integration within France and elsewhere. France, and with it other Western European countries, has increasingly acknowledged that the integration paradigm should make room for strong anti-discrimination policies, such as equal opportunity policies, which rely on an identification of groups and minorities, and which have been called multicultural (Simon \& Sala Pala 2010; Amiraux 2010a).

Criticisms of the assimilationist legacy in integration, Simon and Sala Pala (ibid.) argue, led the Conseil d'État in 1996 to insert the core value of equality into definitions of integration. Afterwards, anti-discrimination appeared on the agenda, and this is the second part of multicultural progress. It has also increasingly been understood that for serious anti-discrimination policy, we must first recognise that there is discrimination and then act on it, for example, by introducing typical multicultural programmes such as affirmative action. Quite a number of French institutions have in fact done that. Yet, Simon and Sala Pala (ibid.: 98) argue, 'despite these trends of action taking and awareness raising, the persisting influence of Republican categories, values and traditions hindered the shift of paradigms from assimilation to a more pluralist understanding of the modes of incorporation' (see also Lucassen 2005, esp. p. 168). In conclusion, there is a mixed context where classical Republican and multicultural discourses and policies are intertwined.

In addition, there is a gap in France between, on the one hand, discourses suggesting that only either multiculturalism or neoRepublican assimilation is possible and, on the other hand, actual governmental practices, especially those at the regional and local levels. In France, as elsewhere, multicultural policies arose at least in part simply to manage contacts with migrant elites. These practices of governance, especially where religion is involved, form a continuation of the long French tradition of gallicanisme, or 'support-and-control of religion', which was officially rejected after the introduction of state laïcité in 1905, but with important pluralising legacies for the governance of religion (Roy 2005; Bowen 2007b; Maussen 2008).

Diminution of the extraordinary power of the nation-state to achieve cultural homogenisation has been accelerated by international development towards more transnational forms of cultural belonging. 
Sociological and anthropological research has demonstrated that globalising tendencies, such as the rise of new media and travelling opportunities that connect migrants to their home countries with greater ease, as well as the visibly more diverse and multicultural character of contemporary liberal societies, have led to an increased heterogenisation at the national level and, at the same time, to a homogenisation around neo-liberal or capitalist values at supra-national levels. Sociologists and anthropologists hence argue that multiple identities and all kinds of cultural exchanges have assuaged the rigid homogenisation inherited from nationalism and encouraged diasporic identity-formation processes (see Waldron 1995; Bauboeck 1998a; Nederveen Pieterse 2007).

Migrant populations themselves have become increasingly diverse. They have various cultural and historical backgrounds and bring with them diverse religious beliefs and cultural practices. Noiriel seems to think that by suggesting that the specificity of the groups of migrants themselves might be a factor in the assimilation process, we encourage a tendency to consider some groups of migrants inassimilable. But this is not necessarily so. Instead, we must recognise that assimilation can be grouped into several social fields. People can assimilate in some fields, while retaining a particularity in others. Language and religion are particularly important for making distinctions. In most liberal nation-states, linguistic assimilation and religious pluralisation processes occur simultaneously, though both take place in different tempos depending on various factors. Zolberg and Lit Woon (1999) noted that migrants usually completely assimilate linguistically, with the loss of the language of origin within a few generations. ${ }^{16}$ Religion, however, is an area in which matters are more complicated. Religion mediates between inherited cultural practices and rituals and ethical views of the good life. People who have assimilated linguistically can opt to remain faithful to the religion of their families, though religions always change in relation to context.

Religion can be detached from ethnicity, for example, when we speak of an Islam de France and consider Islamic belief the private concern of otherwise fully assimilated French citizens, as Noiriel tends to do. We also separate ethnicity and religion when we conceive of Islam in terms of religious purity and belonging to nothing but the religious 'Umma'. Such de-ethnicisation of Islamic belonging can be seen either as an 'is' or as an 'ought', but in either case, religious particularity could be rendered as ultimately irrelevant to the question of assimilation. Religious pluralism could be considered guaranteed by the freedom of conscience and the religious neutrality of the state. Such neutral- 
ity could be achieved once laïcité has overcome some obvious biases in privileging cultural Frenchness and Christianity (Laborde 2008). This is the ideal option proposed by the Stasi Commission (discussed in Chapter 7). Note here, however, that the suggestion of a secularised, 'de-ethnicised' Islam leads us to overlook the relation between Islam as a religion, the postcolonial context, recent and ongoing migration from the Maghreb region and from African countries such as Senegal, the interaction between minorities and majorities, and, lastly, the French tradition of governance of religion (gestion de la religion).

The occurrence of linguistic assimilation does not imply that the language of origin is always lost. While people usually have only one religion, they can easily master at least two languages if these are taught well. If migrants had real opportunities to learn two languages, full linguistic assimilation within one or two generations would not be so certain. There is a specificity with regard to the languages used in the context of religious practice, such as Arabic, Hebrew and Sanskrit. Here, the language of preference need not necessarily be the original language of the parents or grandparents. For instance, in the Maghreb region, some members of the Berber peoples resisted the Arabisation of their cultures after decolonisation. This implied that for some Berber immigrants to Europe it can be irritating to be associated with Arab culture. They may, for example, prefer to learn Tamazight. Yet the necessity of dealing with what the French context has to offer, and indeed with the fact of being 'othered' in terms of Arabness or of being Muslim, together with the role of Arabic as a religious language, may encourage the adoption of Arabic as the language of preference. The complexity of the possibilities clarifies how important it is to hear and follow minorities' and migrants' own (individual) wishes instead of predetermining their identities on the basis of ethnicity, citizenship and religion.

The abovementioned arguments explain that assimilation at some points, even at structural points, does not necessarily imply the loss of legitimacy for claims of culture or for a politics willing to make allowances for such claims. To see this, we need not revert to those sources in international sociology and the humanities that have argued these points over the last years. Noiriel's own theoretical model leaves space for a more differentiated interpretation of the assimilation process and a milder judgement of references to ethnicity. After all, in the footsteps of Durkheim and Elias, Noiriel emphasised that objective collective forms mediate between 'natural' ethnic ties and the 'modern' abstract ties of citizenship. Noiriel (1996a, 1996b, 2007) himself fully acknowledged and extensively described the cultural memories that 
generations of immigrants have brought with them. Nevertheless, he seems to ignore that some of these memories may lead to objective cultural discourses and practices that could undermine the monocultural character of France, including at an institutional level, and could amplify its deep pluralisation.

We also need to question whether multiculturalism necessarily leads to ethnicist or culturalist discourses that fuel racism. Top-down differentialism, which has been advocated in France as much as elsewhere in Europe, has had the effect of enforcing ascriptive categorisations of immigrants and racism. It stays too close to the right-wing inassimilability thesis, by suggesting that immigrants will not want to assimilate or integrate. This may not be particularly helpful in preventing xenophobia, especially in a context of rising populism (see Lucassen 2005). ${ }^{17}$

But acknowledging the many problems of top-down multiculturalism does not save us from ambivalences. The increase of ascriptive categorisations has not been the only effect of top-down multiculturalism. It has also led to changed opportunity structures for migrants to resist their forced assimilation and it has brought about opportunities for ethnic and religious identifications in a more positive sense than just as the result of ascriptive categorisations by dominant majorities (this has especially been corroborated for Canada, see, e.g., Winter 2011). Moreover, a dynamic, relationally-defined multiculturalism-ascitizenisation, focused on the agency of migrants themselves in shaping the conditions of their participation in society and on possibilities for effective (self)criticism of majority habits and hierarchies, would probably suffer less from the culturalising problems of top-down multiculturalism (see Bader 2007; Tully 2008; Mookherjee 2010).

Noiriel's notion of assimilation can be reinterpreted in line with these arguments. Noiriel argued that his socio-historical concept of assimilation overcomes both assimilationism and anti-assimilationism by surmounting the overly political view of assimilation held by these two factions. Yet at a deeper level, his interpretation shares a crucial position with both. This concerns the suggestion that there should be unequivocal interpretations of what assimilation and multiculturalism mean and that policies should be based on these true interpretations. Instead of purifying the political concept into an empirical one, we should modify the concept into one that considers both structural elements and the perspectives of all different actors, thereby diversifying it. The most problematic aspect of top-down multiculturalism is the fact that the state decides whether the preservation of cultures is good or bad based upon a single, simplistic theory of assimilation and 
of culture. Noiriel's concept does not overcome this search for an ultimate meaning of assimilation on which to base policies.

Noiriel's suggestion is that culturalisation is the problem and a solid analysis of the process of assimilation could provide at least a partial answer. However, we must challenge this argument's suggestion that xenophobia and segregationist tendencies are sufficiently combatted by immigrants eventually assimilating. This idea stems from a superficial understanding of the relation between xenophobia and assimilation itself. Establishing the scholarly certainty that immigrants will assimilate appears to be, at first, a realistic way to prevent xenophobia in the majority population. Yet this bypasses a critique of the logic of assimilation, which holds that newcomers have to be like 'us' in order to be accepted as full citizens. If we do not try to alleviate the force of this logic by undermining the apparent self-evidence of assimilation, we establish assimilation as a norm and seem to legitimise the notion that full citizenship can be acquired by migrants and their children only at the price of declaring their former or 'different' selves as not belonging. The notion that references to difference lead to racism precludes the insight that if we are not allowed to have different views and practices, segregation has already started: that was the moral paradox of assimilation analysed by Alexander (2006) discussed in Chapter 1.

It is also questionable whether racism, ascription and, more recently, securitisation, could be remedied by difference-blind tactics. These exclusionary ideologies and practices have their history in assimilationism itself. The intricacy of assimilationism and racism has been theorised in the context of French postcolonial studies more thoroughly than in Noiriel's nation-state-focused context; and over the last ten years critical postcolonial studies have been integrated with French sociology more deeply than earlier work. Authors in that tradition have analysed how assimilationist practices of colonial governance went hand-in-hand with early forms of securitisation and racialisation, and how they have been translated to the contemporary French context (Nordmann 2004; Vidal 2007; Barkat 2005; Bouamama 2006; Guénif-Souillamas 2006; Lazreg 2011; Geisser \& Zemouri 2007; Rosello 2007). In the French context, however, this insight has led few authors to an argument for multiculturalism like that of Nathan Glazer (1997), who argued that we simply had to become multiculturalists because assimilation failed to happen in the context of American racism. This may have to do with the fact that multiculturalism is often translated by communautarisme in the French context, and because relational understandings of multiculturalism have hardly been received in France (Simon and Sala Pala 2010 forms an exception). 
Questioning the logic of assimilation becomes particularly important when at least some of the members of specific groups do not want to assimilate, at least not fully. Assimilatory pressure has always led to problems with national minorities, but longstanding conflicts with immigrants rarely arise, because they generally do wish to assimilate promptly. However, some groups may not want this. In such cases the logic of assimilation might lead to a hardening of the conflict on both sides. Of course religion is a relevant factor here. The reification of cultural and religious claims on the side of minorities under the influence of assimilatory pressure was described by Shachar (2001) in terms of 'reactive culturalism', and by Balibar (2007: 56) in terms of 'the assertion of a collective identity experienced as discriminated against and stigmatized'.

In conclusion, from a normative perspective guided by ideals such as freedom and equality, liberal democracies seek to develop policies that consider migrants' wishes and take all options, including (partial) nonassimilation, seriously. For this, we need to develop our institutional imagination and think of procedures to organise processes in ways that are more just, democratic and peaceful than Noiriel suggested as possible. Top-down multiculturalism is not the only form of pluralism. The central issue is how liberal democracy should and could respond to migrants' own considerations about whether and in what ways they want to assimilate, while at the same time not falling into the trap of reifying cultural differences. Liberal democracy can achieve this by creating diverse institutional options providing as many choices as possible to migrants, both as members of groups but also as individuals that may come into conflict with those groups (see Bader 2007).

Noiriel's concept of assimilation needs differentiation, and its opposition to ethnicity, or rather, to non-national forms of belonging in general, needs criticism. What should be kept in mind, however, is his convincing analysis of immigrant assimilation as just one special form of the more general processes of assimilation that accompany nationbuilding, which migrants and others alike undergo in some way from their early years onwards. A version of this insight is one of the basic premises of multiculturalism. The analysis of the force of national (or more multilevel) cultural homogenisation processes undermines the thesis of those who suggest that the state can be, or even is, culturally (or religiously) neutral, or that assimilation could be dichotomised into an acceptable, liberal version and an unacceptable, forced, homogenising version. This assumption, however, forms the basis of the political philosophy underlying well-known liberal-secular conceptions of citizenship, to be discussed in the following chapter. 


\section{The liberal sociology of assimilation and citizenship and its transnationalist alternatives}

As a normatively charged concept, assimilation, in this sense, is opposed not to difference but to segregation, ghettoisation and marginalisation (Brubaker 2001: 543).

It is not ethnic, cultural or religious peculiarity that divides people into ethnic categories. Rather, it is social segregation (prohibition of communality and commerce, ritualisation of intercourse, maintenance of symbolic distinction, refusal of social esteem, etc.) which leads to the self-construction and self-perpetuation of ethnic identities (Bauman 1988: 66).

\subsection{A sociological debate about assimilation and its normative implications for multiculturalism}

This chapter critically discusses two central contributions to the recently-developed position in migration studies, here called a 'liberal sociology of assimilation', which tends to be critical of multiculturalism. The first is Joppke and Morawska's (2003) programmatic introduction to Toward Assimilation and Citizenship: Immigrants in Liberal Nation-States. The second is Brubaker's (2001) reconceptualisation of assimilation, on which Joppke and Morawska's reintroduction of the concept is founded. Brubaker's article, entitled 'The Return of Assimilation? Changing Perspectives on Immigration and Its Sequels in France, Germany and the United States', summarises a reconceptualisation of assimilation in American sociology without explicitly linking it to a liberal political theory. This reconceptualisation stands at the basis of the more normatively-oriented 'liberal assimilationism' outlined by Joppke and Morawska.

The major reason for Brubaker, as well as for Joppke and Morawska, to reintroduce assimilation is their claim that its use as a legitimate sociological and normative concept prevents us from focusing on differences only. It also helps us to avoid theoretically endorsing or masking processes of social exclusion in terms of (desirable) cultural difference. These authors criticise the multiculturalist argument that 
the cultural diversity produced by migration in liberal societies should lead to the explicit recognition of migrants as distinct ethnic groups or ethnic minorities. In this sense, their view is related to Noiriel's, who Brubaker (2001) mentions as an important resource. Like Noiriel, Brubaker, Joppke and Morawska argue that assimilation as a concept was rejected for the wrong reasons in the late 2oth-century age of postmodernist differentialism. It is necessary, they suggest, to reflect on assimilation's morally legitimate uses. Unlike Noiriel, however, the liberal assimilationists do not consider assimilation as necessarily a violent social process that forces migrants and their children to adapt to the receiving society at multiple levels. Instead, they argue that liberal societies have changed in such ways that a new form of assimilation, which is 'morally defensible as well as analytically complex', occurs on a large scale (Brubaker 2001: 531).

This new assimilation does not imply pressure towards cultural homogenisation; it requires only adaptation to the most general principles or core values of liberal societies as citizens, and a liberal version of linguistic adaptation. Such assimilation would lead to a gradual cultural convergence within a few generations. But this convergence has clear limits, for the liberalisation and pluralisation of modern cultures implies that there will always be divergences: this is precisely the condition for the moral legitimacy of the new assimilation. The liberal assimilationists present their view as a 'new trend' in migration studies (Joppke \& Morawska 2003: 1), as it turns away from the three concepts that dominated most theories of migration from the 1990 s onwards, namely integration, transnationalism and multiculturalism. Instead, it emphasises the importance of both assimilation and citizenship. Chapter 1 mentioned Joppke's (2009) adoption of the terminology of civic integration instead of assimilation in the course of his more recent work. This chapter further analyses the significance of that transition.

\subsection{Critique of postnationalism, multiculturalism and integration}

\section{POSTNATIONALISM AND MULTICULTURALISM}

The liberal assimilationists' analysis of what went wrong in the incorporation of immigrants in the 1990 os underlies their view of the need to re-emphasise assimilation and citizenship. Most importantly, they criticise postnationalist and multiculturalist perspectives on global 
migration. In their view, these perspectives have played an important role in immigrants' exclusion from their host societies.

First of all, the liberal assimilationists reproach postnationalism for idealising sources of rights other than citizenship, particularly human rights. In arguing that, with the gradual decline of the importance of the nation-state under conditions of globalisation, citizenship becomes less relevant because other kinds of inclusion, such as non-citizen membership or 'denizenship', have taken its place. The postnationalist idea was summarised by Soysal (1994: 3), who stated that foreign labourers in Europe had not been integrated as citizens, but as persons, and that ' $[\mathrm{t}]$ his new model, which I call post-national ... derive[s] from transnational discourse and structures celebrating human rights as a world-level organizing principle’.

The liberal assimilationists' basic reproach against this view is that the trust placed in transnational institutions for the protection of immigrants is unfounded, because they have clearly been insufficient. In Germany, for example, Joppke and Morawska argue that postnational membership has been unable to prevent the exclusion of foreign labourers and their children. Instead, the expectation that workers would remain visitors who would return home and not become citizens was for a long time tacitly extended even to their children born in Germany. This sometimes led to exclusionary measures, such as, for example, education in separate classes, and therefore to grave disadvantages for their socio-economic integration. ${ }^{1}$ Moreover, as early as in the 1990s, the South German Bavarian right-wing populist CSU government used the fact that immigrants' children had not acquired citizenship rights to justify 'sending back' youthful delinquents to their 'home countries', which had never actually been their homes at all. ${ }^{2}$ Such 'sending back' has become common practice in recent years in European countries.

Next to postnationalism, multiculturalism became an increasingly important concept in the 1990s. Joppke and Morawska (2003: 8) distinguish between what they call the 'de facto multiculturalism' present in all liberal states, which they endorse, and 'official multiculturalism', which they reject. De facto multiculturalism denotes two things. First, it describes the actual cultural diversity that we encounter in liberal nation-states precisely because they abolished assimilationist practices. Second, as far as de facto multiculturalism also designates certain policies, it implies a practical tolerance of many of the religious and cultural claims of immigrants, such as the right to wear religious clothing, to obey religious holidays and to pass on one's maternal language. It is grounded in the 'principles of public neutrality, non-dis- 
crimination, and protection of individual rights' - in short, in the basic principles of liberalism. De facto multiculturalism arose in all Western countries because policymakers had to deal with the multicultural character that societies inevitably developed as a result of migration. Joppke and Morawska argued that even a country like France, with its strong assimilationist tradition and Republican discourse, developed practical multicultural policies combined with a quite common philosophy of integration, very much like other Western countries (in line with the arguments by Simon and Sala Pala (2010) discussed in Chapter 2). For Joppke and Morawska (2003: 7), this common philosophy of integration basically implies a strategy designed to 'tolerate cultural difference in private and associational life, but refuse to give it public status'. Once again, this is a brief reformulation of the basic liberal way of dealing with cultural diversity. 'Official multiculturalism' goes one step further, and this is the multiculturalism that Joppke and Morawska oppose. It exists in those countries that define or have defined themselves as multicultural at a political level and that advocate collective rights and official multicultural self-definitions of the state. Although a contested concept from the beginning, countries like Canada, Australia, the Netherlands and Sweden officially declared themselves 'multicultural' in the 1970 s and 1980s. They gave public recognition and collective rights to (certain groups of) migrants as distinct ethnic groups or ethnic minorities. The European countries that had officially defined themselves as multicultural in the 1980s (the Netherlands and Sweden) abolished this self-definition in the course of the 1990s; only Canada and Australia still officially define themselves as multicultural.

Joppke and Morawska (2003: 10) take Kymlicka's liberal multiculturalism as the standard justification for official multiculturalism and consider it 'difficult to defend' at a normative level. In their explanation, Kymlicka argues that official multiculturalism should empower migrants to renegotiate the terms of state-imposed integration, without being able to explain what that really means. "For Kymlicka, individuals need "societal cultures" (which he defines, much like "nations," in terms of a shared language and territorial rootedness) as context for free and meaningful choices' (ibid.: 11). They understand Kymlicka as arguing that because migrants need their cultures as a context for free choice, they should have the right to maintain them. In addition, they think he argues that because the host country cannot be as culturally neutral as the standard liberal view suggests, and thus imposes itself on migrants unjustly, migrants should receive special collective rights to maintain their cultural practices. This is an incorrect interpreta- 
tion of Kymlicka's view of migrant multiculturalism. What he in fact argues is that migrants cannot take with them the social practices and institutions linked to the vocabularies that they do bring. Therefore, with regard to migrants, a commitment to 'multiculturalism and polyethnicity is a shift in how immigrants integrate in the dominant culture, not whether they integrate' (Kymlicka 1995: 78). The problematic aspects of the concept of societal culture have been criticised by several political theorists from within the tradition of multiculturalism (see, e.g., Carens 2000).

From as early as 1999, Joppke had criticised official multiculturalism. Here, he followed the critique of official multiculturalism levelled in the name of the anti-essentialist, constructivist concept of culture discussed in Chapter 1. Briefly summarised, that criticism implied that multiculturalism stems from an incorrect, reified concept of culture which suggests that members of 'different' cultures can live together in one society, but nevertheless remain separate, as in a mosaic. The use of the image of the mosaic reveals a distorted view of what culture means, particularly in the context of global migration, where people cannot be considered as members of one or even of two cultures, but constantly pick elements from diverse cultures, creating individualised and hybridised mixtures from cultural sources. For example, following Rushdie's concept of culture as 'hodgepodge', Waldron (1995: 783) argued that in the cultures of global migration, 'meaningful options may come to us as items or fragments from a variety of cultural sources'. In a similar vein, Bhabha (1994) stated that multiculturalism is, in fact, a pleonasm, because culture itself always implies cultures in the plural. This criticism leads to a rejection of identity politics as founded on an overly closed view of culture (Joppke \& Lukes 1999; for a similar argument see Gilroy 2006 and Phillips 2007). Many of these critics, however, turned to notions such as multiculture and hybridity, without taking the step towards a redefinition of assimilation. The introduction of a new notion of assimilation and a stronger politics of citizenship was however a commendable further step in the eyes of Joppke and Morawska.

With regard to Europe specifically, Joppke and Morawska identify another aspect of the problematic status of multiculturalism. The European context for multiculturalism is different from that of Canada and Australia. These two countries introduced multiculturalism as an official self-understanding of the entire nation. For example, the Canadian Multiculturalism Act of 1988 required the following of government: 
[to] recognise and promote the understanding that multiculturalism reflects the cultural and racial diversity of Canadian society and (to acknowledge) the freedom of all members of Canadian society to preserve, enhance and share their cultural heritage (quoted in Joppke \& Morawska 2003: 12, quoting Kymlicka 1998: 185).

This understanding of multiculturalism implies that all members of Canadian society are supposed to consider their membership as multicultural in some way. In Europe, by contrast, Joppke and Morawska (2003) argue that multiculturalism is usually associated only with migrants and minorities, who are thus transformed into ethnic minorities different from the members of majorities. In such a context, it leads to exclusion rather than recognition. Their argument is in line with Brubaker and Noiriel when they argue that in France, for example, differentialism was quickly adopted by the Front National and helped legitimise those who did not want migrants to belong to the French 'us' against the long French tradition of assimilation. ${ }^{3}$

With regard to the fate of multiculturalism in Europe, Joppke and Morawska frequently refer to its progress in the Netherlands. There, multiculturalism was introduced mainly as an extension of the Dutch corporatist model of organising polity and society, also called 'pillarisation'. The Minorities Act (Minderhedennota) introduced in 1983 designated eight official minorities. In line with the tradition of pillarisation, these minorities received state funding for their emancipation, which they were expected to realise by developing 'separate institutions' such as 'religious schools and ethnic broadcasting' (Joppke \& Morawska 2003: 14). According to Joppke and Morawska, however, multiculturalism did not lead to the expected emancipation. Instead, it fed a 'small elite of ethnic activists, along with infights and factionalisms' (ibid.), without improving the lives of ordinary immigrants. Moreover, multiculturalism introduced a form of pillarisation for Muslims, even though the model had been left behind by the rest of Dutch society in the decades of secularisation in the late 2 oth century. In so doing a new pillar was added, whereas the others had already, at least partly, crumbled. Pillarisation, moreover, had always found an embracing element in a shared sense of 'being members of one nation' among the diverse cooperating elites. Yet, this was precisely the element that was structurally underestimated in ethnic minority policies. Following the analysis of the Dutch sociologist Han Entzinger, Joppke and Morawska suggest that consensus-building was neglected and that multiculturalism only yielded segregation and exclusion (ibid.: 15; for a critique of pillarisation as a historical myth, see Vink 2007). 
Summarising, the liberal assimilationists' central critique of both multiculturalism and postnationalism is that while these concepts and the practices based on them seemingly help migrants to integrate and find their way, they actually lead to the exclusion and segregation of immigrants, including even their children, from the nation-states in which they live, both culturally and institutionally. For Brubaker, Joppke and Morawska, only stronger notions of citizenship and assimilation can help to counter these tendencies.

\section{INTEGRATION}

The third dominant concept in migration studies criticised by Joppke and Morawska (2003) is integration. Their criticism is twofold. In the first place, it is directed against the introduction of integration as a replacement for the morally reprehensible assimilationism that preceded it. In the 1970 s and 1980s, most liberal countries gradually adopted integration, because of the colonial and nationalist connotations of assimilation. In fact, however, 'whoever uses the word "integration" wishes to say what is allegedly not meant by it, "assimilation"” (ibid.: 4). Instead of replacing one concept with another, the old concept should have been redefined in such a way as to no longer imply old-style enforced cultural homogenisation. A liberal redefinition of the concept would have prevented forgetfulness of the legitimate, structural side of assimilation, namely the 'socio-economic equalisation of the life-chances between immigrants and native population (in employment, income, education, etc.)' (ibid.: 6). Joppke and Morawska blame the discourse of integration, and particularly the 'abhorring of the old, culture-focused "assimilation" approach' (ibid.) leading to the 'difference-oriented rhetoric' of the 1980s and 1990s, for causing a forgetfulness of that part of the vocabulary of assimilation.

This is not the only criticism of integration, however. Following Favell (2001), Joppke and Morawska also criticise the use of the concept of integration because, while it was introduced to overcome the legitimisation of violence and ethnic particularism inherent in the concept of assimilation, the concept of integration itself emphasises the need for social cohesion or even unity, perhaps more so than assimilation. 'Integration' suggests the existence of an integrated society that can also disintegrate. It implies the existence, in relation to immigrants, of specific and structurally different problems from those concerning already 'integrated' persons.

However, contemporary societies are not built as integrated wholes. They are differentiated into fields or systems in which some participate 
and others do not. Here, Joppke and Morawska follow macro-sociological theories like Pierre Bourdieu's theory of social fields and Niklas Luhmann's system theory. Both have argued that modern societies are built up of different, relatively independently functioning systems or fields that all have their own mechanisms of inclusion and exclusion. In this sense, from the first moment of arrival, everyone is similar to certain others participating in some field or system, for example, in terms of the economy or housing. This diversification into different fields or systems implies that we cannot speak of gradations of integration, let alone of integrated and non-integrated persons. There is simply no centre or integrated whole. ${ }^{4}$ This perspective leads Joppke and Morawska to also argue that the notion of 'immigrant' is limited in scope. The concept suggests that those entering a country for an extended period of time have a fundamentally different position from residents, while in fact this is only the case with regard to the political system, because only this system defines membership on a spatial, territorial and therefore exclusionary basis (Joppke \& Morawska 2003: 3).

Anticipating my later comments, I note here a striking aspect of the critique of the three concepts of postnationalism, multiculturalism and integration. That is, while the liberal assimilationists' theoretical reproaches are twofold, in the sense that they criticise both differentialism and integrationism, the central practical problems they attack are specific kinds of difference, or rather, inequalities: segregation and socio-economic marginalisation. In reply to these problems, the liberal assimilationists urge the reintroduction of the concept of assimilation to replace that of integration, ideally leading to 'an emphasis on assimilation [that] can be used to conceptualise and normatively found inclusion' (Brubaker 2001: 543). Against postnationalism, the liberal assimilationists insist on the continued importance of citizenship. The next section looks more closely at these alternatives.

\subsection{The alternatives proposed by the 'liberal assimilationists'}

The central alternatives proposed by the liberal assimilationists to differentialism are, firstly, a restructured concept of assimilation and, secondly, a new emphasis on citizenship. Their basic argument is that the normative charge of these concepts should be adapted to their changed empirical content. Their content has changed because of de facto multiculturalism and tolerance of dual citizenship in contemporary liberal societies. Basically, they suggest that the exclusive character that both citizenship and assimilation once had, and which caused their moral 
illegitimacy, has been overcome in the new shapes these concepts have taken: they are no longer exclusive, but additional.

\section{Assimilation Without assimilationisn: AnAlogies With JÜRGEN HABERMAS' NOTION OF ASSIMILATION}

As Brubaker (2001) teaches, in the heyday of nation-state formation, assimilation meant the loss and sometimes the abolition of the cultural practices of minorities under pressure of the state and its culturally homogeneous majorities. Assimilation was based on the literal, physiological meaning as complete absorption. For example, the oldstyle 'Germanisation' of Poles habitual in Imperial Germany necessarily meant their 'de-Polonisation', like the French Jacobin Republic forced members of national minorities like the Bretons and also colonial subjects to use French or to face contempt or even punishment (ibid.).

For the liberal assimilationists, contemporary assimilation, by contrast, is founded on an abstract meaning of assimilation. It entails only 'becoming similar' (ibid.: 542). Assimilation used in this sense implies that people can assimilate to the host country's culture, but that they do not have to abandon older cultural practices to do so. It implies that assimilation has become a gradual process parallel to the ethnic selfdefinitions of migrants that usually live on for a few generations:

Regarding the practices and adjustment of immigrants and their children there is no evidence that assimilation is not occurring. In fact, one can observe both: adaptation and use of host-society resources and the maintenance of 'transnational' linkages with the society of origin (Joppke \& Morawska 2003: 2).

In connection with Joppke and Morawska's critique of integration, Brubaker (2001: 543) argued that assimilation has ceased to mean a shift from one homogeneous group to another. Instead, it now means a shift from 'one mode of heterogeneity - one distribution of properties - to another mode of heterogeneity' (ibid.). Brubaker explained that this implies a shift from a holistic approach that conceptualised assimilation as a movement towards a 'taken-for-granted' reference population, to a 'disaggregated' approach that discards the notion of assimilation as a single process, considers multiple reference populations, and envisions distinct processes occurring in different domains. This means a shift from a 'monodimensional [analysis] - how much assimilation? - to a multidimensional one: assimilation in what 
respect, over what period of time, and to what reference population?' (ibid.). Furthermore, it implies that assimilation has become transitive instead of intransitive: populations of immigrants are no longer seen as mouldable objects, but as active subjects (ibid.).

For the liberal assimilationists, this new, acceptable, even necessary use of the concept of assimilation is systematically different from the old, disreputable and discredited one. Brubaker (2001: 548) calls this 'assimilation without assimilationism'. In the same vein, Joppke and Morawska (2003: 3) argue that assimilation should be used to indicate that, in a contemporary society, everyone can be 'conceptually assimilated to other individuals and groupings with similar positions on some critical indices or indicators'.

The liberal version of assimilation is possible because of the general tendency in Western nation-states towards simultaneous linguistic assimilation and religious and ethnic pluralisation. With regard to language, assimilation is possible alongside pluralisation. Although mandatory language acquisition is 'the small rest of distinctly cultural adap[ta]tion that every liberal state... demands of its newcomers' (ibid.: 9), it does not harm the de facto multiculturalism of the liberal state because learning a new language does not exclude the original language. Thus, people can linguistically assimilate by learning the language of their new country, while also retaining their mother tongue and passing it on to their children. With regard to religion, Joppke and Morawska (ibid.) argue that the separation of Church and State in liberal nation-states guarantees plurality and freedom of conscience. With regard to ethnicity, tolerance of dual citizenship and transnational or cosmopolitan identity formation is said to guarantee plurality. This constitutes the legitimacy of contemporary assimilation: it can exist without having to exert strong pressure on immigrants to shed their original cultural and religious backgrounds. (This is what Joppke and Morawska claim, to which I return in the next section.)

For the liberal assimilationists, the legitimacy of contemporary assimilation depends on an interpretation of what culture means in the contemporary liberal nation-states that gradually developed after World War II. After the end of that war, these states profoundly changed their attitude with regard to culture. Aggressive nationalising practices were definitively de-legitimised by Nazism and left behind after its defeat. These kinds of practices were also no longer 'necessary'. Industrialisation, wars and infrastructural incorporation by expanding welfare states led to the post-war phenomenon of Western states 'securely sitting on top of thoroughly nationalized societies' (Joppke \& Morawska 2003: 4). The relaxation made possible by this sense of secu- 
rity led to a liberalisation which ensured that no substantive, homogeneous cultures remained that could be imposed on immigrants or minorities. Parallel to the idea that social systems or fields are at least partly autonomous and that there is no centre to which we could integrate, it can also be said that there is no longer a substantive, general culture to which migrants could be forced to assimilate. The emergence of lifestyle enclaves and the general tendencies of individualisation have undermined homogeneous cultures in all nation-states, for what, after all, is the 'shared substantive culture of a hooligan, a homosexual, a New Age devotee, an anti-abortion activist?' (Joppke \& Morawska 2003: 5). This does not mean that there is no longer any shared culture at all. What remains is the shared culture of liberalism:

From a liberal point of view, which became the point of view in Western states in the second half of the twentieth century, it is a violation of the dignity and autonomy of the individual, citizen or immigrant, to force a substantive culture on her, except the thin and procedural culture of liberalism itself (Joppke \& Morawska 2003: 5, their italics).

This argument is closely related to Habermas' (1994) view concerning assimilation. He suggested, based on the earlier historical work of Rogers Brubaker comparing German and French traditions and practices of citizenship, that we can distinguish, 'philosophically', between two levels of assimilation:

a Assent to the principles of the constitution within the scope of interpretation determined by the ethical-political self-understanding of the citizens and the political culture of the country; in other words, assimilation to the way in which the autonomy of the citizens is institutionalized in the recipient society and the way the 'public use of reason' is practiced there;

b the further level of willingness to become acculturated, that is, not only to conform externally but to become habituated to the way of life, the practices, and customs of the local culture (Habermas 1994: 138).

Habermas (ibid.) distinguishes these levels in terms of political socialisation and ethical-cultural integration. The first only implies adaptation to the receiving country's 'public use of reason', while the latter also implies adaptation to the more clearly culturally-specific ethoi, that is, customs, habits, languages, beliefs and faiths, dominant in that country. To require the first, Habermas suggested, is legitimate. $\mathrm{He}$ associated this level of assimilation with assimilation policies like 
those practised in Republican France. To require the second is illegitimate and nationalist. Habermas (ibid.) mentions the Bismarckian Germanisation policies with regard to the Poles as an historical example. Habermas, in Brubaker's footsteps, thus distinguishes between a French universalist, Republican and a German nationalist model. This is in his view the historical background of the philosophical distinction.

In the French context, as we saw in Chapter 2, the idea that we might neatly distinguish between philosophical levels, as Habermas suggests, or even between liberal and homogenising forms of assimilation (the new assimilationists' distinction), is clearly problematic. Joppke and Morawska (2003) go one step further than Habermas by suggesting that the migrants, on whom liberal states do not force a substantive culture, can legitimately be forced to accept the thin and procedural culture of liberalism. Although it is not the force itself, but only the just limit of the force that is at stake, this suggestion may be a significant slip of the pen, for this small phrase leads us to question whether Joppke and Morawska's version of liberalism has entirely shed the heritage of its classical, 19th-century version. For was not one of the central problems of J. S. Mill's classical liberalism that it constructed an image of non-liberal peoples as 'illiberal peoples', who could be forced to adapt to liberal norms only because they were intrinsically alien to them (Parekh 1994)?

\section{'DE-ETHNICISED CITIZENSHIP'}

With regard to the arguments for a return to citizenship in normative theories of immigration, the liberal assimilationists take a parallel step to the one they took with regard to assimilation. Instead of rejecting citizenship as a heritage of nationalism, as Soysal (1994) did, they redefine citizenship in such a way that it fits the contemporary liberal state and loses its exclusionary character. This shift, they argue, is essentially symbolised by the recent increase in European countries of possibilities for dual citizenship and by the erasure from the definition of citizenship of nationalist and ethnicist heritages, which have been exchanged for political ones. Immigrant-receiving liberal nationstates have largely realised what Joppke and Morawska (2003) called 'de-ethnicised' citizenship.

De-ethnicised citizenship means, first of all, that citizenship is conferred according to what we call ius soli (the right of the soil), hence a territorial definition follows. In this case, migrants acquire citizenship rights based on their residency in a specific country for a certain 
amount of time, and their children acquire citizenship based on the fact that they were born in the country. Ethnic definitions of citizenship, on the other hand, rely on the ius sanguinis (the right of the blood). 5 This rule implies that we remain members of the same nation to which our parents or grandparents belonged, whatever trajectories we make as migrants. In other words, those with parents from elsewhere must retain the nationality of the parents. Liberal nation-states have gradually started to converge around ius soli with regard to citizenship (ibid.: 18). A second aspect of de-ethnicised citizenship that strengthens its principle is dual citizenship. This makes it possible for migrants to retain official and political links with their home countries, while they can also acquire citizenship in the country of residence (ibid.). Dual citizenship is the formal equivalent of the idea that one can fully function in the country of residence, without this having to imply that one is forced to become a member of a particular cultural community or that one is forced to leave behind the cultural practices and bonds of another country (ibid.: 19; see also Bauboeck 2009, 2011).

With this convergence around its de-ethnicisation, citizenship, for Joppke and Morawska (2003: 20), has at last become the 'one domain where liberal states are finally getting serious about the "liberal" in their names'. With its transformation, citizenship lost its historical ties to the development of nations as 'war-making bodies' that led to confrontations with 'hypostatized Others', and has become constituted by political values instead (ibid.). The motor of this development was not so much migration, but the fact that the North Atlantic region has been transformed from 'a Hobbesian zone of war, into a Lockean zone of trade' (ibid.: 19). Hence, according to Joppke and Morawska, the boundary crossings of modern capitalism in particular have pushed the European states out of their nationalisms and into a globalised world where boundaries are highly relative. Both assimilation and citizenship have lost their association with an exclusive nation-state and with the group thinking on which they were founded. Instead, these concepts can now help to realise the necessary inclusion into European societies of immigrant groups that have suffered from exclusion. Joppke and Morawska (2003) argued this. The extent to which liberalisation and securitisation have become empirically interwoven in current EU policies with regard to migration, has only become clearer since the date of publication of their book (Huysmans 2006, De Genova \& Peutz 2010). But the systematic thrust of the argument also needs to be addressed, as I will do below. 


\subsection{Complications for a diagnosis: 'On their turf'}

\section{EXCLUSION AND SEGREGATION}

We have seen that the liberal assimilationists consider the main problem inherited from the 1990s with regard to immigration in Western countries to be the exclusion and segregation of immigrants and their children from the receiving societies. They blame this on the dominance of the concepts of multiculturalism, transnationalism and integration. What is missing from the analysis is, first of all, an acknowledgement that other, likely more structural socio-economic factors than the policies based on these three concepts, also play a role in processes of inclusion and exclusion. Another omission is reflection on a way of distinguishing between when we are dealing with exclusion or even segregation, and when we are dealing with forms of migrant agency.

Analysis of exclusion and segregation cannot be reduced to cultural politics alone. The liberal assimilationists suggest that the concept of assimilation should lead to a focus on 'the socio-economic equalisation of life chances between immigrants and native populations' (Joppke \& Morawska 2003: 6). But their failure to analyse the causes of exclusion in economic terms, and locate them instead exclusively in cultural policies, reveals the neo-liberal aspect of their proposal. Debates should be redirected towards the necessity of redistributive policies if we want to address socio-economic inequalities (Fraser 2003). Moreover, blaming the culture of migrants themselves, or blaming multiculturalism as a policy (which hardly ever really existed) for socio-economic inequalities, can be explained as part of the neo-liberalisation of political (and sociological) discourse, where the focus goes from structural macro-analysis to an emphasis on those factors that individuals could be taken to be responsible for themselves. ${ }^{6}$

Another structural factor leading to exclusion overlooked by the liberal assimilationists is the possibility that exclusion is caused by a lack of openness on the part of the receiving society. It may be the result less of ideologies of difference but rather of a heritage of cultural hierarchies and a resulting lack of social mobility for immigrants and their children. Such ingrained cultural hierarchies can be related to racism, civilisationism, reinvention of 'frames of war' and securitisation processes with regard to at least certain categories of migrants (Butler 2008; Cesari 2010). Such exclusion is also structurally related to assimilationist processes of nation-building in the nation-state, as 
we learned from the discussion of Noiriel's analysis of assimilation in Chapter 2.

Furthermore, the liberal assimilationist diagnosis neglects the fact that some groups of migrants may want to assimilate more than others, and their definition of what is liberal procedural culture may substantively differ from that of cultural majorities. In this case, we have to be careful about replacing the concept of difference with segregation, for this would mistake migrants' agency in maintaining a certain distance from majority culture for an effect of multicultural policies by the receiving state (Bader 2007; Merry 2013).7 The liberal assimilationists, furthermore, provide no norm for deciding when we are dealing with exclusion and segregation, and when we are dealing with actual differences between groups.

To anticipate the further discussion of secularism as a specific answer to the alleged flaws of multiculturalism, it is important to mention that the sustained debate about the meaning of the culture in multiculturalism has been cross-fertilised with debates about the specific place of ethno-religious minorities within multiculturalism. This chapter already discussed Morawska and Joppke's adoption of arguments by which Bhabha, Gilroy and others distinguished convivial multiculture from an official multiculturalism that institutionalises differentiated forms of ethnicity or culture. Their concept of multiculture as an alternative to multiculturalism has been opposed by sociologists, who argue that multiculture leads to the exclusion of thicker, often ethno-religious identities, and Muslims in particular. This is, for example, what Modood and Meer (2008) argue in reaction to Gilroy's (1993) multiculture. Modood and Meer (2008) critically reflect on a question asked by Gilroy regarding what it means that 'the political and cultural gains of the emergent black Brits go hand in hand with the further marginalisation of "Asians" in general and Muslims in particular' (Gilroy 1993: 94). According to Modood and Meer (2008), the multiculture view - which has become the dominant one in Britain insofar as there is still support for multiculturalism - imagines an atmosphere of urban, consumerist, secular, youth-culture conviviality and excludes religious identifications. It is not able to counter, and even partly encourages, 'a built-in interpretative bias that has led scholars to see religious identification as a backward or reactionary form of "false consciousness" (ibid.: 486, in part quoted in Statham 2005: 164). Modood and Meer (ibid.) suggest that multiculture as an ideology may even lead to the delegitimising of claims Muslims might make and thus contribute to their marginalisation and even racialisation. 
As early as in 1993, in his comments on the Rushdie Affair, Asad argued that Gilroy's and Bhabha's celebration of anti-essentialism, particularly the kind of hybrid identities they were proposing, would lead to easily manageable minorities from the perspective of the assimilationist state. Denying a distinct unity to populations, he said, is just as much a tactic of political power as their essentialisation (Asad 1993: 264). He added that 'the politicisation of religious traditions by Muslim immigrants is, however, quite a different matter: such a development serves to question the inevitability of the absolute nation-state - of its demands to exclusive loyalty and its totalizing cultural projects' (ibid.: 265). He later formulated this in terms of a problematisation of secularism: 'the fact that citizens inhabit several public spheres that overlap and extend laterally and do not coincide with national boundaries produces difficulties for the modern secularist state' (Asad 2004: 4).

It is perhaps worthwhile to question Asad's choice of words here. He spoke of the absolute nation-state and its totalising cultural projects as if no multiculturalisation of the nation-state could ever take place at all. This suggests that deep cultural conflict is, consequently, more or less inevitable. If we follow this line of reasoning, the original multicultural idea which posits that the 'we' should also be open to critique and change and that this 'we' may not simply determine the rules which 'they' must follow, ends up in a context where this idea is almost immediately associated with hostility and deep cultural conflict. The current global context includes increasing securitisation on the part of nation-states and majorities. It also contains acts of violence committed in the name of Islam, which unfortunately gives succour to this idea. This underlying reason has contributed to the alienation that has emerged towards multiculturalism in the European context.

Modood and Meer (2008) are somewhat more trustful of the possible multiculturalisation of the nation-state, but still as an alternative to multiculture and hodgepodge. They argue for the political accommodation of collective Muslim demands and incorporation of differences within the mainstream, alongside fostering commonality across differences. The specific multicultural way, here, is 'to recast part of this civic inclusion as proceeding through claims making upon, and therefore reformulating, national identities' (ibid.: 489). For that reason, they argue for a strong, accomodationist but at the same time dynamic and relational multiculturalism, instead of a withdrawal upon multiculture, especially with regard to the position of ethno-religious minorities. 


\section{Cultural neutrality?}

My criticism of the liberal assimilationists' analysis of immigrant exclusion is directed at a question that they avoid analysing, namely, 'What is the effect of conceiving the liberal state as a neutral state?' At the basis of their optimism about contemporary societies is a theory of the neutral liberal state, reinforced by a systematic theoretical emphasis on the pluralisation of contemporary societies.

Here, my critique of the liberal assimilationists proceeds in the opposite direction from my critique of Noiriel's view of incorporation. My critique of Noiriel's view emphasised the differentiation that has occurred because of the pluralisation of contemporary societies. This caused me to criticise his Durkheimian thesis that full assimilation is the only possible outcome of the immigration process. Noiriel structurally underestimates the ability of liberal societies to organise a certain measure of ethnic and religious pluralism and to allow for people's agency in shaping complex identities. Yet, this is no reason to reject his view entirely. Instead we adopted the notion that the state is, or can be, culturally neutral.

With the liberal assimilationists' views in mind, a more modest version can be developed of Noiriel's perspective that cultural homogenisation and the cultural hierarchies that produce it do still play a role in contemporary societies. At many levels it is simply not true that culture, and in particular nationalised majority culture, remains within the borders of private and associational life. Culture penetrates the public sphere and the state in numerous ways: through the media, education, required language acquisition, daily experience of cultural hierarchies, and the heritage of earlier ethnically distributed power relations.

The suggestion that there is little relation between the distribution of (state) power and culture should therefore be rejected. The basic insight of pluralism is not that there are minorities, but that there are majorities in the sense of dominant groups. These do not have to be numerically dominant, but they can, for example, be over-represented or particularly powerful in politics, the media or economically.

The crucial need to take minority-majority relations into account is a basic argument of numerous multiculturalists (e.g., Bader 1998; Bauboeck 1998a; Benhabib 1996; Kymlicka 1995, 2002; Shachar 2001; Williams 2000; Young 1990, 2000; Alexander 2006; Tully 2008). Acknowledging the non-neutrality of the liberal state does not necessarily lead to the view that the preponderance of majority cultures means inevitable full assimilation of immigrants. In different societal 
fields, assimilation by migrants is not the only option; there is also cultural blending or even the disappearance of 'autochthonous' habits altogether (see, e.g., Alexander 2006, which explores the gradual recognition of Jewish culture in the USA through, for example, Woody Allen's movie Annie Hall).

Yet, even if the pluralisation of Western societies has led to a general increase in processes of mutual accommodation rather than in full assimilation, the burden of adaptation remains on immigrants:

[A]lthough some deplore the 'give' by the hosts as leading to unmanageable cultural diversity, such an outcome is very unlikely because the hosts retain overwhelming advantages: incorporation is taking place on their turf, within an institutional framework which they control (Zolberg 1997: 151, his italics).

The penetration by culture of (semi-)public fields and institutions does not depend on a centralised context like that of France. In Britain, for example, historians and cultural scholars argue that at an institutional level, cultural homogenisation has become stronger rather than weaker since World War II. The state can afford to be liberal because so much has already been homogenised and because institutions penetrate into aspects of life that have never before been so controlled. With the gradually increasing socio-economic solidarity within the nation-state, many aspects of life that were previously less infiltrated by the state became nationalised (Marshall 1965; summarised in Kymlicka 2002).

We must also consider that, even if the state could ensure equality for members of minority groups, it would still be uncertain whether this would prevent strong pressures for cultural homogenisation in specific social fields. The liberal assimilationists' own analysis of the differentiation of societal fields should have led them to suspect that at least in some of these different fields and their related (sub-)cultures, structural advantages may be found for members of majorities - alongside related pressures for homogenisation - even if they have largely been extinguished in others. The assimilatory pressures exercised at school provide a clear example. Even if strategies are available to the people concerned for 'escaping', modifying and countering these pressures, or for turning them into advantages, and even if we all experience these kinds of pressures, we are again dealing with matters of degree.

The construction of national histories plays a specific role in the non-neutrality of the state and of public cultures. A 'polity is always 
conceived as a transgenerational community and this makes it imperative to interpret its history' (Bauboeck 1998a: 45). Because of its historical depth, every polity, whether liberal or not, will always build on certain culturally-specific stories. Thus, public cultures will inevitably tend to 'exclude some groups (and especially recent immigrants) who have not shared this history' (ibid.).

Noiriel sees the lack of openness of France's national history to the memories of immigration as one of the markers of the assimilationist Republican tradition. The state's historical bias concerns not only immigrants, although their recent arrival makes achieving a place in public history perhaps systematically difficult. Inclusion in 'public histories' is difficult for members of minorities in general, especially those minorities that have suffered from exclusionary and assimilationist practices in the past (e.g., Jews and Roma). With regard to the history of the Jews in France, Birnbaum (1996) documented how difficult it was for them after World War II to acquire a place in French public history as a group with a special history of suffering. Under the pressure of critiques such as those of Noiriel (1996b) and Birnbaum (1996), French historiography has become (a little) more open to minorities' memories and their roles in French society. However, this openness is hindered by the fact that minorities' memories and histories tend to be discussed separately from what is considered public history, especially after the debates on 'national identity' and the 'positive sides of colonialism' started in 2007 (for a critique, see Noiriel 2007; Vidal 2010).

In conclusion, there is little reason to think that the contemporary nation-state has overcome its cultural hierarchies and the related pressures to assimilate. With regard to this insight, Joppke and Morawska's (2003) propositions are inconsistent. When arguing macro-sociologically, they suggest that the differentiation of lifestyles and social fields or systems has become so overwhelming, and that cultures have become so separated into different fields, that no homogenisation in a more general sense (overarching these separate fields) is taking place any longer. When arguing political-theoretically, they suggest that, in the liberal state, culture can be restricted to private and associational life, while the domain of the state, or of law and politics, can be nearly culturally neutral. This implies that the limited public domain is at least to some extent homogeneous: they admit that we have to share a minimal political and linguistic culture, and they even suggest that people can be forced to live by this. Later, arguing historically, they added a third, less liberal possibility in admitting that the contemporary state has only been able to become so liberal because, since the end of World War II, it is 'usually securely sitting on top of thoroughly 
nationalised societies' (ibid.: 4). This inconsistency is telling: the more they motivate their argument empirically or historically, the less the liberal presupposition of culture's minimal penetration into the public sphere seems a defendable interpretation of society. Contemporary calls for multiculturalism take precisely this observation of the nonneutrality of the nation-state as their starting point.

\subsection{Alternatives}

By neglecting the problem of the non-neutrality of the nation-state, Morawska and Joppke overlooked or even simply failed to address the basic problem that multiculturalism seeks to tackle. As we saw, they think that multiculturalism depends on an overly territorial and mono-cultural conception of culture, as if in our globalised world something like coherent communities could exist and as if the members of certain groups want to stick to their identities or cultures quite independently from their position within the larger society (Joppke \& Lukes 1999; Joppke \& Morawska 2003).

I leave aside here the question of the extent to which this is a good interpretation of all earlier versions of multiculturalism. More recent versions of multiculturalism, Kymlicka's included, left behind any justification of multiculturalism in terms of a naturalising defence of cultures. They justify special rights and attention for minorities' voices in the openness of the public sphere in a relational and dynamic way, with an eye to balancing power and achieving equality rather than with the aim of preserving cultures. These versions of multiculturalism interpret it as a response to nation-building and, hence, as a response to the non-neutrality of the nation-state (Kymlicka 2002). ${ }^{8}$

The central focus, then, lies not with an aesthetic or even moral defence of cultural diversity, but rather with a criticism of the denial of cultural hierarchies in the public sphere and the state. The insight that these structural power inequalities cannot be remedied by equal citizenship rights alone has been the central stake for differentialism since Young (1990: 123, 130) argued for differentiated citizenship. According to Young, those groups that had experienced the 'epidermalizing of their world' should receive collective rights and are entitled to affirmative action. The politics of difference was explicitly meant to fight 'racism, sexism, homophobia, ageism, and ableism' (ibid.).

Such a view is founded on a concept of justice in which formal neutrality hides the structural advantages of majorities. This does not mean that neutrality should not be strived for. However, with regard to 
political, legal and socio-economic opportunities, neutrality should be understood in an 'inequality-sensitive, relational' way, as 'prohibiting moral particularism and precluding injustice ... [S]ex, gender, "race", "ethnicity", state-membership, and religion should not matter when it comes to the distribution of resources and rewards' (Bader 2003a: 267). This is not a requirement that we can assume is realised with formal equality and neutrality. Instead, it should be deployed as a normative concept that can make us sensitive to actual inequalities (similar to Laborde's (2008) 'critical Republicanism').

Striving to achieve neutrality in the sense of declaring differences irrelevant denies particularities that cannot be overcome, and that need not be overcome either. Instead, we should try to determine cultural fairness by finding balances between different particularities. This argument has been made most elaborately by Carens (1997), who suggests 'evenhandedness' instead of a 'hands-off' approach to determine conceptions of fairness in liberal societies:

Instead of trying to abstract from particularity, we should embrace it, but in a way that is fair to all different particularities. Now being fair does not mean that every cultural claim ... will be given equal weight, but rather that each will be given appropriate weight under the circumstances and given a commitment to equal respect for all. History matters, numbers matter, the relative importance of the claim to those who present it matters, and so do many other considerations (ibid.: 818; see also Carens 2000).

Adhering to this definition of fairness implies much work and debate, but as a moral norm it takes into account the fact that we do not all start from equal positions in our societies. Moreover, such pluralism justifies special rights, not as exemptions from civil rights and liberal values, but as supplements to them.

Specifically, to counter the possibility that special rights may restrict the rights of minorities within minorities, multicultural policies can be realised within a - minimally defined - liberal framework. This implies that not all claims for minority rights are consistent with multiculturalism, but only those that '(a) protect the freedom of individuals within the group; and (b) promote relations of equality (nondominance) between groups' (Kymlicka 2002: 342). These conditions should lead to the rejection of claims sold under the label of multiculturalism but violating the principle that multiculturalism should realise more equality instead of less. One type of claim that should be excluded are those that restrict the rights of individuals within groups; 
for example, claims for tolerance of contested practices like female circumcision and punishment of apostasy. ${ }^{9}$ A restriction should also pertain to claims that fail to promote relations of equality between groups, such as, for example, the claims made by South African white people wishing to protect their 'minority cultures' under Apartheid.

If we take into account the point that relational criteria are the central ones in contemporary multiculturalism, then what Brubaker (2001: 531) calls 'differentialism' entails not a defence of a communitarian conservatism or an enthusiasm for cultural diversity at the expense of attention for equality, but specifically a philosophy of how to respond to inequality. It is precisely this version of pluralism in the name of a more equal distribution of power that is neglected by both Noiriel and the liberal assimilationists. It is furthermore hardly ever considered in the French context in general, which has nearly always understood differentialism as a wish to conserve certain traditions against their eradication by capitalist Western modernity. This is also explained by the ubiquitous use of the term communautarisme for multiculturalism in today's debates about pluralism and laïcité in France.

With regard to ethno-religious groups specifically, I would like to anticipate my later arguments on secularism by explaining the relevance of relational arguments also for understanding the intercultural dynamics related to ethno-religious claims. This is relevant when we discuss justifications of multicultural policies with regard to nomoi groups. These are groups whose ritualised practices, often explicitly orthodox religious, have implications for their conception of law, as is the case with orthodox Jewish and Islamic groups (Shachar 2001). Nomoi groups may not feel entirely at home in a state such as Joppke and Morawska's (2003) liberal state, because it requests their assimilation to liberal values by fully secularising their conception of law.

Requiring such assimilation, Shachar (2001) signals, may drive these groups into a more rather than a less culturalist and defensive explanation of their claims. The sometimes quite reified self-identifications of nomoi groups are at least partly the effect of their position within the larger community and are thus not thought to have existed intact prior to joining this community. Pressures to assimilate may therefore lead to a 'religionisation of cultural claims' (Parekh 2000: 199) or to an increased stubbornness in maintaining religious claims.

Shachar (2001) argues that processes of self-separation ensuing from assimilationist pressures may result in the repression of minorities within minorities. Therefore, it is not certain that a pressure to assimilate to liberal values will help prevent violence against minorities within minorities. Some forms of internal inequality may be 
inherited from cultural or religious values themselves, but others may be encouraged by (rather than overcome through) outside pressures to assimilate to mainstream culture; probably, we are nearly always dealing with a mixture of both. If this is so, it is important to try to organise ways of mediating between the claims of the nomoi groups and the larger society, instead of simply arguing that their religious concept of law is wrong or backward.

Relational multiculturalism starts from an analysis of minority-formation within the nation-state and does not take the cultural claims of minorities as 'claims of culture' in any absolute sense (see Shachar 2001; Bader 2007). ${ }^{10}$ In such a complex analysis, liberal-democratic reasons can lead us to be careful about imposing assimilationist (or secularist) requests on ethno-religious minorities.

\section{TRANSNATIONAL CITIZENSHIP; ELEMENTS FOR A GENEALOGY}

With regard to transnationalism, as with regard to multiculturalism, Joppke and Morawska (2003) offer strong arguments against a postnationalism that denies the relevance of nationality and citizenship. Their consistent emphasis on the importance of citizenship represents a more realistic approach to contemporary migration than the postnationalist suggestion that migrants derive enough protection from human rights. Being a member of a specific state is crucial to migrants, and so is the possibility of becoming a member of one's state of residence. This was foreseen by Arendt (1979), who argued for the 'right to have rights' for the stateless. Those who can travel freely are the people with the right papers. Non-documented migrants encounter borders on every corner of every street; they are made into illegals who can legitimately be detained or deported (see further De Genova 2007; Mezzadra 2006; De Genova and Peutz 2010).

The liberal assimilationists' enthusiasm for dual citizenship is a welcome antidote to the re-emergence of the diverse European nationalisms. However, even though they acknowledge the importance of dual citizenship, the liberal assimilationists, by their wholesale rejection of ethnic aspects of citizenship, downplay the ethnic identifications that migrants may have with the countries in which they previously resided.

Not all transnationalist views of migration simply neglect the importance of citizenship. The liberal assimilationists could have discussed transnationalist proposals that do not evade citizenship, but, alternatively, those that develop differentiated models of citizenship and options for extending it outside the nation-state (Bauboeck 2009, 
1994; Bader 2005b). Such a transnationalism will not pit de-ethnicised, either territorial or Republican, conceptions of citizenship against ethnic ones, or stay within the confines of the nation-state of residence. Instead of replacing ethnic citizenship with de-ethnicised citizenship, transnationalism seeks to differentiate citizenship itself, acknowledging its residential, cultural (ethnic or national) and political (Republican) aspects (Bauboeck 1998a, 2009, 2011).

These aspects of citizenship have actually always been intertwined in various ways with European political thought and practice. We can see this if we very briefly trace the interlaced concepts of the citizen and the bourgeois in European political thought and if we understand that the focus on citizenship as 'de-ethnicised' nation-state membership is the heritage of a specifically modern conception of citizenship that should be pluralised in the age of globalisation. ${ }^{11}$

The Aristotelian politaes actively participated in governing the polis, the republic. In the Roman Republic, too, participation in government was decisive for being defined as a civis. In the 'Constitutio Antoniana' (212 A.c.), conquered peoples were for the first time admitted to the civitas. This implied a simultaneous process in which, on the one hand, the distance between citizen and non-citizen decreased (because being a civis was no longer reserved for those actively involved in government), while, on the other hand, a gradual convergence occurred of the citizen with the 'subject' in the sense of the 'subjected'.

The word by which 'citizen' is translated in Germanic languages is related to the French bourgeois: 'Bürger'. In the Middle Ages, this word denoted the members of corporations formed by the inhabitants of the cities. The 'burgari' (old German) or burgware (old English) actively participated in government. In the Germanic countries, and also, for example, in Denmark, the 'participatory' meaning of citizenship long remained the central one, while in France and England the mixed terminology of citoyen (citizen) and bourgeois (English 'burgess') testified to the early fusion of the 'active' and 'passive' meanings of citizenship.

In early modernity, the development of state absolutism caused the immediatisation of the relation between citizen and state at the expense of intermediate levels of association. The citizen became the subject of the state and the 'burger' became the bourgeois, operating in society but not involved in shaping general rules or laws. Eighteenthcentury modern democrats like Rousseau and Kant protested against the reduction of the citizen to the subject and demanded participation as free and equal citoyens, as authors of law in the state. Yet they still did so within the framework of the immediate relation between citizen and state: Kant and Rousseau showed little interest in the Aristotelian 
or, in their view, medieval concept of the citizen, which was related to privileges and immunities, and hence, to inequality.

The democratic revolutions went together, at first, with exclusions from citizenship that had been inherited from the Republican definition of citizenship, such as the exclusion of women and slaves. These exclusions were only gradually overcome, but ultimately nearly all residents were included in formal definitions of citizenship (through the struggles and disagreements analysed by Rancière 2006). Yet, as the overcoming of internal exclusions proceeded and the internal universalisation of citizenship as 'Staatsbürgerschaft' (literally translated as 'state-citizenship') succeeded, a rigidification of the nation-state's external boundaries occurred, which led to increased exclusion at these boundaries.

The modern nation-state turned out to be a jealous state that wanted to see all the political energies of its subjects concentrated on itself. Moreover, it excluded the stranger more strictly than was usual before. Internally, this concentration on national boundaries resulted in the politics of assimilation, and externally, it gave rise to the introduction of the passport, state-organised border controls, and the construction of the 'foreigner' (see Noiriel 2001). Consequently, the ambivalence of the process of immediatisation between citizen and nation-state lies in the way it, on the one hand, brings about universalisation and equality on a specific territory, but on the other implies a rigidification of stateborders and a neglect or distrust of associations smaller and bigger than the nation-state itself. Today, we can see a similar process unfolding at the borders of Europe (see also Mezzadra 2006).

Transnationalism wants to return flexibility to citizenship. It does not want to do this by effacing ethnic, national, linguistic or other boundaries simply because such boundaries would divide or separate people - this is what some critics have argued for in terms of 'postnationalism'. Instead, transnationalism argues for the recognition of boundaries at many levels at once and for their mutual flexibilisation (see Bauboeck 1998a, 2009; Bauboeck \& Faist 2010). Such transnationalism is based on a multi-level understanding of multiculturalism. It tries to build upon actual practices of power distribution, pluralisation and mediation, which have never been as 'dead' as modernist political theory declared them to be. Today, for example, pluralisation is taking place within the process of unifying the European countries into the eU, in regionalisation, and in internal pluralisation as multiculturalism, when this is understood in a non-reifying way that allows for multiple identifications and dual, or perhaps even triple, citizenship. Thus, transnationalism focuses on the gradual permeation of bounda- 
ries, in particular those of the nation-state, by 're-mediating' political relations while preserving the democratic achievements of the modern state, for example, by providing citizens with options for having a voice and for exiting (having the freedom to leave), as well as by providing a reasonable number of aspirant citizens with the option of entering (see also Bader 2006).

The 19th-century concept of assimilation was crucially related to the immediatisation of the relation between citizen and nation-state I have just briefly discussed. The chapters to follow scrutinise this history more closely. But let us now return to the proposal for reintroducing a concept of assimilation in the present-day context.

\subsection{Against the new discourses of assimilation}

\section{Performative effects}

If processes of cultural homogenisation are likely to be more complex and more intrinsic to incorporation in the contemporary nation-state than the liberal assimilationists suggest, where does a transformation of the concept of assimilation along the lines they propose lead? Can policies based on such a concept produce the required countering of exclusion and segregation? What are the unintended effects of the use of this contested concept? Here it is useful to distinguish between the actual contents of the policies that are advocated by the emphasis on assimilation and citizenship, and the performative effect of making a normative use of the concept of assimilation in today's debates about incorporation.

The policies for which the liberal assimilationists argue are founded on a reinforcement of the classical liberal model that tolerates and recognises difference as long as it stays outside the public sphere. The emphasis on assimilation leads us back to a version of liberalism that is less wary of the use of force than, for example, Rawls' political liberalism, and more self-assured about its potential to realise the religious and cultural neutrality of the state. Moreover, the emphasis on citizenship propels this liberalism in a direction that is Republican, culturalist and even moralising, specifically with regard to migrants (Schinkel \& Van Houdt 2010).

It is quite unlikely that such a brand of liberalism can provide us with the answers to the problems of exclusion and socio-economic inequality which the liberal assimilationists are most concerned with. De-ethnicised notions of citizenship and a 'neutral' concept of assimi- 
lation will not likely lead to equality, but rather to a perpetuation of inequalities, for they do not help us to analyse the causes of inequality at a sufficiently structural level. They exclude the consideration of cultural hierarchies (Young 1990; Kymlicka 2002; Alexander 2006). Even if they return towards a robust politics of redistribution, they only revive the old competition between culture and economy. It should not be a question of either/or but of aiming at both and of cleverly analysing how cultural hierarchies and economic chances are entangled (Fraser 2003; Mookherjee 2010).

Another problem concerns the performative effects of reintroducing assimilation and a 'neutral' notion of citizenship. The primary concern here is not that this will probably lead to a perpetuation of existing inequalities. Rather, it is that their reintroduction in the context of 'fighting segregation' may actually enhance these inequalities. Advocating assimilation and citizenship specifically for migrants, even if we do so in a liberal version, may actually have marginalising, and even exclusionary, effects.

In recent years, we have witnessed nationalist groups and political movements deploying the scholarly use of the concept of assimilation to legitimise a politics of assimilation in a more literal sense. We cannot control the meanings of the concepts we use, particularly not the meanings of concepts with such painful histories. Making assimilation into a normative concept, scholars have taken the risk that the larger public would link it with earlier 'hegemonic assimilationist practices that linguistic minorities, Jewish communities and Roma and Sinti, have had to suffer' (Prodolliet 2003: 25). They have not only risked stirring up these memories but also risked legitimising the politics of those who seek a perpetuation or revival of assimilationist practices.

Liberal assimilationists argue that we should shed the cultural connotations of assimilation and use the word only in the sense of its 'structural' understanding, as 'the socio-economic equalisation of life chances between immigrants and native populations' (Joppke \& Morawska 2003: 6). We might ask why they would want to use the concept of assimilation at all, since it is precisely this aspect of incorporation processes that has been associated with 'integration' over the past 20 years. For this reason, the social scientist Matteo Gianni (2003: 20-21) argues that Brubaker's new concept of assimilation delivers only a dubious new denominator for what is now common practice in European countries under the heading of integration. Joppke and Morawska's (2003) argument as to why assimilation is preferable to integration is not very convincing here: they argue that integration suggests an emphasis on unity that a formalised and disaggregated 
concept of assimilation does not. However, both concepts are associated with unity and processes of unification, and if we wanted to avoid that connotation we could choose a concept with a less tainted history and abstain from encumbering it with normative expectations.

These are reasons for sympathising with the reluctance of Gianni (2003) and Prodolliet (2003) to use the concept of assimilation. But the answer is not to restrict ourselves to using the concept of integration instead. That would only prevent us from seeing the actual links between contemporary integration policies and earlier versions of assimilation. Instead of rejecting the use of the concept altogether, we should therefore examine the sense in which assimilationism is not altogether foreign to contemporary processes of incorporation, even when they are called 'integration.' What we should problematise is the idea that we can neatly distinguish between political citizenship and legitimate assimilation (or 'integration', for that matter) on the one hand, and ethnic citizenship and nationalist assimilation on the other. The continuities and discontinuities between both concepts and both historical forms of assimilation are precisely what can bring us to a more nuanced view of contemporary processes of incorporation.

\section{SPILLOVER}

A problematisation of the abstract distinction between culturalist assimilationism and liberal assimilation finds an empirical motivation in the fact that they quite easily transform into each other. For example, in the Netherlands, some policies that initially seemed to fall under the heading of encouraging liberal assimilation or de-ethnicised citizenship, and which are therefore mentioned by Joppke and Morawska (2003) as examples of new ways of dealing with incorporation, have by now depreciated into more literally assimilationist ones. Indeed, we may question whether some of the new Dutch policies with regard to immigrants can be justified from a liberal standpoint at all. Some policies that could stimulate the development of mixed identities are actively discouraged, such as, for example, special education in the mother tongue for young children. But even self-comprehension in terms of hybridity is actively discouraged in many contexts (Vasta 2007; for Britain, see Back et al. 2002). This may impair people's choices to participate in several cultural surroundings and to blend them as they wish. It is also highly questionable whether it meets the requirements of Joppke and Morawska's (2003) new definition of assimilation, which is the 'equalisation of life chances'. For example, with regard to lessons in the mother tongue, it is questionable whether no longer sub- 
sidising them will lead to 'equalisation'. Generally, when citizenship is specifically advocated for migrants, they risk being burdened with the obligation of being better citizens than long-time residents, which clearly contradicts the equality that is sought (Bauboeck 2001; Schinkel \& Van Houdt 2010).

In Dutch public debates, too, a new assimilationism quickly emerged that was more clearly an old-style assimilationism than that put forward by Joppke and Morawska (ibid.). There were more or less two versions of the return of assimilation and justifications for the need for 'more severe' policies of integration. One version was very prominent in public and political debates. It stressed that underachievement and the exclusion of migrants and their children was the result of their 'backward cultures' and especially their religious (Islamic) traditionalism. Dutch spokespersons for this group included Ayaan Hirsi Ali and Pim Fortuyn. They either suggested that assimilation was nearly impossible (Fortuyn), or that severe pressures to assimilate - among them, insulting Islam - would do the job of extinguishing the backwardness (Hirsi Ali, as well as Theo van Gogh).

Other, more academic, discourses proposed a milder version, in which an emphasis on the universal desirability of liberal democracy and secularised religion was accompanied by a critique of multiculturalism. In these discourses, however, strands of old assimilationism often pierced through the surface of the critique of multiculturalism as a policy. A telling example is contained in a booklet called The Multicultural Illusion: Plea for Adaptation and Assimilation by Paul Schnabel, Director of the Social and Cultural Planning Office of the Netherlands (SCP). Schnabel (1999: 15) embellished his call for assimilation with comments like, 'no one wants to introduce Turkish pedagogical methods in the Netherlands' and 'no one is hailing the Moroccan view of women'. Thus, in the Netherlands, the new assimilationism has been polemical, and unafraid of making ill-founded and generalising claims about the characteristics of entire 'cultures'. This is a feature which would never appear in the discourse of, for example, Gérard Noiriel or Rogers Brubaker.

Many participants in the debates, like feminist and former Muslim Hirsi Ali, adhere to Okin's (1999) liberal critique of multiculturalism. Yet Hirsi Ali's concerns about minorities within Muslim minorities coincided and even overlapped with a changed political climate with regard to migration, particularly Muslim immigration. Right-wing talk of the Netherlands as 'the drain of Europe' (Frits Bolkestein, European Commissioner for the Internal Market, 2000) came to be seen as legitimate by more and more people, and Muslims were increasingly 
described as possible or even probable members of a (future) 'fifth column' (Pim Fortuyn) that ought to 'integrate' more seriously and that should make a clear decision on Dutch citizenship. ${ }^{12}$

Just as their defence of liberal assimilation conceals a return of assimilationism, the liberal assimilationists' suggestion that de-ethnicised citizenship has actually come into existence conceals the return of nationalistic and nationalising tendencies in citizenship policies in many European countries. Whereas before 9/11 it was already somewhat idealistic to suggest that dual citizenship had become less problematic and that the 'liberal state was finally getting liberal', it increasingly became so afterwards. Dual citizenship became less popular after $9 / 11$, and some countries that had experimented with this concept have abolished those policies. The North Atlantic Lockean 'zone of trade' is penetrated by Hobbesian zones of war at its borders and within it. Examples of exclusionary mechanisms framing or treating aliens as 'others', instead of as negotiators, abound, which frequently leads to illiberal border practices (see Lucassen 2005; Huysmans 2006; Mezzadra 2006; De Genova \& Peutz 2010). Moreover, since 9/11 a general concern about the loyalty of Muslims has been heard in multiple European countries. This has gradually led to an imaginary of war and to processes of securitisation; precisely the kind of imagery that Joppke and Morawska (2003) suggest has waned (Amoore 2007; Cesari 2010; Edmunds 2011; Morey \& Yaqin 2011; Norton 2011). This merely proves that the liberal state cannot keep its promises in the contemporary historical context.

In conclusion, we need a subtle concept of assimilation to analyse those forms of assimilationism that cannot so easily be uncovered as such precisely because they are called liberal. In that sense, we cannot avoid the use of the concept of assimilation, but we should apply it with a critical perspective in mind and without a 'normative charge'.

\section{INGREDIENTS FOR A CRITICAL CONCEPT OF ASSIMILATION}

In conclusion to the first two chapters, I want to argue that a critical concept of assimilation has at least two levels: a sociological level and an (inter-)subjective one. For both, the memory of European assimilationism offers a crucial site of reflection.

1 In relation to the non-neutrality of the nation-state and the need to analyse the occurrence of processes of cultural homogenisation at a sociological level, assimilation must be used in a more sober empirical sense than either Noiriel or the liberal assimilationists propose. They 
turn it into a 'normatively charged' concept by placing it central in designating the direction of incorporation policies in general. Rather than forgetting about assimilation's older sense of cultural homogenisation and shifting away from it, we should instead stick to this older sense but strip it of its normative use. It can then be used as an empirical notion to try to grasp the degree of voluntariness or force actually occurring in processes of cultural homogenisation, and to grasp the differentiations in different fields of societies as well (see also Lucassen 2005; Silberman, Alba \& Fournier 2007).

Such a definition is not founded on the assumption that assimilation is necessarily undesirable; that would depend at least partly on whether it takes place voluntarily. There are three conditions for this. It requires, first, that people are not pressured to shed cultural practices just because they are not those of the majority. Second, majorities must abstain from denying the existence of cultural boundaries to which the members of minorities may be more sensitive. Third, an openness is required on the part of majority populations to revise their own views of their culture and on the part of the members of minorities an openness to critique.

However, the norm of voluntariness is not unproblematic. As we will see when analysing Proust's view of assimilation, the actual degrees of voluntariness and involuntariness in processes of assimilation are difficult to distinguish. This complicates not only our understanding of what assimilation means, but also our normative view of what legitimate policies of incorporation are. A further question should be whether we should keep calling voluntary adaptation 'assimilation'.

With regard to assimilation's relation to exclusion and segregation, it is furthermore crucial to recognise that a concept of assimilation should help to analyse the process as it appears not only from the viewpoint of the person that assimilates, but also as it appears from that of the majority. It is crucial that the members of majorities recognise the person who assimilates as 'one of them' in order to achieve a legitimate form of assimilation (Bauboeck 1998a; Alexander 2006). The extreme case that should be avoided - and remembered, as the following chapters will argue - according to Bauboeck (1998a: 42), is the nightmare of Jewish assimilation. This concerns assimilation as a double bind that the Jews were forced into: many of them voluntarily assimilated in order to be recognised as full citizens, but once they had done so and had lost much of their former identities and institutions, they were nevertheless frequently rejected by members of the national majority culture. This is what Pierre Birnbaum calls disassimilation, and others call the paradoxes of assimilation. ${ }^{13}$ For Bauboeck (1998a), this is a rea- 
son to stress the necessity of preventing a mechanism that could lead in such a direction, He argues that 'the state should tie its own hands' and accept anyone who wants to assimilate and become a member of the cultural majority (ibid.: 42). As we will see in the chapters to follow on the paradoxes of assimilation, it is however not certain that the state is the only relevant actor. Attitudes of co-citizens towards one another are important here as well.

It is important to note too that references to the paradoxes of assimilation as they were experienced by the European Jews are mostly lacking in the sociological literature that seeks to reintroduce the notion of assimilation. Interestingly, for example, in a 1997 article titled 'Paradoxes (and Orthodoxies) of Assimilation', American sociologist Rumbaut speaks of 'paradoxes' of assimilation when urging his colleagues to take the notion seriously. But he makes no reference to the 'paradoxes of assimilation' that were experienced by the European Jews. Neither do Brubaker, Noiriel or Morawksa and Joppke. Perhaps this is partly because these authors concentrate on the notion of assimilation in the early sociology of migration rather than in the pre-sociological 19th-century use of the term.

2 Liberal assimilationists deny the relevance of the old concept of assimilation for contemporary societies by constructing two analogous conceptual oppositions and then projecting them onto history. First, they create an opposition between what assimilation means in a culturally homogeneous state and what it means in a pluralised liberal state. Second, an analogous opposition is constructed between ethnic citizenship and de-ethnicised citizenship. They project these abstract theoretical oppositions onto history by contrasting pre-World War II assimilationism with the new liberal assimilation, and analogously, pre-World War II ethnicised citizenship with contemporary de-ethnicised and dual citizenship.

It is perhaps crucial to more seriously consider the memory of Europe's assimilationist past and its vicissitudes. In the construction of the abstract opposition of de-ethnicised citizenship and ethnic, nationalist group identifications, the narcissism of contemporary liberalism is complemented by a projection of its imagined perfection onto the counter-image of the culturally homogenous nation-state in the 19thcentury past. Both images deny deep inequalities and tensions inherent in contemporary, but perhaps even more, in past, societies. While the image of the contemporary liberal state denies cultural and social conflict by exaggerating its achievements in overcoming them, the myth of the homogeneous past denies them by simply forgetting them. 
If we think only of France's past, it is clear that homogenising policies have existed, but homogeneity has not. Pre-World War II France knew conflicts of dimensions that we can hardly imagine, if only because of the number of deaths they caused (Birnbaum 1998). ${ }^{14}$ Both images should be nuanced, and this can be achieved by thwarting the neutral self-image of Europe in a confrontation with its own complex history of assimilation.

Exploring that history may also help us to nuance the caricatural view of pre-World War II assimilationism. It is too easy to suggest that we have left behind its practical and moral problems. It is precisely the link between Republican, universalist citizenship and assimilationism as it existed in France that Joppke and Morawska (2003) fail to address when they locate assimilationism exclusively in explicitly ethnic or homogenising definitions of citizenship. That is another reason to scrutinise the memory of the complex relation between assimilationism and Republican citizenship to be elaborated in the next chapters.

3 What the liberal assimilationists systematically avoid analysing, aside from the sociological complexities in the context of the nationstate's non-neutrality, are the subjective aspects of processes of assimilation, in particular, the deep psychological pressures exercised upon individuals that Noiriel considered essential for the process of assimilation. Compared to Noiriel, the liberal assimilationists lack a sensitivity to experiences of cultural hierarchy.

This unawareness of the subjective aspects of processes of cultural homogenisation may relate to the focus of the liberal assimilationists. Although they do address the topic at several disciplinary levels at once (macro-sociologically, political-theoretically and historically), they avoid a focus on individual experience. We saw that Noiriel came to his view of the psychological costs of the process of assimilation thanks to his interest in individual narratives and literary accounts of what it means to be treated like someone who does not entirely belong. The liberal assimilationists, however, evade the perspective of the individual. Brubaker (2001: 543) justifies this choice by asserting that a concentration on assimilation as a process at a subjective level is no longer necessary, because the relevance of assimilation as a 'conscious activity' is dependent on the brand of assimilationism practised prior to World War II. For contemporary historians and social scientists, he writes, assimilation is an 'emergent tendential property of social processes at an aggregate level, rather than something that happens (consciously or unconsciously) at the level of individual persons' (ibid.). Its ideal type is the contemporary legitimate concept of assimilation, 
which does not designate a process undergone by one person but by a multi-generational population, a process that can occur without any individual-level assimilation. ${ }^{15}$

However, it is at least plausible that assimilation at a subjective level has not been overcome entirely, consciously or unconsciously - if only because, as Noiriel argued, assimilation is a social process with some specificities for migrants, but that, due to its link with modern (educational) institutions, also has more general characteristics from which no one in modern society can escape. Since Brubaker admits that assimilation as an activity at a subjective level can have tragic ambiguities and ambivalences, I propose we try to learn more about these ambivalences. We can do so, as I will try to make plausible in the next chapters, by turning to the memory of the ambivalences and paradoxes of assimilation in detail, through a contextualised reading of Marcel Proust's narrative of assimilation. 
TRANSIT I

\title{
Proust as a witness of assimilation in 19th-century France
}

\begin{abstract}
Proust's play with his own Jewishness - and the career of the Jews in the 'West' it so spectacularly embodies, not despite but because of his profound ambivalence - has thus this dual salience: it can remind us both why we seek to deny the firm bounds of identity that our cultures construct for us ... and why we should be wary of the claims of our abilities to escape those bonds altogether. It suggests that we cannot reimagine ourselves - as we know we can and must do - without reckoning with the ways we have been imagined. It means, put simply, that we cannot do without history. And history, as Fredric Jameson once reminded us, is what hurts (Freedman 2001: 546).
\end{abstract}

The following chapters are founded on the idea that a critical rethinking of Jewish assimilation in 19th-century France - or the process which has been interpreted as such - is important for an assessment of the moral legitimacy and practical wisdom of (re)introducing liberal-assimilationist discourses and practices in the European context. Rethinking Jewish assimilation will also help us trace assimilation's connections to secularisation in the France of the Third Republic. This will facilitate our understanding of the connections between secularism and assimilationism today. I try to contribute to such a rethinking of assimilation by scrutinising the ways in which assimilation's practical and discursive effects appear in Proust's oeuvre, and particularly in his novel In Search of Lost Time. This novel was written between 1909 and 1922. It allots a central place to the position of the Jews in the early French Third Republic (1870-1940), often in relation to the Dreyfus Affair (1894-1906). I read the novel in connection to three other kinds of sources: historical documents about the Emancipation of the Jews, the interpretation of French Jewish assimilation by prominent historians of French Judaism - most notably Pierre Birnbaum and Esther Benbassa - and the more general interpretations of the paradoxes of assimilation in 2oth-century philosophy and sociology.

Arendt was one of Proust's first readers to consider him a central witness of the paradoxes of assimilation as they came to prominence within the French context. Also for Adorno and Benjamin (1999 [1940]: 
329), Proust's oeuvre was a key reference when seeking an understanding of the 19th-century roots of what Benjamin called the 'highly precarious structure of assimilation' of the French Jews, and what Adorno, more radically and after Auschwitz, called the 'failed [gescheiterte] emancipation' of the European Jews (Adorno 1994 [1954]: 98). More recently, literary and historical studies have once again made Proust into a witness of the vicissitudes and complexities of Jewish assimilation in France, most notably Bem (1980), Brun (1988), Kristeva (1994), Hughes (2001, 2011), Freedman (2001) and Carlston (2002). Almost all of these authors have read Proust in connection with a more general view of assimilation and cultural diversity in some way, as the earlier philosophers had done.

Historians and sociologists, working more broadly on the paradoxes of assimilation, frequently connect their interpretations of 19th-century Jewish assimilation to the contemporary position of ethno-religious minorities in France. These authors often do so in connection with a reading of the law prohibiting the wearing of conspicuous signs of religion at school (most notably Benbassa 2003; Silverman 2007).

The aim of the following chapters is to mediate between the more general readings of the actuality of the paradoxes of assimilation and the specific readings of French Jewish assimilation through a reading of In Search of Lost Time and its interpretations. This methodology will help us to remember and rethink these paradoxes in the context of secularist and assimilationist discourses today, without positing complete analogies or transhistorical continuities.

Rethinking the actuality of the paradoxes of assimilation in the context of today's debates about assimilationism and secularism, as argued briefly in Chapter 1, does not imply tracing any complete analogies between the assimilationism of the French Third Republic and today, nor between Muslims and Jews as specific ethno-religious minorities, or between contemporary Islamophobia and modern, Third Republican, anti-Semitism. Let me introduce here a little more elaborately my conception of the actuality of the paradoxes of assimilation, and what we can contribute to the understanding of them through a contextualised reading of Proust's novel.

\section{On making historical and sociological comparisons and analogies}

Comparisons and analogies, both historical and sociological, are always partial. They are not meant just to convey similarities, but to 
rethink patterns of similarity and difference. There will be overlap to some extent, in some fields and not in others. For historical comparisons, Wittgenstein (1967: 31-32) offers a metaphor to explain why we cannot give essential definitions of complex phenomena, but rather have to analyse overlaps and differences:

[T] he strength of the thread does not reside in the fact that some one fibre runs through its whole length, but in the overlapping of many fibres.

The intention of the following chapters is to present a nuanced and broad picture of the 'culture of assimilationism' as it was experienced by the French Jews in the late 19th century. The aim is to better understand how some of the fibres of assimilationism were knotted together at that particular, crucial moment. We can then see how some of the threads have run on, although they have been knotted together in new configurations, together with other threads.

It is relevant to note that there are always political sides to historical comparisons. Anthropologist Bunzl (2007), editor of a collected volume comparing anti-Semitism and Islamophobia, recently made valuable comments about this in an interview with Bangstad (Bangstad \& Bunzl 2010: 214):

[O]n a general level, two groups are never identical. This is a philosophical point; Jews and Muslims will never be the same, and Muslims of today could not possibly be the Jews of the early twentieth century. I am for comparison, but no comparison is neutral: it is not intellectually neutral and it is not politically neutral. We also need to understand from a philosophical perspective that if one undertakes a comparison - as anthropologists, sociologists, or historians do - in the broadest sense we can always find, between essentially any two groups, similarities and differences. And it is often a political choice or an analytic choice whether we want to foreground the similarities or the differences.

I would add two remarks to this observation. Firstly, admitting that comparisons inevitably have their own politics does not mean that making a comparison immediately turns one into a partisan of a certain politicised view, as opposed to someone taking an analytical approach. The Wittgensteinian point is that pure analysis is impossible, as are essential definitions. Comparisons are our way to acquire knowledge, but they have to remain methodologies to distinguish essential points for debate and deliberation, they cannot help us uncover politically neutral, final and stable truths. 
Secondly, especially in relation to any comparison made between the position of today's ethno-religious minorities and the position of the Jews in Europe before the Shoah, we have to realise that the Jews' historical position is not a relatively stable historical object, but one that is highly affectively loaded, and that forms part of a living, and traumatised, cultural memory. In a reflection on 'the abuses of memory' in the context of the debates about the unicity of the Shoah, Todorov (1998) called for a comparative use of memory in which historical events are not read in a literal way but, without denying the singularity of the event, in an exemplary, metaphorical way. The most important objective of historical metaphor is to 'draw a lesson' from the comparison, Todorov argues. Such lessons, in this context, are not purely intellectual ones; they strongly affect our understanding of who we are and they touch on important moral-affective layers of our experience as well. This also means that they can modify our insight in more significant ways, and perhaps also more effective ones, than mere intellectual argument.

Theories of cultural memory have emphasised that the structure of memory itself is metaphorical. Memory always involves a complex relation between personal experience, cultural representation and shared histories. It depends on re-articulations and re-enactments, and its performative dimensions of transmission and testimony entangle it with present-day political interests:

The mode of memory is recherche rather than recuperation. The temporal status of any act of memory is always the present and not ... the past itself, even though all memory in some ineradicable sense is dependent on some past event or experience (Huyssen 1995: 3).

As mentioned, the affective layer in historical metaphor is especially attendant when we associate the Jews' pre-war circumstances with the contemporary circumstances of migrants and minorities from other backgrounds, because of the moral charge present in any reference to the experiences of the European Jews and because of the exceptional cruelty and systematism of anti-Semitism, which was particularly vigorous in the France of the Third Republic.

What may make us particularly reluctant to make comparisons with the pre-War situation of the Jews is the understandable focus, when it comes to Jewish history in Europe, on the Shoah, and the more problematic projection of the Shoah back into the past, as if it constituted the unavoidable direction of this history. American historian Schechter (2003) argued, specifically with regard to the historiogra- 
phy of 18th- and early 19th-century France, that we should be careful about projecting the Shoah back onto European history. Borrowing a term from the literary historian Bernstein, Schechter (2003: 4) warns against a teleological presentation of Jewish history as one of 'victimsin-waiting'. Therefore, Schechter (ibid.: 3) proposes that we methodologically 'forget/shachoch' rather than 'remember/zakhor' the Shoah for our rereading of post-revolutionary Jewish history in France in order to develop a less teleological interpretation.

I am not sure that an approach of methodological forgetfulness even if it were possible, which I doubt - might not lead to a reification of the Shoah and its isolation from the history (or histories) that preceded it, which is precisely what Schechter wants to avoid. In this sense, Schechter's proposal mirrors the overly singular use of memory criticised by Todorov. A different methodology, pursued here, is to allow ourselves to trace the many moments of contingency and complexity that make it impossible to imagine the Shoah as the single terrifying telos of this history, while at the same time also being aware that, together with myriad other threads in the history of the European Jews, the complex historical situation in the France of the Third Republic is to be read as forming one of the many aspects of this history.

It may not be superfluous to state, in relation to the above, that I bring to attention the memory of Jewish assimilation in France not to relativise the particularity of Franco-Jewish history or to moralise contemporary views of immigration that mention assimilation as a normative option. There are great differences between the position of Jews and Muslims, both historically and today. Bunzl (2010: 214215) mentions the differences related to 'geopolitics, population movements, and histories of migration', and we might add that there are important differences related to the historical position of the Jews as an internal minority in European countries for centuries, before the acquisition of citizenship rights. Bunzl also strongly emphasises that the fate of European Jewry is not conceivable today for any population, and that it would be alarmist to suggest anything similar.

I make no claims as to the comparability of both minorities within the dimensions mentioned above. Rather, I pursue the suggestion, in line with Bunzl (ibid.), that 'Muslims are the victims of extraordinary discrimination, and we need to be incredibly vigilant and struggle against that kind of discrimination', and that we can understand more about these forms of discrimination by analysing specific elements of the history of the Jews in Europe. My contribution, then, is to analyse these forms of discrimination as having a genealogy in which explicit 
racisms play a role as well as secular-assimilationist expectations and demands. The following chapters pursue the suggestion that in order to understand and counter these forms of discrimination, it is important to look not just at the explicitly discriminatory cultural and political discourses today, but also to those insufficiently reflected legacies of mainstream and majoritarian European cultures that may enhance these currents, or at least encourage a relative indifference towards them.

The comparison to be made will be based on a spectrum, and it will be elaborated carefully in the chapters to follow. At some points the comparison concerns Muslims and Jews as specific minorities in relation to the French Republican state. At other points there will be an overlap between both these groups and ethno-religious minorities in general, mostly in relation to the French state, or to the doctrine of modern citizenship. A central role is played by conceptions of Republican citizenship having inherent problems with visible difference, especially when this visibility has both religious and ethnic connotations. The specific analogy between Jews and Muslims will then be how racial, ethnic and religious dimensions of the minority status of both groups are imbricated in each other under assimilationist expectations.

I will try to make plausible the suggestion that we can learn a great deal if we compare the history of French 19th-century Jewish assimilation with the contemporary resurgence of assimilation and strong concepts of integration, in connection to secularism. My aim is not purely scholarly and comparative, but also poetic. It is to help develop, by rereading the painful experience of assimilation as it appears in the Proustian novel and in its various readings over the last century, a reinvigorated inspiration for a pluralisation and pluralism of the French public sphere, and also for pluralisation in Europe more broadly. In that sense, my aim is indeed also political, as I hope to add to the cultural self-reflection on one of France's, but partly also of Europe's, most deeply held narcissisms concerning the promise of secular modernity, and to enhance our sensitivity to the forms of racialisation, culturalisation and othering that can be among its paradoxical results.

\section{Comparisons in existing literature}

With regard to the comparability of the position of the 19th-century French Jews and that of Muslims today in Europe, and in France in 
particular, and also with regard to the comparability of anti-Semitism and Islamophobia, important things have already been written over the last years. Let me outline three lines of comparison that have been made.

COMPARISONS VIA A MODEL OF ASSIMILATION, REPUBLICANISM OR MODERNITY

The idea that there are good reasons for bringing up the ambivalent history of assimilation today has been put forward particularly with regard to the French context. Here, often, the analogy being made is not one, in the first place, between Jews and Muslims as specific minorities that share a certain number of characteristics. Instead, the comparison is made via an analysis of what French studies scholar Max Silverman (2007: 630) has called the 'paradoxes of the Republican model', which are similar to what French philosopher and sociologist Shmuel Trigano (1982: 253) had already analysed in terms of an essential 'paradox of modernity'.

The paradoxes put forward by these authors, which they call the paradoxes of modernity, of Republicanism and of assimilation, are all closely affiliated, and they even broadly overlap. What is the content of these paradoxes and how do they emerge? The basic idea, already briefly discussed in Chapter 1, is that the French Republic, introducing, after the Revolution, equal citizenship for all, and by doing so inaugurating modern liberal democracy, unwittingly also introduced new inequalities. These inequalities arise at the boundaries between citizenship and diverse 'others' - such as not-yet-citizens, minors, and citizens who still have to be integrated in order to be recognised as full citizens. The idea of these critics is that the French Republican ideology of universal citizenship doesn't recognise the Republic's own role in perpetuating and even creating these boundaries, because it conflates the national and the universal. Because boundaries do exist, an unconscious focus on boundary drawing and on who belongs or not is stimulated, instead of actual universality (see Silverman 2007; but also Noiriel 1996b; Alexander 2006). The French Jews, in this analysis, were the first to experience new boundaries produced between them and other French citizens instead of their unequivocal inclusion as full citizens. Silverman (ibid.: 630) grasps the basic problem in terms of the idea that some (the Jews) had to assimilate while others did not or hardly have to do so, in the experience of the majority: 
Hence, the very fact that the Jew must undergo the process of transformation and assimilation in order to become a citizen (or 'regeneration' as it was termed at the time of the emancipation of the Jews just after the French Revolution) is a permanent reminder of the essential difference between Jews and 'natural' Frenchmen and women in the first place: the former will always be 'acculturated' (and hence duplicitous, mimics) compared to the latter, for whom culture and mores do not have to be acquired but are as much a part of their make-up as their very own skin.

Silverman takes the paradoxes of Franco-Judaism as a first and exemplary proof of a general paradoxicality of Republicanism. The paradox is produced by a French Republican blindness towards the dynamics of racialisation under its drive towards universalisation. According to Silverman, the paradox of universalisation was later transposed to the French colonial system (as analysed by Bancel, Blanchard \& Vergès 2005, in the footsteps of Fanon 1952). It has been brought back again to today's France, where it was manifest in the law on the headscarves, Silverman (2007) argues. In sum, the paradox of Jewish assimilation under modern conditions could be generalised to explain 'the fundamental paradox in the French Republican model of the nation and of cultural difference, which wants to create equality but produces its opposite effect' (ibid.: 630-631).

As already mentioned, Trigano (1985: 253) analysed the paradoxes of Jewish assimilation in terms of an essential paradox of modernity, which almost automatically produces the return of the repressed, in terms of the return of difference in equality:

At the dawn of modern France, a process was thus set in motion that eventually led to the collectivisation of the Jews despite the fact that such a phenomenon was ruled out by the logic of the one and indivisible Republic. This irrepressible tendency of the republican system to turn the Jews into the very entity that the system forbade them to become could be likened to the psychoanalytic logic of the return of the repressed.

Elaborating on that analysis, Bellamy (1997) argued that the disavowal of difference on the conscious level is premised on the fetishisation of difference on an unconscious level. In the footsteps of Bellamy, this is affirmed by Silverman (2007: 631):

The splitting and Manichaean boundary-drawing at the heart of this Enlightenment model - dependent on the by-now familiar binary oppositions between universalism and particularism, assimilation and differ- 
ence, citizen and subject, civilisation and barbarity, secularism and faith, public and private, individual and collectivity, and so on ensures that any ambivalence remains firmly repressed and displaced.

This idea that the paradoxality of assimilationism is so thorough and deep that it can be seen as a main and central paradox of modernity, was put forward by Trigano (1982), when he wrote:

\begin{abstract}
Nineteenth-century and, subsequently, 2oth-century French anti-Semitism has its (secret) sources in the 18th-century Republic, in the republican, revolutionary myth, in the principle of the Rights of Man and the Citizen itself; I would add, in spite of itself ... anti-Semitism got its hands dirty, something the Republic never did, but which it made possible in the abstract and in principle (Trigano 1982, quoted in Birnbaum 1988: 47, my translation).
\end{abstract}

Following Schechter's criticism of a teleological reading of FrenchJewish history, we may object to some essentialising traits of Trigano's and Silverman's interpretations. For example, Trigano argues that the Republic enables anti-Semitism 'in the abstract and in principle', and that the anti-Semitism contained its sources in the Republic, which suggests a kind of perfect teleology. Schechter (2003: 4) explicitly mentions Trigano as one of the representatives of the teleological interpretation of Jewish history. Silverman as well, insofar as he defends the idea that there is one central paradox of Republicanism as a model, might be defending a somewhat too strong and near transhistorical interpretation of French Republicanism. One of the things demonstrated by my reading of Proust, however, is that a careful hypothesis can be defended that is structurally related to that of Trigano and Silverman; that is, Republican conceptions of citizenship tend to contain contradictions which risk turning the promise of assimilation into a series of paradoxes, and these played a role in the emergence of new, modern forms of anti-Semitism in the French Third Republic. Let us first turn to a second line of comparison, which is more historically oriented.

COMPARISONS OF THE POSITION OF JEWS AND MUSLIMS AS OTHERS OF THE FRENCH STATE AND OF EUROPE; INITIAL CONNECTIONS WITH THE SECULARISM-RELIGION FRAMEWORK

A related line of comparison between Jews and Muslims was briefly described by Bangstad and Bunzl (2010: 215): 
I would say that there are some structural similarities. These are both groups that are imagined, not by everyone but by a large part of the [European] population, as being Other, as being outside the frame of what is considered normal.

Benbassa (2003) and Birnbaum (1998) are among the historians of Jewish history who have signalled that Jews have been considered a paradigmatic minority in France, crucial in defining the relation between citizens and state, while their relatively low number did not justify that status. Their becoming paradigmatic had rather to do with the fact that Jews were considered both ethnically and religiously 'other'. The opacity of how these two aspects of their otherness were related caused part of the fascination and the state's attempts to control them (Birnbaum 1998; Benbassa 2003).

In her contribution to the recent volume Islamophobia and AntiSemitism, Benbassa (2007) even urges us, in line with the above reasoning, to be careful when talking about Islamophobia in the French context. This is firstly because part of the racism against persons of migrant origin is connected to stereotypes concerning the Arab, rather than Muslims. Secondly, talking about Islamophobia pushes us towards thinking that many people who have origins in the Islamic world are indeed Muslims. This is a problematic assumption, especially in the contemporary French context, in view of the large population of African or Middle Eastern descent who give no serious consideration to religion at all (see also Noiriel 1996b; Roy 2005; Balibar 2007).

This point is immediately related to the salience of today looking back at the position of the Jews in late 19th-century France. For what caused the troubles for the Jews, and what stimulated the intricacy of anti-Semitism and assimilationism, was precisely the fact that the meaning of Jewishness became increasingly unclear during the process that was called 'assimilation'. Was Judaism 'only' a secularised religion? Or did Jews 'still' form a 'people'? Did that mean that there was another 'nationality' at play, or another 'race'? All these terms became increasingly ambiguous and equivocal in the process of assimilation, and this caused an ambivalence concerning their difference. This ambiguity is comparable (but not equal) to the ambivalence of the categories being used today to classify Muslims, Arabs and Africans. Questions arise, such as 'Are there secular Muslims?'; 'Is secularism separable from racism?'; 'When we talk about Muslims, are we talking about religion or culture or both, and how are they related?'

A central line of thought followed through my reading of Proust traces how the meaning of 'being Jewish' was affected by the assimila- 
tionist-secularist expectations towards the Jews. There was an intricate link between these expectations and the experience that being Jewish was considered fully legitimate on the one hand, while on the other hand it was not. I suggest that the logic of assimilationism has returned in discourses of secularism, and that it is likely that the category of 'Muslim' will become increasingly loaded with a cultural memory of the histories of migration of the individuals concerned. At the same time, and paradoxically, Muslims are asked to make their difference invisible or private.

The ambivalence and complexity of what it meant to be (called) Jewish in late 19th-century France was especially salient there. It is relevant to note, however, that the ambiguity and complexity of Jewishness were not reserved for France alone, because of the expansion in European culture of the concepts and practices related to citizenship and modernity. The position of the Jews in France has been exemplary, again in complex ways, for the position of the Jews in modernity, and especially in modern Europe. This is why analysts of the paradoxes of assimiliation tend to refer not only to France, but also allude to a broader, European problem with assimilationism, or even, as we have seen many authors do, to talk about the paradoxes of assimilation in general.

Especially relevant for the European dimension of assimilation's paradoxes is a second aspect of the shared Otherness of Jews and Muslims. This concerns the fact that there is a dynamic relation between the majorities in the diverse European countries and the qualities of the Other. This intuition was powerfully expressed, in the case of the European Jews, by philosopher Yirmiyahu Yovel (1998: xi), in a remark reminiscent of the interpretation given by Bunzl in the above:

Jews ... provided Europeans with a mirror, a crooked, passion-laden mirror, in which to see a reflection of their own identity problems. The 'Jewish problem' was basically a European problem: that is, not only a problem for Europe but a reflection of Europe's own problem with itself, of how, in an age of rapid transformation, Europeans were understanding their own identity, future, and meaning of life.

So 'Jews' and 'Europe' were co-constitutive, dependent for their meanings on their relation to each other. As we will study more closely in connection with my reading of Proust, in the late 19th and early 20 th century, Jews, especially those who had undergone the process of assimilation, were functioning as such a mirror for Europeans because 
they formed a mirror of modernity: all the ambivalences of modernity were projected onto them.

When authors such as Benbassa, Klug and Bunzl suggest that today, Muslims are increasingly becoming the more or less paradigmatic Others of European cultures, then a reminder of Jewish assimilation may help us to see that Muslims may also increasingly become the Others of Europe. This is not just because of their being perceived as religious, premodern Others, but also because they are the mirrors, passion-laden, of fundamental and existential uncertainties and ambiguities related to globalisation, and to the position of European modernity in that process. Once again there is a complex mixture of imageries connected to the Other, who is being perceived as more premodern, as well as more modern, or global, than European majorities.

The reminder of Jewish assimilation's a mbiguities therefore informs my interpretation of the debates about secularism later in this volume. If Jews and Muslims share a tendency to be perceived as religious Others, while also being perceived as Others who cannot be easily categorised, they might become the objects of the subconscious boundary-drawing that is so typical of assimilation. The debates about secularism therefore should be rethought insofar as they suggest that we are literally dealing with questions about how religious Others should be incorporated into secular nation-states and Europe. This literal question should be complemented by a more culturally informed and semiotically complex one: What do we actually do when we frame Muslim incorporation - whereby I take 'Muslim' in its complex, ambiguous role of co-defining the meaning of 'Europe' - in terms of questions about how to incorporate orthodoxies unfit for a secular space?

As we will see in the further discussion of secularism and Islam, contemporary debates about secularism have not sufficiently recognised this dimension of cultural complexity connected to what it means to be Muslim. Even for those who do make the connection between the situation of the Jews in 19th-century Europe and that of Muslims today, the connection made is often rather literal in the sense that concepts of 'Jews' and 'Muslims' as religious minorities are considered as rather unproblematic in themselves. For example, us philosopher William Connolly (2005: 55), in a reaction to the headscarf debates, argued that across Europe, Muslims today are widely considered, like the Jews were once were, to be a 'special minority... with distinctive rituals residing outside the orbit of the Enlightenment distinction between private faith and public reason'. He later explained: 
Indeed, the best definition of Europe itself - as presented by those constituencies assuming themselves to be qualified to define its core authoritatively - is the idea that to be European is to express religious beliefs in the private realm and to participate as abstract citizens in the public realm. This innocent and tolerant-sounding definition promotes Christian secularism into the center of Europe and reduces Islamic peoples into a minority unlike other minorities; they are distinctive because they alone are unwilling or unable to abide by the modern agenda. The definition, one might add, carries important implications for the current debates in Europe about immigration policy. You might even say that the inner connection between Christianity and Europe today is not that all Christians still demand common belief in Christianity as a condition of citizenship - though too many still do; rather it resides in the demand, growing out of the Christian Enlightenment, to disconnect the expression of religious belief from participation in embodied practices, so that it becomes possible to imagine a world in which everyone is a citizen because religious belief is relegated to the private realm and the interior of the self (Connolly 2006: 78).

Our reading of the genealogical connections between assimilationism's ambiguities and secularist expectations and demands will enable us to see that part of the problem might lie, contrary to what Connolly thinks, not in intolerance towards the public aspects of religious practice, but in the cultural dynamics that result from the demand to secularise or assimilate. The problem to be analysed, I argue, is destabilisation of the meaning of being Muslim itself, and how this process can engender new boundaries, not necessarily racialised or phobic ones, but potentially so. The memory of the coincidence of Jewish assimilation with new forms of anti-Semitism that arose in reaction to the ambiguity of Jewish identity could make us more sensitive to similar dimensions of today's position of Muslims.

\section{ISLAMOPHOBIA AND ANTI-SEMITISM}

Our last aspect of comparability, as signalled in earlier literature, is more directly connected to the history of European racisms. Here the focus is not the specific position of Jews and Muslims but the fact that both are minorities that tend to become the object of racialisation. For example, Brahm Levey and Modood (2009: 239) argue that Muslims today tend to be confronted with forms of negative stereotyping that were typical for anti-Semitism. They refer to the analysis of 
anti-Semitism by British philosopher of language Klug (2003: 6), who argued that the kernel of anti-Semitism is formed by

a form of hostility towards Jews as Jews, in which Jews are perceived as something other than what they are. Or more succinctly: hostility towards Jews as not Jews. For the 'Jew' towards whom the antisemite feels hostile is not a real Jew at all. Thinking that Jews are really 'Jews' is precisely the core of anti-Semitism.

Here the hatred is based on deduction from a non-existent, but culturally dominant image of who Jews or Muslims are. It is important to note that race is actually secondary here. The hatred is based on a specific logic related to a particular group of persons, but their groupness can be based on cultural notions as well as on more classically racial ones. Klug (2012) refers to his earlier analysis of anti-Semitism in order to understand contemporary Islamophobia. Now, in what follows we will not focus on explicit hatred or phobias of Jews or Muslims. As we will see, however, analysing and tracing the Proustian narrative of assimilation enables us to encounter forms of stereotyping which exemplify the perception of the Jew as 'Jew', while remaining within the discourse of assimilationism rather than that of explicit anti-Semitism. This will help us to understand how the two are connected.

\section{The Proustian prism}

There is no reason to pretend that only by reading Proust we would be able to trace the ambiguities of identity formation under assimiliationist expectations. However, reading the Proustian novel as a literary response to the complexity of the meaning of 'Jewishness', after this had been placed under the mark of assimilation, helps us draw out the ways in which assimilationist expectations - and we will trace how secularist expectations are implied in them - can set in motion cultural, semiotic processes that lead to ambiguous relations between members of majorities and those identified as having minority backgrounds. This is especially true concerning mixed ethno-religious backgrounds. In my reading, I make this connection more strongly than previous readings of the novel. My reading firmly embeds the novel in historical documents about, and historians' readings of, the 'paradoxes of assimilation'. The literary character of the novel enables us to bring out the complex processes of meaning formation about Jewish identity in the context of assimilationism. Elaborating on what 
earlier commentators have argued, I read Proust's novel as a literary witness to assimilation's paradoxes. This demonstrates that the novel can help us to elucidate their late 19th-century emergence, and the transformations of the meaning and experience of 'being Jewish' as an effect of these historical events.

I have already indicated a few of the directions that my reading of Proust's novel will take. I focus on those threads in the narrative which can be read as reflections on how expectations about assimilation enhanced certain everyday attitudes towards Jews, and those of Jews themselves. I also draw on other authors who take Proust to be an exemplary witness to the ambivalences and paradoxes of assimilation in the France of the Dreyfus Affair. One of these is Arendt (1979 [1948]), whose work I examine in connection with French-Jewish historian Reinach's (1901 [1884]) interpretation of assimilation.

Arendt (1979 [1948]) leaves more or less implicit the role of the literary character of Proust's work in producing his insight into the paradoxes of assimilation. Later interpreters of Proust's work have drawn out the way its literary dimensions enabled him to be sensitive to the discursive, complex dimensions of the intricacy of assimilationism and anti-Semitism. Moreover, they put forward the idea that its literary form can be read as a strategy for resisting such tendencies. For example, British literary scholar Hughes (2001: 153) emphasises 'the ambiguous nature of much of his [Proust's] reflection on ethnic specificity', and suggests that 'such ambiguity reflects a strategy designed to create a space of cultural hybridity in which a homogenised and in a sense totalitarian ethnicity can be resisted and undone'.

Bem (1980), Kristeva (1994) and Carlston (2002) provide sensitive analyses of how Jewishness and homosexuality arose as signifiers of secrecy and treason in the course of the late 19th century. Each in their various ways discusses the paradoxical experiences of Jews and homosexuals. In Carlston's analysis, for example, Jews and homosexuals could not openly show Jewish or homosexual practices without incurring discrimination and rejection; yet their adapting to the norms of majority society led to the accusation of their dissembling to be different, and therefore led to the further charge of being secretive and treacherous (Carlston 2002: 939).

My own reading of Proust draws on these earlier readings. It also takes a few new directions. It focuses specifically on the ambiguity of assimilation where Judaism was seen as fully legitimate (in contrast to homosexuality) while also being considered problematic by at least some of the societal actors of the time. Because I see the emergence of the specific ambiguities surrounding assimilationism as the result of a 
process of decades in which assimilationist expectations were built up, I trace, firstly, how the narrative threads in the Proustian novel give us insight into these temporal dynamics of assimilationism, where the paradoxes are not always as prominent, but can always turn up because their logic is present in discourse and practices. My reading looks at the development of the relation between the protagonist, Marcel, and two other characters, Bloch and Swann. It rather faithfully retells threads of the story related to that development, construing them as discursive after-effects of the imaginary and discursive field concerning Emancipation.

While placing the novel firmly in the historical tradition of assimilationism, I focus on what Proust's literary devices, of both the narrative and the metaphors, enable us to learn about how assimilationism worked in the long term and in practice. This will enable us to give a 'temporally' extended reading of the paradoxes of assimilation, of their own historical and narrative dimensions, and to trace how they come to light very clearly, but in differentiated articulations. Chapter 5 reflects extensively on how the Proustian style of metaphoric writing can help us to analyse assimilationist attitudes in terms of the ways in which cultural memory and actual perception interact. I also analyse the specific form that secularist expectations took under assimilationism. We will see that Proust makes use especially of the literary trope of the metaphor to express the 'disappearance' of the state of being Jewish simultaneously with the enhanced and racialised actuality of it. References are made to rubbing out and palimpsests, he fantasises about the forefathers of certain characters, images of one character intrude upon another, identities are uncertain, multi-layered and intriguing. Cultural memories also play a role in which stored-up memories of images of certain groups and identities steer the mutual perceptions of the other's (to a great extent imagined) identities. Here we will be able to trace how perceiving Jews as 'Jews', identified by Klug (2003) as the kernel of anti-Semitism, is one of the semiotic processes encouraged by the logic of assimilationism.

We will also see that there is irony among the characters themselves about these forms of identification, and that the return of the repressed, the paradox of assimilation in its full meaning, is often balanced by more multi-layered, more self-conscious methods of identification. The Jewish characters in the book do not allow themselves to be caught in the trap of assimilation; and they do not allow themselves to be simply identified as Jews. The characters Bloch and Swann, the protagonist who is occasionally identified as (partly) Jewish, the narrator looking back on his life, and the half-Jewish novelist Marcel Proust 
with his writer's tricks of the trade all have their own answers to the paradoxes of assimilation. At the same time, difference, notwithstanding the elements of social irony in the identification of the Other, can lead to tragic rifts and confrontations, as emerged during the Dreyfus Affair.

My reading focuses less on explicit anti-Semitism or philo-Semitism and explicit racialisation than do some of the earlier readings mentioned. I go as far as I can towards understanding passages where Jews appear as 'Jews'in terms of a discursive effect of assimilationism, instead of an expression of anti-Semitism. In doing so, I try to understand how the logic of assimilationism itself can help us to understand the emergence of late 19th-century attitudes towards Jews.

My reading will show that, in a sense, Jewishness was more legitimate and in the open than some of Proust's earlier interpreters suggest. Hence, the promise of assimilation was not as squarely, unequivocally and visibly wrong as some of these interpreters have suggested, especially where they focus on tracing anti-Semitism and pure homogeneity (as in the quote above by Hughes). Rather, my idea is to show that the picture was less grim than is sometimes suggested, but that still the logic of assimilationism could turn against the Jews in times of societal conflict. I do so in order to bring out how, at the time, the fact that assimilation was paradoxical was not something that was easy to trace or understand. It was more like assimilationism today than we might initially think, and this might be precisely why it is useful to look at that experience again.

\section{In Search of Lost Time and the Dreyfus Affair}

In Search of Lost Time is an exceptionally long, 3,00o page novel that is structured as a first-person narrative by a narrator who tells about his earlier life, as the protagonist. The novel makes no attempt to give a realistic account of the life of any one real person - it in fact follows an explicitly anti-realistic, perspectivist poetics. The protagonist is an extremely passive character, entirely adapted to the necessities of Proust's narrative techniques. This also makes it impossible to neatly distinguish between the protagonist at the moment of experience, and the narrator telling it.

It has often been suggested, as far as the novel's relationship to history is concerned, that the narrative and its requirements, rather than the wish to provide a historical account, determine the shape of the novel (Kristeva 1993; Hassine 1996). Proust was fascinated by the struc- 
ture of the fairy tale, which features social reversal and sudden change instead of the presumed continuity and causal structure of natural and positivistically understood historical reality.

I will suggest, however, that this does not mean that the novel's structure is a-political or a-historical; rather, Proust regularly suggests that historical reality, at certain moments, shares characteristics with the fairy tale. The novel thus mimics Proust's philosophical take on human history, which, set against the realism and positivism dominant in the French 19th century, is sensitive to the contingencies and discontinuities of history and society. Proust's narrative of precarious assimilation fits his own literary strategy, and thus has its own, parallel, literary rationale as well.

This becomes particularly evident from his reflections on the temporal structures of social change in the Dreyfus Affair. In the context of this affair, Proust often compares society to a kaleidoscope, both in his letters and in the novel. Reflecting on the Affair, the narrator writes that when Marcel was a toddler, no worldly salon dominated by the aristocracy would ever have received a Republican, let alone a Jewish Republican. A few years later (at the time of his first communion), this was very different, and Jews, who were identified with Republicans in general, were admitted into high society. But then, after the Dreyfus Affair started, everything changed once more. The narrator writes:

But, like a kaleidoscope which is every now and then given a turn, society arranges successively in different orders elements which one would have supposed immutable, and composes a new pattern. Before I had made my first Communion, right-minded ladies had had the stupefying experience of meeting an elegant Jewess while paying a social call. These new arrangements of the kaleidoscope are produced by what a philosopher would call a 'change of criterion'. The Dreyfus Affair brought about another, at a period rather later than that in which I began to go to Mme Swann's, and the kaleidoscope once more reversed its coloured lozenges. Everything Jewish, even the elegant lady herself, went down, and various obscure nationalists rose to take its place (Proust 1996: II, 103 [I, 507-08]).

This reflection is not just the fanciful interpretation of history by a novelist concerned with adapting historical reality to the needs of his creativity at the expense of 'realism', as some critics have suggested (Hassine 1996). Rather, it is the projection back into the novel of the experience of the contingency of certain historical moments, in opposition to a causal structure of history. So the fascination for the 'romanesque' and its fairy-tale structures does not at all imply a 
benign or naïve view of society or history. Instead, 'this novelist who places himself inside a subjectivity and on the margins of the political world is able to represent politics as a cruel dreamlike charade' (Bowie 1995: 132). We will study this charade specifically as that of assimilation's paradoxes, which occur in unexpected circumstances, where 'assimilation' at first seemed to imply a much less grim process of pure, even totalitarian homogenisation than has sometimes been suggested. Reading the novel extensively and noting the development of its narration, the culture of assimilationism as a temporally differentiated process with long-term effects that can, but need not be effectuated, can help us to see how this culture stands much closer to our own than were we to stick to the rather 'dry' picture of assimilation as pure homogenisation. Let's now turn to the novel itself. 



\section{Alfred Bloch's personal integration test at the threshold of his friend's home}

\section{1 'And what's the name of this friend of yours who is coming this evening?'}

In the first volume of In Search of Lost Time, the initial part of which is called Combray after the village where the protagonist's family has a country house and spends its holidays, the narrator tells us about his friendship as an adolescent with his Jewish schoolmate Alfred Bloch. ${ }^{1}$ We read the narrator's account of Bloch's visits to his family as a literary reflection on crucial elements in the process of Jewish assimilation in France.

The first two things we learn about the friendship between the protagonist and Bloch is that it is founded on long and high-flown discussions about literature, and that it does not last long. After a few visits, Bloch is not invited to the house again, although he was heartily received at first. In order to explain why his family's attitude towards Bloch changed, the narrator first recounts how his grandfather usually displayed peculiar behaviour upon receiving his friends. The grandfather subscribed to the theory that whenever the protagonist wanted to bring home a friend

that friend was invariably a Jew; to which he [the grandfather] would not have objected on principle - indeed his own friend Swann was of Jewish extraction - had he not found that the Jews whom I chose as friends were not usually of the best type (Proust 1996: I, 107; I, 90).

The narrator does not explain what the grandfather found objectionable about these friends. We do learn something about his expectations and norms by scrutinising the short performance with which he confronts the visitor in front of the protagonist. The narrator describes how, whenever a new friend entered the house, the grandfather would nearly always hum a tune: 
Oh God of our fathers' from La Juive, or else 'Israel break thy chains', singing the tune alone, of course, to an 'um-ti-tum-ti tum, tra-la', but I used to be afraid that my friend would recognise it and be able to reconstruct the words (Proust 1996: I, 107; I, 90). ${ }^{2}$

By humming these tunes upon the visitor's entrance, the grandfather creates an atmosphere of invisible difference around Jewishness, which is simultaneously shared by both the protagonist and the guest. The words of the arias themselves make it even more justifiable that the protagonist should fear his guests recognising them, as they recall a Christian, medieval representation of the Jews. The remainder of the verse from $L a$ Juive goes as follows:

O God of our Fathers,

Thou who illuminates us

Please come down to us again!

Oh God of our Fathers,

Hide our mysteries

From the eyes of the wicked men! (Act I, scene I, my translation). ${ }^{3}$

The verse clearly broaches a cultural memory of self-separation and enmity. The prayer asks that the mysteries of the people of Israel be hidden from the view of outsiders, and the outsiders connoted in the opera are mediaeval Christians. Humming precisely this aria from this opera adds several layers to the grandfather's performance, making it impossible to distinguish his intentions from the web of references that he weaves. ${ }^{4}$ As a first layer, the grandfather hums an aria intended for a Jewish voice. This points to his fascination, even identification, with Jewish mystery. A second, ironic layer is added upon considering that the story of the opera portrays medieval Catholicism as the crueller faction in comparison with the Jews. ${ }^{5}$ Deploying this story, set in a medieval Austrian setting, for an opera-libretto after the French Revolution in Paris, might be interpreted as a portrayal of Christian cruelty toward the Jews which had been overcome after the Revolution, or even as a criticism of its heritage. Yet, even as the opera portrays Christians as the crueller and more hypocritical party, it revives stereotypes of the Jews as stubbornly different, as policing their daughters, and as unwilling to 'integrate'. The grandfather hums precisely those arias in which this stereotypical portrayal is central, suggesting a Jewish mystery inspired by religious belief.

With his performance, the grandfather creates an audible but nondiscursive and non-public boundary between the house and the Jewish 
guest, which contrasts with the professed openness of the house and the family. This openness is symbolised by the fact that the protagonist's friends are welcomed after all. The openness is qualified from the beginning, however, by the fact that the grandfather determines the game's rules of entry. On the one hand, he does this by making it difficult for the friend, who might indeed recognise the tunes, to react, and on the other, by making it impossible for the protagonist to approach this friend in an uncomplicated manner from then onwards.

The narrator goes on to say that the grandfather would 'divine' (Proust 1996: I, 107) immediately when the protagonist was talking about a Jewish friend, no matter whether or not this could be easily discerned from the name:

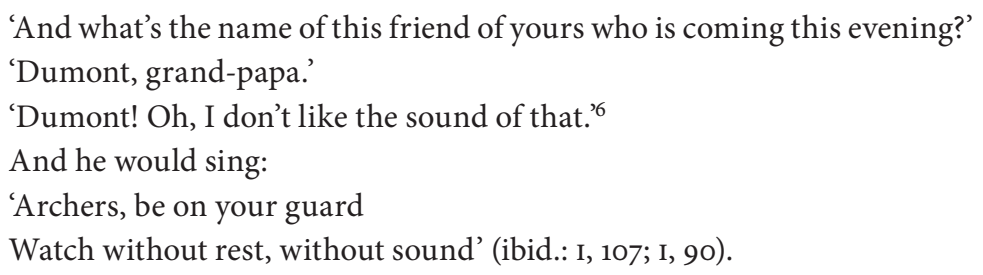

Here again, the atmosphere of distrust and fascination for uncovering something hidden is immediately connected with the entering friend. Once the friend has arrived and has been 'unmasked' by means of clever questions, the grandfather, in order to demonstrate that there were no doubts left, would start to hum:

'What! Do you hither guide the feet

Of this timid Israelite?'

... or, perhaps, of

'Yes, I am of the chosen race' (ibid.: I, 108; I, 90).

Humming these verses on the occasion of a visit from a Jewish friend suggests that modern Jews may have inherited an underlying sense of distinction, or indeed, superiority, at least in religious matters, which nevertheless remained hidden under modernity's practices of admixture and equality. All of the verses impute a self-chosen 'otherness' to the Jews. The fact that they are only hummed and not spoken makes it implausible that the visitor would choose to overtly deny it. Whatever the guest were to say, he would always be denying something that the grandfather knew would never be admitted openly.

The narrator refers to the hums of the grandfather as 'little eccentricities' (ibid.: I, 108), but his performance is actually quite shrewdly 
planned. It creates an unspeakable barrier between the protagonist and his friend. At the same time, it involuntarily involves the protagonist in a game with him, the rules of which are determined by the grandfather. Playing this game reveals whether the visiting friend is 'of the best type'. To win the game, the friend first has to demonstrate that he is refined and French enough to acknowledge this high cultural product that fuses Jewish and French culture. In this sense, if the protagonist's hope that the friend will not recognise the tune is realised, this friend will also partly have lost the game. In the eventuality that the friend shows some sign of recognition, he must demonstrate that he is assimilated enough to abstain from an explicit reaction based on his immediate identification as a Jew, for such a reaction would shatter the unspoken rule that, at least after having passed the threshold of a Catholic house, a Jew should prefer to appear as a 'neutral' citizen of France.

\subsection{The Revolution's conditions of Emancipation}

With his performance, the grandfather causes at least three persons to be suspended in a cultural space that is neither public nor private. This space of cultural difference is sensible and undeniable, but cannot possibly be made explicit. Let us now try to trace some of the historical mechanisms that played a role in the creation of this specific cultural space.

The grandfather's malignity stands within a late 19th-century French context in which Catholics and Republicans were extremely divided in their struggles for centralised state power, the so-called guerres francofrançaises, which had been going on throughout the 19th century. They reached their peak in the competition between (clerical/Jesuit) Catholics and anti-clerical laïcist Republicans after the installation of the Third Republic in 1870 (see Birnbaum 1998, 1988; Baubérot 2000). The struggles between a 'Catholicisme intransigeant' and anti-clerical laïcism resulted in a general 'hatred of minorities' (Baubérot 2000: 69). ${ }^{8}$ Catholic traditionalists blamed the Revolution on Jews, protestants, metics and free-masons. These groups were all considered to have ruined the 'cultural identity' of France as the eldest daughter of the Catholic Church. With the Dreyfus Affair, however, the Jews became the most visible minority and became the victims of an increasingly anti-Semitic hate press. This press associated the Jews with the Republican idea of equal citizenship, while also arguing time and again that the Jews could not really be French. 
We could suggest that the grandfather's performance merely reflects the explicit anti-Semitism of the Catholic Reaction. However, Proust presents the family in which the scene takes place from within the realm of a warily accepted Republicanism and moderately secular Catholicism. The narrator's family belongs to the middle class, which has a quite conservative worldview, but it is also too moderately bourgeois to be fiercely anti-Republican or anti-Semitic. It conveys an atmosphere of hesitant inclusion rather than one of explicit exclusion. This is also clear from the grandfather's friendship with Swann, which is based on the fact that he is the family's neighbour in the village of Combray and is not hampered by Swann's Jewish descent.

The family does criticise Swann, but this criticism is, at first sight, class-related. The family knows Swann as the son of the protagonist's grandfather's best friend, a stockbroker. When they learn that Swann has friends among the highest ranks of France, they discuss this as something morally objectionable. But they suggest that this is not because Swann is Jewish, but because he transgresses the well-defined boundaries of his inherited class.

However, it is not impossible that the family's reaction to Swann has something to do with his Jewish background after all: the family had once felt it had been a generous gesture on their part to receive Swann ('despite' his being Jewish). Proust subtly suggests that some family members resented Swann's subsequent ability to climb to ranks that they themselves could not have reached.

An explanation of the grandfather's performance in terms of purely reactionary anti-Semitism fails to account for the specificity of the cultural space created by it, a space in which there is intimate, private contact between persons of diverse cultural backgrounds, while the sense of their different origins is not something that is explicitly talked about, even though it is palpably present 'in the air'. Such culturally different backgrounds can also be at least partially invented or exaggerated: the family refers to Swann as Jewish in Combray. Only later in the novel does the narrator write that Swann had one Jewish grandfather, who was married to a Protestant (Proust 1996: IV, 79).

We can understand the grandfather's 'little eccentricities' performed at the threshold of the bourgeois family, which render the protagonist's friends' welcome conditional on their ability and wish to play the grandfather's game, as a literary exploration of the long-term effects of the conditions under which the Jews were given citizenship rights in 1791. From the late 1820 on onwards, this event has been called the 'Emancipation' of the Jews. ${ }^{9}$ Recalling these conditions will clarify that, to obtain an 'exit visa from the ghetto', which Heinrich Heine 
thought required conversion in Germany, also had its price in the context of French Republican modernity. Here, it did not require conversion but full secularisation (in the sense of the privatisation of religion) instead, accompanied by a complete cultural and political identification with the Etat-nation. These requirements were only later summarised under the heading of assimilation.

There is no systematic study of the history of the concept of assimilation in 19th-century France. Assimilation as a social concept came to be used only gradually over the course of the 19th century, while concepts like 'fusion' and 'amalgamation' were used more frequently at the beginning (see Birnbaum 1998; Berkovitz 1989). Schechter locates the first use of the word in its sociological meaning with regard to the Jews - referring to the ARTFL database of French literature - in the Journal of the brothers de Goncourt. In 1878 they recorded a conversation in which Ernest Renan offered 'a wordy dissertation ... on the faculties of assimilation of the Judaic races' (Schechter 2003: 250). In Proust's work we find the use of the term '(non)-assimilated' in several places, and it was obviously quite common to use the term in the $1910 \mathrm{~s}$ (Proust 1996: II, 368; II, 98; III, 472; III, 702).

The acquisition of citizenship rights was a major achievement in Franco-Jewish history. In the course of the 19th century, praise for overcoming ages of exclusion and religious persecution, or, at best, periods of being tolerated just because Jews had proven to be economically useful or even indispensable, came from numerous sides. A particularly eloquent Jewish person captured the feelings of many by talking, in the late 18th century, of 'these generous French to whom we owe the first example of justice that the world has given to our unfortunate Nation. Yes, my children, this is your fatherland, your Jerusalem, the land that God promised to our ancestors' (quoted in Burns 1992: 12).

However, Emancipation was also a paradoxical event. It created new problems caused by the homogenising, assimilatory tendencies within Revolutionary thinking and practices, particularly within Jacobinism. The Revolution gradually developed a distrust of all privileges and particularisms, which led to an attempt to not only do away with the absolutist monarchy and the privileges of the Catholic nobility, but with religious and regional institutions and associations in general. ${ }^{10}$ In this sense, the Revolution inherited the unitarian dream from the absolute monarchy, leading to the attempt to eliminate cultural and political diversity and to the immediatisation of the relation between the citizen and the state. This tendency in the Revolution becomes tangible, for example, in the project for a 'furious campaign of assimilation' 
(Birnbaum 2001: 47) designed by the Revolutionary Abbé Henri-Baptiste Grégoire (1750-1831) that tried to eliminate all patois and even accents:

The language of a great nation needs to be standardised so that all the citizens who compose it can communicate their thoughts without hindrance. This enterprise, which has not been fully achieved by any people, is worthy of the French people, who centralise all branches of social organisation and who must jealously consecrate as soon as possible, in a single and indivisible republic, the unique and invariable usage of the language of liberty (Grégoire 1788; quoted in Birnbaum 2001: 48). ${ }^{11}$

Grégoire summarises two intimately intertwined layers of Revolutionary thinking. The first is an idealistic, metaphysical layer, explaining freedom as closely connected to the unity of a 'people' and as opposed to difference, plurality or diversity. The second is an affective layer, which involves jealousy, anxiety and the desire to control, or perhaps, 'securitise'. This desire produces a phantasmagoria of a centralised and fully transparent social organisation and communication. Ozouf (1984) describes this tendency in the Revolution as follows:

The essence of Jacobinism lies in the impossibility of conceiving a divided popular will, the boundary between minority and majority, between the public and private sphere. The world of Jacobinism is one ... where one's innermost thoughts are themselves criminal. This ideal of perfect social and psychological visibility is the basis of Jacobinism (Ozouf 1984: 83; quoted in Birnbaum 2001: 64).

Thus, the Jacobinic tendency in the Revolution not only implied the fantasy of unifying the public sphere and its equalisation with the domain of the visible. It also implied, following Ozouf (ibid.), the desire to extend control into privacy, and even into subjectivity. Public visibility itself should be extended to intimacy and the psyche. Foucault (1976) famously analysed the intricacy of the diversifying and disciplining effects of this desire for control and unification.

In the 19th century, the Jacobin tendency in the Revolution was already being criticised for reasons other than the wish to restore the Catholic past. De Tocqueville (1966 [1836]) was one of the first to criticise the systematic institutional implications of the Jacobin tendency in the Revolution: 
Revolution [was] pronounced at the same time against royalty and against provincial institutions. Revolutionary hatred was directed indiscriminately against all that had gone before, both the absolute power and those elements which could temper its rigors (quoted in Birnbaum 1998: 48).

De Tocqueville captured, first, a hugely important transition in the self-interpretation of the Revolutionaries. They understood the Revolution not just as the abolition of the absolute monarchy and the privileges of the nobility. They went one step further and understood these institutions themselves as the epitome of the past, and then turned the Revolution against 'the past' in general - declaring the post-Revolutionary Republic 'modern'. De Tocqueville (ibid.) also captured the political consequences of this translation of a political hatred against a Catholic distribution of power into a hatred of 'the past', of 'tradition'. He writes that this hatred then directed itself against those institutions that could have 'tempered the rigours' of centralised power, such as provincial or regional institutions that were often either religious or 'patois accentuated'.

Jewish Emancipation occurred in this context of the Revolutionary unification of the entire French nation. Both Protestants and Jews were only gradually admitted to citizenship. The rich and quite assimilated Sephardic Jews from Southern France were the first, in 1790. The poorer and more traditional Alsatian Ashkenazim, who had some autonomous legal-religious institutions and some of whom usually spoke Judeo-German, acquired citizenship rights only in 1791, after long debates in the Assembly. ${ }^{12}$

Though the Revolution was shaped by the struggle with centralised Catholicism, the Revolutionaries' theories about the Jews seemed to epitomise the rage against diversity. Some of the most rigorous theorists of the Revolution, such as Grégoire, were preoccupied with the Jews, though few Jews lived in France. Birnbaum (2001: 47) interprets their symbolic place within Revolutionary discourse as an echo of their earlier position:

The symbolic place occupied by the Jews in this forced rebirth of the French nation was linked with the place they had occupied several centuries earlier, when their expulsion prefigured the imminent unification of Catholic France. This France, eldest daughter of the Church, had been unified and given its raison d'être by rejecting first its Jews, then its heretics and Protestants. 
Perhaps the fact that the Jews were legally, religiously and sometimes also linguistically different, instead of manifesting difference only with respect to one or two of these factors, partly determined the systematic place that the Jews occupied within the symbolism of assimilation. Schechter (2003) mentions that referring to Jewish groups as a 'nation within the nation', or variations of this view, had been common for several decades before the Revolution, and that Jews were considered obstinate for not wanting to convert to Christianity.

In 1788 , a competition was organised by the Royal Society of Arts and Sciences of Metz (in Eastern France), which asked the contributors for essays on ways to 'make the Jews more useful and happier in France' (quoted in Birnbaum 2001: 46). Grégoire (1989 [1788]) sent in his Essay on the Physical, Moral and Political Regeneration of the Jews. Together with, among others, Mirabeau, Duport and the Count of Clermont-Tonnerre, he was among the great proponents of citizenship rights for the Jews, and a friend of Jewish spokespersons like Berr Isaac Berr. His arguments were not put forward in order to exclude the Jews from citizenship, but instead to include them. In his essay, Grégoire analysed what constituted in his eyes the 'profound moral deprivation' of the Jews. In order to overcome this deprivation, Grégoire proposed 'to melt them, so to speak, into the national mass, to the point of making them citizens in the fullest sense of the term' (quoted in Birnbaum 2001: 47). During debates in the Assembly, Grégoire gave arguments for citizenship rights which were based on his idea that the alleged vices of the Jews were caused by their exclusion from citizenship and from the possession of land: 'The Jews always form a State within the State, because they are never treated as the sons of the country ... And you require them to love a country? Then give them one.' Explaining his point, Grégoire argued that the Jews' exclusion led to their being 'dispersed everywhere, home nowhere', to their having only an 'esprit de corps' instead of an 'esprit national'; to their not being French in France, English in England, or Dutch in Holland. The responsibility for these vices was entirely lifted from them: 'the epitome of inconsistency would be to blame them for their crimes after forcing them to commit them' (quoted in Bernet 2004: 4, my translations). Similarly, Robespierre argued that 'Jewish vices are rooted in the lowly status to which you have reduced them', and proposed to restore to them their 'inalienable human rights', in order to also 'restore them to happiness, ... by restoring to them the dignity of human beings and of citizens' (quoted in Katz 2004: 87). ${ }^{13}$

From Grégoire's and Robespierre's arguments, we can see that they conflate the crimes imputed to the Jews (and their not yet acquired 
dignity) with the ways in which they are organised: either too strongly or not strongly enough. On the one hand, Grégoire considers them to form a strong separate 'corps/body' (a State within the State), yet on the other hand, he regards them as being 'at home nowhere'. Arguing that the Jews themselves are not responsible for their vices may seem a generous explanation, but its consequence is that no agency or responsibility is ascribed to the Jews until they are French citizens and, moreover, that the empirical justification of the judgement about the Jews' alleged vices is not questioned in the first place. The combination of these elements in Grégoire's reasoning is a crucial aspect of the patterns in early assimilationism.

Grégoire's arguments for giving the Jews citizenship rights had consequences for his view of the future of their ethno-religious difference. Firstly, to achieve the aim of melting, their 'tudesco-ebraico jargon' should be eliminated. ${ }^{14}$ Another difficulty, according to Grégoire, was that 'their religion encompasses all the details of life by means of rules that our political constitutions will never adopt' (quoted in Benbassa 2003: 136, my translation). Grégoire makes clear that a choice will have to be made between either following Jewish religious rules and laws and political belonging (to France). In sum, the right to French citizenship for the Jews was linked from the beginning to the idea that something else, namely that which was considered Jewish particularism, had to be uprooted.

Emancipation, therefore, meant protection by the state and legal recognition, but it was also the result of a longstanding tradition in which the Jews had been depicted by Catholics and philosophes alike as a yet to become dignified people, whose ethno-religious practices were problematic, if not borderline criminal. The difference between emancipators and exclusionary thinkers at this point was their answer to the question of whether the 'Jewish problem' should be blamed on their circumstances or on their 'character'. But it did not lie in respect or even tolerance for Jewish difference.

Not all those who pleaded for Jewish citizenship held such extreme views about the new, exclusively national boundaries to be drawn. Options more open to pluralism had been considered during the Revolution. Before De Tocqueville, Mirabeau had already criticised the Jacobin rage against syndics and community structures, defending, to use Birnbaum's words, 'small private societies' (quoted in Lerner 2001). Some Revolutionaries also proposed a model that was more akin to the American Constitution. In December 1789, during one of the debates in the Assemblée, Duport, one of the speakers, proposed that the Jews 
should only do what the French State obliged them to do, but could retain their own laws as long as they did not contradict the French ones:

What if the Jews are faithful to their own laws? For France as a whole it should be enough that they accept their obligations under the civil code of the state. There are, certainly, prejudices against the Jews and they have their own separatist tendencies, but the law can take no notice of either; it must simply give them citizenship in return for their agreement to perform their civic duty (quoted in Hertzberg 1968: 364).

Also Jewish voices were not homogeneous. Some pleaded for the inclusion of the Jews at the expense of their own institutions, such as, for example, a group addressing the Assemblée Nationale during one of the debates about emancipation on 26 August 1789:

We want to be subjected to the same jurisprudence, the same police, the same tribunals as all French people and we consequently renounce, for the public case and for our own advantage, which is always subordinated to the general interest, the privilege that had been accorded to us to have leaders taken from our midst and appointed by the government (quoted in Birnbaum 1988: 44, my translation).

Others, however, like the Ashkenazim politician Cerf Berr from Metz, wanted to keep some of the autonomous legal-religious structures intact. Cerf Berr did not succeed in the end, partly because he was accused by several lawyers of dissembling taxes for his personal gain and of behaving like a 'king'. ${ }^{15}$ It is difficult to evaluate whether pluralist options like those proposed by Duport and Cerf Berr could have worked in France if only different choices had been made at the time of the Revolution. Birnbaum does not present his critique of the Jacobinic turn in the Revolution as a 'wrong choice', but rather as the result of the ways in which France's path was dependent on the earlier centralising legacies:

If a more liberal interpretation like that of Mirabeau had been adopted by the revolutionary assemblies, the multiple cultures and traditions inherent in the history of French society would perhaps have remained more alive. Such a hypothesis, however, is hardly compatible with the centralising tendencies which have long emerged as the specific means of moving beyond a particularly accentuated feudalism (Birnbaum 1989: 170; translation quoted in Lerner 2001: 201). 
Birnbaum leaves undecided whether we could criticise Jacobinism as a moral and institutional error, or whether we would have to interpret its centralising tendencies as inevitable in the face of the heritage of the absolutism and feudalism preceding the Revolution. He even seems to think the latter option is more realistic. In the context of the struggles about laïcité, more than two centuries later, Roy (2005: 63) still refers to such path-dependency when arguing that the French obsession with laïcité should at least partly be ascribed to France's irrevocable 'fascination with the monarchy'.

During the debates in the Assemblée, the arguments for inclusion mostly followed from a wish to control the population and 'civilise' it. This, like the arguments of those who wanted to expel the Jews, had much to do with early state-organised security politics, but the tactics differed. It was a tactic not of exclusion, but of inclusion to the point of 'melting' - the concept used by Grégoire. The dynamics of this process can be read in a famous remark by one of the discussants in the final debate on citizenship rights, the Count of Clermont-Tonnerre:

We have to refuse the Jews everything as a nation and to give the Jews everything as individuals ... they should no more constitute a political body or an order within the State; they must be citizens individually ... It is an abhorrent thought that within the State there would be a society of non-citizens and a nation within the nation ... If they don't want to be this [individual citizens, YJ] they have to say it so that we can expel them (quoted in Noiriel 1992: 278, my translation). ${ }^{16}$

Clermont-Tonnerre's concept of a nation within the nation is a reference to earlier, similarly conceptualised fears of separate organisations by Protestants and Jesuits. ${ }^{17}$ The count's argument is linked to the general process of modernisation and centralisation, and to the decreasing legitimacy and public visibility of associations other than the state. Yet, as we have already noted, around the time of the Revolution the Jews had been made into the epitome of minorities in general. Consequently, the demands were made of them most systematically.

We can now understand the contemporary significance, in the context of the headscarf debates, of a proposal allegedly made by another speaker in the debate on citizenship, that 'we have to begin by destroying all the humiliating signs which designate them as Jews, so that their garb, their outward appearance, shows us that they are fellow citizens' (quoted in Burns 1992: 11). Burns, an American historian of the Dreyfus Affair and its aftermath, is unclear about the source of the above quote and merely mentions that it was one of the arguments 
made during the debates about the accordance of citizenship rights to the Jews. I have not been able to trace the quote back to any French origins. If it were not for this somewhat uncertain origin, the quote would seem to epitomise the Revolutionary origins of the ban on headscarves in public places because of their being 'conspicuous signs' of politico-religious belonging. Exchange 'Jews' for 'Muslims' and the phrase might appear as a quote from a present-day neo-Republican strongly opposing the scarf.

The speaker proposes to put an official end to the old practices of forced distinction imposed on the Jews. For him, however, this also means that their distinctive dress has to be generally abolished, and he fails to address the complexity of the actual practices of distinctive dress. The interpretation of religious dress as a possible sign of non-belonging hails from the Jacobin equation of the public sphere with the visible and its interpretation of religious expression as a sign with regard to citizenship. Forced distinction was common in many European countries before the Revolution. In France, the situation was complicated. Forced distinction had long been imposed (since the Middle Ages) but control of these practices had become less rigid over time ${ }^{18}$ Rules were partly determined locally: in the 17 th century, for example, the Jews from Metz were forced to wear yellow capes for a certain time, but this practice gradually disappeared. However, because up until the Revolution Jews in Metz were not allowed to copy non-Jewish fashions, most of them dressed in black coats known as 'manteaux juifs'. Only towards the end of the 18th century did members of the elite gradually take over majority habits and start to wear wigs and shave off their beards. Yet some aspects of the Jews' distinctive dress were not forced by the majority but prescribed by religion, such as, for example, the beards and the wearing of a 'couvre-chef' for the men. Not all Jews wanted to give up these distinctive marks. Religious authorities, in particular, protested their gradual disappearance (Benbassa 2000: 103).

The speaker in the Assemblée does not take this ambivalence into account and interprets the Jews' particular dress only in terms of their humiliating signification in the eyes of the majority. By suggesting that only the wearing of modern dress could prove they were fellow-citizens, he seems to create room for suspicion of their solidarity if they stick to their religious dress. Moreover, it is the elite 'we' who have to destroy the signs covering 'their' bodies - which de-centres the internal dynamics between the diverse groups within the Jewish community that had already led to the partial disappearance of religious dress. It turns the struggle about dress into an issue of minority-majority 
relations. This proposal clearly anticipates the present-day Republic's thesis that it has the right to determine the meaning of the dress of its citizens. On this basis, Benbassa (2003) calls her chapters 'Napoléon version Sarkozy' and 'Le président Chirac en nouvel abbé Grégoire'.

Arguments for inclusion, such as those discussed above, highlight the ambivalences of the accordance of citizenship rights. Just below the surface was a fear that the Jews might not want to belong entirely; a fear of treason; of a loss of control; or, in Grégoire's terms, of jealousy. A desire to neutralise this fear is discernible in many arguments for inclusion.

In summary, the result of Emancipation - as conceived by the Revolutionaries - was that Judaism, which had been allowed to exist in the open only for a few centuries after the heritage of marranisme had been overcome, had to eliminate the traces of what appeared to be its 'national' aspects, which were equated with what was visible. ${ }^{19}$ The next chapter further scrutinises how this process came to be understood, in the course of the 19th century, as the transformation of Judaism from a 'nation' into a privatised, secularised 'religion' by the abolishment of the connection between Judaism and its particularising law, language and cultural practices (Birnbaum 1998; Benbassa 2003). ${ }^{20}$ But let us first return to the protagonist, Alfred and the grandfather.

\section{BACK TO THE GRANDFATHER}

Proust's oeuvre was written more than a century after these events took place. Yet the 'rough' form of Jacobin distrust of Jewish particularity had a strong echo after 1870-1871, when the fear of treason was stoked once again by the Franco-German war. After the loss of this war, the nationalist meaning of Grégoire's desire to eliminate the 'tudesco-ebraico jargon' was again in the air. ${ }^{21}$

The grandfather's humming, suggesting the need to be on guard when a Jew enters the house while he is officially welcomed at the same time, can be read as an echo of Clermont's argument that the Jews are welcome, but that the nation within the nation will not be accepted. The specific cultural space that Bloch encounters upon his arrival in the family, of being visibly welcome on the one hand, and of being audibly distrusted on the other, reflects the fact that Bloch enters as a citizen, but he has to prove that he has no trace of difference around him that could be judged incompatible with this citizenship. Proof of his full allegiance to France will have to be provided, and this must include acceptance of inherited hierarchies about who sets the rules of the game. The irony of the situation is that the person who sets the 
rules of the game imputes the difference to Bloch before he has had time to deny it, and Bloch will therefore be unable to prove anything. Let us turn to how Bloch tries to cope with paradox while carrying out the imperative to assimilate.

\subsection{Bloch coping with paradox}

What about the reaction of those who participate in the cultural space that has been created, or rather, made explicit, by the grandfather most notably the protagonist and Bloch, but also the rest of the protagonist's family? First of all, what about Bloch? Will he prove able and willing to boldly transgress the boundary of his friend's household, something that Swann's family had obviously done one generation before?

We read no report of what actually happened when the grandfather hummed his arias on Bloch's first visit to the family. But the narrator does speak of his various visits in immediate connection with the passage on his humming grandfather. It turns out that not only the grandfather, but the whole family dislikes Bloch. During one of Bloch's visits, when the protagonist's father amicably asks him why he is wet and whether it has been raining, Bloch replies:

Sir, I am absolutely incapable of telling you whether it has rained. I live so resolutely apart from physical contingencies that my senses no longer trouble to inform me of them (Proust 1996: I, 108; I, 91).

We may interpret this reaction as a subtle reply to the grandfather: if one does not sense physical contingencies, one also does not have to hear or react to humming grandfathers. Moreover, such a person lives in the independent realm of the conceptual, of that which has continued its existence without fear or shame for a long time already. The family does not interpret Bloch's insensibility to contingencies in such terms, however. The father's judgement is clear, for he says to the protagonist 'he couldn't even tell me what the weather was like. ... He's an imbecile' (ibid.: I, 108).

The father's fascination with Bloch's reply about the weather is demonstrated by the fact that the whole scene is repeated once again, as if Bloch has to be reminded once more of the possibility of being touched or at least made to feel uneasy. But after the father's second question about the weather the young man strikes back, adding an irritating aestheticist sociology to his earlier 'insensitivity': 
I never allow myself to be influenced in the smallest degree either by atmospheric disturbances or by the arbitrary divisions of what is known as time ... I know nothing about those ... pernicious and moreover flatly bourgeois implements, the umbrella and the watch (ibid.: I, 109; I, 91).

Bloch reacts in similar ways many times throughout the novel, and dis-identifies with the acceptable friend the family and others want him to be, by producing deviant behaviour. He does want to be admitted to society, but at least to some extent on his own terms. I am not sure that we can interpret his irritating, unsubtle remarks as social mistakes stemming from the fact that this nouveau venu simply does not know how to behave. The narrator often suggests this - also later in the novel - and distinguishes himself from Bloch on this point. Kristeva (1994: 55) follows the narrator here, although she does defend Bloch as a parvenu activist. Yet if Bloch is partly deliberate in choosing to make his gaffes, are they still gaffes? They are at least partly performances. Later in the novel, it turns out that Bloch has not become a poet, but a playwright, and a convinced and strong Dreyfusard; he knows the rules of the game, but doesn't accept them.

Voluntarily unprotected from meteorological disturbances, Bloch declares the world of appearances to be relevant only to bourgeois society and identifies with something higher, though this may be a little airy. With his rejection of the watch, he also distances himself from the body disciplined by modern techniques of time control, and thus announces the Bergsonian metaphysics of the next generation.

However, Bloch's ideal of transcending contingencies can also be read as an ironic, absurdly consequent identification with the neoKantian, Republican, laïcist philosophy of morality that was being developed and taught in French universities and public schools in the late 19th century, and which Proust was familiar with. ${ }^{22}$ Scrutinising this connection teaches us more about the paradoxes of assimilation, insofar as they were produced by the way Jews were identified with both poles of the dichotomous relationship between reason and contingency, and citizenship and particularity, established in neo-Kantian philosophy.

Neo-Kantian Republicanism advocated free rational moral judgement untainted by prejudices caused by the contingencies of religious beliefs and traditional moralities. It understood tradition as a past from which we have to cut ourselves loose into modernity, by freely determining our own actions. In the neo-Kantian view, this did not necessarily imply the overcoming of religion, but rather its separation from cultural practice and law, which is partly understood in terms of the 
religious privatisation required for laïcité. For example, French neoKantian philosopher Renouvier (1896: 142, quoted in Laborde 2002: 172) argued for the need for citizens to be capable of critical (rational) judgement and to not submit to 'a priesterly and absolutist' religion. The idea was that we can be good citizens only on the basis of reason, and that existing traditions and practices tend to imply submissiveness to authoritarian religion.

The neo-Kantian view of morality and of citizenship was not appreciated by right-wing conservatives such as Maurice Barrès, who stressed the rootedness of morality, the weight of the past, and the value of the Catholic nation. Yet the conservatives did not deconstruct the Republican divide between reason and tradition itself (as the romantic and Hegelian traditions in Germany did with Kantianism). Instead they exaggerated it by introducing a naturalistic and deterministic conception of race, which came to replace earlier, more dynamic and historical understandings of tradition, of belonging and of race. ${ }^{23}$

In his description of the philosophy lessons at public schools, Barrès writes that the professor would aim to 'lift those admiring children above the passions of their race, toward reason, toward humanity' (quoted in Tadié 1996: 152, my translation). The Kantian assignment to transcend traditional morality was summarised as transcending one's race. Barrès also denounces the educational power he ascribes to the State. In Les déracinés (The Uprooted), he writes, 'the university is a powerful State instrument for forming minds... In the public schools, one is republican' (Barrès 1897, quoted in Tadié 1996: 152, my translation). The result of rational transcendence, according to Barrès, was in the end not morality but uprootedness. This presumed result of modern morality was one of the major charges laid against Republicans in the Third Republic. Barrès greatly exaggerated Republican educational power and also did not acknowledge the liberal tendencies within actual Republican schooling, emphasised by contemporary historians like Maurice Agulhon and Mona Ozouf (Birnbaum 1998: 161). Yet he contributes to the political myth of the authoritarian, illiberal République, or what Ozouf calls the 'République intégriste'. By doing so, he contributes to a conceptual divide between Catholicism, rootedness, and belonging to the French 'race' on the one hand, and Republicanism, uprootedness and authoritarian rationalism on the other.

Especially in late 19th-century France, Jews, even more so than Protestants, became the emblems of such alleged uprootedness hidden under abstract morality. Anti-Semite Édouard Drumont, in particular, presented them as closely affiliated to the state and also to Republican pedagogy: 'the centenary of 1789 , it is the centenary of the Jew' 
(quoted in Birnbaum 1998: 154, my translation). We saw in Chapter 2 that Durkheim was presented as being a Republican because of his Jewish background.

The racialisation of Judaism has often been analysed as one of the most vicious manifestations of the paradoxes of assimilation. For example, Brown $(2004,2006)$ analyses racialisation and its role in transforming anti-Semitism. She argues that, under the influence of new 19th-century traditions of knowledge formation and categorisations in terms of race, the gradual de-collectivisation of Judaism could take place, while at the same time Jewishness as a racial characteristic of individuals could emerge. This, according to Brown, caused the typical modern contradiction of inclusion as a citizen and simultaneous exclusion on the basis of belonging to the race of individual Jews.

The small detour via Barrès and Bloch suggests that there was another side to the problem which produced part of the venom of antiSemitism. On one hand, the Jews were definitely associated with a race, biologically and culturally irreparably different. But on the other hand they were associated with the destruction of the French nation (and race) in the name of the Republic, and with uprootedness. The dynamic of being racialised and taken as cosmopolites at the same time was an extra cause for their experience of never being able to do the right thing.

The experience of paradox is once again turned into literature when we return to Bloch. He suggests that time and space are irrelevant to him, and he identifies with the Republic's culture of universalism, be it more the poetic than the political version. However, in a climate of strict divides, doing what the Republic asked of you led to new aversions; not only on the part of the explicit Reaction, but also on the part of the quite moderate Catholic bourgeoisie. Why do the protagonist's parents not like Bloch? Precisely because Bloch, by not subscribing to a continuous, habitual form of morality, might be unable to offer the protagonist the certainty of a stable friendship:

[T]hey knew, either instinctively or from experience, that ... regard for moral obligations, loyalty to friends, patience in finishing our work, obedience to a rule of life, have a surer foundation in habits solidly formed and blindly followed than in these momentary transports, ardent but sterile (Proust 1996: I, 109; I, 91-92).

Bloch's world of ideas is understood by the parents as a sign of a lack of solidly formed habits. They may even find him uprooted. And as 
good conservative bourgeois, to uprootedness they prefer the virtues of habit and self-discipline.

Bloch is caught in a double bind which he cannot transcend. $\mathrm{He}$ has consciously tried to shed 'solidly-formed habits', refused to develop them, and has become a poet or philosopher. He may have identified with the Republican ideal of citizenship. Yet insofar as Bloch does have such solidly formed habits, he must conceal them, make them 'private', because the moment he were to make them public, they would make it possible to identify him as a Jew instead of as a co-citizen. Whatever he does, he will not be liked by the family, for they apply more universal standards to him than they do to themselves. That's why the literary character Bloch turns universalism into a joke, by exaggerating its validity as a weapon against racialisation.

In summary, rejection could be expected not only of explicit antiSemites, but also of those who did want to include the Jews, but who required them to fully assimilate and secularise on the one hand, and judged that they had no solid habits, and were untrustworthy, on the other. What they were unable or unwilling to see is that they themselves had only recently assimilated and secularised, and in much more modest ways.

At this point it is worthwhile to reflect again on the specific position in which Bloch is introduced in the novel, namely at the threshold of the house of his friend's family. It is precisely here, at the threshold of the private life of the majority, that problems arise for the one who assimilates. These problems appear within civil society, but they pass into politics. It is only on the basis of the contestable idea of a strong boundary between the social and the political that we can allow ourselves to believe that they do not interfere with each other.

\subsection{Partiality, perspectivism and assimilation}

And the protagonist? Or the narrator? Or Proust? What about their role in the somewhat caricatured portrait of Bloch? Does it make sense to interpret the novel as slightly anti-Semitic or at least steeped in assimilationism, as stereotyping Jews who were squeezed between the many requirements imposed upon them?24 In what sense can we see Proust's novel as a valid testimony to the experience of assimilation? In what sense does it form part of assimilationist and even anti-Semitic discourses instead?

Let us first briefly turn to some aspects of Proust's life that might be illuminating here, and then return to the novel. Proust's parents 
formed a mixed couple. His mother was Jewish, his father was a Catholic. His mother was born Jeanne Weil, and she married Adrien Proust in 1870. Although mixed marriages were rare at the time, this was less so within the context of the rich bourgeois elite to which she belonged, and which had secularised to a large extent. She encountered no obstacles to her marriage to Adrien Proust, and although she did not want to convert to Catholicism, she did not actively practise the Jewish religion and consented to baptising her children. Her father had been the last generation to actively practise the Jewish religion. He did so in a modest manner only. Nathé Weil observed the grand religious holidays and went to temple on Yom Kippur, but this was the only time in the year that he did so (Tadié 1996: 45).

It was the milieu also of Mme Straus, one of Proust's models for Mme de Guermantes. She was born Généviève Halévy, daughter of Fromental Halévy, composer of the opera La Juive. She was the mother of Proust's friend Jacques Bizet and the aunt of his other friend Daniel Halévy. Mme Straus famously answered the question of why she did not convert to Christianity by saying: 'I do not have enough religion to change it' (quoted in Marrus 1971: 61, my translation).

For Proust, his mother's Jewish background constituted a complicated social and psychological issue in light of the historical situation of the Third Republic and the Dreyfus Affair (see Probst Salomon 2000 and Carlston 2002 on Proust's personal political views and actions and the Dreyfus Affair). The role of anti-Semitism was never acknowledged by the army and government or their defenders. This made it difficult to address, even after the Affair had grown into a major political row throughout France. It also made it difficult to be a Dreyfusard when one was Jewish, as this invariably incurred the accusation that one was only a Dreyfusard because of group ties - an accusation that the army and government would never extend to themselves, for they always retained a pretence of strict neutrality. Proust was involved in the Dreyfus Affair himself. He was one of the first to start a petition for Colonel Picquart, who had defended Dreyfus. Proust allegedly called himself 'the first Dreyfusard', since he was the one to convince the then-famous writer Anatole France to sign the first public petition in favour of Dreyfus' case (Probst Solomon 2000; Carlston 2002).

Since Proust did not live in Jewish surroundings but among the elite, which was mainly fully secular or Christian, he was often confronted with openly professed anti-Semitism. In 1896, he wrote a letter to his anti-Dreyfusard friend Robert de Montesquiou, to explain why, at a party, he had not replied to a question about Jews in the context of the Dreyfus Affair: 
It is for this very simple reason: while I am Catholic like my father and my brother, my mother, on the contrary, is Jewish. You understand that this is quite a strong reason for me to abstain from these kinds of discussions (Correspondance II, 66; quoted in Fraisse 1996: 318, my translation).

Proust's explanation makes clear to what extent having a Jewish background was a private matter which one did not share with Catholic friends until an emergency made it necessary to speak out about it. It also makes clear what genre of discussion this must have been - if one had to appeal to one's mother's religious origins in order to be exempted from pronouncing a judgement (see Probst Solomon 2000 for a more elaborate reflection on the salience of his mother's Jewish background for Proust). ${ }^{25}$

Although loyalty to the Republic, while remaining religiously Jewish, had proven sufficient for inclusion in official political society as citizens, this was not the case, Proust suggests, with respect to inclusion in the culturally, socially and politically dominant high society. Admission there required stronger forms of assimilation and great skill in handling humiliation and prejudice. In the Proustian world we constantly encounter characters, often Catholic aristocrats, who are convinced that a Jew cannot also be French. For example, Baron de Charlus tells the protagonist while talking about Bloch:

'It is not a bad idea, if you wish to learn about life, ... to have a few foreigners among your friends'. The protagonist answers that Bloch is French. Charlus replies: 'Indeed', said M. de Charlus, 'I took him to be a Jew' (Proust 1996: III, 330; II, 584).

Although only reactionaries among the French held the view that being French and being Jewish were mutually exclusive, it obviously entered Proust's experience with quite some force, as we witness from another letter, written in 1915 during World War I. One evening, Proust was addressed by a foreign guest at a party. Proust recounts that he had been moved by this guest's admiration for France, which he had expressed by saying 'you chased away the Germans, you defeated them, etc.'. On the one hand, Proust was embarrassed by this 'you' since he himself had not fought. But, on the other hand, he says, 'I felt that this meant that I was French, and it was precisely this which produced my emotion' (Correspondance XIV: 175; quoted in Fraisse 1996: 323, my translation). 
The impact of the DREyfus Affair

The Dreyfus Affair confronted the French (and particularly the Jews) with the political actuality of being identified as a member of a group at a time when many expected group identities and identifications to have become unimportant outside of the private sphere. We can trace Proust's early reflections on the relation between belonging and political judgement in a passage from Jean Santeuil, Proust's first project for a novel. This novel was written in a more realistic, more documentary style than In Search of Lost Time. A narrator relates a third-person narrative about a boy called Jean. Jean's parents are Catholic, but politically they are rather on the Republican and Dreyfusard side. Jean Santeuil contains quite a few accounts of the court cases during the Affair, which Proust himself attended regularly. They contain minute descriptions of the appearances of those who were called as witnesses, such as, for example, General Picquart, who risked his own career and eventually ruined it by maintaining that Dreyfus was innocent. The passage to be discussed forms part of a section called 'Truth and Opinion'.

The passage is anticipated by the narrator's account of one of the court sessions. In the session, a scientist is asked for his opinion on whether the handwriting of the famous bordereau, the piece of paper on which Dreyfus was suggested to have written the information he transmitted to the Germans, could actually have been that of Dreyfus. Against the judgement of all the military experts, and at considerable risk to his career, the scientist testifies that the handwriting cannot possibly be that of Dreyfus. His testimony greatly impresses Jean. The episode ends as follows:

If among the signatories of the protest in L'Aurore we see the name of an illustrious lawyer, who is known to be a monarchist and a Christian, the emotion we feel is the more intense, because by reason of this deviation in his behaviour, we are made to see what truth really is. It is a pleasure too - and a very great pleasure - to find ourselves confronted by a certain form of courage, a certain air of intellectual freedom, in such men who by a word can justify opinions which we ourselves should have liked to express, but have rejected because, in our constant effort to be sincere (I am talking now of natures like Jean's) we feel that we ought not to rely on our own opinions and range ourselves on the side of those whose opinions are the least favourable to our own attitude. If we happen to be Jews, we make a point of trying to understand the anti-Semite point of view: if believers in Dreyfus, we try to see precisely why it was that the jury found 
against Zola, and the civil authorities cast a slur on the good name of the Scheurer-Kestner. It comes to us therefore as a pleasurable shock to be able to enthrone henceforward an idea previously expelled and humiliated because we lacked respect for what we genuinely felt, when we read a letter written by Monsieur Boutroux in which he states that anti-Semitism is abominable, and that Jews are just as good as Christians (Proust 1985: $352-353){ }^{26}$

The narrator explains Boutroux's step in terms of the classical distinction between independent judgement and received opinion or prejudice, but the impartiality and truthfulness that Boutroux displays is only partly related to impartial science. It is dependent on the courage to come out as a party in conflict. Proust traces what happens if we try to avoid the possible accusation of partiality while being in conflict: in solidarity with his Jewish mother, he invents a Catholic boy trying to find a neutral standpoint, and a narrator contemplating neutrality in general, in order to address the most painful issues surrounding belonging. In addition to inventing these two intermediaries, the narrator casually dresses up that which is actually the central problem being addressed: the fear of being accused of partiality upon defending Dreyfus as a Jew. He also addresses the partial interiorisation of the anti-Semitic judgement that follows the attempt to be sincere and to judge the two parties impartially: we reproduce, within ourselves, the majority's judgement about Dreyfus. We start to humiliate and disrespect ourselves and our feelings, just as the anti-Semites disrespect the Jews, and we become dependent on the judgement of an authoritative person like Boutroux. The awkwardness of this position can be sensed from the physical relief that ensues when someone from outside breaks the ban and tells the truth.

\section{The Perspectivism of the novel}

In Search of Lost Time can be read as an exploration of the complicated field that lies between independent judgement and culturally formed perception and opinion. The narrator (and the protagonist) are bodily and historically involved in their judgements, which, at least partly, depend on their position in the social field. Through its narrative structure, all views are put into perspective by means of specific perspectives which change over time. ${ }^{27}$

This general perspectivist tendency of the novel is conveyed to the reader by means of a reflection on Marcel's family's one-sided view 
of Swann as a neighbour and son of a stockbroker rather than as the classy, worldly man that he also is:

But then, even in the most insignificant details of our daily life, none of us can be said to constitute a material whole, which is identical for everyone ...; our social personality is a creation of the thoughts of other people. Even the simple act which we describe as 'seeing someone we know' is to some extent an intellectual process (Proust 1996: I, 20; I, 18).

By 'intellectual process', the narrator appears to mean a process that contains elements of interpretation, of social meaning. This principle thoroughly individualises experience. Every individual experiences every other individual in a different way than does a third individual. Moreover, every individual experiences every other individual in a way that is different from the way in which one experienced this individual in the past. The constructive work implicated in our perception of other people is crucial to Proust's novel. Throughout it, we are confronted with the protagonist's constructions of characters at certain specific moments, based on memories, expectations, fantasies, lies and the ways in which these constructions are subsequently transformed over the course of his experiences, while they are being remembered by the narrator. There is no final revelation of truth: the narrator remains implicated in his socialised habits with regard to perceiving others.

There is also perspectivism from the beginning in the portrait of Bloch. He is introduced into the situation that the grandfather has created. From this point onwards, the protagonist clearly perceives his friend with his grandfather's and father's judgements in mind.

\section{Perspectivism AND ASSIMILATION}

Yet perspectivism also knows degrees, depending on who tries to know whom and in what context. We can trace a deeper layer of complexity within the portrait of Jewish characters by noting the author's own choices about what should be published in the novel and what should be protected from being made public, perhaps because it was too harsh, too mythical or too painful. The corrections Proust made to his first versions are sometimes breathtaking, specifically when they concern the relations between Catholics and Jews. These corrections were extensively studied in the so-called critique génétique that was first developed by Bernard Brun, one of the most important French Proust scholars. The passage on Bloch exists in an earlier version where the visiting friend is not yet identified as Bloch, who did not exist as 
a character at the time. Instead, Swann is the one who is confronted by the grand-uncle's (instead of the grandfather's) now explicit antiSemitism:

M. Swann, although much younger than my grand-uncle, was my granduncle's best friend. This was bizarre for several reasons, one of which was that M. Swann was Jewish and that my grand-uncle did not like Jews. This was one of those small weaknesses or absurd prejudices in him as exist even in the natures of the most righteous persons, those who are firmest in their service to the good. This sort of antipathy, which by the way was only slight, was a little aggravated by my grand-uncle's claim that every time we [The protagonist and his brother, YJ] connected ourselves strongly with one of our friends more than with others and brought this friend to our house for dinner, it was always a Jew. He received them well overall, but never stopped humming 'O God of our Fathers' from La Juive, changing to 'Israel, break thy chains' from Samson and Delilah, humming only the melody of course (ti la lam, tam ta lam, ta lam ta lam, ta lam, talam talim talilalam, tim talam) ... But when the Israelite visiting us was M. Swann, he did not hesitate to sing these airs openly and to distinctly pronounce the words of the libretto, knowing very well that M. Swann would not get angry, saying that: 'With Swann it is no use leaving out the words, he knows my entire repertoire.' 'Yes, isn't that so, Swann', and Swann would answer with a laugh: 'Yes and I do not blame you for it.' And more seriously: 'You will learn one day that everything you respect and of which you consider the Jews to be deprived, such as generosity, charity, solidarity, and the forgiveness of sins are precisely Jewish virtues par excellence.' ... Swann's father was an associate banker (the fact that he was Jewish was not considered relevant because he only frequented Catholics, and at most it incited curious wives to ask him whether on certain days he was forced to eat the flesh of a Christian child, a question their husbands, with somewhat of a bad temper, advised them not to ask) (Cahier 8 [N.A. Fr. 16 648], quoted in Brun 1988: 118-119, 123; compare Brun 1988 for the entire quote, my translation).

This early version is ruder and less literary than the one eventually published. Swann explicitly contradicts the grand-uncle's negative opinion of the Jews and claims Christian values for them. This makes the conflict explicit and thus misses the ways in which the published version renders its unspeakability palpable. The supposition that certain curious wives were tempted to ask Swann whether he was forced, at any time, to eat the flesh of a Christian child, reveals Proust's early experience of anti-Semitism as something deeply hidden within privatised 
Christian cultural memory. The husbands, less secluded within private spheres, know that these myths should not escape from the boundary of the Catholic home. This passage ties the narrator's reflections on the family's limited knowledge about Swann's social position to their limited knowledge of Jewish private life in general, which caused them to remain bound to myths that they knew were foolish but nevertheless found fascinating.

It was in the act of rewriting this passage that Bloch was invented. Kristeva (1994: 54) believes that separating Bloch from Swann had the function, for Proust, of creating in Swann 'a positive alter ego', while 'Bloch takes on the negative aspects of Judaism, though not without retaining some complexities and affinities with the narrator, born as he is from an initial version of Swann' (ibid., my translation). However, Proust may have had other reasons for creating two Jewish characters instead of a single one. He may have invented Bloch because he needed to narrate the historical problems of assimilation that he encountered and that varied across different generations and classes. Bloch does not function as a negative portrayal of Judaism in general, but as a portrayal of the position in which those Jews that had not yet assimilated as fully as Swann had, found themselves. Swann only gets into trouble at the time of the Dreyfus Affair, when he starts identifying himself as a Jew. In addition, Proust needed Bloch for his portrayal of the structures of judgement exhibited by (some) members of the Catholic majority and by (some) assimilated Jews towards those who were less assimilated.

In his reading of the changes made by Proust, Brun (1988) interprets the transition from brouillons (draft versions) to public versions that are partly brouillages (radio interference), as the result of mixed motives, impossible to unravel. Proust is led by a wish to adapt his story to the narrative structure he projected, which was to demonstrate that we have only perspectival knowledge of our social surroundings. Therefore, he eliminates those elements of the story that determine the backgrounds of his characters too clearly from the beginning, such as, for example, a clear, objectifying determination of 'who Swann is'. On the other hand, Brun (ibid.) argues, the eliminations may have been stimulated by a wish to hide the most painful and incomprehensible associations around anti-Semitism and racialised desire from the public.

Brun might have added a reflection on the question of why the perspectivist poetics is introduced when Swann enters the familial territory. While Proust's perspectivism is a general narrative procedure, Swann (and Bloch) remain less graspable than the other characters, 
because the novel reflects the structure of assimilation. The reader receives a much more detailed and coloured picture of the family than of Swann, in spite of remaining perspectival. By emphasising the family's perspectival knowledge of Swann as they speculate on his identity, Proust explores the ways in which Judaism, which had become more or less private and invisible in the 19th century, experienced a second life in a semi-public memorial space without being admitted in a more explicit sense. The Republic guaranteed equal entry into the public sphere for Jews, but only as neutral citizens. It produced complete inequality at the point of their visibility as private persons and as the producers of a specific culture. Instead of leading to actual immateriality at the public level, this created speculation. The entire cultural space is Catholic-secular, and Swann and Bloch only appear in the context of their confrontation with it. This not only ensures that they will be scrutinised according to how well they have adapted, but also that this lack of visibility is projected onto their behaviour as demonstrating a propensity for incomprehensibility and 'excessive' social mobility.

The next chapter analyses Proust's metaphorical style as an ambivalent reflection and critique of this exclusion of Jewish culture from the public sphere at a discursive level. 



\title{
CHAPTER 5
}

\section{Stuck in a revolving door}

\author{
Cultural memory, assimilation and secularisation
}

\subsection{Assimilation, metaphor and cultural memory}

Let me now further explore the semi-public, semi-private cultural realm of unspeakable 'otherness' connected to expectations about assimilation introduced in the previous chapter. I will trace how this realm, in 19th-century France, was connected to the idea that assimilation implied secularisation in terms of the transformation of ethnoreligious culture into privatised 'religion'. By exploring this cultural realm through In Search of Lost Time we will be able to trace how it hosts a specific kind of ethno-religious difference in which othering and secrecy, shame and the cultural memory of religious and cultural difference, intermingle and sometimes clash.

My interpretation takes shape as we follow our friends, the protagonist and Alfred Bloch, in their confrontation with a third, new friend, the Marquis Robert de Saint-Loup-en-Bray. Saint-Loup only features in the second volume of the novel, entitled Within a Budding Grove. The protagonist and Bloch first meet Saint-Loup in Balbec, the small, luxurious Normandy seaside resort where they spend their summer holidays.

In section one of this chapter, I analyse the protagonist's perceptions of Bloch and his family in Balbec in the context of Reinach's (1901 [1884]) concept of assimilation as secularisation. Section two addresses Benbassa's, Arendt's, and Bauman's analyses of the paradoxes of assimilation, and I read Proust's metaphorical style as a powerful literary critique of these paradoxes, and as a literary reflection on the habitual conceptual framework in 19th-century Republican thought that connected, on one hand, politics, the French nation, and the public, with, on the other hand, religion, other nations and privacy. In section three, I read Proust's metaphors as carriers of a cultural memory of hierarchy and power distribution over diverse societal groups and of this cultural memory's agency in the present; as literary devices that recall layers of identities and their interwovenness, cutting through 
the Republican divide between citizenship on one hand, and religious, diasporic and social belonging on the other.

Let me add a brief methodological note. Analysing metaphors when we want to learn about assimilation and secularisation compels us to develop a sociological concept of metaphor that is unusual in the existing literature, which mostly occupies itself with inquiries into the rhetorical and metaphysical functions of metaphor, particularly when dealing with In Search of Lost Time (Deleuze 1964; Genette 1966, 1972).

Barthes (1980), however, proposed a reading of Proustian metaphor in sociological terms. For him, Proust's novel presents an exploration of social mobility, with metaphor functioning as the vehicle for exploring this characteristic of modern society. Barthes first suggests that there exists a grammar of modern societal life, the essential formal characteristic of which is reversal:

A ceaseless permutation animates, shatters the social interplay (Proust's work is much more sociological than people say: it describes the grammar of social advancement, of social mobility, in an exact manner), up to the point that society life can be defined by a form: reversal (of situations, opinions, values, feelings, languages) (Barthes 1980: 37, my translation).

Social reversal, Barthes argues, is figured through metaphor in the Proustian novel. In his elaboration of this idea, Barthes opposes Proust's syntax of modern societal life to a classical social syntax. In Proust's universe, characters are able to radically change roles. They can, for example, be vulgar one moment and distinguished the next, without being the one in truth and the other only in appearance. Barthes takes Princess Sherbatoff as an example. She is a Russian princess, who at one time appears to the protagonist as a brothel keeper. In classical syntax, such as the moralistic one represented by the famous French writer La Rochefoucauld (1613-1680), the princess would be 'deciphered' as 'nothing but' a brothel keeper (Barthes 1980 [1971]: 35-36). Proust replaces this syntax of 'nothing but' by a 'concomitant syntax' in which the woman can be both a princess and a brothel keeper. This new syntax should be called 'metaphorical', Barthes suggests, because metaphor, notwithstanding the longstanding tradition of rhetorics, indicates a work of language without any 'vectorisation: it passes from one term to another in a circular and infinite way' (ibid.: 38).

Barthes's interpretation of metaphor stresses the relaxing of fixed semiotic categories in Proust's modern universe, but it neglects a different aspect of this universe's mobility, which is also explored through 
metaphors, this time more vectorised. The Proustian metaphors bring to light the ways in which group belonging, though officially only privately relevant, in many complex ways saturates the different layers of a public, shared culture: as visible traces, as cultural practices, as ways to organise specific groups, as shared cultural memories, as persistent prejudices, as shared hopes and expectations, and as something transformative as well.

\section{BLOCH AND HIS FAMILY BEING 'PICTURESQUE RATHER THAN PLEASING' AT THE BEACH}

The second part of the Proustian novel narrates the adolescent protagonist's holidays in Balbec. There, he befriends Robert de SaintLoup, nephew of Combray's Duchess of Guermantes. The protagonist is eager to gain his friendship, but he expects this will be more difficult than befriending Bloch, because Saint-Loup appears arrogant and unapproachable. Once Saint-Loup shows an interest in becoming his friend, the protagonist admires him almost without reserve. SaintLoup remains the protagonist's best friend until his untimely death on a battlefield during World War I. The narrator ascribes to Saint-Loup a nearly absolute sincerity, which is also reflected in the fact that SaintLoup, as a nobleman, is a Republican. According to the narrator, SaintLoup's inability to find satisfaction in egocentric sentiments such as love makes him capable of true friendship, unlike himself (and Bloch) (Proust 1988: II, 416). In sum, Saint-Loup is exactly the kind of friend the protagonist's parents would have wished for him.

Not long after their first acquaintance, the protagonist discovers that Robert, mixing curiosity with his Republican ideals, wants to get to know people that the protagonist's parents, following the 'sociological theories of Combray', would never expect him to be interested in (ibid.: II, 367). The narrator writes that one day, sitting on the beach with Saint-Loup, they hear the following words coming from a tent not far from their own:

You can't go a yard without meeting them ... I am not irremediably hostile to the Jewish race, but here there is a plethora of them. You hear nothing but, 'I thay, Apraham, I've chust theen Chacop.' You would think you were in the Rue d'Aboukir (Proust 1996: II, 367; II, 72). ${ }^{1}$

To the protagonist's astonishment, it turns out that the person speaking is 'his old friend Bloch' (ibid.: II, 367). We may explain Bloch's remark as self-irony, self-hatred perhaps, but we have to acknowledge 
that he also distinguishes himself from the 'plethora' as a more assimilated person by imitating a Yiddish accent which he himself does not have. The next astonishing surprise follows when Saint-Loup tells the protagonist that he would like to be introduced to Bloch.

It turns out that Bloch is not the only one to have problems with the Jewish presence in Balbec. The protagonist himself 'was not particularly anxious that Bloch should come to the hotel' (ibid.: II, 367). This is because the protagonist does include Bloch in the undesirable 'plethora'. He notes that Bloch is not alone but with his sisters, who, in turn, have 'innumerable relatives and friends' staying in Balbec (ibid.).

In the protagonist's eyes, the category of 'other Jews' from whom Bloch distinguishes himself does include Bloch, and they all form part of a single group connected through private links of family or friendship. The narrator then provides the following comment on this group:

Now this Jewish colony was more picturesque than pleasing. Balbec was in this respect like such countries as Russia or Romania, where the geography books teach us that the Jewish population does not enjoy the same esteem and has not reached the same stage of assimilation as, for instance, in Paris. Always together, with no admixture of any other element, when the cousins and uncles of Bloch or their co-religionists male or female repaired to the Casino, the ladies to dance, the gentlemen branching off towards the baccarat-tables, they formed a solid troop, homogeneous within itself, and utterly dissimilar to the people who watched them go by and found them there again every year without ever exchanging a word or a greeting, whether these were the Cambremer set, or the senior judge's little group, professional or 'business' people, or even simple corn-handlers from Paris, whose daughters, handsome, proud, mocking and French as the statues at Rheims, would not care to mix with that horde of ill-bred sluts who carried their zeal for 'seaside fashions' so far as to be always apparently on their way home from shrimping or out to dance the tango. As for the men, despite the brilliance of their dinnerjackets and patent-leather shoes, the exaggeration of their type made one think of the so-called 'bright ideas' of those painters who, having to illustrate the Gospels or the Arabian Nights, consider the country in which the scenes are laid, and give to St Peter or to Ali-Baba the identical features of the heaviest 'punter' at the Balbec tables (Proust 1996: II, 367-368; II, 98 , my italics).

Rather than reading this passage in terms of a typically 19th-century example of anti-Semitism, I propose to read it as a narrative critique of the effects of assimilationism. Why is 'being picturesque' used by the 
narrator as a qualifier of a Jewish colony which has not reached a certain stage of assimilation?

The appearance of the Jews gives rise to visual abstraction and unity: the women are dressed fashionably and perhaps a little indecently, while the men wear brilliant clothes. Thus, the colony is qualified as picturesque because it stands out, and this is linked to its not being pleasing: it appears as a big group of not-us. They do not appear to be less assimilated because of a non-modern appearance. Rather to the contrary, they appear as not yet fully assimilated because they are perceived as a solid group. The images used to designate the Jews in Balbec shift from 'plethora' to 'colony', to 'the cousins and uncles of Bloch or their coreligionists', to a 'solid troop, homogeneous within itself'. The suggestion that there are many Jews is linked to the perception that they are members of a single family. This family quality derives from the impression that there is no 'admixture of any other element'.

Here, in a space of shared leisure, the Jews are suddenly perceived as a family, an ethnos, instead of the public individuals whose Jewishness was officially declared irrelevant to their citizenship. The passage suggests that for all their access to French society, the Jews live completely separated from the other French in their private time; and this separation itself stimulates the perception of them as a unified group. This recalls Katz's (1972) view that social emancipation remained

a far cry from the vision that had sustained Jews when they first started to leave behind the boundaries of their traditional society ... Jews, even in countries where they had obtained political freedom, were economically advanced, and assimilated culturally, remained separate, even conspicuously so (quoted in Bauman 1988: 55).

While the narrator perceives the Jews as a united family, he divides the French, by contrast, into classes and professions, ranging from nobility to the judge's little group, to professional or 'business' people, and finally to the petty bourgeois (simple corn-handlers).

The metaphors used should make us aware that there is something peculiar about this perception of unity. Underlining the differences between the groups, the metaphors contrast with what the narrator actually sees. Why do the Jews stand out? What the narrator sees is that they dress fashionably. The girls are qualified as 'ill-bred sluts' because they do what is hip and modern: dancing or shrimping. They are more modern than the daughters of the Christian bourgeoisie, who are statuesque ('like the statues in Rheims') and probably quite prim and 
prissy. This fashionable appearance is ingeniously associated, through metaphor, with what makes them into 'co-religionists', into an ethnically and religiously separate group: not the fact that they really share a religious culture. On the contrary, reference to a shared religious practice is conspicuously absent. There is instead a metaphorical association of their modern appearance, firstly, with the lives of ghettoised Russian and Rumanian Jews, and secondly, with classical religious narratives from the Orient.

The narrator establishes these associations in a perfectly circular way: from the brilliance of the baccarat players we detour to the Orient as a geographical place, then to the mythical Orient, only to return to the (Jewish) model for these cultural memories found at the baccarat table. The narrator recalls the pervasiveness of these associations by seeking the cause for them in the stereotypes used by popular painters. Thus, the Jews' modern appearance is itself associated with religious origins and with their unity as a group. What is missing is a reference to social differentiations within the group, such as those with regard to class or profession that the narrator makes with regard to the other French. ${ }^{2}$

The narrator judges that his perception of the Jews in Balbec is produced by their stage of assimilation. An indication of the irony and self-contradictoriness of this analysis follows immediately, when he writes that Balbec is like Russia and unlike Paris - even though the Jewish guests all come from Paris and are more rather than less assimilated to modern Republican standards than are the other guests. They are just a little less classy and less culturally Christian. The rest of the narrator's 'perception' is actually metaphor, a product of cultural memory. Bloch, by contrast, links the group to the Rue d'Aboukir in Paris, which indicates that the narrator's perception of homogeneity, of separation and of imperfect assimilation is linked to the fact that he knows little about non-elite Jewish life in France (or outside it).

British cultural scholar Bowie (1995: 148) provides a relativist interpretation of the anti-Semitism in the quoted passage:

One value system is used to expose another to ridicule, but the relation is a reversible one: the instrument of ridicule may become its object as the satirical text presses manically ahead. One of the hallmarks of the Proustian political vision is to be found in this extreme instability, in this resistance to all principles of social order and continuity. And this instability is jealously protected by Proust's text, even if this means giving room from time to time to reprehensible views. 
However, if we analyse the passage's voices together, they do not celebrate instability. Rather, the passage as a whole can be interpreted as a critique of the assimilationism it professes at the explicit level through the contradictions and inconsistencies of several voices brought together in the passage. I propose that we now address Reinach's (1901 [1884]) definition of assimilation in order to get a better grasp of the precise setting in which the passage should be understood.

\section{REINACH'S DEFINITION OF ASSIMILATION}

In order to grasp how assimilation was generally understood in the early French Third Republic, let us address the view of Théodore Reinach, one of the early historians of French Judaism (Benbassa 2000). His older brother Joseph Reinach was among the most important Dreyfusards. Proust refers to Joseph Reinach several times in In Search of Lost Time (1996: III, 276, 283; in 1996: IV, 169, he visits Mme Verdurin's salon). Théodore Reinach himself was the librarian in a library often visited by Proust (Tadié 1996: I, 688).

In his history of the Jews, Reinach (1901 [1884]: 305-306) proposed the following transformation of Jewish identity after emancipation, which he called 'assimilation':

The French Revolution heralded a new era in the history of Judaism, as well as in that of Western Europe. For the old notion of the State of divine and historical right, founded on distinctions of caste and race, the Revolution substituted that of the purely human and secular State, where one does not make people accountable for the blood that flows through their veins, not of their intimate beliefs, not of their way of adoring God, but where all citizens have the same rights, on the condition that they fulfil the same obligations. The consequence of this principle is that, on the one hand, the Jews, like the Catholics, the Protestants, the Muslims, and the freethinkers, can partake within a civilised State, without any restriction, of all civil and political rights; and that, on the other hand, the Jews, after they have ceased to be treated as pariahs, must identify themselves, in heart and in fact, with the nations which have accepted them, renounce the practices, the aspirations, the peculiarities of costume or language which would tend to isolate them from their fellow citizens, in a word cease to be a dispersed nation, and henceforth consider themselves only a religious denomination... The emancipation and assimilation of the Israelites remains an ideal, realised by three-quarters in certain parts, by half in others, and which elsewhere still remains a faraway utopia (in part quoted in Marrus 1971: 92, in part my own translation). ${ }^{3}$ 
Reinach's view reflects a great trust in Emancipation when he writes of those modern nations which have accepted the Jews and which first treated them as pariahs. The crucial point in his understanding of the meaning of emancipation for Judaism is that he thinks that, in return for their participation as citizens, Judaism can and should be transformed from a 'dispersed nation' into 'a religious denomination'. This is what he understands by assimilation.

Following this interpretation, assimilation does not imply the rejection of religious particularity, or, in today's terminology, of religious difference. Reinach envisions the possibility of Judaism as a particular religious denomination which has shed its non-religious, what he calls 'national' traces, especially the earlier (customary) legal, visual and linguistic dimensions of Judaism. In earlier Enlightenment thought, it was often suggested that Judaism, Catholicism and Protestantism represent different stages in development toward a universal religion which, in the end, would imply discovery of universal moral laws. Spinoza, among others, argued that Judaism was a more ritualistic, 'exterior' religion than the more universalist (Protestant) Christianity, and therefore less proximate to natural religion, a view which was inherited by Kant (and criticised by Mendelssohn 1989).

Reinach's idea that Judaism can subsist as an equally valid religious denomination next to others within the modern state departs from the older hierarchy between religions. Hence, from the point of view of earlier Enlightenment conceptions of the future of Judaism, Reinach's view represents progress in its more pluralistic interpretation of secularisation. However, his view of secularisation as assimilation does not depart from the idea that ethno-religious minorities have to shed particularising practices as much as possible and move toward their interiorisation and privatisation, this time however not in the name of a more universal religion or morality, but in the name of the jealous nation-state of which the Jews were the citizens.

Reinach's option is based on the assumption that we can separate a private religious domain, governed by a specifically Jewish ethico-religious concept of the Good, from a religiously neutral public domain. But what does this privacy entail? What precisely remains of a 'dispersed nation' when it becomes 'just' a religion? And what does it mean when we conceive of public traces of religion as 'national' traces?

Reinach's definition of assimilation requires full identification with the French nation-state at a public, civil level on the part of the Jews. To stop being a dispersed nation means to stop identifying in any way with a 'national' group other than the French. Such a transformation was indicated by the transformation from so-called 'Juifs' into 
'Israélites' in late 19th-century France: the latter word was reserved for assimilated Jews. For Reinach, assimilation thus implied that Jews should avoid any public sign of belonging to Judaism as a different group, because this would be associated with belonging to a different nation. He was thus carrying out the assignment by Clermont-Tonnerre discussed in Chapter 4, believing that if the Jews would do so properly, the French majority would then also fully trust and respect them as co-citizens.

Here, one senses a lack of mediating concepts that would have prevented the full conceptual overlap between the visible, the particular, and the national. It is the discursive function of concepts such as culture and ethnicity to provide a vocabulary for speaking of differences that can be mixtures of religious, linguistic and cultural practices, but that do not qualify as either religious (i.e., in this context, publicly invisible, or even fully interiorised) or as national.

\section{BENBASSA'S HISTORICAL ACCOUNT OF ASSIMILATION}

Let me now briefly compare Reinach's concept of assimilation to the findings of historical research into actual 19th-century French Judaism. Assimilation functioned, also in the 19th century, as a normative ideal, instead of representing a historical reality.

The French historian Esther Benbassa (2000) insists that the understanding of assimilation as privatisation of religion does not grasp what actually occurred in the 19th century. Assimilation in the sense of a 'fusion' and 'amalgamation' of the Jews with the French citizenry, which Reinach translates as the deculturalisation of Judaism and its transformation into a religious denomination, is a myth far removed from the reality of 19th-century France.

Instead of the privatisation of religion, what took place was an étatisation of religion; religion was brought under the control of the state and institutionalised (Benbassa 2000). Napoleon had institutionalised, or, as was the official term, 'recognised', four official religions (Catholicism, Calvinist Protestantism, Lutheran Protestantism and Judaism). For Judaism, in 1806-1807, he founded the Grand Sanhédrin, the first official Jewish Court after the Diaspora, which was later changed into the 'Consistoire'. In the 19th century, the legal and political recognition of Judaism was often interpreted by Jews and progressive gentiles with the same enthusiasm as the citizenship rights from 1791, but recognition went together with similar ambivalences. The Sanhédrin was subjected to similar mechanisms of surveillance and control as the earlier Jewish organisations, and Napoléon used the terminology of the regen- 
erators: 'it would be weak to chase the Jews away; it would be better to have the force to correct them' (quoted in Benbassa 2000: 140).

However, within the confines of recognition, Judaism officially developed into a respectable minority religion over the course of the 19th century. Jews were generally able to gain access to French society without having to renounce their religion. During the Second Empire, synagogues were built and members of the Jewish community could obtain high posts in French society while remaining religiously active. ${ }^{4}$

However, Benbassa (2003) argues that while Judaism was an officially recognised religion, this did not mean, in practice, the disappearance of all cultural or communal aspects of Judaism reminiscent of a Jewish people - that is to say of 'a collective culture and identity that surpasses the frame of rites and religious beliefs' (ibid.: 66, my translation).

This was partly because Jews themselves resisted this transformation. An indication of resistance to the full religionisation of Judaism was many Jews' insistence on referring to themselves as 'Juifs' instead of as 'Israélites'. Benbassa explains that in the word 'Jew' [Juif] the affiliation to a community and to the religious merge, but always within the French citizenry. This was the option more or less excluded by Reinach's conception of assimilation (Benbassa 2003: 67, my translation). A significant detail is that a Jewish hospital was founded in Paris during the Second Empire. Moreover, even though intermarriage was quite frequent in the small Parisian elite of which Proust formed a part, the large majority of Jews did not intermarry. ${ }^{5}$ Lastly, many French Jews expressed solidarity with Jewish immigrants in France and with those living in other European countries. Reinach himself wrote one of the first histories of Judaism in Europe. Even though he professed full assimilation, his work exudes a firm solidarity with the Jewish people in Europe, and he writes from the perspective of a strong concern with emerging nationalisms and anti-Semitism around the time of the Dreyfus Affair.

If we now return to the passage from Proust, we can deepen our understanding of the unintended discursive effects of expectations about assimilation, where societal and historical differences have not, in reality, faded.

We have seen that the narrator projects biblical origins onto the modern Jews in Balbec. Although the narrator perceives no cultural practices distinguishing the Jews from the others in any religious or traditional sense, the metaphors he produces 'fill in' this absence by, first, an association with religious origins and second, book knowledge about Eastern European ghettoised Jews. A reified image of the Balbec 
Jews as copies of the two stereotypical originals is inescapably linked to their modern appearance. Clearly, the presentation of the Jews as a group is a fantasy, one that exists independently of the actual communality of lower-class and less-assimilated Jews described by Benbassa, with which Bloch is familiar but the narrator is not. The passage therefore suggests that a reified, mythical image of Judaism tends to take the place of the cultural difference which the assimilants have been told to make invisible. The fact that the Jews of Balbec do not in any particular sense distinguish themselves from the other guests does not help them to overcome their isolation, since the absence of visible culturally distinctive practices only leads observers to fill in their inevitable idea of Jewishness with reified, mythical images of religious difference.

The metaphors used by the narrator suggest that Judaism as a visible culture is absent, but that this does not lead to the irrelevance of the Jewish background of the guests in Balbec. We do not know about each other's religious or cultural practices, but we do have stereotypical ideas about them. The replacement of the cultural memory of religious practice by these religious references explains how modern difference can turn into myth. The associations are only imaginary, but they do form part of an inescapable public culture that transmits intercultural and mythical images of religious and cultural difference.

This might lead us to add a further layer to the analysis of the paradoxes of assimilation beyond Benbassa's historical account. Even if assimilation had taken place to the extent that the Jews had secularised away the practical, differentiating and collective parts pertaining to their Judaism, the cultural memory of difference caused majorities to fill in their perception of how assimilated the Jews were with these cultural images; the absence of objectively distinguishing practices could even have stimulated that process.

One of the nice ways in which Proust deals with such reification of cultural memory, and the ensuing concepts of race and of national character, is by pushing mythical images to the ironic point of their total imbrication and mixture. For example, in one passage, Bloch refers to his Jewish background in his explanation of his own sentimentality, and the narrator reflects on what Bloch says:

'You cannot imagine my grief when I think of you', Bloch went on. 'Actually, I suppose it's a rather Jewish side of my nature coming out', he added ironically, contracting his pupils as though measuring out under the microscope an infinitesimal quantity of 'Jewish blood', as a French noble might (but never would) have said who among his exclusively Christian ancestry nevertheless numbered Samuel Bernard, or further back still, 
the Blessed Virgin from whom, it is said, the Lévy family claim descent (Proust 1996: II, 377; II, 108).

Let us now consider Arendt's (1979 [1948]) account of the construction of otherness through a reading of Proust's work in the context of the Dreyfus Affair. We will see that she was too indebted to Reinach's definition of assimilation to be able to trace the layered character of assimilation's paradoxes and the complexity of the historical context in which they emerged.

\subsection{Hannah Arendt reads Proust; from Judaism to Jewishness}

In The Origins of Totalitarianism, Arendt draws out the political consequences from Proust's presentation of the modern construction of difference. She posits that modernity itself produced Christian antiSemitism's transformation into racism. Following a similar definition of assimilation to Reinach's, and presenting Proust as her witness, she considers Judaism as a distinct collective life with socially objective distinguishing marks of affiliation, such as its adherence to a specific religion, language, law, and nationality, had been abolished at the time of the Dreyfus Affair, and that religion had been relegated to an ever smaller private, even subjective, realm. However, contrary to the idea that assimilation implies 'dejudaïsation', Arendt (1979 [1948]: 84) contends that assimilation's 'result was that [the Jews'] private lives, their decisions and sentiments, became the very centre of their "Jewishness"'. This resulted in the naturalisation of Judaism into Jewishness, implying its definition in terms of character, race and innate qualities. (Brown 2004 and 2006 gives a very similar account of this transformation, but surprisingly she does not quote Arendt.)

Among the supposed innate qualities of Jewishness, especially after the start of the Dreyfus Affair, was 'traitorousness' (Arendt 1979 [1948]: 86). Arendt thinks that it was from a fascination with 'vice' that high society began to be interested in the Jews; hence, the Jews were admitted to society not despite the fact that they were associated with Dreyfus, but precisely because of this. Arendt motivates this argument by using the example of Bloch's social ascendance at the time of the Dreyfus Affair.

While there was no longer any objective difference between Jews and gentiles, Proust demonstrated, in Arendt's view, that Jewishness had become a trait of a purely constructed, 'different' identity. She suggests that while equality was established in the political realm, dis- 
tinction became ever more important in the social realm once the bourgeois took over from the citoyen. Hence, she suggests that there existed an intricate link between political equality and citizenship on one hand, and the emergence of social inequality, expressed in naturalistic terms as a difference between races, on the other.

On the basis of my previous analysis of Proust's representation of the paradoxes of assimilation, I would suggest that certain aspects should be interpreted a little differently from Arendt. Her interpretation is overly dialectical, exaggerating the subjectivation of Judaism in Proust's work. Elements of self-construction, ascription, and a (dynamic) heritage of objective difference are all inextricably intertwined in the novel. This is precisely what analysing Proust's metaphors enables us to see. Also, Bloch's social ascendance does not occur because of a fascination with vice or, more particularly, traitorousness. The narrator provides a different, less awkward explanation. Bloch's ascendance (which, by the way, does not go very far in the beginning because he is teased and disrespected by many other characters) is possible only because he was from 'the lowest rung of the social ladder' and 'might go unnoticed' (Proust 1996: III, 214), whereas more wellknown, classy Jews such as Swann were gradually excluded from society as a result of the Dreyfus Affair.

Arendt takes the concept of assimilation as a historical instead of a normative one and therefore sees remaining aspects of Judaism only as pure constructions. Thinking that a Judaism with objectively distinctive cultural practices had vanished, she forgets, at the very least, the class differentiations. This does not mean, however, that her interpretation does not remain acute in its problematisation of the relation between Republican citizenship and the production of difference or group thinking. She rightly evokes the words of Saint-Loup, who complains about the enormous energies people put into forming 'a tribe, a religious order, a chapel' amidst the Republican context: 'The question is not, as for Hamlet, to be or not to be, but to belong or not to belong' (Proust 1932: II, 299; III, 410). ${ }^{6}$

With her analysis of Jewishness as a social construction effected by modernity, Arendt adds a layer of understanding which escapes the Republican Saint-Loup, namely that there is an intrinsic relation between political equality and social distinction. However, we should consider this relation not as the collapse of the citoyen into the bourgeois, of public equality into private distinction, but rather as a byproduct of the assimilationist Republican conception of citizenship itself. 
We can better understand this when we turn to the Dreyfus Affair as Proust explores it in the following passage. (We have to diverge a little from our three friends here and introduce some other characters.) The passage explains why the love of the Princesse de Guermantes for the Baron de Charlus puts into perspective the Dreyfusism of her very French husband, the Prince de Guermantes. At a certain point during the Affair, this Prince, an anti-Semite by principle, becomes convinced of Dreyfus' innocence. Because of the credibility of his standpoint - as a convinced anti-Semite and Christian French aristocrat with deep roots in French soil - his view is a threat to those persuaded of Dreyfus' guilt. However, what aids these anti-Dreyfusards is that the Prince's closest affiliates, namely his wife, the Princesse de Guermantes, and his cousin, the Baron de Charlus, both have a peculiarity. The Princesse comes from an aristocratic Bavarian background and the Baron is a homosexual, a practice he gradually, over the course of the novel, ceases to hide, but which is surrounded by taboos within the larger society. These particularities give rise to the suspicion that the two do not fully belong to the French nation but to separate groups or communities. The following quote gives us the opportunity to scrutinise the finer aspects of this suspicion:

And in spite of the fact that the Prince's Dreyfusism had not been prompted by his wife and had no connection with the Baron's sexual proclivities, the philosophical anti-Dreyfusard would conclude: 'there, you see! The Prince de Guermantes may be Dreyfusist in the best of good faith; but foreign influence may have been brought to bear on him by occult means. That's the most dangerous way. But let me give you a piece of advice. Whenever you come across a Dreyfusard, just scratch a bit. Not far underneath you'll find the ghetto, foreign blood, inversion or Wagneromania.' And cravenly the subject would be dropped, for it had to be admitted that the princess was a passionate Wagnerian (Proust 1996: IV, 623; III, 1390, my italics).

Scratching the surface is necessary with everyone who has a different opinion, for it will be caused by belonging to a different group, a nation, a clan. Such belonging is perceived as absolutely deterministic, but hidden: the Prince's belief imposes itself 'by occult means'. The delegitimisation of visibly different practices and backgrounds leads to the suspicion, on the part of anyone seeking to denounce a politically divergent opinion, that under so-called equal citizenship, something is being covered up instead of replaced, hidden instead of removed. In short, replacing difference with citizenship, rather than enabling the 
intertwinement of the two from the beginning, leads to a fascination with 'otherness' instead of its disappearance.

Assimilation as an assignment can never be fulfilled. Arendt explains the fact that Jews came to be associated with treacherousness as a result of the Dreyfus Affair and of a social fascination with the Jews, who were seen as a 'race of traitors' (see as well Carlston 2002). Yet the damage had to some degree been done before. It was not a strange social fascination for vice and distinction that led to exclusion and suspicion, but partly a side-effect of citoyenneté itself, because it stimulated an assimilationist focus on detecting and then destroying difference.

\section{3 'The Christians at the surface'; Zygmunt Bauman and the paradoxes of assimilation}

Bloch ... had to support, as on the floor of the ocean, the incalculable pressures imposed on him not only by the Christians at the surface but by all the intervening layers of Jewish castes superior to his own, each of them crushing with its contempt the one that was immediately beneath it (Proust 1996: II, 374; II, 103).

The assimilation-induced shame of one's own unreformed identity was displaced at the embarrassment felt at the sight of the close kin's otherness. Ever renewed embarrassment did not allow the shame to die out, but it deflected the most painful assimilatory pressures and indefinitely postponed the moment of truth (Bauman 1998: 326).

We have to add one more layer to our analysis of the paradoxes of assimilation. According to the above quotes, the always-impending possibility of the gesture of scratching led to a powerful internal dynamics among the assimilating Jews, who were pushed to differentiate themselves from those who were more easily distinguishable as 'others'. We can trace this mechanism through the narrative about our three friends in Balbec, making use of Bauman's analysis of the paradoxes of assimilation as it emerges at the intersection of class and (ascribed) ethnicity, while adding a gender perspective to his analysis.

Not long after our three friends meet on the beach and the narrator reflects on the Jews in Balbec, he comes up with the following explanation for the Jews' segregation: 
Bloch introduced his sisters, who, though he silenced their chatter with the utmost rudeness, screamed with laughter at the mildest sallies of this brother who was their blindly worshipped idol. Although it is probable that this set of people contained, like every other, perhaps more than any other, plenty of attractions, qualities and virtues, in order to experience these one would first have had to penetrate it. But it was not popular, it sensed this, and saw there the mark of an anti-Semitism to which it presented a bold front in a compact and closed phalanx into which, as it happened, no one dreamed of trying to force his way (Proust 1996: II, 368 ; II, 99)

This reflection sheds new light on the narrator's earlier observations. Again, Proust uses the technique of circular reasoning to represent assimilationist expectations. At first, the narrator admits that he does not know any members of the group as individuals, from personal experience. Then he retreats, adding a second cause for the group's homogeneity that is located in the outside world: Jewish homogeneity is a reaction to, and serves as a protection against, the anti-Semitism of the surroundings. The narrator's assimilationist mistake lies in the fact that he translates the Jews' experience of being excluded into the 'real' cause of their exclusion, which is that they are a closed group. Thus, he presents self-isolation on the part of the Jews themselves as the ultimate reason for their exclusion, instead of anti-Semitism.

Although Bloch presents his sisters to the protagonist, he immediately makes them shut up. From Bloch's action, the narrator makes a subtle transition to the general remark that 'this set of people' may have many virtues, but he doesn't know them. From there he goes on to explain that 'one' would not have wished to 'penetrate' or 'force one's way into the group' anyway. Hence, he suggests an interaction between, on the one hand, their self-isolation as a group, and on the other, aggression and penetration, suggesting that the only imaginable way to break the group's solidity would be sexual violence. We could interpret this as a reminder of certain not-so-pleasant, mythical roots of majorities' attitudes towards intermarriage. In any case, this helps to explain Bloch's possessive behaviour towards his sisters not just as a matter of group protection, but also as a reaction against aggression towards the group as a whole.

\section{DINING AT BLOCH'S}

At this point, not surprisingly, it emerges that Saint-Loup does wish to penetrate the group, and he and the protagonist accept an invitation 
to dine with Bloch's family. At the dinner we witness a mise en abyme of intra-cultural shame about the lingering traces of Jewish culture among Bloch's family members. While Saint-Loup and the protagonist discuss the people they know and the salons they frequent - a discussion during which, the narrator suggests, it is quite obvious to them that a Jewish family like Bloch's will not have been admitted to the highest circles - the two friends are highly aware of the family's Jewishness. The narrator partakes of this shame, portraying them condescendingly as yearning for recognition to the point of humiliating themselves.

All this occurs while some family members try not to identify themselves as Jewish. When Nissim Bernard says of the writer Bergotte that he makes one think of Schlemihl, the narrator traces the father's irritation about this remark to the fact that the epithet made one think of the 'half-German, half-Jewish dialect' (Proust 1996: II, 408). Although the father loves this way of talking 'in the family circle', he finds it 'vulgar and out of place in front of strangers' (ibid.).

The narrator suggests that while outsiders may perceive the Jews as a unified group, even as a family, within the group there exists an important hierarchy. It is important to notice here that this hierarchy is not determined by class alone. Those occupying the highest ranks have relatively deep roots in central France. It is the great-uncle who understands least of the combined assimilationist and class pressures and who falls victim to the disrespect of all. Bloch and his father are mainly judged by the narrator, who projects his judgement, partially, onto Saint-Loup. The latter is considered, on the one hand, to be afraid of underestimating his 'adversary' (the Bloch family) and, on the other, to be all the more fascinated by Nissim Bernard as the great-uncle demonstrates his obsessive social falsifications (Proust 1988: II, 134).

Yet why does this internal hierarchy become so prominent; even more prominent, perhaps, than the general hierarchy between classes? Bauman offers the following explanation. He interprets the rise of modern anti-Semitism in line with Arendt's reading of Proust, insofar as he, too, suggests that the overcoming of the religious and national boundaries between Jews and gentiles in post-Revolutionary France did not lead to actual assimilation, but rather to the development of new principles of segregation, with the introduction of the category of race as its most exclusionary form. Bauman, in contrast with Arendt, ascribes this dynamics to the more general social-anthropological process accompanying the modern project of the nation-state, which led to boundaries being drawn and blurred, as well as to the specific forms 
these processes took in relation to Jewish assimilation in European countries.

For Bauman (1988: 65), then, the strategy of assimilation in the sense of 'individual adaptation to the social order' was a failure not because the idea of amalgamation itself was flawed, but because the strategy resulted in different outcomes from the ones promised. While those individuals who had embarked upon the path of assimilation and who had shed most references to Judaic religion and culture, especially the use of Yiddish, did not expect to remain different in the eyes of members of the majority, they discovered that this was indeed the case in many respects. The very possibility of social mobility resulted not in being welcomed and blending in, but was instead perceived, at least by some, as a 'Judaification' of specific social fields such as science, high culture, and the free professions. It was cause for resentment? This resulted in a society where a principle of segregation remained intact, even though full acculturation had taken place. Political and legal emancipation led to 'a semi-neutral society... where the inferior status of the Jews was ignored by conscious effort rather than eliminated by actual equality' (Katz 1972: 201, quoted in Bauman 1988: 55).

Hence, once the Jews had done everything on their side to level the boundaries, they discovered that new ones had been drawn by the members of majorities, precisely as a result of the fact that the old ones had been blurred. This meant that the 'rules' of the game established at the outset of the emancipation process were being changed by members of the majority while the game was still going on, resulting in an exclusion that was no longer based on objective criteria but on subjective, purely differentiating ones. This is why Bauman (1988: 56) argues that 'without control over the rules, it was impossible to win'.

The continuing rejection of the Jews by the majority led to a mechanism producing an internal hierarchy and control. The elusiveness of the goal of being accepted as 'one of us' by the members of the majority was usually not thought to result from the impossibility of individual adaptation to a set of rules imposed and reinterpreted by a majority. This insight was kept at bay by the idea that the fault lay with those less assimilated. For this reason, the pressures on individuals to assimilate to the conditions of the majority - which were impossible to satisfy led minority elites to insist that their less assimilated members would adapt and leave behind the remainders of their distinctiveness. Often, this caused hierarchical distinctions to be drawn between those persons of Jewish descent who had been born in countries where they had already acquired citizenship rights, and those migrants, usually from 
the East, who had been living in more rigidly separated religious communities.

This mechanism had been in place since shortly after emancipation. In 1841, Michel Berr wrote that 'what must be obtained for the Jewish population is assimilation, the complete fusion of this population into the bosom of the population of the country' (Report of the Société de Metz, Archives Israélites de France 2 1841: 240, quoted in Berkovitz 1989: 110). Berr, who was a prominent Jewish leader from Nancy, writes this in the context of his refusal to accept that only a few Jewish persons, namely members of the elite, had integrated into French society. However, he does not argue primarily for a greater openness on the part of French society, but wants the Jews themselves to change. He writes that all the 'customs' and 'traces of the deep separation' from the past of the Jewish proletariat should be rejected, so that the 'class apart' made up by the Jewish proletariat will cease to exist. Berr internalises the view of the Jews originally coined by the Enlightenment thinkers who turned the Jews into a standard imaginary object of their emancipatory discourse. Another aspect of Berr's thought makes clear that a division among Jews existed. He does not write about the Jews in general, as had been done so extensively at the time of the Revolution, but already makes the distinction between the 'integrated' Jews from the elite and the proletarian class which should still combat the traces of separation, their alienation and 'repulsions'. Translated into today's terminology, we might say that Berr conceives of part of the Jewish population as an 'ethnic underclass' to which he himself does not belong. He goes along, albeit in careful and sympathetic terms, with the idea that there is an inherent link between the Jews' problems as a class and the fact that their ethnic background is different; consequently, their problems as members of a class are not addressed in those terms, but in terms of their ethnicity. It is a similar ethnicisation of social inequality that Noiriel and other contemporary socio-historians want to avoid, but they still implicitly follow Grégoire's line when they suggest that adaptation to the majority's habitus is a necessary requirement for a struggle on the right terms, namely those of social inequality. Consider a final quote:

The host majority is extremely difficult to satisfy. It would be quick to point out that the ostensibly assimilated citizen of Jewish origin wears a mask too thin to be trusted; that, when scratched, the mask readily reveals the unprepossessing likeness of the uncivilised being the assimilants swore to have left behind. By far the most expedient way to divert 
the hosts' suspicions was to compete in casting aspersions on one's own discredited past (Bauman 1988: 57; my italics).

Here we see the return of the gesture of scratching. The relation between, on the one hand, the majority's distrust and low esteem of Jewish identity lurking beneath the official equality of citizenship, and, on the other, the internal pressures to assimilate as quickly as possible, becomes clearer. When the majority retains the assumption that people have to assimilate before being worthy of respect, equality and their own associations, and when it continues to associate a minority's religious and cultural practices with a lack of integration, then the process of assimilation will always lead to hierarchies and disrespect, first of all between majorities and minorities and second, within minorities themselves.

It does not seem likely that a moral theory of multicultural recognition would be able to remedy any of the deeply anchored structures of assimilation laid bare here. At best, it can morally delegitimise them, but at worst, it hides them from view (see also Markell 2003). What we need is a thorough revision of the major conceptual and imaginary schemes concerning citizenship underlying assimilationist expectations. We can call that, as Alexander (2006) does, a multiculturalism as a project of hope, focused on minorities' equal access to the rules of the game with majorities. ${ }^{8}$

\section{4 'A consubstantial malaise of republican society'}

I will now focus on Proust's specific ways of deploying metaphor to scrutinise the cultural, public memory of hierarchy and its effects on political judgement. For this, I concentrate on the relation between the protagonist and Saint-Loup and study how the metaphors that shape their relation dislocate the old class hierarchies between the bourgeoisie and the nobility. Bloch, however, also reappears, and it turns out that he and his Dreyfusard Jewish friends play important roles in the Republic's social transformations.

The literary historian Rosen (1995) has argued that the Proustian salons were the places where the meanings of the social relations between nobility and bourgeoisie, and therefore between Catholic and Republican elites, were renegotiated. In the decades between 1870 and 1918, the salons were dedicated to maintaining the nobility's inherited social distinction. But in actuality they turned out to be places where everyone could change positions; where bourgeois women could turn 
into princesses, as happens to the, initially, very bourgeois Mme Verdurin, who, at the end of Proust's long novel, turns into the 'Princesse de Guermantes'. By studying the social mechanisms of salon culture, Proust is said to have uncovered the mechanisms of snobbery (i.e., the logic of social distinction):

[S]nobbery screens and masks a consubstantial malaise of republican society, that of the difficulties it experiences in accommodating itself to a past which it renounces and worships at the same time. In the republican ideology with a vocation to democracy, there is no room for a hierarchical phantasm inherited precisely from the Ancien Régime (Rosen 1995: 79 , my translation).

We have already seen that metaphor is an important literary device for Proust to uncover cultural memories in diverse shapes. Now, I will try to show how Proust can make us aware that not only 'the nobilities live by their memory' (Bloch, quoted in Brelot 1994: 347), but that this memory is also shared by others and that it causes an afterlife for power in the cultural imagination. Here again we will see that the metaphors are not quite as egalitarian and without vectorisation as Barthes suggests in the introduction to this chapter.

\section{Being Republican hypothetically}

The passage I want to discuss starts with the sudden appearance of Saint-Loup in the protagonist's room, some time after the episode in Balbec. He invites the protagonist to dine in a café where he often goes, and the protagonist accepts. We have seen that the protagonist greatly admires Saint-Loup, and the naiveté of his admiration is confirmed by the following anecdote.

Françoise, the protagonist's family's servant, initially has some doubts about Saint-Loup because he is a Republican. She cannot understand this of an aristocrat who, in her eyes, should love rural Catholic France and be a Royalist like her (Proust 1996: II, 415). She only forgives Saint-Loup his Republicanism when she concludes from her observations of how brusquely he treats his coachman, that he is only hypothetically a Republican. To her, his behaviour proves that he scorns the people after all (as he should, in her mind).

However, when the protagonist reproaches him for his treatment of the coachman, Saint-Loup answers that getting angry with the coachman means treating him as an equal, whereas it would be to follow the detestable habits of the aristocracy to treat a servant with égards, while 
at the same time considering him as irreparably belonging to a different class. The protagonist takes Saint-Loup's argument seriously and connects his attitude of moral purity, which is linked to Saint-Loup's dismissal of his aristocratic status, precisely to his nobility: sometimes his 'mind distinguished in Saint-Loup a personality more generalised than his own, that of the "nobleman"" (ibid.: II, 365). In these moments, the protagonist discovers this 'pre-existent, this immemorial being, this aristocrat who was precisely what Robert aspired not to be' (ibid.).

In the passage to be discussed here, the narrator recounts the protagonist and Saint-Loup's journey to the café, as well as the dinner itself. The protagonist's perception of Saint-Loup, and the judgements he infers from it, differ greatly in each situation. The contrast between his judgements is expressed by the metaphors and comparisons employed: the protagonist compares Saint-Loup to contrasting comparants, and through these comparisons Saint-Loup appears in such different lights that he nearly undergoes a metamorphosis.

The protagonist and Saint-Loup travel to the café in a carriage. Because outside there looms a terrible fog, they are completely isolated for some time. Inside the carriage, the protagonist is confronted with an unexpected statement by Saint-Loup. The protagonist knows SaintLoup as an honest person who would never betray somebody or gossip, but all of a sudden Saint-Loup begins to talk about Bloch:

'You know,' Saint-Loup suddenly said to me, 'I told Bloch that you didn't like him all that much, that you found him rather vulgar at times. I'm like that, you see, I like clear-cut situations' ... I was astounded ... his face was seared, while he uttered these vulgar words, by a frightful sinuosity which I saw on it once or twice only in all the time I knew him, and which, beginning by running more or less down the middle of his face, when it came to his lips twisted them, gave them a hideous expression of baseness, almost of bestiality, quite transitory and no doubt inherited. There must have been at such moments ... a partial eclipse of his true self by the passage across it of the personality of some ancestor reflecting itself upon him (Proust 1996: III, 460-61; II, 693).

This passage establishes a radical opposition between Saint-Loup and the protagonist in several regards. At the very moment Saint-Loup states that his words about Bloch reveal him 'as he is', the protagonist has the impression that Saint-Loup's identity is being taken away from him. Saint-Loup's face is violently torn apart and a natural ancestor takes his place. 
Metaphor is the site of this contrast. It is important to note the difference between the 'clear-cut' aspect by which Saint-Loup identifies himself and the sinuosity, searing, and twisting of his face perceived by the protagonist. 'Clear-cut' is a particularly happy translation of the French, which is 'tranchées' (ibid.: II, 693). It recalls Descartes' 'jugements clairs et distincts'. By his own words, Saint-Loup identifies himself as a representative of Enlightened French rationalism, while the protagonist discerns the opposite in his face, namely that of raw and transitory forms. Extending this interpretation further, one might say that Saint-Loup identifies himself as a representative of modern French civilisation at the very moment the protagonist sees nature (or 'race', or 'nobility') shining through his manners. While Saint-Loup identifies himself as a descendant of modernity, the protagonist associates him with natural heredity and premodernity, just like it happened with the Jews in the passage discussed earlier. In what follows, the narrator plays on these divergent associations.

\section{STUCK IN A REVOLVING DOOR}

In the dinner episode itself, the protagonist's view of Saint-Loup is directed by that of the people surrounding him: the other guests, the proprietor of the café, and the servants. The narrator introduces their arrival at the café with a description of the habitual clientele, which is divided into two groups: the company of Bloch and his friends (Dreyfusard intellectuals, many of whom have a Jewish background) and a party of young noblemen who look down on Dreyfus and consider the Dreyfusards to be traitors. ${ }^{9}$

This introductory account of the separation between the two groups of visitors refers back to Saint-Loup's words about Bloch in the carriage, giving them an extra dimension that makes them exceed the vicissitudes of a relationship between three friends. By calling Bloch 'vulgar' and excluding him from the friendship between himself and the protagonist, Saint-Loup stresses a class division that probably contains not only economic and social aspects, but also an important political one: Saint-Loup sees himself as the representative of the Republic, but excludes the Dreyfusard Bloch. The importance of this judgement is stressed by the narrator, for he mirrors it immediately in his description of Saint-Loup's words, which he, too, calls 'vulgar'. In doing so, the narrator places Saint-Loup at the same level as Bloch, judging him by a criterion that was perhaps only conceivable in the enclosed private space of the carriage. 
Upon arriving at the public space of the café, the protagonist enters first, because Saint-Loup has to tell the driver of the carriage when he is to come back. While entering the café, the protagonist gets stuck in the revolving doors. The proprietor witnesses the protagonist's clumsiness, and this teaches him not only a personal but also a sociological fact about this 'stranger incapable of disengaging himself from the rotating sheets of glass' (Proust 1996: III, 463). This 'flagrant sign of ignorance' leads the proprietor of the café to frown as if he were an examiner who plans not to utter the formula 'dignus est entrare' (ibid.). The Pléiade edition informs us that this formula parodies university rituals. The reference places the protagonist's mistake in the context of needing to know how to behave in certain surroundings according to hierarchical and ritualised behavioural patterns.

On top of the protagonist's first demonstration that he does not belong to the habitual clientele of the café, he ends up taking a seat in 'the wrong room'. The café is divided into two parts: a big room and a smaller one. The smaller room is reserved for the aristocrats, and when the protagonist takes a seat there he is immediately removed by the proprietor to be seated in the big room, occupied by the Dreyfusards. To make matters worse, he is seated on a bench opposite 'the door reserved for the Hebrews which, since it did not revolve, opened and closed every other minute and kept me in a horrible draught' (ibid.: 464).

Still waiting for Saint-Loup, the protagonist feels humiliated and excluded from both groups. Between these groups, because they braved the fog, there reigned 'a familiarity from which I alone was excluded and which was not unlike the spirit that must have prevailed in Noah's Ark' (ibid.: 470). Then Saint-Loup arrives. He is an esteemed client and the proprietor caters to all his wishes. Saint-Loup saves the protagonist from further humiliation, and from catching a cold, by complaining about the protagonist's bad seat and about the open door. Saint-Loup furiously addresses the proprietor, who puts the blame for the open door on his staff: 'I am always telling them to keep it shut' (ibid.). The proprietor, of course, immediately starts to behave in an entirely different manner towards the protagonist.

Following this carnivalesque scene, the narrator recounts the protagonist's thoughts after Saint-Loup has saved him. He introduces this passage in this way: 'Meanwhile I looked at Robert, and my thoughts ran as follows' (ibid.: 471). By means of this introduction, the narrator draws the reader's attention to the object of the protagonist's gaze, Saint-Loup. The protagonist's thoughts, however, only arrive at his friend after taking a detour via the Dreyfusards. Rendering his 
thoughts at this moment, the narrator does not refer to the Dreyfus Affair itself, but writes that there were in this café 'plenty of foreigners, intellectuals' who excited laughter by 'their pretentious capes, their 1830 ties and by the clumsiness of their movements' (ibid.), a clumsiness which they even actively demonstrated in order to show that they did not care that they were being laughed at.

The narrator adds that these intellectuals were disliked, 'the Jews among them principally, the unassimilated Jews, that is to say, for with the other kind we are not concerned', by people 'who could not endure any oddity or eccentricity of appearance' (ibid.). He gives the example of his future girlfriend Albertine's dislike of Bloch. The narrator himself adds that, though 'their hairs were too long, their noses and eyes were too big, their gestures abrupt and theatrical' (ibid.: 472), they were men of real intellectual and moral worth and also of a profound sensibility. At this point, the reader may well ask whether the protagonist's clumsy entrée to the café also demonstrated his affiliation with Bloch.

The rest of the passage traces the interplay between the protagonist's perception of, and his thoughts about, cultural difference. The narrator goes on to compare the 'superficial religiosity' of Saint-Loup's mother and other aristocrats to the 'warmth of heart, the breadth of mind, and the sincerity' (ibid.: 472) of many Jewish parents he knows. Suddenly, by way of this social contrast, the narrator is back with Saint-Loup, this time in his thoughts. He contrasts Saint-Loup with his parents, ascribing to him 'the most charming openness of mind and heart' (ibid.). This time, however, this openness is not contrasted with physical appearance, as in the case of the Dreyfusards. Quite the contrary:

[W]henever these qualities are found in a man who is purely French, whether he belongs to the aristocracy or the people, they flower ... with a grace which the foreigner, however estimable he may be, does not present to us (Proust 1996: III, 472; I, 702).

Throughout the paragraph, the narrator continues to write in generalities, as if the thoughts he developed while looking at Saint-Loup represented general knowledge rather than being dependent on the situation. This shows that he follows a reasoning closely related to the deductive mode of reasoning about 'Jews' that Klug (2003) identified as the kernel of anti-Semitism (see Transit I in this volume). The quote below, with which the narrator concludes his argument, further develops this confusion between general judgement and specifically located perception: 
Of these intellectual and moral qualities others undoubtedly have their share, and, if we have first to overcome what repels us and what makes us smile, they remain no less precious. But it is all the same a pleasant thing, and one which is perhaps exclusively French, that what is fine in all equity of judgment, what is admirable to the mind and heart, should be first of all attractive to the eyes, pleasingly coloured, consummately chiselled, should express as well in substance as in form an inner perfection. I looked at Saint-Loup, and I said to myself that it is a thing to be glad of when there is no lack of physical grace to serve as vestibule to the graces within, and when the curves of the nostrils are as delicate and as perfectly designed as the wings of the little butterflies that hover over the field flowers round Combray; and that the true opus francigenum, the secret of which was not lost in the thirteenth century, and would not perish with our churches, consists not so much in the stone angels of SaintAndré des Champs as in the young sons of France, noble, bourgeois or peasant, whose faces are carved with that delicacy and boldness which have remained as traditional as on the famous porch, but are creative still (Proust 1996: III, 473; II, 702-703).

Here, in public, Saint-Loup's face appears more 'clear-cut' than it did in the carriage. The narrator suggests that it is 'perfectly designed'. This aesthetic judgement echoes the 'pleasingly coloured, consummately chiselled' of the previous sentence, which contains no details and appears to be suspended between a general reflection on 'Frenchness' and an aesthetic judgement of Saint-Loup.

This suspension is important for our understanding of cultural memory as a driving force of intercultural imagination. The sentence just recalled sums up the stream of thought about the differences between Jewish intellectuals and 'purely French' men. It is only after his general statements distinguishing the harmony between substance and form as an exclusively French quality, that the narrator writes, 'I looked at Saint-Loup, and I said to myself ....' With these words, the narrator leaves the general mode and suggests that he will now represent what he was thinking at that precise moment in reaction to what he actually saw of Saint-Loup. The foregrounding of the act of focalisation (I looked ... and ...) suggests the transition from general to specific. However, although the narrator writes that the protagonist looked at Saint-Loup, the protagonist repeats to himself what he had said in general terms before: that it is a beautiful thing when one's physical grace represents one's inner grace.

The final part of the sentence in the passage under discussion no longer refers exclusively to Saint-Loup. It includes all of France's young 
sons, whether noble, bourgeois or peasant. Saint-Loup is made to represent not only his own class, but France, or rather, the opus francigenum. A note in the Pléiade edition shows us the irony of Proust's use of this term. It was used in a nationalist 19th-century discussion on the origins of Gothic art, called opus francigenum, during the Middle Ages. It had first been claimed by German historians as German art, but in the course of the 19th century it was ascribed to France, as French historians claimed the Franks as France's ancestors. This irony is further reinforced by the evocation of the stone angels of St André des Champs. In Combray, in an elaborate description of these stone angels, the narrator states that they expressed the French nation as Françoise would see it: in a sentimental, slightly naïve way. The narrator recounts that Françoise would speak of Saint-Louis (King Louis $\mathrm{XI}$ ) as if she knew him personally, and adds that she did this especially to stress how much less 'righteous' the protagonist's bourgeois grandparents were than Saint-Louis (Proust 1996: I, 180). The protagonist's Saint-Loup is thus closely connected to Françoise's Saint-Louis.

Summarising, Saint-Loup, the inheritor, in his habitus, of the aristocracy and, in his explicit political stance, of the Revolution, reminds the narrator of Saint-Louis, who, ironically, was the zealous king who first forced the Jews to wear distinguishing marks on their clothing (see Benbassa 2000).

Saint-Loup has now come to represent France. However, it would be wrong to contend that the protagonist sees Saint-Loup as an allegory of France. The protagonist does not look at Saint-Loup first to then conclude that he resembles the image of France represented by the sculptures of St André des Champs. Rather, and conversely, this image of France seems to determine how Saint-Loup is seen by the protagonist. The textual play with general statements and suggestive, yet never clearly developed, perceptions, illustrates the subtle interplay, through metaphor, of perception and cultural memory. Cultural memory determines which associations come to the protagonist's mind in the moment he looks at Saint-Loup. Its importance is expressed by the screen of metaphors which these associations raise between him and Saint-Loup. This is how the Guermantes family works for the bourgeois 'thirst for distinction' which cannot be quenched by Republican ideology: 'fetishised, it resembles a screen on which the social imaginary projects itself' (Rosen 1995: 78, my translation).

The abundance of different images and metaphors suggests the need to revise the comparison of Saint-Loup to the fixed, long-lasting sculptures from the 13th century. The rest of the passage emphasises his fugacity by making his sculptural image move and by the acceler- 
ated speed with which comparisons between Saint-Loup and different images of fast movement replace each other. The narrator invokes, for example, a steeplechaser, an acrobat and a knight. Here, the narrator refers to heredity, as he did earlier in the carriage, but this time to fit Saint-Loup both into his image of the aristocracy and into his image of the morally autonomous modern individual:

[S] uch were the quintessentially aristocratic qualities that shone through the husk of this body ... and rendered the movements of that lightfooted course which Robert had pursued along the wall as intelligible and charming as those of horsemen on a marble frieze ... And I was well aware, too, that it was not merely a work of art that I was admiring in this young man unfolding along the wall the frieze of his flying course; ... [but also] a choice that can be made only in the loftiest places of the mind, with that sovereign liberty of which Robert's movements were the image and the symbol and in which perfect friendship is enshrined (Proust 1996: III, 478-479; II, 708).

With this development, Robert comes to represent the opposite of what he had represented in the carriage. He appears to have lost the natural heaviness of the sculpture, moving close to the self-description which had so shocked the protagonist: 'that's how I am, I like clear-cut situations'. Now the frieze is unfolded and the young man is flying, flattened like a movie star. Could the repetition of this image, which first forces Saint-Loup into a standstill by turning him into a marble frieze and then makes this frieze move and unfold, indicate the protagonist's awareness of the projected quality of this image of the Republican Saint-Loup?

In conclusion, Proust's metaphoric style can be read as a subtle critique of the divide between politics and society in the 'Two Frances' that had come into existence in the Third Republic. It provides a literary form for exploring the simultaneous increase of possibilities for social mobility and the lasting heritage of social distinction. Although the struggle for universal citizenship should have resulted in the irrelevance of race and class, it actually produced, for a long time, the contrary: a secrecy surrounding belonging and a semiotic social game of 'scratching the surface', on the basis of a semi-public memory of difference.

This exploration of semi-public cultural memory also teaches us that modernity may seek to overcome the divisions and privileges produced by the traditional links between religion and power, but that, to achieve this, it will have to deal with the heritage of this distribution of 
power more intensively than simply by driving it into a private sphere. Proust invented a literary way to subtly critique liberal or Republican conceptualisations of the divide between private and public. The dimension added by the novel is to show that not only the state or the attitudes of majorities, but also the concept of Republican citizenship itself causes problems, because it leads us to overlook the role of historically and culturally transmitted inequalities in those differences that we perceive as 'merely religious'. Let us now make the transition to considering secularism and laïcité in today's context. 

TRANSIT II

\title{
Laïcité and assimilation in the Third Republic and today
}

\begin{abstract}
My holistic strategy, characteristic of pragmatism ... is to reinterpret every ... dualism as a momentarily convenient blocking-out of regions along a spectrum, rather than as a recognition of an ontological, or methodological, or epistemological divide (Rorty 1991: 84).
\end{abstract}

Laïcité creates the religious by turning it into a separate category, which has to be isolated and circumscribed. It reinforces religious identities instead of letting them dissolve into more diversified practices and identities (Roy 2005: 167, my translation).

The struggles for recognition by minorities in the 1990s acquired a particular sensitivity in France, where the myth of Republican, universal and difference-blind citizenship was less corroded than in many other Western countries, a phenomenon that was also experienced by, for example, sexual and gender minorities, and that has delayed the introduction of postcolonial studies and multiculturalism in France (Nordmann \& Vidal 2004). Nordmann and Vidal aptly summarise the central problem:

All questioning of the universalism of the national/social, (post)colonial and heterosexist State, automatically incurs the accusation of communautarisme ... And yet, if there is communitarianism, wouldn't it rather be found on the part of the State? For it is true that the majoritarian character of this communitarianism enables it to ignore itself as such and to claim a universal status (ibid.: 7 , my translation). ${ }^{1}$

Around 1989, public intellectuals who called themselves neo-Republicans found the public assertiveness and the struggle for recognition especially problematic when religion was involved, and Islam in particular. We already saw that this singling out of religion from the philosophies of difference and multiculturalism also quickly emerged in other European countries partly as a result of the Rushdie Affair. But they did so most strongly in the context of the French headscarf affairs. 
The affairs more or less began with the question of whether three Muslim girls from Creil (a Parisian suburb) had been rightly expelled from school after they had refused to remove their headscarves in class. This question grew into a public conflict when in November 1989, five neo-Republican intellectuals placed an advert in Le Nouvel Observateur about the threat of the 'Republic's Munich moment' at the time of the 'bicentenaire' of the French Revolution, when the wearing of headscarves in public education was not forbidden by law. ${ }^{2}$ This was the beginning of a long series of debates which are still continuing, and which now include debates about many other practices, such as the building of mosques, the provision of halal meals in schools and, of course, the wearing of the burqa on French streets.

In the late summer of 2003 public debates about the veil focused on a case in which two daughters of a Jewish human rights lawyer, Alma and Lila, attended their school in Aubervilliers (a suburb of Paris) wearing veils and long dresses. President Chirac set up in September 2003 what became known as the Stasi Commission. This commission was contracted to write a report in which the idea of laïcité was to be reassessed and a definitive position on the headscarf question established. The commission was officially called the 'Commission for the reflection on the adaptation of the principle of laïcité in the Republic', but this was soon abbreviated to 'Stasi Commission' after the chair of the commission, the Christian-Democrat politician Bernard Stasi. In the report, published in December 2003, the commission redefined laïcité for contemporary France and advised prohibiting the wearing of 'signes religieux ostensibles' (conspicuous religious signs) in schools and while performing public functions. Well-known members of the commission were, among others, sociologist Alain Touraine, historian Jean Baubérot, migration expert Patrick Weil, philosophers Henri Pena-Ruiz and Régis Debray, lawyer Jacqueline Costa-Lascoux and Islam expert Gilles Kepel. The historian of laïcité Jean Baubérot was the only member of the Stasi Commission who abstained from voting in favour of a ban.

The law was enacted in 2004, and prohibited the wearing of conspicuous religious signs such as headscarves, kippahs and large crosses in public schools. In practice, this implied mainly the prohibition of headscarves, because orthodox Jews, for whom wearing a skullcap has the same status as a religious obligation, usually went to Jewish schools, whereas there were hardly any Islamic schools in France at the time of the adoption of the law (Tévanian 2004). By 2010, mothers wearing headscarves had also been declared unwelcome in public schools, and women wearing burqas (face veils) had been denied access 
to public space generally, having even been arrested and fined. Headscarf issues spread all over Europe, for teachers, for pupils, for public servants, and for mothers of pupils. (For an overview of Western European conflicts and debates, see Joppke 2009; Mathieu \& De Hert 2011 about France and Belgium, and Elver 2012 about Europe including Turkey.)

The 2004 law has been widely associated with laïcité as a specifically French version of secularism. However, laïcité is an essentially contested concept in France and it is as politicised as secularism is elsewhere. ${ }^{3}$ French political historian Pierre Rosanvallon (quoted in Bhargava 2009) captured the situation rather well in stating that laïcité had become the most cacaphonous term in French debates in the last two decades. Furthermore, there was much less consensus in France concerning the law on headscarves than the large parliamentary majority voting in favour of it might suggest. Well-known French intellectuals and scholars, such as Monique Canto-Sperber and Paul Ricoeur, Bruno Latour, Etienne Balibar, Jean-Luc Nancy, Pierre Tevanian, Cécile Laborde and Gérard Noiriel, opposed the law.

Despite Rosanvallon's complaints about the cacophony about laïcité, there are some clear lines in the debates. Many critics of the law argued against it in the name of a different, non-exclusive, more liberal laïcité: the dissenters interpreted the law as a sign of the restoration of a specific version of laïcité, close to the heritage of the Jacobin Republic. Some saw it, relatedly, as a relapse from a pacified, liberal laïcité into its precursor, the so-called laïcité de combat (e.g., Baubérot 2004a, 2010). ${ }^{4}$ International critics have explained the law as a digression from or misinterpretation of the defensible, perhaps even crucial principle of secularism or laïcité. For example, Joppke, whose liberal assimilationism was discussed in Chapter 3, opposed the law from the beginning. He still does so in Veil (2009) because he thinks it transgresses religious liberty rights, and simultaneously defends a liberal, rights-based understanding of laïcité (Joppke 2009: 48-49).

More generally, intransigent interpretations of laïcité have been criticised for being too ideologically liberal, in the sense of expecting a privatisation of religion to a degree that is blind to its practical limits, and overly distrustful of religion's necessarily public aspects (Modood 2005; Bader 2007). This too-abstract understanding of private-public relations becomes manifest, for example, in the many recent appeals to the law of 1905 instituting the strict separation of Church and State. Chapter 1 already mentioned that, in practice, abundant examples show the complex interrelations between Church and State, and between religion and state more generally (see further Bowen 2007b, 2010b). 
On the other hand, the French practices of religious governance that do exist have been criticised for not being liberal enough, as they are the legacies of a-liberal or pre-liberal policy traditions and intellectual motives - for example, Rousseauian civil religion (Laborde 2002; Baubérot 2010); the policy tradition of gallicanisme (support-andcontrol of religion) (Bowen 2007b); a combined 'ideological obsession with the religious' and 'a fascination for the monarchy' (Roy 2005: 63). The basic problem for all of these critics is the (neo-)Republican focus on civic unity and, basically, a deficiency in the recognition of the fact of moral and religious pluralism.

A current political philosophical interpretation argues that the problem with secularist civic unity lies in its implication of the idea that all citizens should subscribe to a 'secularist moral philosophy', and thus to a particular conception of the good. The interpretation that the moralising, or even theologising, state is the problem with French (and Turkish) secularism has been given by Maclure and Taylor (2011) and many others. An alternative liberal secularism, it is then suggested, will take a 'true position of neutrality' towards all conceptions of the good (ibid.: 14). In accordance with their critique of the moralising and theologising state, Maclure and Taylor (ibid.: 16) argue that what we need today is political laicisation without the idea that the state should try to play a role in social secularisation as well.

It is not entirely clear, however, how such proposals for a different, liberal laïcité are related to the observation raised in Chapter 1, which is that nearly all of the more detailed interpretations of the French context implicitly or explicitly contest the idea that the law on the headscarves more or less naturally follows from an institutional model of laïcité, or even that such a model exists. The only near consensus is that it is impossible to read the headscarf law as an implementation of a specific institutional framework. From here opinions start to diverge. American anthropologist Bowen (2005, 2007a) has stressed the many diverging governmental practices that actors themselves explain as in compliance with laïcité. Bowen (2007a: 249) argues, 'Muslims who demand the right to be visibly different defy older cultural notions of France, not the political and legal framework of the Republic'.

In what follows, I further scrutinise this cultural and discursive side of laicism and connect it to the genealogy of assimilationism traced in Chapters 4 and 5. I argue that notwithstanding the fact that there is no national institutional model of laïcité which could explain (or legitimise) the law on the headscarves, we can hardly underestimate the influence of what I would call a culture of laicism in France on interpretations of religion, of religious practices, and of Islamic ones in par- 
ticular. I will explain why I think that this particular cultural layer in laicism makes it questionable that a solution to the troubles with secularism would be to distinguish a liberal laïcité from a civic unity lä̈cité, as is suggested by many of authors who remain within the frame of rethinking secularism, such as Taylor and Maclure and also French authors like Jean Baubérot and Cécile Laborde, who want to revive the French Republican tradition of liberal or critical, in any case genuinely religiously neutral, laicism as opposed to the civic unity variant.

I argue instead that the laïcité-religion framework itself should be criticised. I suggest that underlying the public and philosophical discourses on lä̈cité and, more generally, on secular liberalism, is a range of semi-sociological, semi-normative conceptual dichotomies related to ideas of secularisation and assimilation which merit criticism for their unreflected modernist and assimilationist heritage. Although the argument will pass through an analysis of these discourses in France, I will try to make it plausible that these cultural and conceptual layers in laicism also form a relatively unquestioned discursive framework for debates about secularism, and religion more broadly, in contemporary political theory.

Let me introduce the contours of the argument. 'We have never been modern(s)', goes the famous dictum of Bruno Latour. But of course we have been modernists, and we have not sufficiently reflected on its heritage in our basic conceptual frameworks about citizenship and cultural and ethnic diversity. Let us briefly recall the way in which the historian Reinach (1901 [1884]) understood the process of Jewish assimilation. For him, assimilation implied a linear process in which the ethno-religious heritage of Judaism would be turned into a privatised religious denomination. He thought that in this process, all visible public traces distinguishing the Jews from the other French should be eliminated, because these traces might be interpreted as signs that the Jews belonged to another nation. This is what Arendt called the transformation of Judaism into Jewishness after Emancipation.

Reinach's brother Salomon envisaged the future of Franco-Judaism in a similar way, and one of his formulations is particularly significant for my argument in what follows. In 1900, in an article entitled, 'The interior emancipation of Judaism', which was mainly directed against Jewish orthodoxy, Salomon declared that ritualism was an increasing burden for Judaism in the modern world, leading to the Jews' isolation. 'The true religion', he wrote, was 'an affair of sentiment, not of practices' (Reinach 1901, quoted in Marrus 1971: 60). The fact that the brothers Reinach wrote about the necessity of shedding the national traits of Judaism in order to be accepted among the European nations, 
and at the same time trusted and endorsed the interpretation of secularisation as the privatisation, or even the interiorisation of religion, recalls the intimate historical link between assimilation and secularisation, between cultural homogenisation and the privatisation of religion in the France of the Third Republic. Public elements of religion were interpreted as remnant traces of ethnicity that should be eliminated. This was the case because the nation-state was a jealous state: all political energies and affects should be concentrated at the nation-state level, and they were not to be divided by the existence of attachments and loyalties to other groups. Suspected diasporic loyalties led to systematic distrust. The requirement placed upon the Jews was legitimised by the interpretation of citizenship as a fundamentally different level of human self-organisation from all others: while other levels were increasingly seen as the illegitimate assemblies of particularities, privileges, etc., nation-state membership (citizenship) was considered to represent the general, even universal, side of human selforganisation.

Today, the transformation of ethno-religious belonging into a modern, individualised, fully private or even invisible belief is no longer seen as a standard condition for, or as a desirable result of, incorporation. Normative standpoints on ethno-religious diversity have nuanced the conflation of the concepts of nationality, visibility, publicity and practice that we discerned in the views of Théodore and Salomon Reinach. Even if these concepts sometimes overlap in contemporary debates, it is no longer common to suggest that the public visibility of certain religious practices can be immediately associated with a different nationality - or with nationalism, separatism or transnational loyalties. Nor will attachments to ethnic or religious groups automatically be associated with treason or double loyalties, although this has become less evident for Muslims in today's Europe (see Cesari 2010). Even today however, after at least ten years of integrationist discourse, we can still say that there is a rather larger acceptance of multiple cultural identifications or loyalties in multicultural polities. The interpretations of cultural practices have diversified and are less immediately inserted into the scheme of a homogeneous nation in which we are either insiders (as citizens) or outsiders.

On the other hand, although full assimilation is no longer the projected end-goal of processes of incorporation, the direction of our expectations surrounding secularisation tends to be assimilationist. Specifically with regard to religion, we tend to interpret modern religion, adapted to secularism, as personal, individual belief or experience, and traditional, orthodox or publicly visible religious practices 
as either the relics of premodernity, or as the 'conspicuous signs' of postmodern identity politics, but in any case, as being on a tense footing within a modern framework. In the 19th century, as I tried to show in Chapters 4 and 5, assimilationist expectations, such as those of the Reinach brothers, led especially to difficulties because of the inconsistency and paradoxy of assimilationism on an everyday, experiential and discursive level.

Some authors have suggested that these inconsistencies had at least partly been solved by the introduction of the doctrine of lä̈cité in 1905. In that year, the Napoleonic institutionalisation and official recognition of Judaism by the state was abolished together with that of the other three recognised religions as a result of the introduction of the state's official laïcité (Baubérot 200o). However, in the above we have already seen that many authors have referred to the complex interrelation between the institutionalisation and governance of religion on the one hand and the doctrine of laïcité on the other. Authors such as John Bowen and Esther Benbassa argue that the tradition of religious recognition has not entirely been superseded by the later tradition of separation of Church and State, but rather has been intermingled with it. This has especially been so in the colonial context, and in the context of Muslim postcolonial presence in France (Achi 2004; Bowen 2007a; Maussen 2008).

Benbassa (2000: 12,194) argues that we should interpret the process of incorporating the French Jews after emancipation as not particularly distinct from contemporary integration. This leads her to argue that we should no longer call this process assimilation. ${ }^{5}$ Contrary to this last proposal, I suggest that contemporary concepts and policies of integration, especially those that are defended in terms of secularism, are reminiscent of assimilation, but assimilation understood specifically as the normative expectation that all or most cultural, visible aspects of religion will disappear, while this cannot be the case in the social and political reality.

In our analysis of Marcel Proust's In Search of Lost Time, we traced the role of the doctrine of assimilation itself in perpetuating and transforming the category of Jewishness, as it changed from an objective difference to a complicated form of difference where objective and subjective, historical and discursive elements played their intertwined roles. The following chapters explore how the dichotomising discursive framework connected to assimilation continues to give direction to secularist expectations with regard to ethno-religious groups, at least partly independently from the question of whether we are dealing with 'combatant' or more liberal definitions and defences of laïcité. For that 
reason, I will comment on the unreflected heritage of the 19th-century dichotomous, abstract conceptual frames in current public and academic discourses about the relationship between religion and culture. And I also comment on the related dichotomies between private and public, sentiment and practice, modernity and tradition, modern religion and orthodox religion. In discourses concerning secularism, the dichotomous relationship between these conceptual pairs keeps being taken for granted (to different degrees). I take up the challenge of looking for mediations, for possibilities to reconcile or deconstruct them, to see their entanglement, and to achieve insight into the possibilities of their permeation. 


\title{
CHAPTER 6
}

\section{Elements of a critique of the laïcité-religion framework}

\begin{abstract}
And you think that the 'Écoles libres' teach their pupils to detest the freemasons and the Jews ... It is true that, for some years now, in the world that comes out of these schools one no longer receives Jews, which does not matter to us in itself, but which signals that dangerous mentality from which the Affair, etc. grew. But I tell you that in Illiers, the small community where my father presided over the distribution of prizes the day before yesterday, one has not invited the priest to the distribution of prizes since the laws of Ferry came into effect. They habituate the pupils to consider those who visit the priest as people that they should avoid, and in this respect, just like those on the opposite side, we are working to create two Frances ... The Christian spirit will not be destroyed if we close the Christian schools, and if it is inclined to die ... it will do so even under theocratic rule (Proust 1903: Correspondance III, 382, 386, my translation). ${ }^{1}$
\end{abstract}

In brief, this world is 'secular' not because scientific knowledge has replaced religious belief (that is, because the 'real' has at last become apparent) but because, on the contrary, it must be lived in uncertainly, without fixed moorings even for the believer, a world in which the real and the imaginary mirror each other (Asad 2003: 64-65).

\subsection{Towards a genealogy of the laïcité-religion framework}

This chapter traces the historical particularity of the laïcité-religion framework to its intellectual, political and cultural backgrounds in the early French Third Republic (1870-1914). This is the same period of time that formed the background to the Dreyfus Affair. I concentrate on the occurrence of several neo-Kantian and modernist schemes in French political culture in the early Third Republic. I analyse four political cartoons from the time of the installation of the separation between Church and State in 1905 and further scrutinise the ways in which the relation between modernity, secularity and religion appears in the work of neo-Kantian scholars and politicians such as Charles Renouvier, Ferdinand Buisson and Émile Durkheim, who were dealing with 
religion and education around the time of the introduction of laïcité as a principle of the French state.

As a second step, I specify how the political neo-Kantianism that formed the intellectual background to laicism still plays a role today in the specific form that cultural laicism takes. I then argue that this should lead us to a problematisation of the laïcité-religion framework as a whole, instead of concentrating on defining a 'better' laicism, as political philosophers have tended to do. To argue this point I first address the debate Kant himself had with Mendelssohn about religion's future during and after the Enlightenment, and how the legacy of Kantianism has become dominant in the European, and specifically in the French, context. I then take a further step by connecting this argument to Asad's genealogies of both secularism and religion, in which Asad problematises the basic notions assumed in the laïcitéreligion framework. I argue, however, that today's current use of the laïcité-religion framework as a whole needs to be even more contextualised than in Asad's reading. This helps us to understand the increasing references made to public order in the context of Islam in France.

\subsection{Laïcité and neo-Kantian liberalism}

Laïcite is a legacy of the struggle by the French Republic to gain political independence from the Catholic Church, a struggle which had already begun during the Revolution, but which was only definitively decided in 1905 when a Republican law institutionalised the separation of Church and State. This law had been prepared by Republicans from the time of the installation of the Third Republic in 1870, after the defeat of France in the Franco-Prussian War. In 1870 the Second Empire was replaced by the Third Republic, which was faced with a defeated and extremely divided country, not only because of the war, but also because of the ongoing struggle between 'les deux France'. The first France was the pre-revolutionary 'eldest daughter' of the Catholic Church. After the Revolution, it was claimed (and constructed) by traditionalists and counter-revolutionaries as the real, authentic France: the romantic Catholic 'tradition' that would have been passed on to new generations had it not been so rudely destroyed by the Revolution (Birnbaum 1998). The other France was the post-Revolutionary 'État-nation', the political nation founded during the Revolution. As the negative of the first France, which received its rulers from God (the king) and, most frustratingly, partly from Rome (the Jesuits dominating education), modern France constructed itself as an autonomous 
self-constituting political nation. The use of 'nation' in this context differs significantly from the internationally most common use, in which nation and ethnic origin are closely linked. In France, the political nation has famously been understood by Ernest Renan as the result of a 'daily plebiscite', which makes it the opposite of 'ethnic' origin, and connects it to the concept of the demos in political thought. Both concepts of the nation have their own nationalisms however, and they are not unconnected.

Laïcité is not a fully positivist French Enlightenment concept aimed against religion in general, as public opinion sometimes has it. Instead, it guarantees the freedom of every individual to have a religion or to not have one, to change this religion, or to have a different religion from everyone else. The 9 December 1905 law separating State and Church, which forms the basis for the centrality of laïcité in French society, has two central articles:

1 'The Republic ensures the freedom of conscience. It guarantees the free exercise of religions with some reservations owing to the safeguard of "public order".'

2 'The Republic does neither recognise, nor pay nor subsidise any religion' (quoted in Baubérot 1998: 117).

In its original juridical formulation, the State does not support any religion - either financially or as far as content is concerned. Yet at the same time laïcité is explicitly concerned with defining religious freedom. In this respect, it is quite different from Jacobinic Republicanism, where universal citizenship was supposed to replace, or at least supersede, particular religious attachments altogether. Laïcité, instead, requires the fundamental separation of Church and State and the explicit assignment of a proper domain to both. It only opposes religion in as far as it is identified as a producer of law, not in as far as it is a source of morality, belief and meaningful experiences. Therefore, institutionally, laïcité is a liberal variety of secularism: religion is not recognised but the freedom of conscience and the free exercise of religious practice are guaranteed (see also, e.g., Weil 2009; Baubérot 2010).

To a certain degree, laïcité contrasts with forms of secularism that take the concept of tolerance as the central one to deal with diversity. These forms occurred in those countries where the divides between various Protestant denominations and Catholicism had already produced a division of political power in early modernity. This division had already partly dethroned the Catholic Church in the only hesitatingly Enlightening Europe of before the French Revolution. This 
process had produced various national churches in distinction from a monistic Catholicism. In the Protestant countries, therefore, it was easier to produce a division of power without radically separating the religious domain from the worldly domain. This meant that the religions of minorities could be more easily tolerated within the public sphere (Gauchet 1998). ${ }^{2}$ Yet even in France, as we already saw in earlier chapters, contemporary political practices, like those in other Western countries, create ample space for religious pluralism, as well as encouraging the exercise of religious freedom. As in other Western countries, the French state does finance private religious schools and religious associations. This not only implies religion's accommodation within the public sphere, but also, more strongly, its centralisation and at least partial control by the state. French practice is therefore closely related to what Modood (2005) has called 'moderate secularism', intent on institutional compromises and pluralistic institutional integration. This is so precisely because it does not fully realise the idea of laïcité. ${ }^{3}$

The common understanding of laïcité in French political culture, however, is closer to what Modood (ibid.) calls the 'ideological' concept of secularism. In contrast with a more moderate version, such secularism focuses on a strict private-public divide. Ideological secularism neglects the many ways in which religion is a public, collective practice, and not just private 'opinion' or a matter of individual conscience. While laïcité in its juridical form is explicitly concerned with freedom of conscience and the separation of religion and politics, and it does not aim at a competition between religious (or other group) affiliations and citizenship, at the level of political culture a competition between citizenship as 'universal' membership of the nation-state and the community of (enlightened) 'reason', as opposed to all kinds of particularisms, still determines some of the expectations with regard to persons with a different ethnic or religious background (Laborde 2008).

This cultural layer in laïcité as a public discourse concerns civic unity and is closely related to concepts of integration or assimilation. Citizenship implies the priority of membership of the state over all other kinds of attachment to specific groups. This gives an extra dimension to laïcité, which persists in its contemporary understandings where the concern is not so much the freedom of conscience and the disestablishment of religion, but rather a 'communitarian concern for civic unity', which tends to try to 'substitute democratic civic loyalty for religious and traditional allegiances' (Laborde 2002: 170-71). Depending on the amount of sympathy for the competition between citizenship and other, ethnic or religious attachments, this older cultural layer in 
discourses concerning secularism is either called Jacobin, 'combatant' or just (neo-)Republican (see Transit II).

Through the focus on civic unity, discourses about laïcité had much to do with the Republican tradition of assimilating 'peasants into Frenchmen' (see Bowen 2004, 2010a). Assimilation, as we saw in Chapter 1 , is crucially connected to national education. To establish unity during the struggle between les deux France, Republicans needed to develop a moral doctrine that could replace, or at least complement, Catholic morality and that would spread the ideal of secular citizenship across the country. Schooling had been discussed from the Revolution onwards, most famously by Condorcet. In the Third Republic, however, it became one of the focal points of government (Baubérot 200o). Due in particular to the introduction of the suffrage universel, for men only, in 1848, public schooling became crucial to Republicans for preventing the people from voting for an authoritarian (Catholic) regime. As the famous Republican Buisson, one of the great proponents of public education, aptly stated in 1899:

Two conditions must be fulfilled to help a Republic on its feet; one is easy: you have to provide it with a republican constitution; the other is difficult: you have to provide it with a people of republicans (Buisson 1899: 30 , my translation). ${ }^{4}$

Buisson made clear that the Republic required more than merely a legally and politically defined secularity; it needed a pedagogy to institutionalise a culture of Republicanism. Public, secular education was the most central institution called upon to help create the required 'people of Republicans'. Most of the laws, passed in preparation for the law of 1905, concerned education (Baubérot 1998: 116).

The modern conception of citizenship adopted by the Republicans squarely opposed the heritage of the absolute monarchy and especially the moral and political authority of the Catholic Church, which had become strongly politicised in the course of the 19th century. Rejections of Catholicism's political pretences were formulated in terms of the need for pedagogies that could create citizens capable of critical (rational) judgement and not submitting to 'a priesterly and absolutist' religion, as neo-Kantian philosopher Renouvier (1896: 142) put it. Renouvier (ibid.) argued that laïque morality should explicitly aim to 'take minds away from superstitious beliefs'.

For Taylor and Maclure, Renouvier formulated the kernel of a laïcité transgressing the boundaries of liberal neutrality, as he was advocating a 'morality independent of all religion', which was to take 
'moral supremacy' over all religions, and which was to be founded on a 'rational theology' akin to Kantian moral philosophy (Renouvier quoted in Maclure \& Taylor 2011: 15). Similarly, Laborde (2002: 172) explains Renouvier's view as follows: 'Under the influence of Enlightenment critical rationalism and 19th-century positivism, many Republicans believed that a secular, critically orientated life was more valuable than a religious and conformist one.'

By this interpretation, Laborde, Taylor and Maclure give a philosophical explanation of Renouvier's view in terms of his secularist juxtaposition of religiosity and conformism, contrasting it with a 'secular, critically orientated life'. Historian Gauchet (1998) gives a more political and contextualised reading of Renouvier's neo-Kantianism. He emphasises the importance of the context of the struggle against an intransigent and politicised, reactionary Catholicism in which Renouvier and other Republicans had to operate. Gauchet argues that a rhetoric of moral truth-claiming against the dominant religion on the Republican side was inevitable, especially during the Dreyfus Affair and we also saw, in Chapters 4 and 5, that 'truth', 'science' and political courage were related in Proust's account of the Affair.

This led Gauchet (ibid.: 69) to put his finger on a specificity of the French-Catholic case, when arguing that while secularism, for example, in the United States or in the Northern countries, was more about state neutrality towards several confessions (or denominations) without turning against religion in general, in France the conflict turned into one between secularism and religion in general. This gave an extra dimension to laïcité, which persists in its contemporary understandings and links it to a general discourse about the advent of a modernity where religion, which in that context meant the Church, has been politically neutralised.

This historical context is a reason why we do not want merely to propose one model of secularism instead of another, but wish to revise the underlying conceptual and cultural framework related to secularity more generally as well. Four political drawings from the time of the separation law help to clarify the relevance of this historical context.

The first drawing is a didactical one, made, perhaps not incidentally, in 1905 (see figure 1). In Fournigault's drawing, we see 'once upon a time' (autrefois) opposed to 'today' (aujourd'hui). Parallel to this, preRevolutionary Catholic icons such as the castle, serfdom and the commune or the village as a precursor to 'community' is opposed to the Republican institutions of school and the vote, which stand for modern 'society'. The transition from the premodern 'once' to modernity's 'today' takes place through the teaching of The Declaration of the 


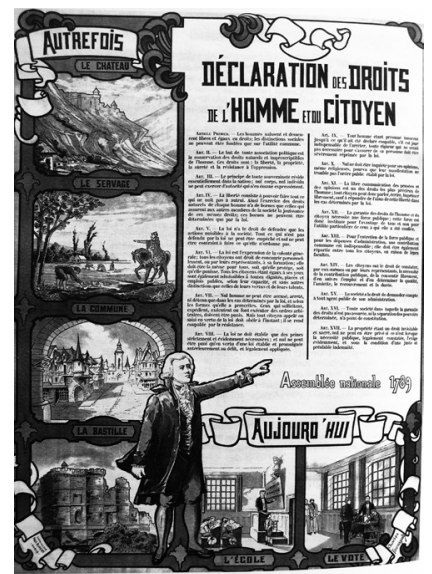

Figure 1 "La déclaration des droits de l'homme et du citoyen' ['The Declaration of the Rights of Man and the Citizen']. Affiche de Charles Fournigault, 1905.

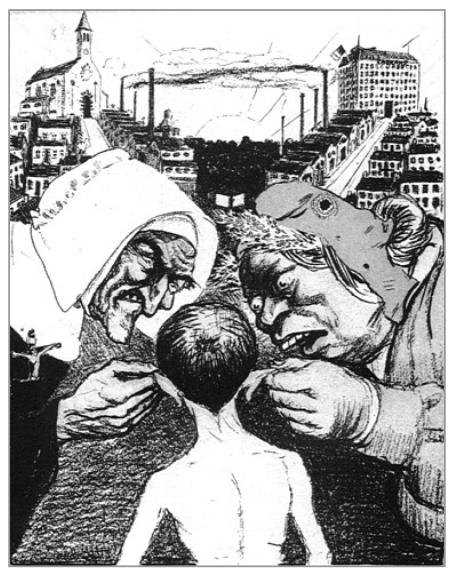

Figure 2 'Choisis, tu es libre' ['Choose, you're free']. Drawing by Auguste Roubille for a special issue of the anarcho-syndicalist magazine L'Assiette au Beurre, on the freedom of education, 1904 .

Rights of Man and the Citizen. Note the strong symbolic opposition between religious belonging and citizenship. Public school is presented as a crucial institution for the transition from a 'natural' provincial situation of communal social hierarchy to a 'civilised' urban democracy made emblematic, for example, by the orderly partitioned windows. These windows act as mediators of a modern, mathematical view of the natural world 'outside'. If we push the interpretation a little, they function as symbols for the equality and (moral) freedom of all individual citizens.

The cartoons reproduced here could be read as ironic answers to the didactic efforts of those such as Fournigault. These cartoons, drawn by the famous political cartoonists Roubille, Jossot and Grandjouan, were published in the critical, anarcho-syndicalist magazine L'Assiette au beurre (see figures 2, 3 and 4). 'Choose, you're free' suggests that the transition from premodern to modern times also meant, for some, the replacement of one unitary moral system for another.

Roubille's cartoon shows the struggle between Church and State as a struggle about the centre of pedagogical power. It deconstructs the opposition between Catholic belonging and traditionalism on one hand, and the freedom associated with modern citizenship on the other. It is either catholicité or catholaïcité, as laïcité was famously dubbed by Edgar Morin, and there is little freedom for the pupils on both sides of the spectrum. The two teachers depicted are women, and this is not acci- 


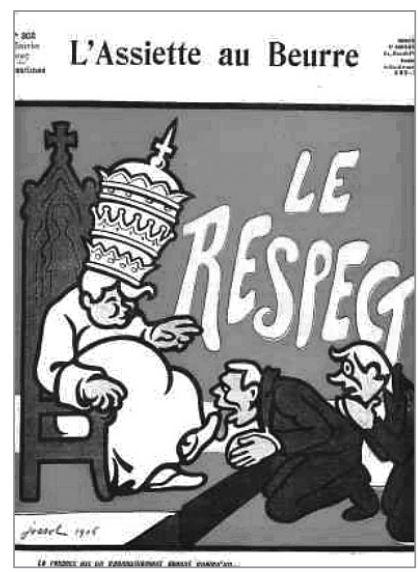

Figure 3 'Respect'. Drawing by GustaveHenri Jossot for L'Assiette au Beurre, 1907, available at «http://www.assietteaubeurre.org/respect/respect_f1.htm> [June 2010].

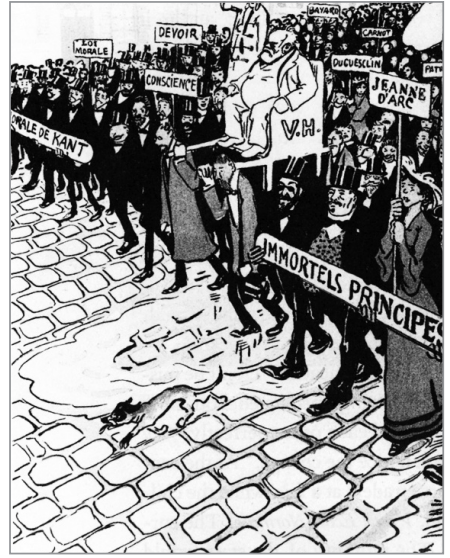

Figure 4 'Toujours les idoles' ['Idols forever']. Drawing by JulesFélix Grandjouan for L'Assiette au Beurre, special issue on the freedom of education, 1904.

dental. The first great laïc educational law, of August 1879, obliged every department in France to have a women's teacher training college. Jules Ferry, then minister of education, argued that Catholicism upheld its influence through women, positing that 'women must belong to Science (and not) to the Church' (quoted in Baubérot 1998: 108). The smoking factory chimneys in the background of the cartoon suggest that underneath the superficial difference between public and private schools is found the same inescapable 'capitalist hell' (Langlois 1996: 109).

These cartoons show that there was as much criticism of the authoritarian sides of laicism as of moral and political Catholicism already in the early Third Republic. It also teaches us that the opposition between Republicans and Catholics was already complemented by a critique of the conceptual and metaphorical dichotomies created in the struggle between the two Frances. The critics also pointed to other, more socioeconomic dimensions of the divides between the diverse populations (see further Langlois 1996).

'Declaration' and 'Respect' contain some of the key concepts from the discourse of multiculturalism (figures 1 and 3). The occurrence of 'respect' and 'commune' is particularly striking. It is as though the slogans of those forms of pluralism that seek to overcome the neglect of difference and inequality in formal conceptions of liberal and Republican citizenship central to political theoretical definitions of multiculturalism, were anticipated in France in such a way that, as a cultural 
memory, they appear to imply a return to a premodern traditionalism linked to pre-democratic social structures.

'Declaration' and 'Choose, you're free' also share a specific conception of history in which societal change takes place by going either radically backward or forward. It is not the gradual mediation between group belonging and formal citizenship that shapes the direction of modern society, but sudden change through revolutionary steps; what is implied is that only through such change can inherently immobile systems be moved. We can either fall back into premodern (i.e., communal) social structures, or be dragged in the direction of the inescapable capitalist hell, or else perhaps in the direction of a second Revolution promising a new community. Because of this revolutionbased conception of history, it is difficult for memory, tradition, community and religion to be interwoven with modernity, freedom and democratic politics.

The next cartoon reminds us, in line with the argument with Gauchet in the above about Renouvier's philosophical position, how politicised the debate about (neo-)Kantian thought had become during the struggles about schooling at the turn of the 19th century (figure 4).

In this cartoon, Victor Hugo, a hero of 19th-century anti-clerical pedagogy, is carried around accompanied by idols from both the Republican and the Catholic side: Jeanne d'Arc, Kantian morality, duty and the moral law, and immortal principles. The central concepts of the philosophical debates about religion and secularity have been turned into idols in a political struggle, and they serve their symbolic function just as effectively in a political contest as they do concerning the 'real' sources of morality.

As a preliminary conclusion, we can say that the transposition of the frame of laïcité onto the contemporary questions concerning the presence of religious minorities and Muslims in France, and regarding secularism and its redefinition, implies that the struggle between Church and State has been reframed in terms of an abstract opposition between (secular) politics and religion, to then be translated into a concern about the role of 'political religion' in contemporary society. Questions of minority formation, or about the extent to which secular education also means 'French education', tend to remain outside this framework. Moreover, by the quite general characterisation of religion in terms of 'absolutism and conservatism', the secularist framework tends to presuppose religion's conservatism, as well as normalising such conservatism too. Not only, as Roy (2005: 167) writes, does laïcité as a cultural notion create the religious. It also implies a specific concept of religion, quite naturally placing it on a conservative, conformist and 
authoritarian side. If we put our trust, as for example Maclure and Taylor (2011) do, in political laicisation without pressures for social secularisation, we leave the implicit reading of religion inherent in cultural secularism intact, risking to normalise, or at least to uncritically 'tolerate', similarly conservative and authoritarian forms of religion that the Third Republicans had to struggle against, while at the same time forgetting the questions I raised earlier regarding the framework itself, such as those about minority status, democracy and racialisation.

Let us now further scrutinise how the framework of secularity and religion came to be constructed and interpreted in the course of the early Third Republican debates, and how this resounds in the contemporary debates about the headscarf and public schooling.

\subsection{Kant at school; Durkheim and Buisson}

We saw that the philosopher Renouvier was adamant about the need for a secular morality that was more or less in competition with religious morality, but there were several other articulations of the Republican concept of laïcité, and especially of what was desirable for Republican schooling. It was argued, for example, by pedagogue Buisson and by sociologist Durkheim - who was at the time still considered to be a pedagogue as well - that a universal morality of citizenship and freedom would not have to supersede religious morality, but rather could be compatible with inherited religious moralities. They were neo-Kantians, just like Renouvier, who had been an important mentor for both of them. However, to Durkheim and Buisson, Kant's concept of a 'thin' universal morality rather enabled the idea that a universal, public morality of freedom could also complement particular religious moralities instead of competing against them. ${ }^{5}$

Kant had drawn the final consequences of a development in the early modern philosophical tradition of abstracting a universal concept of 'religion' from the diverse religious 'cults'. The idea of 'religion' as essentially independent from specific religious practices, and therefore from particular religious traditions (or 'confessions' or 'cults'), emerged in early modernity in the context of a search for a common denominator that would help end the religious wars. Summarising this tradition, Kant distinguished religion from the diverse confessions:

Religious differences - an odd expression! As if we were to speak of different moralities. There may certainly be different historical confessions, although these have nothing to do with religion itself but only 
with changes in the means used to further religion, and religious books (the Zend-Avesta, the Vedas, the Koran, etc.). But there can only be one religion which is valid for all men and at all times. Thus the different confessions can scarcely be more than the vehicles of religion: these are fortuitous, and may vary with differences in time or place (Kant 1991 [1795]: 114).

Kant interpreted 'cultual' (or cultural!) difference as an effect of history by which confessions were connected to power hierarchies, the Catholic one in the first instance. 'Religion' was more independent from organisational hierarchies and from 'cultic', practical aspects. Religion converged with a (minimal) universal morality and could be shared by many confessions, which made it possible to conceive of a compatibility of secular morality and religious beliefs. Buisson formulated his ideal of a laïcité interiorisée very similarly, as follows: ${ }^{6}$

To teach the child that there are indeed many ways of believing in God and serving God, but that there is but a single one on which all the world agrees and that is obedience to the laws of conscience and the laws of reason (quoted in Nicolet 1994: 263).

In a somewhat more liberal interpretation of Kant than Renouvier's, Buisson suggests that there exists a separation between religious moralities and the single moral law of reason, but that religious moralities can be compatible with this moral law. In the interpretation of Agulhon (1981: 157, quoted in Raulet 1999: 31), moral law was considered not the result of a totalised conception of the world, but the 'common denominator of all cultures'. Laïcité was not considered anti-religious because the universal humanist morality was deemed to merge with Christian morality, or at least to be compatible with it on the basis of a common denominator.

A further step in theorising secularity and religion, turning both categories into sociological rather than theological or moral ones, was again developed from within the tradition of laïcité. It can be found in Émile Durkheim's rethinking of Kantian morality. Durkheim was the first Republican professor of pedagogy at the Sorbonne. He deconstructed the opposition between rational and religious morality, detranscendentalising the secular idols exposed in Grandjouan's cartoon about Victor Hugo in the process.

Durkheim thought that Republican morality could not be entirely derived from an imagined - ideal or universal, but ultimately nonexisting - Reason. Therefore, he translated Kant's conception of the 
moral law into the idea that the law is the product of a collective labour. In doing so, he subtly transformed Kant's metaphysics of morality into a sociological view of humanity. Durkheim reads Kant as follows: morality on the one hand implies that the law should be produced by reason. In this sense, the law is given to the subject rather than constituted by it: it implies a certain kind of heteronomy, a 'deep respect for the law' [Achtung für das Gesetz]. On the other hand, morality implies that the subject gives itself the law: it implies autonomy.

In his explanation of Kant's antinomy, Durkheim translates it into a slightly different one. As far as the autonomy pole of the antinomy is concerned, Durkheim stays close to Kant: we cannot think that 'the will can be fully moral when it is not autonomous, when it passively receives a law of which it is not itself the legislator' (quoted in Raulet 1999: 123, my translation). But Durkheim's explanation of the heteronomy pole of the antinomy marks a distance from Kant. According to Durkheim, heteronomy means that 'the moral rule is the product of a collective, we receive it much more than we make it' (ibid., my translation. What precedes the subject for Durkheim is not reason but the collective, and with this argument Durkheim makes the Kantian concept of morality, oxymoronically, 'sociologically transcendental'.

For Durkheim it was important that Kantianism, in line with Protestantism, supposed the translation of the heritage of religious, transcendent morality into moral principles:

With Protestantism, the autonomy of morality becomes even more apparent, if only because the part of the cult in the narrow sense is diminished. The moral functions of the divine become its only reason for being; this is the sole argument invoked to prove its existence ... We must look, at the very heart of religious conceptions, for moral realities which appear there as if lost and dissimulated; we must free them, find out what they consist of, determine their proper nature, and express them in a rational language. We must, in a word, discover the rational substitutes for these religious notions which, for so long, have served as vehicles for the most essential moral ideas ... We must discover these moral forces which man, until the present, has not learnt to represent to himself except in the form of religious allegories (quoted in Raulet 1999: 8, 10, my translation).

Durkheim considers the heritage of the religious past as a reservoir of moral forces, not unlike as Habermas does today (see Habermas 2008; for comments see Jansen 2011a). Autonomy does not mean that we reject religious heritage or that we rise above it in order to evaluate it critically from an Archimedean point of view. It is simply not clear 
what will be found there. Perhaps nothing, or probably, at least partly religion or tradition again, Durkheim suggests. What we need, rather, is a rational translation of the concretely developed historical moral forces that religions have carried with them. This preliminary deconstruction of moral autonomy by Durkheim teaches us that laicism's moral-philosophical and pedagogical basis is more complex than some of the contemporary claims about public schooling suggest.

We encounter the modernist either-or between communal belonging and citizenship, cult and morality, which had been deconstructed to some extent by Buisson and especially by Durkheim, in contemporary neo-Republican explanations of the function of the public school in terms of laïcité. Neo-Republican philosopher Kintzler (2003: 63), who was one of the first to sign the famous petition in 1989 against the wearing of the headscarf in schools, restated the Republican idea of the public school as a place that pupils attend not as consumers or in order to enjoy their rights, but in order to 'constitute oneself as a subject' (my translation). According to her, this means that pupils get the opportunity - but are also obliged - to distance themselves from all pre-rational, social and religious forms of belonging. Pupils should be encouraged to critically evaluate all kinds of worldviews without already having made a decision about their membership of any particular one. Freedom can only be the result of schooling. The students present in the school are not constituted liberties (as is the case with citizens in the public space), but liberties that are in the process of being constituted, and the school is an institution that produces freedom (Kintzler 2003: 64, my translation).

The Stasi Commission gave a similar definition of pedagogical laïcité in the context of public schooling. As we will see in more detail later on, it presents the transition from 'appartenance' (belonging) to 'autoconstitution' as something quite unproblematic that we can decide on when we pass the threshold of the school. In the process, the committee adds on the making of the citoyen:

At the school of the Republic are welcomed not simply users, but pupils destined to become enlightened citizens. [... The school] must encourage a distancing from the real world to permit this being learnt (Stasi 2003: 4.2.2.1, my translation).

This requirement of a mise à distance from the real world is crucial to understanding what contemporary laïcism actually requires. We can ask whether we really breed 'enlightened citizens' by forcing people to suspend the religious practices related to the ways in which they are 
attached to the 'real' world. But we can also ask what it means to think that distancing is deemed especially relevant with regard to a contrast between secularity and religion today. By the affirmation of the laïcist foundations of public schooling, religion in general is once again brought into competition with a modernist conception of subjectivity.

As we have just analysed, Kant himself, and moderate neo-Kantians such as Buisson and Durkheim, already complicated such binaries between (citizen) autonomy and (religious) heteronomy. Ironically, the great philosopher of autonomy referred to veiling in order to make clear how complicated the sources of our moral sense are:

The veiled goddess before whom we of both parties bend our knees is the moral law in us, in its inviolable majesty. We do indeed perceive her voice and also understand very well her command. But when we are listening, we are in doubt whether it comes from man, from the perfected power of his own reason, or whether it comes from another, whose essence is unknown to us and speaks to man through this, his own reason. At bottom we would perhaps do better to rise above and thus spare ourselves research into this matter; since such research is only speculative and since what obliges us (objectively) to act remains always the same, one may place one or the other principle down as a foundation (Kant in Fenves 1983: 71, English quoted in De Vries 1999: 375).

Once we, in line with Durkheim, start keeping track of the social and political dimensions of the other sources of morality than reason, there is all the more cause to complement the theological and metaphysical dimensions of the debate with one about democracy. However, we cannot do so by circumventing the history and aftermath of the theological debate entirely, for it has co-shaped the laïcité-religion framework itself.

\subsection{Privileging Protestantism and the genealogy of the religious sign with a French twist towards ordre public}

French historians have emphasised, in line with the, by now, widely spread knowledge about the intertwined genealogy of Reform and secularisation (e.g., Taylor 2007), that the interiorised, Kantian side of laïcité, for all its universalism, followed a rather Protestant teleology in the way it conceived of the historical development of the relation between morality and religious belief. For this reason, the introduction of laïcité has also been interpreted as a 'Protestantisation' of French 
political structures, advocated in the Third Republic by particularly those philosophers and pedagogues influenced by the neo-Kantianism dominant at Republican universities and in governmental circles - where a Protestant background often dominated (see Agulhon 1981; Ozouf 1984; Baubérot 2000; Raulet 1999; Birnbaum 1998). ${ }^{7}$

For Raulet (1999: 32), in Agulhon's footsteps, this is a reason to suggest that laïque morality could only conceive of itself as a complement to, instead of a competitor with Christian morality, because it 'constitutes a more or less secularised, that is to say "Protestantised", and ultimately "Kantianised" variety of it' (my translation). The teleological progress from the Reformation to the Enlightenment to the Republic, Raulet (ibid.) suggests, obsessed as it was by the 'free' citizen, might not have been as easily compatible with other religious moralities, particularly because in the end the Republic hoped for an 'affective community' united around Republican values.

Tracing secularism's link to a Protestantism that tends to overestimate interiority and universal morality as sources of good action should not lead us, however, to the suggestion that, for example, Islam and Judaism (and also Catholicism) are essentially more particularist religions than Protestantism, and less compatible with modernity. These kinds of essentialising typologies are precisely the result of the modernist framework itself. For example, in Kant's own interpretation - in line with many other early modern interpretations of religious difference - Protestantism was the pre-stage of an even more desirable freestanding, secular morality guided by reason. Catholicism, Judaism and Islam were connected to a medieval world in which political and religious hierarchies were thoroughly intermingled.

Kant (2003 [1793], part IV) criticised religious worldly power, clerical hypocrisy and the policing of people's minds, and he did not exempt Protestantism from critique. But he did argue that we encounter the links between religion and power in Catholicism, Judaism and Islam more systematically, because these religions conceptualise God as requiring obedience, not moral conviction (and reasoning) from individual believers. He denied Judaism the status of religion, calling it a 'cult' (ibid.: 125), a 'statutory' confession. In a debate with his contemporary Moses Mendelssohn, Kant even suggested that Mendelssohn wanted the Jews to submit themselves to a 'yoke of exterior observances' (ibid.: 185). Kant did not treat Islam systematically, but he wrote sparsely about it in his anthropology, in the part on mental diseases in fact: 'Fanaticism' (Schwärmerei), 'the most dangerous human deceptive screen' (Blendwerk), leads to extremities such as 'putting Muhammad on the throne' (Kant 1838 [1764]: 25). 
So at a time when all confessions were deeply entangled in political processes of nation-state and minority formation, the idea emerged that Protestantism was a pre-stage of an Enlightened, rational religion, converging with an independent, interior - or, in our terminology, secular - morality, while other religions were essentially political (and potentially fanatical) because of their theological contents.

Mendelssohn's answer to Kant is important, especially in the context of historical Judaism in Europe, but also with regard to the contemporary position of Islam. Because Mendelssohn wanted to retain a meaning for Judaism within modernity, Kant saw him as someone who did not exact the full consequences from the Enlightenment. Mendelssohn himself argued that Enlightenment could be reconciled with particular religious practices, and saw that this was also the case with regard to religions that do not strictly separate a pure or at least private concept of religion or morality from (cultural) practices. Mendelssohn argued that universal morality is not only compatible with Jewish moral law, but with the religious practices of many peoples. He refused to go along with the Kantian 'either-or' suggestion about the meaning of Enlightenment:

According to the notions of true Judaism, all inhabitants of the earth have been called to happiness and the means to achieve it are as extended as human beings themselves...! (Mendelssohn 1989 [1783]: 412, my translation).

The debate between Kant and Mendelssohn shows that, apart from being problematic philosophically, 'religion' is not a neutral concept with which to understand the 'religions' of other peoples (or of earlier periods in European history). Moreover, it demonstrates that this insight has long formed part of a European tradition within the Enlightenment which has however remained far less known than the Kant-Protestant-secular thread. Failing to acknowledge this leads to a monolithic presentation of options that have been available in Europe, and that have been tragically unequal in competing for the meaning of the Enlightenment.

Reminding ourselves of such diversity within historical Europe might help to accommodate and recognise the practices of Muslims today (see also Brahm Levey 2009; Bader 2010). This would also help to further deconstruct the strong distinction between interiority and law, between sentiment and practice (Reinach), or between universal(isable), liberal religion and orthodoxy. It would help us to see that these are themselves the products of a modernist secularism- 
religion framework instead of preceding it. This shows us how urgent it is to critique the very concepts of secularism, of laïcité, of secularisation and of religion.

A programme of rethinking these categories has been taken up in an international anthropological and religious studies context, where the thesis of the progressive interiorisation of the confessions into 'religion' in modernity - and its desired convergence with moral reason - has been contested from many sides as a central element in the contestation of the secularisation thesis in general (Asad 1993; Casanova 1994; Connolly 2006; Bader 2007; Jansen 2010, Dressler \& Mandair 2011). Such research has established that the modern concept of religion presupposes essentialised notions of belief - and also of reason and morality, as something interior, or even mental, and similarly essentialised notions of ritual and religious practice, as mechanical and exterior. In sum, 'religion' has been shown to be intimately connected to modernist, mentalist theories of the subject. This places the critique of secularism in the larger philosophical tradition of questioning how reason itself is related to the body, to social practice and to power, a tradition ranging from Nietzsche to Wittgenstein to Foucault, which has been made fruitful in deconstructing the secular-religious divide especially since Asad's Genealogies of Religion (1993).

Questioning the framework of secularity-religion itself implies that we cannot take it for granted that some religions (or moral systems) are essentially less compatible with, or even supportive of, minimally universalisable values than other religions or moral systems. The question of how universalisable they are should be made less dependent on the question of whether these religions tend towards interiorisation - or have turned into secular morality. Instead, it depends on the historical processes in which they are involved and on the choices made by believers themselves - which is fully in line with Mendelssohn's argument against Kant. For example, Muslim feminists have stressed the egalitarian morality available within Islam (Ahmed 2011), and Casanova (2006) has traced the complicated road of Catholicism towards a more open self-understanding and gradual convergence with human rights.

Yet we have to take a further step to see the full consequences of the secular-religious framework for the position of Islam today in the French context, especially insofar as religious practices have been conceived in terms of 'signs' of a religious identity in the course of the headscarf debates. Or at least, this is what Asad has argued. I will briefly trace how Asad has theorised French secularism's role in the definition of the headscarf as a religious sign itself, to then add a few 
contextualising remarks that can help to question the laïcité-religion framework itself even more thoroughly. ${ }^{8}$

Asad has been influential in tracing the pervasive legacies of the Enlightenment concept of religion, specifically the Kantian version, to today's understandings of religion in which it is considered as a system of meanings to be symbolised by certain practices (as 'signs') instead of being constituted by their performance. Asad (1993) explains this in his analysis of Clifford Geertz's concept of religion. The idea inherited from Kant that religion could and should be separable from its historical forms implies that religion becomes something interior, a belief, a moral disposition that can lead to certain actions, but that is not itself grounded in practice, training or mind-body interaction. The ensuing interpretation of religious practice is that it forms a representation, sign or symbol of an interior mental state. The idea is, then, that such an interiorised and mentalist concept of religion can only grasp religious traditions (or rather, traditions more generally) on its own terms, and will always reduce practice to something exterior, servile and inessential to what religion really is (ibid.; Connolly 2006). It makes manifest how, in modernity, we have come to lack sensitivity to the ways in which practices in general, habits, customs, ethoi, and also non-reasoned motives such as affects and drives - in sum, 'the visceral register of intersubjectivity' - are relevant to our moral, political and religious actions, and suggests their intertwinement to a degree that the secular concept of religion as belief cannot help us understand (Connolly 2002: 27) ${ }^{9}$

The most salient example of such a modernist interpretation of religion today is the interpretation of the headscarf, where the scarf is taken as the outward sign of an identity or belief. This occurred in the definition of the scarf as a conspicuous religious 'sign' which, as we have seen, was the interpretation deployed by the Stasi Commission. This neglects to emphasise, Asad (2006: 502) argues, that wearers themselves often interpret the scarf not as a sign, but as a religious duty constitutive of 'a way of being. ${ }^{10}$

Asad (ibid.: 514) sees the headscarf law as a 'window into laïcité', noting that contemporary political cultures, as modern nation-states, are fixated upon ideas of integration. He traces this fundamental problem of the modern nation-state to the emergence of the state itself in late mediaeval Spain, when religious difference started to be interpreted in secular terms of nationality and minority formation (ibid.: 494-496). He interprets contemporary French secularism against the background of the early modern emergence of the secular, and particularly stresses the relevance of the cuius regio, eius religio principle 
that emerged at the end of the European religious wars. For him this entailed the installation of a single absolute power, the (Hobbesian) sovereign state, which Durkheim interpreted in terms of integration (ibid.). Its principal attitude toward religion is not neutrality but a political concern with identifying and controlling religion, and with homogenising populations. Analogously, he suggests, the French debates about the headscarves were 'not so much about tolerance ... not even about the strict separation between state and church' (ibid.: 500). What was at stake 'is sovereignty, which defines and justifies exceptions' (ibid.: 507). Whereas the laïc Third Republic homogenised the many Catholic standpoints into a Catholic Christianity, Republican 'political theology' is now vital again in 'the struggle with another enemy - a homogenised fundamentalist Islam' (ibid.: 507).

Now, I do think that the headscarf law may be interpreted in terms of a Republican political theology insofar as it has created, or at least corroborated, the image of a homogeneous Islamic population posing trouble for public order. However, I am not convinced that the law itself can be interpreted as a window into laïcité, which we can take as a principle characterising French political culture as incapable of practising religious tolerance or any real separation between Church and State, private and public, toward contemporary Muslims. The debates in France were about tolerance, religious freedom and separation, and, as I argue more fully below and in the following chapter, French political culture made a shift toward a securitising discourse to justify the headscarf law.

We have to further contextualise the definition of the scarf as a religious sign. It does not stem exclusively from a secularist epistemological framework leading to the radical separation of belief and practice. Instead, this interpretation has arisen from the interaction of that epistemological framework with the actual politicisation of religious practice in French political history, which occurred, for example, during the Third Republic, during the period of the Front Populaire, and, with regard to Islam, during the Algerian war and its aftermath.

The discussion about religious signs (or emblemes) in schools is as old as laïcism itself and has surfaced particularly at times of confrontation between the Republic and clerical or militant Catholicism. This was the case in the 188 os in discussions concerning the confiscation of old school buildings by the state and about whether all the reminders of their Catholic origins, such as the crosses on the walls, ought to be destroyed. For example, Buisson took a moderate position and thought that turning the law which ordered the laïcisation of schools into a 'iconoclastic crusade' against religious signs in school build- 
ings might have the wrong effect. Therefore, addressing the prefects, he advises, 'you should always remember that the government, full of confidence in the public's good sense, even as it seeks to make the people respect the law, also claims to make the people understand and love the law' (Buisson 1888: 1473, quoted in Raulet 1999: 22, my translation). Because of such moderacy, or rather, such diplomacy, Baubérot (2004: 70) argues that the early Third Republican laïcists knew 'how to deflate conflict' and that their laicism was motivated by their 'long term intelligence', an intelligence he finds lacking in today's neo-Republicans claiming the legacy of laïcité.

Later, in 1937, when the minister of public education of the Front Populaire, Jean Zay, prohibited the crosses worn by scouts and the insignia of the 'Jeunesse étudiante chrétienne', which was linked to the extreme right, he did so by appealing to ordre public and not to laïcité. Zay did not prohibit the Catholic signs because they were religious, but because they were associated with the fascist or at least the nationalist and rightwing side of militant Catholicism in the thirties (Poulat 2003).

Interpreting the headscarf as a sign implies that it is not evident what the scarf means in the French context today. In line with Asad, we could argue that this interpretation is related to the typically modern simultaneous production of interiority and insecurity. The secular in terms of religious interiority produces a fundamental insecurity and invisibility of religious meaning, precisely by locating religion in conscience, and by interpreting religious practice as accidental, and potentially being nothing but a mask. This modern insecurity has been thematised from the secular's emergence in early modernity, when for example Bacon started to reflect on the uses of dissimulation and secrecy in politics (Asad 2003). We have seen that a semiotic of hiding and displaying played a major role in the construction of the meaning of Jewishness in the Proustian novel (see Carlston 2002).

However, this tendency towards religious insecurity is not always as strong, and it is triggered by experiences that cause fear, and by the real possibility of religion's politicisation and fanaticisation, which Asad tends to overlook. In France, with regard to Islam, 9/11 provoked fear, partly because it revived the memory of the metro terror attacks in Paris (1995) by members of the Algerian GIA - causing the death of 208 people. There was also great awareness in France of the Algerian terror of the 1990s, especially among immigrants, many of whom were refugees from Algeria. The extremely violent struggles between the Algerian state and various groups of Islamists caused between 150,000 and 200,000 deaths (the numbers are contested). 
Ironically, in the French-Algerian context, the scarf had been an exemplary icon of typical secular, modern politics long before the events of the last decades, and before the terms in which we understood political conflict became those of political religion and secularism. For example, in Gillo Pontecorvo's famous movie about the Algerian War of Independence, The Battle of Algiers (1966), Algerian women hide weapons and their inimical intentions toward the French behind their scarves just as pragmatically as behind their modern dresses. Starting by hiding the guns of the Algerian underground under their haïks (long white scarves covering the whole body) while playing out their piety against French soldiers, when it becomes appropriate they take off their scarves, cut off their hair, and dress in a very French way in order to carry bombs into the French Algerian quarters of Algiers. The curious thing is that the scarf, obviously an icon of a refusal of secularity, is actually also, in French cultural memory, an icon of the modern and secular motive of violent political resistance potentially hidden behind the religious sign. This ambiguity is an important reason for the mix of fascination and fear that the scarf produces. ${ }^{11}$

My critical addition to Asad's reading is that he suggests that there is a long tradition of laïcité, grounded in early modern politics of religious homogenisation, which quite naturally politicises religion and which can only understand religious practice in terms of insecure, secular signs. Instead, the current interpretation of the headscarf as a sign, and its implication of being understood not in terms of a religious way of being, but rather in terms of a communication about identity, has a more concrete historical-political dimension which has to be added to the criticism of laïcité. ${ }^{12}$ In the following chapter I consider the Stasi report and some French sociologists dealing with religion and secularity in detail, and I further pursue this suggestion there. 



\section{CHAPTER 7}

\section{Secularism, sociology and security}

At the same time, however, precisely because of the ways in which the end of colonialism came about, postcolonialism denotes a situation in which the 'metaborder' between metropolis and colonies [between citizens and not-yet-full-citizens, YJ] no longer organizes any stable world cartography but the possibility is given that it reproduces itself, in a rather fragmented way, within the territory of the former metropolises themselves (Mezzadra 2006: 35).

Not only popes and ayatollahs have to learn that they cannot be king and that, if there is to be a sovereign at all, it has to be the vox populi; also Western secular elites should learn that 'error has the same rights as truth' (Bader 2007: 90).

\subsection{The sociology of secularisation, normative laïcité and multiculturalism}

This chapter first examines the Stasi report (2003), which imparted to the French government the crucial recommendation to issue a law prohibiting the wearing of conspicuous religious signs in public schools. The report provides a lengthy analysis of the actuality of laïcité. The final recommendation about the conspicuous religious signs forms only a small part of this document, which redefines laïcité in several regards. I relate my reading of the report to the views of multiculturalists who have concentrated on secularism such as Brahm Levey and Bader, focusing especially on the report's reiteration of the modernist dichotomies discussed in the previous chapters. I then concentrate on where public order comes in, and try to make plausible how it relates to the culture of laicism laid out in Chapter 6. This enables me to explore some further motives in the recent French sociological debates about secularisation and religion in the 'age of identities' and securitisation, by analysing the relation between religion, culture, security and politics in the works of Gilles Kepel, Alain Touraine, Marcel Gauchet and Olivier Roy. These authors share an unreflected modernist legacy with 
regard to modernity and religion, independently of their standpoint about the headscarves or about laïcism.

I pay ample attention to the modernist presuppositions of Roy, a French sociologist of religion who criticises both multiculturalism and laïcité (especially in Roy 2005). By analysing Roy's understanding of the relation between culture and religion in a globalised Islam, I demonstrate that the pattern of cultural laicism returns in Roy's analysis and that we require a deeper critique, one that addresses the modernist heritage in his thinking about secularisation. I argue that in order to develop an alternative frame we need, first, to pay systematic attention to the distribution of power and to minority-majority relations and, second, to critically rethink the relation between religion and culture in the sociological concept of secularisation that underlies the political-philosophical concept of laïcité.

\subsection{The Stasi report: Un rapport sans médiation}

The Stasi report was deemed necessary in attempting to deal with the ongoing struggles about the headscarves, but also regarding other contentious issues. Mentioned in the report are, among others, refusals by Muslim women to be treated by male doctors, refusals by Muslim pupils to participate in physical education, refusals to acknowledge the authority of female teachers by Muslim pupils or their parents, refusals by Muslim pupils to attend classes on the holocaust, the general rise of anti-Semitism, the increase of group-thinking at schools in general, and the pressures brought to bear on mainly young people, girls in particular, to define themselves as members of a 'different' community. Although the Stasi report does not mention 11 September 2001, a fear of terror and the generally acknowledged possibility that, with its large Muslim population, France, too, could once more fall victim to a terrorist attack after the bombings by the GIA in 1995, probably also inspired the French government to rethink the merits of laïcité.

The Stasi Commission seeks to answer these challenges by rethinking the compatibility of laïcité and pluralism, as well as its limits. The explicit aim of the committee's redefinition of laïcité is that it should provide a common ground on which to live in diversity, not a denunciation of diversity itself in the name of a Jacobinic heritage. With regard to education, for example, the Commission proposes several pluralist changes. It states that more attention should be paid to immigrants' histories, to colonial history in particular, and to 'the religious fact'. The Commission explicitly distances itself from combatant laïcism 
(Stasi 2003: 2.3, my translation, also in the following). Quite symbolically, the concluding words of the report are 'pluralism, diversity' (2003: Conclusion). These two concepts occur throughout the report (see further Akan 2008 for the report's multicultural side).

Some of the proposals are indeed pluralist, but they also stand in a tradition of the top-down gestion of religion by the state through its nationalisation. For example, the committee proposes founding a national university for Islamic studies, and one of its proposals is to change the official teaching of ELCO (Enseignement des langues et cultures d'origine) into the teaching of 'living languages'. The teaching of Arabic, organised by Koranic schools, should be replaced by courses in the maternal languages of immigrants, for example, Berber and Kurdish. This was to serve the purpose of 're-ethnicising' (and dividing) a globalising Islam (Roy 2005), though it gives little choice to those individuals who might wish to take language courses.

Moreover, there is a sign of a quite extensive memory gap in the Stasi Commission's understanding of the complexities of secularism and of pluralism. Although the Commission distances itself from the old laïcité de combat, it sees no problem in recycling old Republican lieux communs. It revives the 'melting pot' as a viable metaphor for society, arguing that 'the force of our cultural identity can reinforce the melting pot of integration' (Stasi 2003: 35). Without mentioning assimilation explicitly, the Commission refers to it implicitly, now associating it with 'integration'.

Furthermore, the Commission proposes that contemporary Islam and other religions with juridical and public aspects should take Franco-Judaism as a model:

History reminds us of the effort required in the past from religions to adapt themselves to the secular frame ... from the time of the Concordat, Jewish religious law has been the object of various adaptations designed to accommodate its religious precepts to the civil law ...; this 'francojudaism' has allowed a reconciliation between Jewish morals and civil law (Stasi 2003: 16).

I have already addressed the ambivalences accompanying 'FrancoJudaism' in 19th- and early 2oth-century France. I will not restate the major findings here again, but I hope to have demonstrated sufficiently that these ambivalences should have brought the Commission to take a more distanced stance towards precisely this history (see Transit I and Chapters 4 and 5 in this volume and also Birnbaum 1998; Benbassa 2003; Jansen 2011b). 
In my view, in proposing the prohibition of 'conspicuous religious signs', the committee not only creates an exception to its multicultural attitude, but also reveals how deeply problematic ethno-religious pluralism remains in French society, at least among Republican intellectuals. The Commission explains its decision as follows: it does not oppose pluralism, but it does resist a communautarisme intent on drawing legal or political boundaries between ethnic or religious groups within France, as well as the practising of 'aggressive proselytism' (Stasi 2003: 1.2.3). Today, therefore, in addition to indicating the neutrality of the state and the separation between Church and State, laïcité also implies 'the defense of individual freedom of conscience against all proselytism' (ibid.: 1.2.2). Here, rather than a bipolar relation between state and individual, a triangular relation is drawn between individual, community and state. We are dealing not only with the protection of the freedom of individual consciousness from intrusion by the state, but at the same time with the protection of the freedom of conscience - by the state - from a 'duty to belong' (ibid.: 4.1.2.2). This duty is imposed upon individuals by those communities that want to keep their members from merging into the melting pot of general individual citizenship. Headscarves had become the symbol of this struggle.

The result of the duty to belong is that Muslim girls living in the (ghettoised) banlieues, where communautarisme is strongest, are under severe pressure to wear the headscarf. The Commission reports that it has been particularly sensitive to the 'cry of distress' of girls forced to wear headscarves, of which the many teachers interviewed by the committee contended that they formed the 'silent majority' (ibid.: 4.2.2.1). If these girls do not wear the scarf, they pay the price of being harassed, socially excluded, even sexually assaulted, and of being considered whores or infidels. Some girls had to be interviewed behind closed doors because it would have been dangerous for them to speak of their experiences in public. ${ }^{1}$ The most acute formulation of this concern is a phrase from the Stasi report which states that the headscarf now provides these girls, paradoxically, with the very protection that the Republic should provide (ibid.: 3.3.2.1.).

This new constellation of the relation between individual, state and community has convinced some of those known as 'new secularists'. For years they had opposed the laïcité de combat and promoted a moderate multiculturalism, but now moved to endorse the new law on laïcité, including the prohibition of the scarf in public schools. To the surprise of many, for example, Alain Touraine, who had always opposed the prohibition of the scarf and who had defended interpretations of it as a bricolage of the new from the old, came out in support 
of the new law. In an explanation of his change of mind, he said that he had not changed but that France had, and that, to his great dismay, it had become a communautarian country. Whereas at first the scarves could be interpreted as symbols of hybridity and cultural negotiation, as signs of an integration that preserved the agency of the migrants themselves, Touraine now concluded that the girls and organisations defending the scarf were proposing, in the same bargain, an undesirable communautarisme (Touraine 2003). ${ }^{2}$ Let us then take a closer look at that diagnosis and at the remedy proposed: the prohibition of the headscarf at school.

\subsection{Secularism or democratic multiculturalism?}

There is consensus among the critics of the ban that if we are particularly concerned with violence perpetrated against women, or with strong pressures put on them in the name of specific religious claims and communities, the answer should not have taken the form of a general prohibition of conspicuous religious signs at schools (e.g., Carens, Weil \& Bauboeck 2003; Tévanian 2004; Scott 2007; Joppke 2009). It is important to provide Muslim women with as many possibilities for participation in society as possible, rather than putting that participation at risk by the wearing of a headscarf. ${ }^{3}$ Issues of ghettoisation, economic exclusion, and the inability of the educational system to deliver inclusion are waiting to be addressed (see Noiriel \& Beaud 2004; Balibar 2004, 2007; Amnesty International 2012).

However, squarely returning to a concern with the appearance of religion in public places, the committee simply forgets that its primary concern was the 'duty to belong' of the oppressed girls. This return is apparent, for example, when the report states that the difficulty with the legal translation of the principle of laïcite is the tension between its 'two poles that are not incompatible but potentially contradictory' of religious freedom and the neutrality of the secular state (Stasi 2003: 2.2.3). The commission's slippage into the old problematic might explain why, when the problem concerns girls being forced to wear the signs of belonging to a community, the solution is thought to lie in the prohibition of headscarves in schools.

In the previous chapters, I have explained that we have to refer here back to the modernist heritage in laïcité, which not only tends to problematise a 'duty to belong', but also all kinds of belonging to ethno-religious or diasporic communities other than the nation-state. Such attachments tend to be perceived as competing with citizenship 
and therefore as problematic, as traditionalist, and as something that should be overcome (see as well Laborde 2002, 2008).

The legacy of cultural laicism becomes more apparent when we analyse in detail the Stasi Commission's general normative standpoint on the desirable relation between laïcité and communautarisme. We already noted that the Commission distances itself from the classical Republican political philosophical tradition, which defended the unity of the corps politique (political body) and perceived difference as threatening. Yet the report is reluctant to actively endorse diversity. It deploys passive constructions or indefinite pronouns like 'certains' (some people):

Today, diversity is sometimes presented in a positive vein; respect for cultural rights is claimed by some who consider them an essential aspect of their identity. To preserve culture, belief, and memory - real or imaginary - appears as a form of protection while participating in a changing, moving world (Stasi 2003: 1.2.4.)

This explanation actively endorses neither cultural rights nor the conservation of culture, memory or belief. With it, the Commission makes clear its reluctance to accept diversity, but also how conservatively it interprets the possible claims of culture. By not distinguishing in these crucial phrases between claims for cultural rights and those for conservation of culture, belief and memory, it also makes clear that little distinction is being made between the various possible multicultural claims. Talking about conservation does not take the relational aspects of these claims into account. For example, they may be part of a negotiation process designed to increase minority power positions. Nor does the Commission consider the transformative aspects of these claims, which may aim not at conservation but at transformation undertaken at a non-assimilationist pace.

What is also missing from the Commission's analysis, and what is perhaps more crucial here, is a reflection on the possibility that conservative claims may be developed when an assimilationist dynamics encourages a 'reactive culturalism' on the part of orthodox groups (see Shachar 2001). Instead, in the analysis of the Stasi Commission, we encounter a strong, nearly immediate link between 'communitarian sentiment' and identity political rigidities:

To deny the force of communitarian sentiment would be in vain. But the exacerbation of cultural identity [should not] establish itself into a fanaticism of difference, bearer of oppression and exclusion (Stasi 2003: 1.2.4). 
Diversity is only accepted à reculons, because it is inevitable. It is perceived as something to be tolerated, but the perceived danger is immediately noted: the 'exacerbation' of cultural identity should not turn into fanaticism. Again, diversity is seen to turn into violence fairly easily, through the assertion that it should not lead to 'fanaticism, oppression and exclusion', as if this were to be expected. The next sentence is designed to specify what underlies the tendency of diversity towards fanaticism. It states that 'in a secular society, everyone should be able to distance himself or herself from his or her tradition':

[This does not at all imply a] denial of self, but an individual movement of freedom, permitting the individual to define himself or herself with regard to his or her cultural or spiritual references without being subjected to them (Stasi 2003: 1.2.4).

This phrase recalls the modernist dichotomous distinction between, on the one hand, tradition and belonging, connoted here by assujettissement, and on the other, individual freedom. It does so not because of the interpretation of freedom it proposes, but because of what it suggests the 'others' think, do and want.

As a specification of what is necessary to avoid fanaticism, such a generalised norm as to how the individual should relate himself or herself to cultural or religious 'references' should be rejected. It simplifies matters of faith, since it is questionable whether there is an either-or relation between distancing oneself from one's so-called references and being, in a certain sense, also subjected by them (see the earlier discussion about Kant and Durkheim). The phrase appeals to the freedom of conscience, but this time it's an assignment by the state. The concept of freedom here spills over into a thick concept of liberal individual autonomy that is incompatible with recent moderate liberal views of the 'reasonable pluralism of the good life' (Rawls 1999; Maclure \& Taylor 2011).

Both for religious and non-religious individuals, elements of autonomy and heteronomy, of being defined by (a fragmented but partially transcendent) cultural background and by oneself, are always entangled and interdependent. The ideological turn of the debate lies in the way we conceive of modern (French) individuals as being able to distance themselves from their cultural backgrounds rationally, while their 'others' are perceived as unable to reflect on their spiritual references.

It may not be superfluous here to bring to mind the critiques that have been made of the liberal concept of autonomy in the tradition 
of British multiculturalism. I would like to take as a brief example Bhiku Parekh's analysis of the work of John Stewart Mill, one of the great liberal theorists of the 19th century, who was also involved in the administration of India. According to Parekh (1994), the core of Mill's philosophical theory was formed by the idea that man had been made to develop autonomously, on the grounds of individual choice. Only a self-determining person having 'character' or 'individuality' could improve herself or himself and develop a 'striving and go-ahead character' (Mill 1912 [1855]: 125, quoted in Parekh 1994: 86). Individuality would help to create a progressive society because it made persons creative, critical and active.

Mill projected these personal qualities on peoples; he thought that only European societies had been improved by 'free and equal discussion'. He observed that 'the whole East', indeed, the 'greater part of the world', had 'properly speaking, no history because the despotism of custom is complete' (Mill 1912 [1855]: 128, quoted in Parekh 1994: 88). In the course of the Imperial project, liberalism began to define Europe in contrast to colonial societies, unifying itself into 'the other of its other'. It forgot about Europe's internal plurality and became 'obsessively anti-traditional, anti-custom, anti-conformity, anti-community' (Parekh 1994: 93). The presupposed lack of shared values by liberal and non-liberal peoples also implied that cross-cultural dialogue would not be enough to bring about change. Mill saw no objection to rigorous policies of assimilation, which were explained and justified by means of educational metaphors. Precisely this exaggerated systematisation of their difference from non-liberal peoples, Parekh remarks, made it difficult for liberals to acknowledge and regulate the use of force.

In the reasoning of the Stasi Commission, we encounter the unreflected modernist (and colonialist) heritage of the binaries analysed and criticised by Parekh (also Chakrabarty 200o). The binaries turn up not as explicit norms or judgements, but as a conceptual heritage that is insufficiently reflected and that perpetuates modernist dichotomies (whether in a secularist or a liberal guise) when reflecting on Islam, and on religion more generally, in society and politics. Historicising them helps us to understand how a debate on individual autonomy and collectivity may have culminated in such binary oppositions, as 'these are our values and these are yours', 'we are the secularists and you are the communautaristes', or, vice versa, 'we are the communautaristes and you are the secularists'. In particular, doing so may make us sensible to the need for cross-cultural deliberation rather than a use of force that also includes the introduction of specific laws. 
A turn for thinking away from this secularist modernist element in liberalism has been developed by Bader (2007), who argues for the 'priority of liberal democratic constitutionalism' over secularism. He argues that instead of sticking to a secularism that is crucially intent upon drawing lines of validity around the question of whether arguments and behaviours are either religious or rational and autonomous, we should rid ourselves of this focus. If we turn away from privileging arguments based on the claims of a neutral, rational truth related to secular reason, we might come to see that the liberal norm of freedom of conscience and expression for all, and the democratic norm of voice for all, bear within themselves enough universality to be able to do without the layer of secularism. Voice is particularly crucial here: democracy implies that all should have an equal voice, not only those who (appear to) know the (scientific) truth and who have learnt to argue their points rationally, but perhaps even more so those whose voices we tend not to hear because they have non-mainstream sources of knowledge or little access to the media (see also, e.g., Tully 2008; Mookherjee 2010).

But can the liberal and democratic moments in the modern state do without the layer of active, anti-dogmatic secularism? I agree with Bader, who argues that the contemporary liberal-democratic state, with its institutional provisions against theocracy and against the risk of a tribalisation of society, does not need the secular layer that was crucial in early modernity for philosophers such as Hobbes and Spinoza, and that was to a large extent indispensable for the French Third Republican pedagogues as well (Gauchet 1998). ${ }^{4}$ In today's European societies, it would be more democratic and open towards cultural and religious minorities to focus on the question of whether discourses and practices violate liberal and democratic norms, and to declare irrelevant, especially from the perspective of the constitutional state, whether these arguments and behaviours have religious or non-religious sources.

The kernel of the argument is that we do not need secularism as a specific way of dealing with religion within liberal democracy. This is, firstly, because we do not need the specific and misleading term secularism itself, which carries the legacy of the modernist interpretation of secularisation. We can acknowledge and justify the different degrees of differentiation between religion and state without employing that generalising term. Liberal policies for dealing with religion accommodate it to various degrees within various national systems, much in line with other liberal policies towards minorities that can be more or less integrationist or multicultural. 
Secondly, dropping 'secularism' does not mean that no norms are left for dealing with religion. It only suggests that we have to understand them in terms of what they are: liberal democratic norms of freedom and equality. And we do of course have to deliberate on the tensions that can exist between them, as also in religious contexts (Bader 2007, Brahm Levey 2009). We can then argue for a pluralism that is firmly anchored in human rights and constitutional boundaries, but which neither positively nor negatively privileges religious identities. Brahm Levey and Bader also make clear that the actual ways of accommodating religion in liberal societies, Islam included, are not that different from other multicultural policies today, nor from earlier liberal policies for dealing with diversity, both linguistic and religious. Brahm Levey (2009: 24) characterises them by the term 'principled pragmatism'. I'd like to add that these liberal traditions have not prevented liberal states from trying to overcome their seemingly pragmatic ways of dealing with diversity: there is nothing specifically new in today's assimilationist dealings with Islam. Strong pressures for homogenenisation or universalisation have caused liberal states to become less realistic and pragmatic, and also illiberal, especially towards indigenous peoples and religions in colonial contexts - and this is something that France, Britain, the Netherlands, Canada and others share. Arguably, these policies were among the causes of much violence throughout the course of modernity (see, e.g., Césaire 1950; Fanon 1952; Young 1990; Asad 1993, 2004; Bader 2007; Laborde 2008; Lazreg 2011).

Thirdly, Bader and Brahm Levey argue against the idea that Islam is different from other religions. Very briefly summarised: Islam is transnational, but so are Catholicism and Judaism. Piety is not specifically Islamic, and neither is its preference for ritual and law, which it shares with Judaism. This doesn't undermine these religions' capacities for tolerance, religious freedom and pluralism, as Mendelssohn already suggested in the Enlightenment age as a reaction to Kant (see Brahm Levey 2009; Bader 2010).

What Bader and Brahm Levey propose is more or less in line with what other liberal multiculturalists have proposed insofar as they understand multiculturalism as a way of ameliorating unfulfilled liberal equality. Like Bader, Kymlicka (2002) anchors multiculturalism squarely within the framework of liberal democracy and urges us to look there for the norms for determining whether specific claims should be accommodated or not, for example, in human rights law with regard to freedom of conscience. Kymlicka (ibid.: 340) formulates the liberal crux as follows: multiculturalism is meant 'to regulate the power inequalities between minorities and the larger society, but not 
to legitimise internal restrictions on the actions of individuals within specific minorities'.

The specific problematisation of secularism from a multicultural perspective does urge us, however, to be critical about liberal democracy as a normative framework itself, and this is what is missed in Kymlicka. This is not because it should be complemented by a 'communitarian', thick multiculturalism à la Taylor (1994) and Parekh (2000). Nor is it because of the related post-secular argument that religion should be respected more because of its indispensable semantic content (as it is argued in Habermas 2008), or because of its privileged access to a world of meaning and fulfilment (à la Taylor 2007). Instead, liberal democracy should rework itself insofar as it has, historically, tended to give religion a special status in terms of its being the remnant of a premodern, pre-liberal age within modernity. In as far as liberal democracy takes that secularist line of argument on board, it has stood in the service of an 'us' wanting to assimilate (or exclude) an as yet illiberal (or premodern) 'them' (see Parekh's (1994) argument about Mill (1863); Chakrabarty 2000; Mezzadra 2006).

In tandem with the contemporary sociology of religion and the anthropology of religion, the counter-argument is that religion's relations to modernity are simply much more complex than this secularist strand of thought can acknowledge. We cannot say anything general about such a complex, thoroughly historical and historically constructed concept and its related cultural practices. Here it would help if we took a lead from liberal democratic institutionalised practice, and not from liberal political philosophical ideas, because it is especially the philosophies, more so than the practices, which are often fraught with the remnants of the idea that religion is a necessarily a-liberal, premodern power, and the related idea that Reason (or reasonability) can and should free itself from this irrational Other. Therefore, we should criticise secularist biases in liberal democracy and especially in philosophical, foundationalist liberalism, more than actual liberal democratic constitutions and institutions (Bader 2007, 2008).

Such a historicising reading of religion offers the contribution of accommodating some (or many) religious claims without seeming to require a brand of communitarianism that is at odds with liberal values. Conversely, however, it can bring up for discussion religion's placement in a position of privilege, when it is suggested as being an almost sacrosanct domain, where freedom of conscience constitutes a licence for absolutist alignments. Such alignments do not form the essence of religion, in contrast to the way that religion is represented by contemporary fundamentalisms, and even by some versions of liberal- 
ism and secularism. They cannot be justified by the liberal-secular idea that religion is, almost by definition, irrational and premodern and opposed to a liberal, modern state. This argument is related to the position adopted by Habermas in 2008, but in his work we find implicit references to the idea that deeply religious points of view should, almost for their own sake, also be dogmatic (see further Jansen 2011a). Elsewhere, I argue that Taylor (2007) facilitates a critical reading of religious absolutism with his genealogy of religion and secularity, but he fails to make this explicit (see further Jansen 2013b).

The institutional and self-reflexive philosophical programme that I outlined above should, however, be complemented with historical and cultural work if we want to analyse and possibly help to break down the cluster of associations that have arisen around multiculturalism, secularism and Islam. In what follows I try to show that the modernist framework is involved in a securitising interpretation of contemporary religion as a sign and an expression of a combined traditionalism and hypermodernism threatening modernity. In this context, I now address one further element in the reasoning of the Stasi Commission. This concerns the question of what actually comprises a political religion: how is it distinguished from public religion or from a religion that encompasses cultural practices visible in the public realm?

\subsection{Postmodern identity politics and security}

The Stasi Commission does not exactly explain what it means by its statement that the scarf is considered to be a conspicuous religious sign and not just a normal religious sign or even a religious practice. It does suggest that its reason for this is that the scarf is not seen as an element of an ethno-religious heritage passed on between the generations, but rather as an anti-modern construction. This interpretation emerges, for example, in the Commission's claim that the scarf was affirmed in the Muslim world as a new tradition in the 1970 s with the emergence of radical political-religious movements, and that the scarf appeared in French schools only from the end of the 1980s onwards. ${ }^{5}$ While the Commission professes the need for individuals to distance themselves from tradition, it does not interpret the headscarf as the product of tradition, but rather of postmodern identity politics. With Islamism, we are not talking about the capacity to distance oneself from one's tradition, but about the will to do so. This takes us from the realm of cultural laicism to a more political line of analysis also available in the Stasi report. What is the relation between the cultural laicism that I 
explained above and the political arguments that the Stasi Commission gave for the proposal for a law?

From the Stasi report and the subsequent debates, it has become clear that a specific interpretation of laicism was a motive of some of the committee members to propose a ban, but not the motive that constituted the consensus among the committee members about the necessity of legislation. Instead, the near unanimous decision to propose legislation against the headscarf was motivated by the Commission's perception that it was dealing with an issue concerning public order that overruled concern for liberty of religious expression:

In the secular framework, spiritual or religious choices form part of individual freedom; however this does not mean that these things should be confined to the intimacy of conscience, 'privatised', or that all social dimensions or public ways of expressing them should be denied to them. Laïcité distinguishes free spiritual or religious expression in public space, which is legitimate and even essential to democratic debate, from the attempt to control it, which is illegitimate [de l'emprise sur celui-ci] (Stasi 2003: 1.2.1).

The Commission's decision was based on the idea that with regard to headscarves, in 2003, public order was at stake. The question was no longer one of deliberative participation in the democratic debate, nor even of negotiation on the basis of spiritual values, but an attempt, by Islamist groups, to control democratic debate. ${ }^{6}$ This presumed attempt to control justified the measure against the scarves:

Freedom of conscience does indeed form the rule and police measures should be the exception, but public powers always do have the possibility of taking measures that limit the manifestation of the freedom of conscience in order to prevent risks of troubles to public order (ibid.: 2.2.2). The commission thinks that today it is no longer the freedom of conscience which is at stake, but public order (ibid.: 4.2.2.1).

Because of this presumed threat to public order, the Commission deemed it necessary for public forces to send off 'strong signs' to the 'Islamist groups', and the prohibition of the scarf at school was to be the most important one (ibid.). This was done partly at the request of schoolteachers who had reported conflicts between groups of pupils of diverse backgrounds, and of girls who had reported that strong pressures were exercised on them to wear a headscarf. So we have to deal with an exceptional 'police' measure, a proposal for an intrusion by 
the law into a domain of society usually and preferably left to the citizens themselves, not with a reasoning on the basis of comprehensive laicism.

It would be too easy to present this context as being a legalistic front for an underlying comprehensive laicism. Rather, it is important to trace how cultural laicism itself was related to the public order argument. Doing so helps us to understand how the recent motivations for the law on the burqa, which have been phrased entirely in terms of 'public order' and explicitly refrain from referring to laïcité (discussed in Mathieu \& De Hert 2011), are related to cultural laicism. I will show that there is an intricate and complicated relation between secularism's modernist framework and the role of public order in French discourses, and analyse how this role is related to the interpretation of the scarf as a religious sign with distinctly political connotations.

In critiques of the politics of laicism that have been formulated from within France, laïcité has often been seen as an ideology, while racism and processes of securitisation are considered the underlying motives or causes for various policies towards Muslims, and North-African Arab Muslims in particular, as a colonial legacy (Bourdieu 1989; Geisser \& Zemouri 2007; Balibar 2006; Deltombe 2005). These critics saw the discourse on secularism and religious conflict as a distraction from what really mattered with regard to migration from North Africa, starting with Bourdieu (1989) in his comments on the first protests against headscarves at school in 1989. He saw such protests as an expression of hidden opposition to the presence of North Africans in France. In the footsteps of these criticisms of explaining everything surrounding Islam in terms of the framework of laïcité and religion, sociologists have also opposed explanations of conflicts such as the 2006 riots in the Paris banlieues by commentators like Alain Finkielkraut, who argued that it was an 'ethno-religious revolt'. Instead, these critics said, they should be understood in terms of economic exclusion, racism and police harassment (see, e.g., Balibar 2007), and in line with an increasing securitisation of Muslim claims (Bowen 2010a; Cesari 2010).

In a complicated variation of this view, American historian Scott (2007: 173) suggested that security is not so much the issue in France, but that it is more the protection of a universalist culture of laicism, the 'preservation of a mythical notion of France'. She argued, however, much in line with authors such as Nordmann and Vidal, that this universalism is ultimately itself an exclusivist racism.

I would add that the culture of laicism, which is reliant on the unquestioned modernist dichotomies discussed in the previous chapters, and the perception of the Muslim presence as a security issue are 
internally related. This might be an important but neglected aspect in the debates about French secularism, and, by extension, also in some of the international debates about secularism. Let me try to put my finger on how French sociological and political philosophical discourse has influenced interpretations of the scarf as an exceptional issue of public order by discussing a few propositions that are significant for this aspect of the discourse.

\section{GiLLes KePel}

Kepel, one of the members of the Stasi Commission and a specialist in 'urban Islam', has made several observations about the constructedness of contemporary 'communautarian' Islam. As early as 1993, speaking about Islamism in the French banlieues, he stated:

They are tribes [tribus] that establish their communitarian borders around projects and not around what we usually consider to be tribal, namely inherited collective belonging, whether this be ethnic, racial or other (Kepel 1993: 78, my translation)?

By calling them 'tribes', Kepel associates these Muslims with the most premodern, immediate kind of cultural group that 'we', modern sociologists, have been able to document. Yet Kepel shifts the direction of the tribe on the axis of time. His tribes are not related to the past at all, but to the future. From within such an interpretative framework, wearing a headscarf has to be read not as a sign of premodern belonging, nor as the execution of a religious duty or a provocative minority practice, or any combination of those elements, but rather as nothing but a reflexive, 'conspicuous' and demonstrative sign of distinction, perhaps even of anti-Western and (hyper-)modern identity politics. Such a framework would delegitimise beforehand the argument that wearing a scarf, or other public religious practices related to those tribus, could be taken as anything other than an outward sign of an identity. And this is what has occurred in the definition the scarf has received in France as a signe religieux ostensible instead of as the execution of a religious obligation (Asad 2006: 502). Prohibiting the headscarf in public places, following this interpretation, does not imply a denial of freedom of religion - for the wish to wear one does not follow from a religious adherence that is relatively independent from the entry of the individual into the new polity. Instead, it is a sign of the kind of participation the new citizen chooses: she (or the 'he' behind her) positions 
herself as a negative, 'communitarian', perhaps even separatist citizen who deliberately appeals to (religious) authenticity.

Kepel's brief interpretation is an example of the projection of modernist dichotomies between past and future, absolute rule and freedom, onto Muslim practices. This 'others' them out of a more modest or pluralistic modernity by simultaneously ascribing to them the premodern wish to establish tribal ties and the hypermodern wish to fully break with the past. Even to the extent that some of the claims were structured in this way, we might still ask if they were inherited from modernist secularism's dichotomies and the ways these dichotomies were spread across the Muslim world. ${ }^{8}$

\section{Alain Touraine}

Alain Touraine also served on the Stasi Commission. We already mentioned that he was among the proponents of a new, moderate laïcité compatible with moderate, liberal multiculturalism, but that he endorsed the law banning religious signs because France had become, in his view, 'a communitarian country'. He blamed this state of affairs on the radically segregationist claims of Islamist groups. Let us now consider a brief comment he made in 1990 on the emergence of communautarisme. ${ }^{9}$ In his analysis of riots in Vaulx-en-Velin, a suburb of Lyon, that had been described as the 'intifada of the cités' by French media, he wrote:

[N]ational societies are becoming dislocated ... [by an] astonishing movement of demodernisation: we had learnt to define human beings by what they did, instead of what they were; nowadays we follow the reverse route and on all sides agents are being formed defined by what they are. The social and political sphere is breaking up and the individual is faced with the internationalised economy and communities defined by their specific nature, both by their own traditions and by their acceptance or rejection by others (Touraine 1990: 8, quoted in Kepel 1996: 207-208).

Touraine also argues that society's great challenge is to defy this dislocation, where the central conflict is no longer between 'exploiters' and 'exploited', but between 'insiders' and 'outsiders' (ibid.: 208). Touraine's argument is again based on the fundamental modernist oppositions associated with the concept of modernity. He argues that modernity once meant that we defined humans by what they do and not by what they are. Touraine's use of the concept of demodernisation has a strong moral implication because he quotes Vladimir Jankélévitch's well- 
known understanding of anti-Semitism. In 1942, Jankélévitch wrote that fascist anti-Semitism meant that 'perhaps for the first time people are being officially persecuted not for what they do, but for what they are; they atone for their "being" and not their "doing"... This gives full meaning to the immemorial myth of the "cursed people"' (quoted in Taguieff 1987: 25, my translation). Although neither Touraine nor Jankélévitch is overly critical of the modern, absolute distinction between being and doing, the latter at least suggests that the strong distinction itself might also be a product of modernity. This insight is entirely absent from Touraine's understanding.

Touraine's analysis once again constitutes a manifestation of a dichotomy between autonomy and heteronomy. Autonomy is reserved for some levels of human organisation, such as the individual and the state, while heteronomy seems inextricably linked to other levels, such as the global and the ethnic, and mediations between these levels seem nearly impossible. This brings Touraine to suggest that democracy will be lost through the combined processes of globalisation and communalisation, instead of taking new forms. Both processes lead to demodernisation, and modern autonomy will be replaced by a determination by the 'other', by a non-democratically organised world economy and by the laws - or even the (constructed) customs and moralities - of communities.

It might be asked whether such a preconceived idea of the challenges to modernity by a demodernising movement of globalisation can have formed a conceptual scheme that caused, or at least precipitated, Touraine's change of mind about the undesirable communautarisme around the headscarves. Awareness of this conceptual background may also help us to better understand the securitising turn that the debates within the Stasi Commission must have taken in the last weeks of deliberation before the publication of the report. Let us take a closer look at a letter written to all members of the Stasi Commission by Touraine near the end of the Commission's hearings, when Touraine was still not in favour of the prohibition of the headscarf at school..$^{10}$ This letter was published in 2004 by Jean Baubérot:

We have to separate clearly the defense of personal rights from the struggle against communitarianist attacks against institutions ... I add, more concretely, that it would be manifestly absurd to prohibit the veil in the name of feminism and the dignity of women, because such a decision would imply that women are considered manipulatable, incapable of taking decisions themselves and consequently, to consider them 'minors'. In the same manner, in the present circumstances it is impossible that an 
entirely negative or even repressive orientation could be considered as anything else than an act of hostile closure of a West that feels itself being attacked - and justifiably so - by the Islamist offensives (Touraine, quoted in Baubérot 2004: 114).

I have italicised the metaphors and literal references to conflict, violence and even war. Note that Touraine explicitly rejects laicism as a reason to propose legislation. He opposes the law because it would be seen, he writes, as an act of closure. Yet at the time he wrote this letter he already conceived the law against the scarves in terms of public order, namely as a disciplinary measure in a struggle between 'The West' and 'communitarianist attacks', later reinterpreted in terms of 'the Islamist offensives'. This interpretation is fully in line with his earlier interpretation of riots in the banlieues in terms of a threatening demodernisation. We might ask how this initial framing influenced his later diagnosis of an undesirable 'communitarianisation' in France that caused him to vote in favour of the law prohibiting the scarves.

\section{MARCEL GAuchet}

Marcel Gauchet did not form part of the Stasi Commission. In his Religion in Democracy (1998), he analyses the emergence of communautarisme in France. Regularly referring to the work of Charles Taylor and José Casanova on recognition and public religion, Gauchet is one of the French public intellectuals who is most reluctant to reject communautarisme in general. He also interprets public religion in a larger context than that of the presence of Islam in France, namely in the context of what he calls the 'age of identities'. Yet I trace a similarly problematic conceptualisation of contemporary religion going public in his work as in that of the Stasi Commission.

Gauchet interprets public religion in the context of what he calls 'the age of identities', the (postmodern) era in which beliefs have turned into identities. In this new age, according to Gauchet, the individual has started to live her or his beliefs both inwardly, as an experience, and outwardly, in how she or he places himself or herself in the public sphere. Let us now look at the way in which Gauchet presents the historical development of modernity into the 'age of identities'.

According to Gauchet (1998: 123), the emergence of identity transforms the related concepts of subjectivity and citizenship that were dominant in Western society from the end of the 18th century onwards. Being a self no longer implies trying to become a moral subject in the sense of someone who acts with a moral law in mind. In modernity, 
'personal identity' meant becoming 'me' in the sense of transcending one's own point of view in order to ascend to the one supposed to be valid from a universal point of view. However, these ideals of 'individuality, subjectivity, humanity', inherited from the Enlightenment, have been surmounted in the age of identities. We can no longer become selves by freeing ourselves from what determines us and by giving ourselves the law - by becoming autonomous - as in the Kantian understanding of Enlightenment. Instead, the new identities 'make us turn to the antipodes of that [old] identity' (ibid., my translation).

Still following Gauchet, our age is characterised by a systematic shift away from universal citizenship. To be a citizen, we no longer have to break free from what determines us, from our 'natural', that is, traditional, surroundings. Instead, we bring what determines us into the arena of self-definition. What one belongs to and what one inherits, one's sexual orientation, being a woman, having Arab parents, is what one has to join together subjectively. We even make these determinations into the main elements of our self-definition. 'The real me is the one that emerges from the subjective appropriation of social objectivity' (ibid.: 124, my translation).

In his analysis of the transformation of modernity into the age of identities, Gauchet suggests that citizenship at one time implied autonomously exercised subjectivity. This view is a clear example of Republican nostalgia, for such subjectivity never existed. Indeed, the suggestion that it did or should has led to many illusions and played a role in producing the exaggerated imaginaries of 'difference' that we studied in Proust. Talking of 'turning to the antipodes' (basculement) suggests, moreover, that the transformation of modernity into the age of identities did not occur gradually but suddenly. The choice of this image is profoundly indebted to dialectical interpretations of Enlightenment in line with an understanding of the French Revolution as a radical, and violent, break with the past. It is the result of the projection of a simplified Kantian scheme on a complicated history.

The interpretations of Kepel, Touraine and Gauchet have in common the fact that they seek to overcome the old orientalist stereotypes of the East, which associate Islam with premodern backwardness. Yet an equally over-systematised figure of thought reoccurs as a pattern of interpretation: a conceptual framework that closely connects the relation between tradition, modernity and the 'age of identities', or between 'immediacy', 'subjectivity' and 'construction', with radical, possibly violent change, dialectical turning points and epochal breaks. This is an imagery inherited from modernist interpretations of the Enlightenment and the French Revolution. 
Such frames make it possible to construct, essentialised and abstracted from each other, concepts such as tradition and modernity. Yet when we first separate past, present and future, or, analogously, tradition, modernity and the age of (constructed) identities, to then project these separated categories back onto people's attempts to find mediations between freedom and belonging, we are projecting simplified philosophical figures onto actual situations that are much more complex and entangled. Returning to these inherited frameworks cannot serve as a useful basis for normative views, subsumed under the heading of laïcité, about how we should live together in a diverse society.

The binary opposition of laïcité and communautarisme depends on the historically abstract representation of the relationships between tradition, modernity and postmodernity, or, in other terms, between appartenance (belonging), citizenship and identity politics. This representation to some extent seems to determine the perception of Islam in France. It is being reproduced on the side of both Republicans and Islamist groups. While Republican France recurs, in tropes and concepts, as the representative of modernity, Islam is figured as an ingenious and potentially threatening mixture of premodernity and hyper- or postmodernity, as a combination of reified culturalism and globalised political religion.

From within the modernist framework of interpretation, it is not the scarves themselves that cause the worries, but rather the presumed anti-modern communautarianism or identity politics behind them. This is closely connected to the frequent questions in the French context relating to what is 'behind the scarf' or to 'the veil, what does it hide?' (see also Bowen 2010a). In this sense, the scarves derive their public relevance not from their visibility, or even from their allegedly proselytising significations, but from their underlying potentially dangerous, inimical politics. If these politics are hidden behind the scarf, then its public relevance, ironically, is as a sign of something private, not in the sense of 'apolitical' but in the sense of 'secret' or 'interior', but still as something definitely collective. The modernist framework of interpretation provides an underlying, systematising layer to the distrust of Islam and of Muslims, aside from that arising from the real acts of terror that have been committed in Islam's name.

The division, even when subtly argued, between a modern 'us' and an either premodern or hypermodern 'them' encourages polarisation between, on the one hand, the majority of the French, and, on the other, ethno-religious minorities, in particular Muslim ones, and perceptions of them as potential sources of disturbances of public order. 
For this reason, it is important to understand that lä̈cité is not, as its proponents suggest, merely the morally justified anti-discriminatory answer to the communitarian Islamist claims. Rather, it stands in a complicated relation to both securitisation and discrimination. I will trace this relation further through the views of Olivier Roy. This also allows me to return to the concepts of religion and culture with which the debate commenced.

\section{OLIVIER ROY’S LAÏCITÉ AND GLOBALISED ISLAM}

Roy developed his authoritative view of a globalising Islam in Globalised Islam (2004) and La laïcité face à l'islam (2005). I argue that the dichotomous conception of belonging and freedom which I discerned in the discourse of laïcité also appears in Roy's sociological analysis of contemporary Islam, though he is as critical of the frame of laïcité as of multiculturalism.

According to Roy, both laïcité and multiculturalism assume the existence of Islamist 'communities' or contribute to their formation. He considers laïcité the ideology of a Republic 'obsessed with the religious' and 'fascinated by the monarchy' (Roy 2005: 63). Laïcité frames the claims of an Islam that wishes to become visible in the public sphere in terms of a contest for political power, thus translating social religious identities into political ones. In doing so, laïcité enhances the formation of religious identities linked with political contestations, instead of facilitating their merging with more diverse identifications and practices. Multiculturalism, on the other hand, links Islam to migrants' cultures of origin and tends to grant power to conservative elites supposedly representing entire ethno-religious groups. For Roy, however, these elites at most represent the purely religious neo-communities of those who explicitly declare themselves their 'members'.

Underlying Roy's critique of contemporary normative philosophies of integration is a sociological analysis of contemporary Islam, particularly of the 'public' Islam that is challenging the diverse European secularisms. Roy argues that this public Islam is not a traditional Islam inherited from migrants' cultures of origin. Rather, it forms part of a wider 'return of the religious' in a globalising world, also apparent in, for example, Christianity and Hinduism. In the case of Islam, the emergence of such a 'neo-fundamentalism' (salafisme) has become politicised because of the history of the Middle East. But this does not prevent Islam from taking part in a dynamics of globalisation and secularisation just like other religions. This is particularly the case in the West, where Islam has become a minoritarian religion and has been 
brought to recognise a secular realm outside religion. Moreover, in the globalised neo-fundamentalist Islam, all ties to specific cultures (and states) are deliberately cut in the search for a universal religious community, the Ummah. ${ }^{11}$ Second- and third-generation migrants, in particular, may feel attracted to neo-Islam, because they can use it as an 'apology' for the 'deculturation' and 'uprootedness' that have resulted, for some, from migration (Roy 2005: 128).

Roy links the emergence of global Islam to the individualisation processes demanded from individuals living in the West in general. New global media such as the Internet fit this new, deterritorialised religion perfectly. Being a Muslim, like being a believer of other religions, has become a matter of choice, and those who choose to make it a crucial element of their identities should be considered born again Muslims rather than Muslims in any cultural (ethnic) sense.

Roy considers the results of both the frames of laïcité and multiculturalism disastrous. Laïcité squeezes this neo-religion into the old frame of a religion aspiring to state power, though the level of the state is precisely not relevant to this Islam. The emphasis on laïcité creates among majorities fears of an Islamic communautarisme - analogous to those anxieties in the 19th century about the classes dangereuses when, in actuality, these communities hardly exist (Roy 2005: 146). Only very weak forms occur and these develop at the level of neighbourhoods or in even weaker, more imaginary forms at the global level. They do not emerge, however, at the level of the nation-state. Moreover, laïcists tend to create a divide between 'good' (liberal and secular) and 'bad' (fundamentalist) Muslims, excluding from dialogue those that should be included and dealt with. Earlier Roy (2004) argued that the position of Islam in France should be understood in terms of a heritage of merging religious claims with anti-colonial ones in the period of decolonisation, as well as the incapacity to find strategies for pacification in that ongoing postcolonial context. This has become even more complex because of the merging with processes of social-economic exclusion.

Multiculturalism, on the other hand, addresses conservative elites as representatives of pre-defined ethno-religious groups. These elites can acquire political power over non-believers and over those who consider themselves secular Muslims by claiming the right to protect these ethno-religiously defined communities from assimilatory pressures. Policies based on a better understanding of neo-fundamentalist Islam would avoid creating or imagining more extensive communities than there actually are. They would exclude no religious groups from dialogue and would not interfere with other people's dogmas, while at 
the same time never considering the spokespersons of religious groups as representatives of entire ethno-religious communities. ${ }^{12}$

Although Roy's criticism of the frames of laïcité and of a top-down conservative multiculturalism is welcome, I have some problems with his interrelated use of the concepts of culture, multiculturalism and secularisation in his understanding of globalised Islam, which he deems necessary in order to present his critique. With regard to the concept of culture, speaking of the 'deculturalisation' of second-generation immigrants and endorsing the theoretical possibility of a strict separation of religion from (ethnic) culture assumes an essentialist notion of culture that links it to an ethnic particularity and immediate belonging, which members of the second generation lose or can even actively reject. But what about the relation of neo-Islam with a more general concept of culture that encompasses practices, beliefs, ways of doing, seeing and thinking, as well as ways of negotiating with the members of majorities and the making of culture in the process? I will return to this question after addressing my second, related concern. By not distancing himself clearly from the neo-fundamentalist concept of Islam's 'deculturalisation' into a pure religion, even deploying it in his own conceptual scheme, Roy assumes a problematic understanding of secularisation as well. He (and the neo-fundamentalists) seem to follow the modernist understanding of secularisation as the radical individualisation of religion, leading to religion's complete break with tradition and ethnic belonging. In short, with the strong opposition between (ethnic) culture and (individualised) religion, we seem to reencounter in Roy's sociological notion of secularisation the dichotomy between belonging and freedom that I criticised in the discourse of laïcité.

The suggestion that a 'deculturalisation' of religion is possible is based on the 'strong theory of secularisation' inherited from modernist philosophy and sociology. Historically, as we have seen, this notion of secularisation is linked to the interpretation of Protestantism as an individualised 'religion of the heart' that severs itself from the culte, from tradition, and from institutions. We came across this notion of secularisation when discussing Third Republican neo-Kantian pedagogy which suggested the full autonomisation of morality from the 'culte' in Protestantism. Roy's endorsement of a similarly strong version of secularisation overlooks the many criticisms that have been made of the modernist concept of secularisation as privatisation and individualisation, even in the context of Protestantism. In Chapter 6, we saw that Durkheim already voiced such a criticism. 
In contemporary philosophies of religion critical of secularism, the 'return of religion' not only designates a changed state of affairs in society, but in theory as well. The return of religion in theory corrects earlier theories of religion and secularisation, which Roy seems to endorse and which he projects onto contemporary neo-Islam. For example, a systematic critique of individualised, modern religion as separated from cultural practices has been made via Wittgenstein's philosophy of meaning. Wittgenstein (1984 [1952]: 344) rejects the possibility of (Cartesian) subjectivities by refuting the possibility of a private language and by arguing that meaning-making is an inevitably social, cultural practice, a matter of linguistic Gepflogenheiten, or customs. This is also the case with religious meaning-making (Asad 1993). ${ }^{13}$

Such a critique could lead to the view that all three versions of the modernist secularisation thesis should be deconstructed, whether they refer to the privatisation of religion, to its individualisation (the two are often conflated) or to the separation of religion from politics. In reply to the first interpretation, we may suggest that believers may recognise that their beliefs and practices are contingent and minoritarian, but this does not mean that they will (or have to) privatise their religion. Second, religion may individualise to a certain extent, but never to the point of becoming purely subjective or deculturalised - this is my main point contra Roy. Third, organised religions may develop as public religions while at the same time being modern in the sense of being open to democracy: it is a mistake to conflate public religion with religion's monopolistic political pretensions (see Bader 2007). ${ }^{14}$

Roy's interpretation of neo-Islam is not only problematic theoretically, but also politically: it draws boundaries between an Islam inextricably linked to quite immovable cultures of origin on the one hand, and a supposedly deculturalised, deterritorialised neo-Islam as the Islam des jeunes on the other. Furthermore, it links images of a (dangerous) deculturalisation and uprootedness to young Muslims in an overly systematic way.

The concept of uprootedness in particular is anchored in rightwing tradition. We encountered it in Chapter 4 when discussing Barrès's view of the Republic. We cannot just forget about this genealogy. I would remind the reader of my interpretation of Bloch's situation at the threshold of the protagonist's family. In my interpretation, a double bind came to light which entrapped Bloch. In the family's moderately secularised Catholic world Bloch is perceived as too ethnically Jewish but also as too modern, and therefore uprooted at the same time. This is the result, specifically, of the fact that Marcel's family oscillates between Republican and ethno-religious concepts and experiences of 
belonging: they believe in universal citizenship and the requirement to give up one's ethnic identifications on the one hand, while they remain firmly attached to their own identity (actually to their habits) on the other. Bloch is judged according to the letter of Republican citizenship, while the family's own habitual practices remain unperceived.

By understanding neo-Islam as a fully secularised, individualised religion under conditions of uprootedness, Roy presses it into a frame that is as old as the frame of laïcité that he so criticises. This frame, moreover, is based on the same modernist divides between belonging and freedom, autonomy and heteronomy, and private and public inherited from the 19th century.

\section{BACK TO CULTURE}

Instead of assuming the deculturalisation of religion in modernity, we should rethink the relation between religion and culture. I would like to suggest that a sophisticated notion of culture can play a mediating role, linking the emergence of globalised Islam to the particular cultures with which it interacts. I do not mean culture in the sense of a reified copy of the (past) culture of origins, but culture as a nodal point linking (in this case) religious experience and practice to memories, power positions and the experiences constructed by others in the present. To substantiate this, before returning to the headscarf issue, I would like to briefly discuss Bonnie Honig's definition of culture, as proposed in her reaction to Susan Okin's famous thesis that multiculturalism is bad for women:

'Culture' is a way of life, a rich and time-worn grammar of human activity, a set of diverse and often conflicting narratives whereby communal (mis)understandings, roles, and responsibilities are negotiated. As such, 'culture' is a living, breathing system for the distribution and enactment of agency, power, and privilege among its members and beyond. Rarely are those privileges distributed along a single axis of difference such that, for example, all men are more powerful than all women. Race, class, locality, lineage all accord measures of privilege or stigma to their bearers. However, even those who are least empowered in a certain setting have some measure of agency in that setting and their agency is bound up with (though not determined by) the cultures, institutions, and practices that gave rise to it (Honig 1999: 39).

This definition is packed with contrasting elements. To my mind, it grasps what culture can mean once we put aside both its essential- 
ist definition in terms of 'original belonging' and the anti-essentialist or constructivist attempt to empty the concept of culture to the point of denying its relevance. Honig's definition grasps the complexity and pervasiveness of culture. It inextricably links belonging and freedom or, analogously, structure (system) and agency. What might have been added is a note on the relational, negotiational and ironic elements of culture as made by different individuals and groups occupying various power positions. Another amendment should address the way Honig's definition (implicitly) separates culture from practices, a separation that is an unnecessary legacy of modernism. Culture thus defined is relevant to contemporary discussions about Islam in relation to secularism in at least three ways, to be discussed in what follows.

We need to conceive of a systematic link between Islam and culture if we wish to analyse the position of Muslims in France, not only in terms of their self-definition but also taking into account the ways in which they are positioned and made into ethnic others by the members of the cultural majorities. There is a subtext of ethnic othering and xenophobia linked to Islam that is difficult to address if we stay within the discourses that focus exclusively on Islam as religion. Let us not forget that the first headscarf affairs coincided with Marianne wearing a hijab or tchador in political cartoons (Birnbaum 1998). Ethnic othering is not the exclusive domain of the Front National, but it also penetrates the laïcité frame. Most strikingly, this was demonstrated by the fact that, the day before the Stasi Commission presented its report, Le Monde published a petition signed by many famous French feminists claiming to defend the rights of women:

The Islamic veil pushes all of us, Muslims and non-Muslims alike, towards an intolerable discrimination against women. All complacency in this regard will be perceived by every woman of this country as a personal attack on her dignity and freedom (Pétition Elle 2003, my translation, my italics).

We need to link Islam and culture (in the sense of ethnic culture but not in the sense of inherited ethnicity or tradition) theoretically so that we can analyse and criticise the mechanism of exclusion that betrays itself here: 'if you do not think like us, you do not belong to us'. A notion of culture is highly relevant for understanding the position of Islam in France in relation to intercultural memory, which is a memory that links religion to power positions (Bourdieu 1989; Bowen 2007a). This is an evident and necessary step in the case of Islam in France, considering its (post-)colonial background. Let me give a brief example. 
Some years ago, I spent a long day in Paris with Samia Touati, a young Algerian woman who was studying in Paris and wore a headscarf. In reply to my questions about her scarf, she at first stated that the scarf was something between her and God. Yet this was not the only motive she gave for wearing the scarf. Her second answer, that 'our mothers wore headscarves when they cleaned the houses of the French', contains a postcolonial and class-based argument. For Samia, the headscarf became a problem in the eyes of the French when Muslims started to be citoyens. Her argument evoked the fact that in Algeria, until 1947, Muslims were considered sujets and could become citoyens only after having satisfied highly selective, arbitrary and assimilatory criteria, while Christians and Jews were automatically considered citizens (Weil 2009; and specifically, on the headscarves in Algeria, Shepard 2006).

Taking memories seriously does not imply the use of a reified concept of culture. A definition like Honig's will do. Such a concept of culture is more dynamic than Roy suggests; it can help us to embed cultural and religious claims in history and to connect them with agency without declaring them purely constructed or ideological in advance. This should even be considered crucial to a democratic concept of memory (Bauboeck 1998). Use of memories can also help us to understand the relevance, in the European context, of the anthropologist Magnus Marsden's argument about the everyday lives of Muslims in Pakistan's North-West Frontier Province (NWFP), saying that it is time to challenge 'any lingering notion in the anthropological study of Muslim societies that the daily thought and actions of Muslims is best understood in terms of what falls within the domain of the Islamic and what lies in the realm of "practical reason"' (Marsden 2005: 53, quoted in Bangstad 2009). This is one more reason for wariness about the near exclusive focus on the framework of secularity and religion when dealing with questions concerning the position of Muslims in European societies.

Let us now turn to Marcel Proust's literary exploration of cultural memory to increase our understanding of the relationship between modernist categories and dichotomies on the one hand, and the emergence of what we might call, ironically, 'multicultural conflict after assimilation', on the other. 



\title{
CHAPTER 8
}

\section{The highly precarious structure of assimilation}

\author{
Modernist philosophical schemes, memory and the \\ Proustian narrative
}

\subsection{The invention of tense pasts after assimilation}

The previous two chapters have argued that a critique of laïcité invites a critique of the underlying concept of secularisation, and of the ways in which this is related to lingering traces of modernist concepts of the subject, of citizenship, and of modernity. I raised critical questions about the expectation that the conceptual separation of religion from visible, plural, polysemic cultural practices that are suffused with habit, custom, ethos, and, in addition, with others and power, will prove capable of contributing much to stability, fairness or democracy in multicultural societies. Moreover, I argued that the paradoxes of assimilation as they were experienced by the French Jews in the early Third Republic are taking new forms today, especially insofar as secularist discourses and conceptual frameworks are mixed up with motives connected to security.

This chapter fleshes out a further Proustian contribution to the debate about secularism and assimilation, by analysing In Search of Lost Time's complex narrative of how characters transform their memories of their collectively shared assimilatory past in the tense intercultural situation of the Dreyfus Affair (see Transit I).

Proustian memory is usually read in the light of the narrator's individualistic metaphysics of memory, mainly elaborated in the theoretical reflections on writing and memory that form part of Time Regained (Le temps retrouvé), the final part of the novel. The narrator's views show affinities with Henri Bergson's philosophy of time and memory, and many commentators have turned the framework of Bergson's individualist metaphysics into a starting point for their interpretation of the novel, from Poulet (1964) to Deleuze (200o [1964]). A first step in my interpretation is to explain the subtle connection between the modernist view of the (religious) subject, which separates 'sentiment' from cultural practice and these individualising interpretations of memory in the Proustian novel. 
Benjamin (1980 [1938]) develops a striking critique of Bergson's interpretation of memory in his essay Some Motifs in Baudelaire by contrasting it with a historical interpretation of Proustian memory. He understands Proustian memory through two prisms: modernity and the assimilation of the French Jews. I pursue Benjamin's intuition and interpret the cultural and historical aspects of memory in the novel. However, I also argue that Benjamin's interpretation remains indebted to the dichotomous interpretation of modernity criticised in the previous chapters. For this reason, I develop an alternative interpretation of memory in Proust, one that is more attentive to the ways in which individual memories are subtly moulded through their connections with the collectives to which they are affectively linked, particularly in times of deep cultural conflict such as during the Dreyfus Affair. I analyse the role of forgetting for understanding the relation between individual and collective aspects of memory, and for understanding the formation of culture, drawing on the views of Veit Bader and William Connolly.

I explain my interpretation of Proustian memory by commenting on one particular strand in the Proustian narrative about a pair of red shoes, and linking this strand to the fairy tale of that name by Hans Christian Andersen (2005 [1845]). Red clothes, a red necklace and a pair of red shoes appear in Proust's novel each time it touches upon the fact that the aristocratic Madame (Oriane) de Guermantes 'forgets' her old Jewish friend Swann over the course of the Dreyfus Affair.

The red clothes are mentioned for the first time at the end of The Guermantes Way II when Swann and the protagonist pay a visit to the Duchess and her husband, the Duc de Guermantes. On the evening of the same day, the Duchess wears the red clothes to a party hosted by her niece, the Princesse de Guermantes. This episode is described extensively in Sodom and Gomorrah II. At the party, Swann's Dreyfusism is publicly rejected by the Duke and Duchess. In the following two occasions where the shoes and dress appear, they are the object of a conversation between the protagonist and Mme de Guermantes that takes place after Swann's death. On both occasions, Mme de Guermantes has forgotten important facts surrounding them, facts that concern the Dreyfus Affair. While she refrains from mentioning Swann, the Proustian text evokes his memory through repeated references to the red shoes and dress. The first conversation takes place in The Captive, the second occurs at the 'Ball of the Masks' at the end of In Search of Lost Time in Time Regained. 


\subsection{Adorno's and Benjamin's exchange about assimilation and the rejection of Swann}

In his last long letter of 7 May 1940 to his friend Theodor W. Adorno, Walter Benjamin comments on the historical aspect of the experience of time in Proust (Adorno 1977 [1940]: 203-204). Benjamin gives his brief response to a book review by Adorno, in which the latter wrote about the feeling that 'this is not it at all' as soon as one gets closer to a 'higher social circle', in the context of social practices that Bourdieu has captured by the term 'distinction' and that were called 'snobbery' in the late 19th-century literary context. Adorno had argued that Proust was the only writer really to have grasped this mechanism.

In his comment on this review, Benjamin writes that Adorno felicitously speaks of the Proustian experience of 'this is not it at all', where 'time turns into something we have lost' (Adorno \& Benjamin 1999 [1940]: 329). He further suggests that Proust had a 'deeply hidden model' for this experience, namely the experience of 'this is not it' lived by the French assimilated Jews. The Proustian insight into the 'highly precarious structure of assimilation' was, argues Benjamin, externally confirmed by the Dreyfus Affair (Adorno \& Benjamin 1999 [1940]: 330).

Let us now turn to the narrative strand of the red shoes. At the end of Le Côté de Guermantes II, the protagonist is in the Guermantes's salon and is told that Swann will arrive at any moment. Before Swann's arrival, the Duke tells the protagonist that the relation between the Guermantes and Swann has cooled. For twenty years, Swann had been Mme de Guermantes's closest friend, appreciated by her for his fine taste and his behaviour as an experienced homme du monde. The fact that he was of Jewish descent was hardly a topic during the long years of their friendship. Once, at the beginning of this friendship, a niece of Oriane had tried to make her admit that it was a bit strange for the sister of an Archbishop to receive the Jewish Swann, but Oriane refused: 'I am ashamed to confess that I'm not in the least shocked' (Proust 1996: I, 403). When the niece proceeded to argue, entirely in the line of the paradoxes of assimilation, that 'converted Jews' like Swann 'remain more attached to their religion than the practicing ones', Oriane wittily replied, 'I can throw no light at all on the matter' (ibid.).

Via the character of Mme de Guermantes, we find in the novel an extensive narrative of the erosion of the Church as a religious institution and of the after-effects of this erosion on practices of meaning-making and social distinction. In the first, most 'rural' part of the novel, Combray, members of the community from all social layers go to 
church every Sunday. It is around the Church that they are confronted most vividly with the rituals of social distinction - in particular in relation to the Guermantes family. Gradually, as the families concerned turn increasingly to Paris, the Church functions less and less as the symbolic centre of the distribution of social power. Most characters show little religious fervour. Mme de Guermantes is intimately connected by birth to the monarchy and to the Church (as sister of an archbishop), and thus to the history of the Church's worldly power, but she is not devout or even particularly nostalgic for the nobility's political power. She is the queen neither of Tradition nor of secularised Catholicism. Instead, she is the 'Queen of the present moment' (ibid.: $\mathrm{V}, 664$ ), a queen of fashion and ephemerality; in Baudelaire's sense, she is a typically modern character. ${ }^{1}$

Similarly, Swann displays neither religious practices nor religious 'sentiments'. But the Dreyfus Affair greatly affects Swann's 'Jewishness'. At the moment described, Swann has already partially lost Mme de Guermantes's friendship because of a socially unacceptable marriage, but his stance on the Dreyfus Affair now threatens the friendship in a more serious way, for her husband the Duke is a convinced anti-Dreyfusard. The Duke warns the protagonist not to mention that night's party, because he is not sure whether Swann has been invited. He explains that 'Swann ought to have realised that he more than anyone must drop all connection with those fellows [the Dreyfusards]' (ibid.: III, 668, my italics).

Why Swann 'more than anyone'? In the course of the novel, the Duke makes many remarks about Swann's Dreyfusism, invariably accusing Swann of betraying the aristocratic circles he frequented by becoming a Dreyfusard while also being a Jew. The intensity of the animosity during the Affair has caused Swann to distance himself from his old friends as well. When Swann and the protagonist find themselves together during the afternoon visit, Swann explains to him why so many nobles are anti-Dreyfusards: '[T] hese people belong to a different race, one can't have a thousand years of feudalism in one's blood with impunity. Naturally they imagine that it counts for nothing in their opinions' (ibid.: III, 673).

For the first time in his long friendship, Swann is cruelly confronted with the risk of exclusion arising from a conflict between groups whose relevance he had considered passé. Using the available terms of his time, he deploys the concepts of 'race' and 'blood' to indicate the extent to which historically different pasts, which had appeared to have become politically irrelevant, are re-inscribed into public identities at such moments of conflict. ${ }^{2}$ 
After rendering the conversation, the narrator writes that Swann's 'declassing' would have been better described as a 'reclassing', because it was to his credit that his Dreyfusism made him return to 'the paths which his forebears had trodden and from which he had been deflected by his aristocratic associations' (ibid.: III, 673). The narrator touches upon what Benjamin called 'the highly precarious structure of assimilation', which caused the experience of 'this is not it at all' at the time of the anti-Semitic reaction to Dreyfus.

Later in the novel, the narrator connects with this conflict again in terms of memory. He writes:

[Swann might have developed] a sense of moral solidarity with the rest of the Jews, a solidarity which he seemed to have forgotten throughout his life, and which, one after another, his mortal illness, the Dreyfus case and the anti-semitic propaganda had reawakened (ibid.: IV, 104; III, 89.)

The distance between the inheritors of feudalism and the Jews is suddenly not one of history any more, but one of the present. The fact that the Duke accuses Swann of betrayal as soon as his identification with the Jews is foregrounded by the Dreyfus Affair signals the extent to which his 'aristocratic associations' might always have demanded from Swann a negation of his Jewish background. But it also suggests that this negation was only virtually or potentially relevant: the talk of betrayal at least implies that the Duke had once trusted Swann.

When Mme de Guermantes finally arrives in the salon, the group starts a worldly conversation in which none of these sensitive subjects is touched upon. At the end of the afternoon, she even asks Swann to come to Italy with her for an art-historical trip the next spring. At the same moment, however, the Duke presses Oriane to hurry. He wants to leave immediately for the dinner preceding the party at the Princesse de Guermantes's and goes down to wait for her in the carriage. At Oriane's repeated request, Swann answers that he will not be able to come to Italy, because he is fatally ill. The Duchess reacts by asking whether he is making a joke. Swann answers that it would be a charming joke, but he then presses the Duchess to walk on to the carriage, because he understands the force of our 'social obligations'. The Duchess, approaching the carriage, tells Swann that he should not care about the dinner, but this outrages the Duke, who insists on leaving now. At that moment, however, he suddenly notices that the Duchess is wearing black shoes instead of red ones with her red dress, and it turns out that there is enough time left to send her back into the house to change her shoes. 
The intertextual reference to Andersen's The Red Shoes gives full depth to this event. ${ }^{3}$ The fairy tale is about a poor young girl named Karen, who had to go barefoot. Someone makes her a pair of shoes out of old red cloth and she wears these shoes for the first time to her mother's funeral. They are not suitable for mourning, but they are the only shoes she has. An old lady then adopts Karen, and burns Karen's old shoes. Karen buys a pair of red shoes, but the old lady, nearly blind, cannot see that they are red. When Karen wears them to church, everybody stares at her shoes and they tell the old lady that they are red. The lady forbids Karen to wear the red shoes to church and orders her to wear black ones instead. Karen cannot resist wearing the red shoes to church again and is punished, first, by an inability to stop dancing. After another instance of wearing the shoes, they stick to her feet and force her to dance continuously, and she has to have her legs cut off (Andersen 2005 [1845]).

The Red Shoes is a story of social forgetting, of the repression of mourning, of love's link to the past, and of forced integration into a collective or tradition that one is much less connected with affectively. Karen's fantasies revolve around the church, which is both oppressive and provides her with memories of somewhere she belongs. We have two kinds of memories here: one type of memory is loaded with affection and desire, and one close to the 'duty to belong', in the terms of the Stasi Commission.

Mme de Guermantes, in turn, is forced to wear red shoes instead of black ones. The continuity imposed on her is that of parties and princesses, not of the Church. She will have to forget Swann. The red shoes function as a metonymic marker for this aborted friendship throughout the rest of the novel. While the fuss about the red and black shoes takes place, Swann and the protagonist stand outside, waiting to say goodbye, but the Duke makes them leave before Oriane comes back, shouting at Swann: 'you'll bury us all!' (Proust 1996: III, 691).

\subsection{Public and private Dreyfusism}

The party thrown by the Princesse de Guermantes is described in the first chapter of Sodome et Gomorrhe II. The red clothes portray both Oriane's distance from society and her conformity to it. The protagonist witnesses a compulsive aspect that pervades her behaviour. As she takes off her coat, Oriane appears to be wearing 'a huge collar of rubies' (ibid.: IV, 71, my emphasis). ${ }^{4}$ The artificial brightness of her eyes, 'the 
Duchess lit up for the whole evening' (ibid.) - matches that of her jewels, which connects her liveliness with her being yoked to society.

At the party, the reader witnesses Oriane and her husband's betrayal of Swann. After a nationalist, anti-Dreyfusard and also anti-Semitic speech given by the Duke in front of several auditors, in which he again accuses Swann of betraying the aristocratic scene that had so generously 'adopted' him, the Duchess affirms the Duke's complaint that Swann has shown himself ungrateful to them by being pro-Dreyfus. Although Swann himself is present at the party, the Duke and Duchess do not exchange one word with him. Swann has been invited, ironically, because the anti-Semitic Prince de Guermantes, a cousin of the Duke, has become convinced of Dreyfus' innocence. He wants to tell Swann this.

However, there is a striking difference between the openness with which they defend these opinions. The Duke and Duchess are the ones to make their opinions public. The Prince and Swann exchange their words privately, and their convictions as Dreyfusards remain private. As the protagonist's friend Bloch learns about the Prince's conviction and wants to ask the Prince to sign a petition on behalf of Dreyfus, Swann refuses to ask the Prince, 'blending with his ardent conviction as a Jew the diplomatic moderation of a man of the world, whose habits he had too thoroughly acquired to be able to shed them at this late hour' (ibid.: IV, 130).

Swann even refuses to add his own name to the petition, arguing that his conspicuously Jewish name would make the petition less convincing. This is not an unrealistic standpoint given the Duke's reaction, but Bloch finds Swann 'lukewarm, infected with nationalism and jingoistic' (ibid.: IV, 131). Swann's position is significant in terms of the precarious structure of assimilation, as he is now isolated between two groups: the nobility whose mores he had entirely adopted and whose habits he cannot shed at will, and the other group, represented by Bloch, which required a forceful stance to start a public conflict and could not abide his undecided, overly careful behaviour. In the novel, Bloch takes a similar position to the one taken, historically, by the journalist Bernard Lazare. He was important in turning the Affair into a public issue, but was initially not liked by the Dreyfus family because they saw him as lacking nuance, as an irresponsible troublemaker, and they at first wished to arrange things via diplomacy without addressing anti-Semitism more generally (see Burns 1991). 
Henri Bergson and Walter Benjamin on 'MOdern experience' AND THE CONTEXT OF ASSIMILATION

Let us now address Benjamin's (1980 [1938]) analysis of the historical, specifically modern character of Proustian memory, as developed in Some Motifs in Baudelaire. The isolation of individuals is central in Benjamin's analysis, but he does not develop his thought in the specific context of the assimilation of the French Jews around the Dreyfus Affair. Instead, he attempts to analyse the isolation of individuals in the context of what he considers to be the changing features of experience in modernity more generally. He develops his view through a criticism of the late 19th-century philosophy of life, particularly Bergson's, by contrasting it with Proustian memory. The specifically modern aspect of experience had not been questioned by the philosophy of life, which aimed to gain insight into 'true' experience situated above or outside history through addressing poetry, nature, and the age of myth, and whose late representatives, like Klages and Jung, had become gradually associated with fascism. Bergson's work also stood in this tradition, but for Benjamin his work was by far the most challenging and convincing.

In Matter and Memory (1990 [1880]), Bergson argued that the individual, owing to what he called 'pure' memory, has access to a purely individual and metaphysical reality of duration (durée). Bergson wanted to develop a new 'metaphysics' that would finally unravel the 'structure of our experience' independent of history, in reply to Kantian rationalism. He considered memory as divided between pure memory (mémoire pure) and memory-habit (souvenir-habitude). Parallel to this, he saw time as necessarily divided into 'duration' and 'spatial time'. In Benjamin's (1997: 111) interpretation, Bergson suggests that we can freely decide to turn to the 'contemplative actualisation of the stream of life' and away from active social life, which only gives access to memory-habit.

Benjamin argued that Bergson's transcendental understanding of experience neglected its historical conditions: it was like an 'afterimage' received after closing one's eyes to the 'inhospitable, blinding age of large-scale industrialism' (ibid.). Benjamin develops a more historical understanding of memory and experience by turning to In Search of Lost Time, which serves to put Bergson's theory 'to the test' (ibid.). In contrast to Bergson, Benjamin argues, Proust presents the grasping of 'pure memory' as an involuntary, contingent event. Pure memory is replaced in Proust by involuntary memory. According to Benjamin, this involuntariness is not a natural situation, but a marker 
of the ways in which experience has changed in modernity. The unconnected messages conveyed by modern media such as newspapers, but also by the modern poetry of Baudelaire, testify to an increasing inability on the part of modern subjects to connect themselves to the people around them and to narrate their place in the world. Proust's distinction between involuntary and voluntary memory throws light on this 'modern experience' or, as Benjamin calls it, the 'atrophy of experience' (ibid.: 113). Elsewhere, Benjamin (1977b [1933]: 117) calls this the 'poorness of experience' (Erfahrungsarmut, my translation), which stood at the basis of his modernist aesthetics, briefly summarised in his phrase, 'So much the better. Do not cry. The nonsense of critical prognoses. Film instead of story'.

Involuntary memory bears the mark of modernity, 'it is part of the inventory of the individual who is isolated in many ways' (Benjamin 1997: 113). He now contrasts modern experience (Erlebnis) with experience 'in the strict sense of the word' (Erfahrung), and explains:

[W] here there is experience in the strict sense of the word, certain contents of the individual past combine with material of the collective past. The rituals with their ceremonies, their festivals (quite probably nowhere recalled in Proust's work), kept producing the amalgamation of these two elements of memory over and over again. They triggered recollection at certain times and remained handles of memory for a lifetime. In this way, voluntary and involuntary recollection lose their mutual exclusiveness (ibid.: 113; German original 1980: 611).

Benjamin here constructs a concept of experience the structure of which depends on the existence of collectively shared moments, of rituals (or religious practices) in the broadest sense of the term. The split between conscious, voluntary memory and unconscious, involuntary memory for Benjamin results from the split between individual and collective memory, which, in his view, had resulted from modernity. He thus follows the modernist interpretation of secularisation as the 'individualisation' of experience. Yet he does not understand it in terms of secularity, but in terms of an 'atrophy of experience'. He also does not consider here, as he had done in his (more private) letter to Adorno, whether the isolation of the 'modern individual' might have concerned Jews more than other French citizens, because they had been placed under the sign of their 'assimilation'.

Benjamin (1997: 110) developed a concept of tradition in accordance with the concept of modern experience. He had confirmed Bergson's thesis that the structure of memory is decisive for the philosophical 
pattern of experience: 'experience is indeed a matter of tradition, in collective existence as well as private life'. This concept of tradition is then explained as follows:

It [experience] is less the product of facts firmly anchored in memory than of a convergence in memory of accumulated and frequently unconscious data (ibid.: 110).

Benjamin distinguishes between the products of an archival memory, where all past experiences have a fixed place, and tradition, which is presented as a continuous process within which memories can change places and form different connections. Tradition is conceived as a process, as a constantly changing stream into which new experiences are inserted that change the past. It is a process that exists on an individual as well as a collective level; and it is this process, according to Benjamin, which is only accessible by accident in modernity.

The direct political stakes implicit in Bergson's theory of memory did not escape the critical philosophers of the 1930s, and Benjamin's reading should be interpreted through the prism of the politicisation of Bergsonism at that time. Bergson's critique of neo-Kantian rationalism was affected by the deep political fissures within European culture at the end of the 19th century, and also because Kantianism was heavily politicised in France at the time. The interpretation of memory was crucial. During the Romantic reaction to the Revolution the past had been claimed by reactionaries such as De Maistre and Bonald, the early inspirers of French fascism and Catholic Traditionalism. Maurice Barrès, in his late 19th-century struggle against the 'uprooted' rationalist Republicans, revived De Maistre and Bonald's neo-traditionalism. According to Barrès, the Republicans thought that a rational morality based on reason could do without memory, which, for Barrès, meant without national solidarity. In answer to this, Barrès developed a theory of an immediate and sacred solidarity based on the people's intuitive solidarity with their predecessors (Namer 1994: 301).

Bergson's philosophy of memory had been uncomfortably annexed to this Romantic tradition, also because Bergson explicitly opposed Republican rationalism and because his theory of the élan vital had inspired Barrès and other 'irrationalist' thinkers - as well as those on the left-wing side such as Georges Sorel. Reinterpreting memory in a less irrational way than the Bergsonians was therefore considered crucial by left-wing progressive thinkers attached to democracy and the Republic, such as Durkheim and Maurice Halbwachs. Durkheim tried to 'save' memory from right-wing interpretations by giving it a soci- 
etal rather than an ethnic interpretation. Halbwachs, Durkheim's successor at the College de France and a great inspirer of contemporary theories of cultural memory, was a former pupil of both Bergson and Durkheim. By publishing Les cadres sociaux de la mémoire in 1925 he tried to reinstall the tradition of Durkheimian sociology at the Collège, after Bergson had dominated it since Durkheim's death. In a 1925 article entitled 'Matière et sociéte', not unwittingly playing on Bergson's Matière et Mémoire, he argued that collective memories frame individual memories.

Adorno and Benjamin, who admired Bergson and did not discredit his work because of its irrationalism, did, however, criticise Bergson's doubling of the concept of time in a philosophical manner as 'part of a dialectic that remains unconscious of itself' (Adorno 1990 [1966]: 327). Bergson, says Adorno, separates subjective time or duration entirely from the objective, spatial time of the watch (Uhrzeit). In doing so, Bergson essentialises time consciousness. Isolated, the subjective time plus its contents appears to be as mediated and contingent as the subject itself, and is no serious party to the 'objective' time of the watch.

Yet, according to Adorno (1990 [1966]: 327), who clearly follows Benjamin here, Bergson's analysis of time reflects the crisis of time consciousness in modern society, where the individually lived time of experience can no longer be connected to the ways in which time has been objectified. By doing so, the critical philosophers, instead of deconstructing Bergson's analysis of time and memory by foregrounding memory's practical, cultural and habitual but not purely repetitive aspects (as the French sociological tradition initiated by Durkheim and Halbwachs did), went along with Bergson's interpretation of the split character of the experience of time, except they attempted to explain it in historical terms. Like Benjamin, Adorno interprets it as forming part of a modernity that produces a radically new structure of experience, split between repetitive objectivity and an emptied-out subject. Such an understanding of experience is the basis of the exaggerated, dichotomous analysis of the experience of time in an imagined, fully individualised society. It led Adorno (and Benjamin) to the same modernist exaggerations and over-systemic interpretations that I criticised in the French sociological debates:

From the industrial production disappears ... concrete time. It passes ever more in identical and spasmodical potentially simultaneous cycles. With the opposition of feudal traditionalism to radical bourgeois rationality, memory, time, remembrance are ultimately liquidated by the 
progressive civil society as irrational burdens (Adorno 1962: 234, my translation).

A similar over-systematic exaggeration of a radical break between tradition and modernity pervades the contemporary sociological analyses of the alienation, the de-culturalisation, of youth in the French banlieues that we discussed earlier. Theoretically blind to meaningful habit, practice, memory and performance, these interpretations can only perceive identity politics. In this instance, however, and in contrast to Benjamin and Adorno, the alienation is mainly seen as something of the (Muslim) 'other'.

If we now return to the Proustian salon, the division between privately hidden and publicly shared opinion recalls Benjamin's 'isolated private individual', but it also gives us cause to understand the reasons for this isolation somewhat differently. All of the characters are isolated to various degrees. However, they are isolated not so much because of a general loss of tradition in modernity or because of the specifically modern structures of their experience, but because of a specific distribution of social and memorial power in a conflict where individuals are forced to choose one group or another at a public level, while their personal situations, opinions and solidarities may be much more complex. Swann is isolated not only by his friends, but also within himself, between his overly diplomatic habits and his 'ardent convictions' as a Dreyfusard - and also because of his imminent death which no one dares to address. Oriane's red appearance testifies to the isolation from another side. At this point, there is a passage that Proust (1987b) suppressed in the final version of Sodom and Gomorrha - not mentioned in the Pléiade edition but quoted in a footnote in the edition by Emily Eells-Ogée for Garnier Flammarion - which supports the association of Mme de Guermantes' red shoes with Swann's suffering. Proust added the following to his description of Mme de Guermantes at the end of the party:

Now that she was wearing red shoes, I noticed that they completed her [and] that this outfit was perfect. But at that moment I recalled Swann's words, which the Duchess did not have time to listen to, and it seemed to me that it was in her friend's blood that she had been bathed (Proust 1987 c: 357 n. 63 , my translation).

By suppressing the direct association between Swann, the Guermantes' cruelty and the red clothes in the later version, Proust contributes to make the narrative mimic the - at least partly - unconscious and 
social ways in which processes of exclusion and forgetting take place. The narrative strand of the red shoes is not about subjectively isolated, fully private individuals and destroyed traditions. Instead, it tells how individuals are affectively and socially linked to several groups and individuals (husbands, friends, families, classes, nations, republics), and how they can be excluded from several or all of these groups. Swann, who had fully assimilated and individualised, was most at risk, because it turns out that his long-time friends are unable or unwilling to support him, or even to tolerate him, at the moment of conflict.

The story of the red shoes remains closer to Benjamin's remarks on the 'precarious structure of assimilation' than to his analysis of modern experience in the Baudelaire essay, where he projects the modernist idea of a fully individualised society onto the Proustian narrative. As we will see in what follows, the power constellations between these groups also seem to influence the patterns formed by the memories of those belonging to them.

\subsection{The social discipline of forgetting}

The narrative goes on to tell us, or rather to evoke, that forgetting about Swann takes place over an extended period of time after his death and the resolution of the Dreyfus Affair. In La Prisonnière, the protagonist visits Oriane, and recounts her impression of the party of the Princesse de Guermantes: '[Y]ou had a dress that was all red, with red shoes, you were marvellous, you reminded me of a sort of great blood-red blossom, a glittering ruby' (Proust 1996: IV, 34)].5 This is how the protagonist creates myth out of a repressed pair of black shoes, a chain of rubies and some bloody garments.

The narrator begins his account of the conversation in the Guermantes' salon with an explanation of how and why memory, and forgetfulness even more so, is produced by social situations. He writes that those people who are active in social life - and he sees all members of society as active, much like politicians and diplomats, but 'only on a microscopic level' (ibid.: v, 34) - are so preoccupied by the near present that they hardly confide anything to their memory.

We quickly forget what we have not deeply considered, what has been dictated to us by the spirit of imitation, by the passions of the day. These change, and with them our memory undergoes alteration ... As for society people, they remember very little (ibid.: v, 35; III, 547-48). 
Mme de Guermantes' forgetfulness (and that of the other members of 'society') is produced by their need to feel connected to their own social group and to the present. They thus conform to what theorists of collective memory - such as, for example, Assmann (1999: 39) and Halbwachs (1994 [1925]) - have pointed out, namely that collective memory tends to adapt to the social purposes of a group in the present and that, in order to ensure the continuity of that group, it tends to filter out the memories of those events that provoked conflict. The 'ritual', bloody aspect of Mme de Guermantes' redness, which forces her to forget Swann, is not the product of a tradition or even of an invented tradition, but rather of a specific constellation of power in which all the characters are involved and intertwined from different angles and perspectives.

The Proustian narrative here practises a modest and sombre form of sharing memories, which passes through forgetting. It tells the story of a lack of solidarity in memory under collective pressure, and also of the painfulness of such a process of repression for at least some individuals on both sides. The conflicts between several characters produced in the course of the Dreyfus Affair have to be forgotten, as does the fact that Swann had been their intimate friend. Internal divergences resulting from the Affair are repressed and 'society' is once more stabilised. Later, Proust stresses how quickly the Dreyfus Affair ceased to divide French society as it started to prepare for World War I.

The narrator makes clear, incidentally, that the process of fully 'disciplining' memory may take time, and also may not fully succeed. A little later on that same afternoon, Oriane seems less forgetful than the narrator had depicted her before. She dares to contradict her husband about the Dreyfus Affair. As the protagonist, the Duke, the Duchess and a visitor begin to talk about the Dreyfus Affair, it becomes clear that the Duke has increased his hatred towards the Jews. He delivers a terrifying monologue in which he argues that they should be driven out because of the troubles they have caused 'La France' (Proust 1996: $\mathrm{v}, 39$ ). The Duchess defends a much more nuanced standpoint in which she explains why so many Jews may have been Dreyfusards:

[J]ust because they are Jews and know themselves they realise that a person can be a Jew and not necessarily a traitor and anti-French, as M. Drumont seems to maintain ... they knew quite well that if he hadn't been a Jew, people wouldn't have been so ready to think him a traitor a priori (ibid.: v, 39; III, 551). 
But the 'queen of the present moment' will not retrieve the affective source of her standpoint. Oriane is actually called the 'queen of the present moment' in the passage where she talks about Swann to his daughter Gilberte, long after Swann's death. In The Fugitive, the Guermantes invite Gilberte for lunch and Gilberte starts to talk about her father:

At the end of the meal, Gilberte said timidly: 'I believe you knew my father quite well.' 'Yes, I believe so,' said Mme de Guermantes in a melancholy tone which proved that she understood the daughter's grief and with a spurious intensity as though to conceal the fact that she was not sure whether she did remember the father very clearly. 'We knew him very well, I remember him very well.' (As indeed she might, seeing that he had come to see her almost every day for twenty-five years.) 'He used to come here too, in fact he used to come to luncheon here,' added M. de Guermantes with ostentatious modesty and a scrupulous regard for accuracy. 'You remember, Oriane. What a fine man your father was! One felt that he must come of a very decent family. As a matter of fact, I once saw his father and mother long ago. What excellent people they were, he and they!' One felt that if Swann and his parents had still been alive, the Duc de Guermantes would not have hesitated to recommend them for jobs as gardeners ... Thus it is that an anti-semite, at the very moment when he is smothering a Jew with affability, will speak ill of Jews, in a general fashion which enables him to be wounding without being rude. But, queen of the present moment,... Mme de Guermantes was also its slave ... 'He was charming,' said the Duchess with a wistful smile (ibid.: v, 664; IV, 160-161).

As queen of the present moment, Oriane manifests here how our fidelity to our friends, when they turn out to belong to another group, may substantively shift and change over time, particularly when it concerns friends who turn out not to have been 'fully integrated' after all - and that means in this case, those who have not lost their critical capacities towards the dominant and errant majority. ${ }^{6}$

Exclusion from memory can work very thoroughly. Even Swann's daughter Gilberte changed her name from Swann into 'de Forcheville', after her mother's second husband, and tried to avoid being associated with the name Swann (ibid.: v, 670).

This leads us to the narrator's digression on involuntary memory at the end of Time Regained. In it, he suggests that another memory than that of the moi social complicit with Oriane is possible in writing, when there is access to the so-called moi profond. Proust indeed 
develops a narrative of much more individual, less collectivist memory. But we cannot fully separate the two kinds of memory, and we cannot separate Oriane's social forgetfulness from a narrator capable of remembering Swann, the excluded other, even though the narrator himself suggests at one point that this might be possible.

The complicated relationship the narrator establishes between involuntary memory, time regained, le réel retrouvé and writing, is inserted in Time Regained in the narrator's account of an intermediary moment of contemplation by the protagonist, just before he visits his last great social event, the 'Bal de Têtes'.

The narrator recounts that, on his way to the reception, several involuntary memories assail him in rapid sequence, reminding the protagonist of earlier momentary experiences of happiness. He forces himself to analyse why these memories had always made him so happy, and why they had felt as invitations to write. He assumes that the happiness produced by the experiences of involuntary memory must have been produced by the fact that sensation and imagination came together, thus enabling him to actually experience the essence of things, 'real without being actual, ideal without being abstract' (ibid.: V, 224).

The protagonist relativises the happiness produced by these memories, however. He develops the thought that writing must be the only feasible way of extending this kind of happiness beyond the short moments of involuntary memory. This would be possible through the production of metaphors. Linking different impressions, objects and memories in a metaphoric style gives access to truths of which, he realised, he was not 'free to choose them, that such as they were they were given to me' (ibid.: 232). This, precisely, guarantees their truthfulness, their authenticity, and their individuality. Yet the crucial fact that they were 'given' was enabled by the social and cultural embeddedness of memory. To understand this, we have to leave once more the individualised and aesthetic Bergsonian language of interiority.

\subsection{Forgetting and cultural memory}

\section{DELEUZE'S READING OF PROUSTIAN MEMORY AS A CONTEMPORARY BERGSONISME}

Close to Proust's own interpretation and to Bergson's metaphysical notion of interiority and of memory, is Deleuze's hypermodernist reading of the relation between memory and metaphor in Proust and Signs (2000 [1964]), where he goes one step further than Proust himself 
in suggesting a 'moi profond' disconnected from memory, and suggests that there is a gap between Proustian memory and metaphors (or 'signs of art') produced in the novel.

In Search of Lost Time, Deleuze (2000 [1964]: 4) suggests, is not based on 'the exposition of memory, but on the apprenticeship to signs'. The crucial sign is metaphor, the 'sign of art', because it is independent from 'material explanation' (ibid.: 3). Making metaphors is, according to Deleuze, a process - or an event - superior to interpreting the signs of memory, because then we remain dependent on sensation, on something external. The Proustian 'essences', by contrast, turn out to be signs of art, which are the only signs capable of revealing a (monadic) individuality.

However, the signs of art do not reveal a subject, but something 'implicating, enveloping, wrapping itself up in the subject', namely 'Being' or a 'region of Being', which reveals itself to the subject (ibid.: 43). In metaphorising it is as if the world itself is newly created, as is time as well. Deleuze (ibid.: 45) refers to the neo-Platonist 'One' that precedes 'any development, any deployment, any explication, because it is complication, a complication that is essentially instable, containing many contraries, many layers, and that is the origin of a world which is essentially "expressive"'. In metaphor, essence materialises, becomes a 'sign', because metaphor reproduces the instability necessary for transmuting matter by divesting it of its fixed qualities. In sum, Deleuze encounters in Proustian style the signs expressive of something preceding individual memory, which, however, is not (mediated) habit, culture or practice.

What is missing in Deleuze's interpretation of metaphor, however, is a critical reflection on the relation between Being and the habitual, memorial, mediated, textured sides of experience. The Proustian narrative gives us reason to be more careful about the Bergsonian move of uncoupling metaphor from memory, sensation, habit, plurality and also conflict.

\section{FORGETTING AND THE TEXTURE OF CULTURE}

At the beginning of his wait in the library, approaching his euphoric understanding of why involuntary memory and writing are metaphorically related, the protagonist had gathered that forgetting plays a crucial role in involuntary memory. He thought that every moment of our existence is different because we do not experience only those things upon which we concentrate rationally, but also attach to them associations that they have no logical connection with, and which we separate 
because they do not serve any rational purpose. Atmosphere, colours and emotions are all attached to every single sensation. It is through these associations that even the memory of the simplest act or gesture remains 'immured as within a thousand sealed vessels, each one of them filled with the things of a colour, a sense, a temperature that are absolutely different from one another' (Proust 1996: VI, 221). Past and present do not amalgamate because of the work of forgetting:

Yes: if, owing to the work of oblivion, the returning memory can throw no breach, form no connecting link between itself and the present minute, it remains in the context of its own place and date, if it keeps its distance, its isolation in the hollow of a valley or upon the highest peak of a mountain summit, for this very reason it causes us suddenly to breathe a new air, an air which is new precisely because we have breathed it in the past (ibid.: VI, 221-222; IV, 449).

The importance of forgetting lies in the isolation of past moments which preserve their distance only in that isolation. This interpretation of the function of forgetting casts a new light on involuntary memory. It depends on a form of forgetting that is not definitive but that makes the past accessible without reducing it only to those images useful in the present.? Such forgetting causes the opposite of a flowing together in memory. There is no streaming or amalgamation of different memories as in the image of tradition or restored (premodern) experience deployed by Benjamin (1980 [1938]) following Bergson. For Proust, amalgamation results when the subject superimposes different memories on each other. This has the negative effect that our memories lose their consistency and fade out; thanks to forgetting, this process can be put on another track. The function of forgetting in involuntary memory is to cause our past to become 'an inner book of unknown symbols' (Proust 1996: vI, 233). To remember in writing, then, might mean to feel something like truth in practically un-analysable, deeply mediated combinations of images, to feel something like a balance between what should be emphasised and what should be omitted, as well as between what should be highlighted and what should be shaded (ibid.: VI, 233). This process can give access to individuality, but then precisely because it is contingent rather than law-like, and at the same time historical, mediated and cultural.

By coming to a standstill at forgetting, Proust opens a space for deconstructing the suggested independence of creativity, and ultimately of subjectivity, from experience and shared practices of meaning-making. He opens a possibility for a cultural interpretation of 
experience that reaches even into its deepest layers. This helps us to understand memory's function as constitutive of our ability to regulate the relations between experiences and concepts in terms of shade and light, or foregrounding and omitting, rather than in terms of inside and outside. ${ }^{8}$

Recognising the role of forgetting may lead us to take the relative solidity of concepts, habits and beliefs seriously. At the same time, the consciousness by which we are dealing with the results of forgotten learning processes helps us to remember that we could try to change them if we wanted to. We know that we have learnt a common language, cultural and religious practices, an ethos (or customs), and ways of moving our bodies. But we are also aware that we have 'forgotten' these processes to the extent that we ourselves can have no immediate access to all of these beliefs, habits and practices as 'just memories', as mere contingencies. They are not entirely permeable to our own wishes for change on the basis of reason(s), and we may also feel quite dependent upon these forgotten contingencies (see also Bader 1991: 120).

In other words, learning processes imprint themselves on our bodies and affects, which produces the texture of culture and the fact that its lower layers may become 'sedimented' (Connolly 1999: 16, 17). Hence, though we may realise that our (and other people's) habits and beliefs are not naturally given, but produced over the course of learning processes, they may not be that easily accessible to active remembering or conscious change. Or, at least, change would seem to imply the necessity of transformations in many patterns at once, and a desire for change strong enough to inspire a great amount of practice. Thoroughly changing habitualised behaviour is an option not very seriously considered by Proust at all - who seems to have thought that writing about them was already quite an effort. This conforms with his mechanical, modernist concept of habit (as analogous to death and pure repetition!). But there is also realism to it. In any case, the Proustian narrative undermines the either-or of autonomy and heteronomy time and again, by tracing how we are in-between them over time, and through forgetting.

Pursuing such an understanding of the role of forgetting in patterning our experience (and will) helps us to develop a concept of experience that does not consider it enough to state that, from a third-person perspective, we can demonstrate that meaning is constructed and, for example, that (post-)modern religion is just neo-religion, just a politics of identity. Precisely because the things we have learnt are connected to forgetfulness, because they become unconscious and involuntary, 
they may start to function as if they were natural or original - or, in the case of concepts and metaphors, 'pure'.

Perhaps the role of forgotten learning processes also pertains to communities (or societies):

What has grown historically leads to a stability that makes up the nonavailability of collective identity: there is a limit to manipulability - even when we are fully conscious of the historical contingency of communities and the collective identities that are based on them (Bader 1991: 121, my translation).

We can distinguish here between the perspective of individuals and groups themselves, and a more distant or reflexive perspective. What seems mediated and contingent from the second perspective may seem quite natural and primary from the first perspective. We have to recognise that there are degrees of self-reflexivity and no simple either-ors. According to such a view, forgetting plays a structural role in constituting relatively stable communities. Recognising such stability does not lead to the view that cultures (or religions) are unchangeable, reified or essential. To borrow Ricoeur's (1990) terms, it does mean that cultures have a certain continuity in time (ipséité) and a definition of selfhood in contrast to others (identité).

Or, in Connolly's (2002) words, the impact of the sedimented layers of culture, of its objectified, institutionalised aspects, shows us that cultures are 'constituted in part by the perceptions, beliefs and concepts in it'. Much about the tension between different 'constituencies' is lodged in this dimension, and attempts to understand the layered relation between thinking and culture also have to 'gauge' how sedimented

'memory traces' - as intensive thought fragments in a self or culture can affect thinking and judgment without themselves being articulable, and how the application of subtle techniques sometimes affects the shape and intensity of such traces (ibid.: 18).

The textured quality of culture means that we must take into account that people cannot do everything at the same time. We also should be aware that it might not be wise to try to destroy or negate cultural and religious beliefs and practices, or to pressure people to transform them into merely conscious beliefs. It is morally important but also prudent to create options for voice, and loyalty - or rather, many loyalties, both loose and strong. 
Not only subtle techniques, but also social conflict can affect the shape and intensity of memory traces. One of the things we learn from the Proustian narrative strand of the red shoes is that it is not easy to distinguish between those elements of forgetting that make up the texturedness of selves and cultures, and the conscious repression of certain facts that occurs at the moment of conflict. It suggests that the two are entirely interwoven. The fact that Mme de Guermantes forgets Swann and conforms to her group's collective memory is only partly the product of her conscious repression or her choice; such forgetting just happens.

The red shoes are among the final topics of a long conversation between Mme de Guermantes and the protagonist, long after Swann has died. They first talk about the period when Swann was still Oriane's friend. The Dreyfus Affair is not mentioned. Afterwards, they talk about the dress and shoes. Neither Swann nor the Affair are mentioned. As the protagonist reminds her of the red dress she once wore, Oriane melancholically recalls how much time has passed since. At the protagonist's request, she describes the dress in a very precise manner, but then starts to doubt whether she indeed wore red shoes with it. Were they not the golden ones? (Proust 1989: IV, 588; 1996: VI, 4O3). The narrator only writes that he preferred not to talk about the event that made him so certain that the shoes were indeed red.

In the novel, we can distinguish different kinds of remembering and forgetting, without being able to separate them. Mme de Guermantes remembers the past in an amalgamated way from the perspective of the present. The narrator is more precise and makes a detour. Through the work of remembering the forgotten, he separates the different times the red shoes appeared, remembering them in their own period, each surrounded by the painful reflections of the moment. The novel thus reconstructs the memory of an individual, not of a group. At the same time, however, these memories testify to the protagonist and Oriane's painful conformity to collective pressures. The novel reconstructs the memories of several isolated individuals in a minute way, making clear the semi-disparate, semi-shared character of collective memory that appears when it is contemplated in detail and over a longer period.

\section{DEMOCRATIC MEMORY}

Let me now anticipate the conclusion to this study with a brief reflection on the link between Proust's account of memory and forgetting and what Bauboeck (1998) has called 'democratic memory'. He argues for the need for such a concept in a discussion of overly presentist 
concepts of citizenship, defining it as a memory that can include the divergent pasts of all groups who share a common future in a democratic state' (Bauboeck 2002: 8; see also Huyssen 2005). We have seen that Durkheim already grasped the importance of the past and of cultural memory for a progressive project. He included a reflection on the objective memory constituted in institutions, but he remained afraid of admitting memories of difference, of conflict, and also of exclusion.

My reading of Proust's novel gives us a motivation for pluralism beyond the debates about the essentiality or constructedness of difference. The narrative of Mme de Guermantes' forgetting of her old friend Swann made clear that we can also not feel very attached to any specific group and still participate in 'groupness' and in excluding people from society and even from our memories. Disassimilation can even forcefully emerge among groups that have long held the conviction that assimilation has already taken place to a large extent and will continue to do so. Memory is 'recherche rather than recuperation' (Huyssen 1995: 3). This implies that it is always mouldable for narratives that include and exclude with hindsight. Tracing memory in close connection to forgetting in Proust's narrative helped us to realise that we tend to forget the internalisations of social pressures. Not even the hyper-reflexive narrator escapes from the perspectivism caused by such internalisation, although the narrator to a certain extent gains access to voices and perspectives other than his own, and also gets somewhat beyond collective pressures. The novel itself enables us to trace even that limited ability of the narrator. In conclusion, a democratic pluralism that includes reflection on the past should enable minorities, complex as they can be, to remember and thematise exclusions and to take a critical distance from the stories of the majorities. Preferably, they should be enabled to form a counterpublic force against them. Such a pluralism is not based on the idea of a given, essential religion or culture at all, but on the complexity of the relations of individuals to others and to different kinds of social groups of which they may form a part, and therefore, on the power differences between these groups that are always and irreparably at stake. 


\section{Concluding remarks}

\subsection{Introduction}

In this concluding chapter, I bring together four issues that seem essential in looking back on this study. Firstly, I reflect on some uses and abuses of referring today to the memory of Jewish assimilation in 19th-century France. Secondly, I specify lessons that can be learned from reading Marcel Proust's In Search of Lost Time in the context of today's questions surrounding the position of ethnic and religious minorities in Europe. Thirdly, I briefly summarise why I problematise the secularism-religion framework instead of trying to define a 'better' laïcité. Fourthly, I address the question of what alternatives could be developed, and I reflect on the advantages and drawbacks of calling these alternatives 'multicultural' today.

\subsection{The assimilation of the French Jews as a memory for today}

About ten years ago, a strange episode aired on a local Amsterdam television channel. In a moment of inadvertence, the city councillor for education, Rob Oudkerk, was filmed talking with the mayor of Amsterdam, Job Cohen, under the impression that he was speaking off the record. The first was clearly heard saying 'fucking Moroccans' (kutmarokkanen), which has since become a notorious (and often repeated) phrase in the Netherlands. The immediate response of the mayor was to say, 'but they are our fucking Moroccans' (maar het zijn wel onze kutmarokkanen). Oudkerk's insensitive neologism must have taken a very short-circuited route through Cohen's mind, for his reply references a slogan reportedly conceived during World War II, which held that the 'stinking Nazis' (rotmoffen) should keep their hands off 'our stinking Jews' (onze rotjoden). ${ }^{1}$

Cohen's reaction exposes an important factor related to the incorporation of migrants into European societies, which is the memory of the fate of the European Jews in World War II. Migrants not only bring their own memories, but they also arrive in a specific field of memories. The fate of the Jews, in particular, has left deep traces that influ- 
ence present-day thinking about minorities in the European context in ways which are difficult to evaluate because they are not always explicit and result in highly diverse attitudes.

Over the last decades, a significant change has occurred with regard to the role of these memories. In the $198 \mathrm{os}$, at a demonstration against racism in France, it could still be written that 'Jew = immigrant' (juif = immigré), and campaigns against the discrimination of Muslims sometimes referred to the exclusion of the Jews. In 1993, looking back at the Rushdie Affair, Talal Asad compared the situation of Muslims in contemporary Europe with the position of the Jews in post-Enlightenment France: "This "new Jew" had been born into a society which asked him to keep proving that he was worthy of belonging to it' (Hertzberg 1968: 365-366; quoted in Asad 1993: 306).

Over the last decade, there has been increasing resistance to comparisons between the current position of Muslims (or, more generally, migrants) and the position of Jews in the past and present, because such comparisons are often considered to be too quick, too abstract and too morally loaded. ${ }^{2}$ It is sometimes also argued that these comparisons result in blindness to the totally different historical context and entail a form of moral blackmail intended simply to cover up abuses within migrant communities.

There are other reasons to be careful in making comparisons. They could lead to an increasing imagery of Muslims as a sort of contemporary 'victims-in-waiting', the term Schechter (2003) uses when criticising the teleological historiography of the Jews in Post-Revolutionary France (see Transit I). An imagery of Muslims as (future) victims, either of xenophobia or of a hard line, un-reflexive and dogmatic secularism, may encourage strong ethno-religious boundaries rather than help to overcome them, and also neglect the agency of Muslims themselves.

It would also be unfortunate if pointing to a certain precariousness of the position of Muslims in European countries further encouraged the still increasing resistance to migration. The pessimism underlying that resistance could express itself as a reflexive fear concerning the inassimilability of some Muslim migrants. Fear that the confrontation of secularist majorities and Islamic minorities will, in the long run, inevitably lead to protracted conflict. The emergence of such an affective undercurrent 'of fear' might already be playing a role in the further reinforcement of the highly selective boundaries of what is Fortress Europe for only some of us. Internally, it may also lead to stronger pressures on minorities to further integrate, to assimilate, and to perform as actively participating citizens. 
This might lead us to argue, then, that the history of migration has always been accompanied by some amount of violence and discrimination, and that there is also a risk in dramatising this. As Gérard Noiriel has argued more generally, it would help to stop dramatising conflicts in the context of migration as ethnic conflicts, or perhaps even religious conflicts, and to consider their socio-economic, media and political aspects instead.

However, raising the memory of Jewish assimilation does not have to lead to a dramatisation of contemporary migration, nor does it necessarily anticipate an actual course of events (in the way of an overly teleological perspective). Rather, it could enable us to trace the modern origins of the dramatisation of difference itself, and make us sensible to a certain risk pertaining to it. Tracing the genealogy of Jewish assimilation in post-Revolutionary France gives us insight, or so I have tried to demonstrate, precisely into certain deeply historical layers of the way difference has been dramatised in modern European history.

\subsection{Getting stuck in a revolving door in the early 21st century}

In my contextualised study of In Search of Lost Time and of the concept of laïcité as it was conceived by the neo-Kantian pedagogues of the Third French Republic, I showed that intercultural distrust in the culturally mixed late 19th-century France of the Dreyfus Affair had more complex sources than racism, anti-Semitism, populism, nationalism, xenophobia and other counter-emancipatory movements. These sources should also be located in attempts to remove ethno-religious difference from the public sphere by either privatising or interiorising religion in the name of assimilation or secular citizenship.

Tracing a critical genealogy to secularism's and assimilation's intertwinement, and especially to the emergence of their intersections in the context of 19th-century French post-Revolutionary modernity, taught us that contemporary liberal versions of assimilation and secularism, or, for that matter, civic integration, cannot as easily be disconnected from their precursors as is often suggested. The moral ambivalences and paradoxes inherent in the old versions return, in new constellations, in the new ones. This is especially so because these concepts and the practices and imaginaries related to them, much more so than multiculturalism, have dominated and continue to dominate Western and specifically European norms and practices related to newcomers and minorities. 
I believe that if we remain forgetful of the paradoxes of assimilation as they are connected to secularism, we risk repeating crucial mistakes, leading to misunderstandings between citizens and to processes of exclusion. This is why the ambivalences and paradoxes that played a role in the 19th-century process of Jewish assimilation should find their way into a self-critical attitude of present-day Europeans toward secularism.

This leads me to what this book has analysed in terms of the 'paradoxes of assimilation'. Adding to our comprehension of their complexity is the crucial Proustian contribution to understanding secularism, assimilation and multiculturalism today. Reading In Search of Lost Time teaches us the long-term discursive effects, contained in the micro-fibre of society, of incorrect expectations with regard to equal citizenship. I have traced why and in what ways intersected expectations of assimilation and secularisation contributed to the development of a structural and ephemeral othering of Jews in France in the 19th century, which led to explicit, but also to more implicit, forms of exclusion.

Assimilationist expectations led to pressures on the Jews to transform their public difference into private difference. We read in Proust's novel how the officially declared public irrelevance of ethno-religious backgrounds, founded on religion's presumed privatisation and the state's religious neutrality, did not lead to a corresponding irrelevance of these backgrounds in society and politics. The novel narrates on a cultural memory of difference, whose public effects became unspeakable because of the relegation of Judaism to the private realm. This resulted in slippery semi-public differences and boundaries, as we saw for example in the behaviour of Proust's narrator's Christian and secular family members. These differences were constructed after the specific institutional context of modernist Republicanism had rendered visible differences suspect. For example, the story of the grandfather's humming, described in Chapter 4, forms one of Proust's articulations of the short circuit in the promise of assimilation. It helps us to understand that the requirement to assimilate itself causes its own impossibility because it creates the space for majorities to focus on the detection of deviance, especially in times of conflict.

The semi-public status of Judaism played a role in creating a form of exclusion that should not be considered the result of racist intentions alone. Public differences and inequalities did not vanish into a private realm but turned into stereotypes as a result of the delegitimising of public difference within Republicanism itself. We saw that this mechanism caused an unpredictable distrust, which in turn led to a pro- 
cess of creeping exclusion instead of inclusion. In short, the attempt to make ethno-religious difference invisible triggered the opposite.

Proust narrates the emergence of a constellation of Judaism, Catholicism and Republicanism in terms of essentialised group identities precisely at the moment of their presumed disappearance. The expectation of 'national assimilation', rather than a softening of identities, led to entrenched political positions related to group identities. Unnecessarily strong positions were developed that made it more difficult for mediating positions to emerge. At an individual level, they made it more onerous for those connected to specific groups to take up a divergent position within them.

We learn from the literary articulation of assimilation's paradoxes that they do not extend themselves to the state only, as in Rainer Bauboeck's and Markell's shared worry that the 'state must see at all times that each Jew has ceased to be Jewish' (Markell 2003: 146). Through Proust's articulation of the paradoxes of assimilation, we understand that the screening and construction of difference is not restricted, as a practice, to the state, but becomes instead a habitual practice in many contacts between citizens of Jewish origin and their native French co-citizens.

Proust's contribution, in my view, is to unravel, in his narrative of assimilation, why we cannot provide a guarantee to members of ethnoreligious minorities that, once they conceal or lose their visible, public, cultural-religious practices and identifications, they will no longer be considered as being significantly different by majorities. Identifications by majorities on the basis of a cultural memory of past differences do not need to be strong ones. Indeed, it is particularly the ephemeral identifications that can create unspeakable and almost nontransgressable boundaries. This is why we should be extremely careful about delegitimising public differences, including religious ones.

The memory of Jewish assimilation's coincidence with those forms of anti-Semitism that arose as a reaction to the ambiguity of Jewish identity can make us more sensitive to similar dimensions of the position of Muslims today. Reflecting on the paradoxes of Jewish assimilation thus enables us to see that a problematic aspect of today's secularism might lie not only in intolerance towards the public aspects of religious practice, but also in the cultural dynamics that result from the demand to secularise or assimilate. Just like the meaning of 'Jewish' in the late 19th century, the meaning of 'Muslim' itself can become destabilised. This process can engender new boundaries, which are not necessarily racialised or phobic ones, but could potentially become so. 
Problems similar to those narrated by Proust might be the construction of new identifications (in the first place by majorities) around being Muslim, in which the absence or suspected hiding of ethno-religious attachments is precisely what leads to the return of difference (in a context that has delegitimised such difference in advance). The crucial Proustian insight is that it is uncertain whether the members of majorities will trust Muslims' transformation into secular individuals, or whether they will possibly be subtly (or perhaps not so subtly) screened for signs of difference. And an identification of Muslims as 'Muslims' has already occurred in the context of their securitisation (Bangstad \& Bunzl 2010; Cesari 2011; Morey \& Yaqin 2011; Klug 2012). This is analogous to the return of 'being Jewish' that occurred in the France of the Dreyfus Affair.

Evidently, at the social level, a lot more assimilation is required than our institutions officially demand. Testimony to this are the headscarf affairs - regarding whether they can legitimately be worn in public places and questioning their legitimacy in general - as are the debates about the burqa today (Ferrari \& Pastorelli 2013). More generally, the affairs concerning religious signs offer important material for a diagnosis that moves beyond the usual juridical and political theoretical debates to determine whether and when religious people should be allowed to wear these signs. We also have to read secularism's partly self-created religious signs from the perspective of the future of assimilation. Excluding people from public offices and from parity of participation in public institutions invites a sliding scale. Once 'divergent' people have been systematically excluded from serving or even participating in the public sphere, they may be excluded from other parts of society as well. At the moment, we see this throughout Europe. Women wearing headscarves are excluded not only from official positions representing neutrality in an explicit sense (such as the office of judge), but also, at least to some extent, from working in representative functions for private organisations (see Alouane 2012). They can even be banned from the streets, as is the case with those who wear a burqa in France, in Belgium and the Netherlands (see also Tissot 2011; Costa-Kostritsky 2012; Amnesty International 2012). Lila Charef, legal officer at the Collectif contre l'Islamophobie, notes that racist attackers of Muslim women regularly refer to the existence of the headscarf law and to the concept of laïcité (Costa-Kostritsky 2012).

A particularly telling example of the revolving doors of assimilation may be taken from a discussion in the Dutch daily quality newspaper NRC/Handelsblad, which published an article about a woman from a Turkish background who wore a headscarf and encountered barriers 
related to the scarf in finding a job as a lawyer. Some of the letters to the editor sent about this article (31 December 2005) stated that the woman's problem was probably not just the scarf, but also her make-up - visible on a picture accompanying the article. The first writer to the editor argued that the Turkish woman's make-up was too heavy and that this, together with her black clothes, gave her a 'hard face'. The fact that autochthonous future lawyers are not usually selected on the basis of their soft faces, was obviously considered irrelevant. Another letter-writer who mentioned make-up also offered a peculiar explanation for the aspiring lawyer's problems in getting hired. He stated that she was giving off contradictory signals. On the one hand, she wore a scarf, which he thinks Muslims wear because they think scarves 'protect women from unbounded male sexuality'. On the other hand, she wore 'excessive' make-up, which he thinks stresses her 'sexual attractiveness'. Such 'contradictory signals', he argued, would have dissuaded him from hiring her.

Both letters suggest that the woman would perhaps not succeed without her scarf either, since she would still diverge from unwritten norms. Such reasoning recalls Proust's narrator's problems with the insufficiently assimilated Jews in Balbec, whose seaside fashions and dinner-jackets he did not approve of. Members of the majority feeling irritated because of contradictory signals like these is a contemporary way of ensuring that people with a Muslim background will not hit the glass ceiling, simply because they will have gotten stuck in a revolving door long before.

Ironically, it is not up to the people wearing scarves or make-up to decide what kinds of signs they are sending out, or even whether scarves are primarily to be interpreted as signs at all (Asad 2006). The discursive culture of secularism has at least partly determined this. And the more we leave multiculturalism behind as a project of hope in exchange for secularist or liberal assimilationist projects, the more signs of belonging to other groups, especially to religious ones, may be both discursively constructed and delegitimised at the same time.

It is unnecessary to exclude people who visibly practise religion from the public sphere or from representing the state. There is no essential difference between wearing a headscarf and finding God (or not) in one's heart. The first no more proves an automatic tendency to submissiveness (in practice or in ideology) than the latter proves autonomy. Moreover, the heart is invisible and, for this reason, also much less controllable than any visible signs of belonging. Requiring difference to move into the heart (or the home) is precisely what led to anxiety about difference in post-Revolutionary France. Since 'we' 
might not be able to forget that 'they' came from somewhere else (from poor countries, failed states or terror-related contexts) for some time, we might as well not push them in the direction of defining their sense of belonging in terms of their heart and privacy, for it is precisely this trajectory that may cause us to impute to them a semi-public identity as Muslims, especially when we feel that a form of blackmail has been in play from the very beginning (see also Jansen 2010).

Admitting a certain precariousness to the powerful return of this 19th-century legacy in the context of the increasing presence of citizens with practical ways of doing religion might lead us to look for alternative frames. If there is a memorial task for multiculturalism in trying to open up majorities' conceptions of national or European identity, as Rainer Bauboeck argued as early as 2001, and which has only become more urgent since, then we should concentrate not only on criticising nationalism, but also on analysing and criticising the intertwined heritages of Republicanism, secularism and assimilation.

\subsection{Problematising the laïcité-relig framework instead of defining a 'better' laïcité}

Political philosophers critical of the politics of laicism in the French context tend to oppose a better, more liberal, more neutral or more critical laïcité than contemporary Republicanism. They propose, for example, a critical Republicanism (Laborde 2008), a liberal laïcité (Baubérot 2010) or a political laicism (Maclure \& Taylor 2011). They want to be sensitive to actual shortcomings in state neutrality towards religion, in contrast to the vociferous contemporary neo-Republican claims and policies which actually undermine the contemporary French state's religious neutrality rather than strengthen it (Laborde 2008). Such an emphasis on evaluating the reality behind claims of religious or ethical neutrality, and on the need for focusing on where actual neutrality remains unrealised, can surely help to develop a critical evaluation of the privileges of some religions and conceptions of the good life over others. Firstly, focusing on actual neutrality (or the lack of it) helps us to criticise conceptions of laïcité in terms of a secularist moral philosophy. Secondly, it helps us to understand that both Catholicism and Protestantism retain many privileges within European societies, France included. It can furthermore help us to highlight Catholicism's overwhelming cultural presence in the public sphere and remind us of the fact that the concept of religion as belief itself is closely linked 
to the presumed subjectivation and de-culturalisation of religion in Protestantism.

However, defining a better, more liberal, more neutral and, in sum, more acceptable laïcité may not be enough. The laïcité-religion framework itself is deeply problematic, as this book has argued. The danger of this discursive frame is that while we continue to say that religion is not a central problem for liberal democracy, we persist in defining religion in such a way that many of its harmless aspects become suspect simply because they do not fit in with our expectations. Critically reading the secularism-religion framework itself can help to transcend the binaries of Western/non-Western, Muslim/non-Muslim and secular/ religious on which so much contemporary political thought depends. Neither religion as such, nor communautarisme, would be at the centre of what is considered politically problematic today if we step outside of the framework of religion and secularity.

The laïcité-religion framework relies on the assumption of the necessity of religion's de-collectivisation and, at the same time, its depoliticisation. Often, lä̈cité is prescribed to religion insofar as it is conceived as premodern: 'Islam still has to learn to become modern'. Yet, the opposite assumption of the full secularisation of today's religion, Islam included, is sometimes also presupposed, with Islam seen as being thoroughly politicised or 'de-culturalised'. But this too is seen as a problem. What remains unperceived in both interpretations are the diverse forms of interaction between collective and individual aspects of religion, particularly in contemporary Europe, where Islam clearly exists within the context of an intercultural dynamics of ethno-religious othering. Power inequalities, minority-majority relations, the history of migration and colonial history are all evaded by sticking to the modernist secular interpretation of good religion as a private and largely individual affair. This is specifically problematic when questions about incorporation and ethno-cultural diversity are systematically framed within a discourse of laïcité or secularism, as is common in France, and, increasingly, elsewhere in Europe as well. It leads us to focus exclusively on the relationship between religion and politics and, consequently, leads to a structural forgetfulness of the cultural and memorial sides of the associational life of both minorities and majorities.

In conclusion, the laïcité-religion framework can lead us to overlook the fact that many practices which could actually be understood in cultural or political terms are assumed to be primarily or even solely religious ones. Lä̈cité creates its own problematic religious counterparts or, to quote Roy (2005: 152), 'hodgepodge expressions of quests 
for identity are systematically "overislamised"' (my translation) (see also Ivanescu 2013). This insight could also lead us to see that practices - such as the wearing of headscarves - are inevitably diverse and make new interpretations possible. This may be the case even if some people explain and justify them in terms of religious dogma. The immanent divergences within practices guarantee their multi-interpretability. It would be helpful to focus on this aspect of religious practices in order to determine how they tend to dilute dogma, instead of simply going along with their interpretations in terms of dogma (Soloveitchik 1994, Bangstad 2009). This implies that we consider people who practise religion publicly as, in principle, just as reasonable or unreasonable, impartial or biased, as any others. Nor would a woman wearing a scarf be seen as necessarily unable to serve the state's neutrality, or to judge impartially.

\section{PUBLIC ORDER AND SECURITY}

The only potentially valid reason for prohibiting the wearing of specific signs would be that given by Poulat (2003), namely, when wearing them poses a 'real and present danger' to public order. We saw that this reason was ultimately a central one for the Stasi Commission. The public order argument has even entirely replaced laïcité in justifications for the ban on the burqa in constitutional reasoning (for a reconstruction, see Mathieu \& De Hert 2011). However, for this argument to be convincing, it would have required different circumstances than girls with headscarves or boys with kippahs, turbans or large crosses attending public schools or working as public servants (as critics such as Baubérot and Poulat argued in 2003). This argument still applies in the more recent case of the burqa (see further Costa-Kostritsky 2012; Amnesty International 2012; Ferrari \& Pastorelli 2013).

There are several options for a state to react to (potential) insecurity. France is famous for its Jacobin tendency toward further control, toward the creation of a state 'where one's innermost thoughts are themselves criminal' and whose ideal is 'perfect social and psychological visibility' (Ozouf 1984: 83). Legislation targeting the wearers of headscarves to send signals to the potentially violent Islamist groups behind them could be interpreted as a first step in this progression.

It may not be enough for Muslims to take off their scarves. The fear of what might be hidden underneath them could be enhanced if Muslims become more invisible. Relinquishing such outward signs may only enhance an intercultural semiotics towards 'scratching the surface', as discussed extensively in this volume in the context of Proust's 
narrative of intercultural attitudes at the time of the Dreyfus Affair. The suggestion that prohibiting the scarf is a sign to Islamist groups deemed as posing a threat to public order can only enhance the xenophobic perception of Muslims as citizens with potentially something to hide. The islamophobic topos of an Islamic obligation to taqiyya, according to which Muslims should suppress their true theocratic feelings until they are in power - recently appropriated by Dutch politician Geert Wilders and other islamophobes - could perhaps become a further step in the continuation of the fear of what is underneath the scarf once visible differences between Muslims and secular people have disappeared under assimilationist pressure (see also Jansen 2010).

A more liberal reaction would have been to take Muslims at their word unless they had been individually proven to pose a threat to public order, instead of suspecting them collectively. This would have taken seriously the words and deeds of those who do not sympathise with radicalism while wearing a scarf and who argue that there are legitimate reasons for wearing a scarf that do not overlap in any way whatsoever with adherence to a violent Islamism. Such reasoning may be, for example, to claim orthodoxy or piety. But other, more pragmatic, historical or even outright political reasons may be given as well. (For an account of the diversity of reasons that people actually give for wearing scarves, see, e.g., Gaspard \& Khosrokhavar 1995; Bowen 2007a; Chouder, Latrèche \& Tevanian 2008; Costa-Kostritski 2012; Farris \& De Jong 2013).

In the French debates it has become quite clear that even in France, with its many vociferous advocates of comprehensive laicism, securitising arguments had to be added before a law prohibiting the wearing of headscarves was deemed acceptable. It remains to be seen to what extent other European countries will adopt the French arguments and legislation, but they may well do so, especially if real threats to public order exist or are at least perceived to exist. In any case, general laws against the wearing of the burqa on the street or in public buildings are being prepared in the Netherlands and in Belgium. This may lead to increased racism, perhaps especially in those countries with weaker traditions of the egalitarianism inherent in French Republicanism, and especially in nationalist contexts where the authority of the European Court of Human Rights is increasingly undermined. Such a process of ethno-religious securitisation may have long-term consequences. Once religious difference has been interpreted as a sign of potential danger that states should act upon (in the name of protecting majorities), fear and scrutiny of intentions may only intensify when Muslims become less visibly different but still remain potentially 
so. We have only to hope that Muslims (and individuals with a Muslim background) do not end up paying a still higher price for their assimilation, if not in France, then elsewhere in Europe (see also Bangstad \& Bunzl 2010; Jansen 2010; Göle 2011).

\section{DOES BEING CRITICAL OF THE LAÏCITÉ-RELIGION FRAMEWORK IMPLY THE POLITICISATION OF RELIGION?}

My critical view of secularism and the laïcité-religion framework is not meant to be an apology for a politicisation of religion, although it does question whether we can always distinguish between religion's private, its public and its strictly political aspects. But such a problematisation does not prevent us from acknowledging that religion, when rendered explicitly and emphatically political, quite often takes on unhappy forms. Today, we are seeing the emergence of (neo-)absolutist interpretations of human life and their deployment in violent political ideologies of which we have little to expect in terms of democratisation and pluralisation. Liberal philosophies that retreat to a thin concept of morality and leave a great deal of room for the communitarisation of ethics might be too thin here, even as Maclure and Taylor's (2011) plea for political laicisation (see also Laborde 2012). ${ }^{3}$

The stakes for a progressive contemporary critique of secularism are therefore also not a return of religion, or even a religion for atheists or the faithless, as proposed by philosophers as diverse as Simon Critchley, Slavoj Žižek and Alain de Botton. The question remains whether there are no other ways than returning to the vocabulary of political religion or political theology to recognise the role of strong political commitment in the public sphere, or to criticise the legacy of European modernity's rationalist monisms, or to theorise about radical universalism. Instead, a progressive critique of secularism questions whether political issues, especially those concerning the position of ethnic and religious minorities, should be put primarily into a religion-secularity framework at all. It problematises the last essentialist dichotomies upheld within modernist, secularist liberalisms and their Eurocentric histories. These dichotomies lead us to distinguish religion, as a specific form of particularity, from other particularities which can be more easily recognised as being interwoven, mediated and always related to power relations, and therefore always at least partly public (see also Asad 1993; Connolly 2005; Bader 2007, 2010b; Brahm Levey 2009). Criticising the modernist concepts of religion on which these dichotomies are founded, helps us to gain insight into religion's relations to the plurality of human life forms and to democracy. We can 
then declare it only relatively pertinent whether practices, beliefs, proposals and arguments have religious (or other particular, ethical or metaphysical) sources, and discuss them in terms of whether and how they enhance or at least protect freedom and equality (Bader 2007; see Chapter 7 in this volume for the qualification of the argument).

A moderate politicisation of religion would not even be objectionable, in that it might lead us to put more trust in the possibility of debating politics and ethics with everyone. It may thus allow us to justify a critical position towards some forms of religious politics while not amounting to a prejudice towards religion in general. This would enable us to address the ideological, media and corporate-financed aspects of religion today (Connolly 2008; Vatter 2011). Moreover, since religion's relations to politics are simply much more diverse and complex than secularist discourses can acknowledge, a historicising reading of religion can bring up for discussion the placement of religion in general in a position of privilege, where it is suggested as being an almost sacrosanct domain, and where freedom of conscience might constitute a licence for absolutist alignments (Jansen 2011, 2013b; Laborde 2012).

\subsection{Multicultural alternatives}

\section{REVERSING THE BIFURCATION WITHIN MULTICULTURALISM}

This book has reflected on how to counter the discursive tendency exhibited today in liberal democracies throughout Europe to frequently appeal to difference-blind notions of citizenship with regard to religious diversity in the name of secularism, where policies of evenhandedness are more regularly proposed with regard to other differences (Kymlicka 2010). Of course secularism, and laïcité in particular, could come to mean, in the course of time, nothing more than evenhandedness towards religion (Modood 2010). ${ }^{4}$ But today, insofar as laïcité is regularly taken to imply Republican difference-blindness, it privileges European cultural majorities while simultaneously rendering this privilege invisible. Moreover, insofar as Republican differenceblindness itself is taken to imply the public invisibility of religious practice, it is especially biased towards those religious minorities whose religious practices tend to be more visible than those of others (Brahm Levey 2009; Laborde 2008). Lastly, insofar as laïcité comes to be regularly invoked as more or less essential to those European modern identities currently in need of securitisation against religious 
orthodoxy, the discourse ultimately tends to become discriminatory towards religious minorities (Cesari 2010; De Graaf 2011).

This bifurcation within liberal democracy, between religious and other minorities, may have everything to do with religion being conceived as big and transnational instead of minoritarian in the post9/11 cultural imagination. Thus, the struggle is partly about whether we should frame questions of religious diversity as questions about the position of religious minorities and religious citizens/denizens, or in terms of questions about the place of religion in politics. I defend the view that the former perspective, on the individuals and groups, is more important. Awareness of the partly unconscious bifurcation in policies and discourses towards minorities, and of the hierarchisation of minorities on which is it based, will be a first step towards a multicultural alternative. It will hopefully lead to the normalisation of our understanding of the practices and claims of religious minorities, and of Muslims in particular, as just one form of minoritarian visibility in both national and regional contexts (e.g., the European one). The norms for evaluating these practices can be those of liberal democracy without its secularist biases (Bader 2007). I would add that they can be the norms of liberal democracy after having thoroughly revised liberal democracy's modernist legacies more generally. Within such a revised liberal democratic framework, multicultural rights, Mookherjee suggests, adapting an incisive phrase by Gayatri Chakravorty Spivak, will be rights that 'we cannot not want', even if they have paradoxical effects due to their tendency to reinforce stereotyped and culturalised identity formation. These paradoxical effects need to be dealt with from within the multicultural paradigm, instead of by attempting to return to institutional difference-blindness (Mookherjee 2010; see also Carens 2000; Kymlicka 2002, 2010; Brown 2004; Bader 2007; Modood \& Meer 2008).

\section{GIVING PRIORITY TO CRITIQUE OF THE RULES OF THE GAME}

Politics is the type of game in which the framework - the rules of the game - can come up for deliberation and amendment in the course of the game (Tully 2008: I, 141).

Even more crucially, perhaps, we have to return to the initial focus within multiculturalism of adopting a critical distance from assimilationism. Assimilation means, in principle, acceptance of members of minorities as 'one of us' by majorities. Acceptance takes place, however, on the majority's terms (Alexander 2001, 2006). The crucial 
goal of multiculturalism, as Alexander put it, should lie in a much deeper and more culturally implemented form of equality, in which differences in status and power between majorities and minorities, and also therefore the rules of the game of assimilation, are from the outset up for discussion as a matter of principle. To this I would add that such discussions should be increasingly transnationalised, and thus take place between citizens and non-citizens once they find themselves in specific shared contexts that are relevant to them, be they national, regional or global.

In their reintroduction of assimilation, Joppke and Morawska (2003: 12) rightly signalled that European countries have not defined themselves as multicultural in general, as have, for example, Canada and Australia, but only with regard to their minorities. This they characterised as problematic. However, these authors drew a hasty and, in my view, inaccurate conclusion from this observation in arguing that it should lead to a reintroduction of assimilation (or, for that matter, integration), without recognising its similarities to historical assimilationism. Instead, it is necessary for European countries to think about ways to extend multiculturalism to their majority cultures. Memory is crucial here, if, as Bauboeck (2001a: 10) argued, 'multiculturalism has emphasized rights and autonomy, but side-stepped the more difficult task of changing established conceptions of nationhood among native majority populations'. Particularly in Europe, with its assimilationist and simultaneously exclusionist histories, it is instead important to start remembering these histories, for this might be a condition for a pluralisation of European societies in general.

If we view critique of assimilation as central to multiculturalism, there is no reason to expect that it will take the form of essentialist, reifying identity politics. Rather to the contrary, multiculturalism, in critical tension with assimilationism, implies that all groups and claims in a specific context should be subject to public scrutiny, including the claims of 'us' and, moreover, that all norms and values stand to be debatable, including the rules of the game itself. This implies that transformation, rather than protection or recognition of given identities, is (or should be) the central concern of multiculturalism. Instead of being a static concept depicting recognition and protection of specific given identities, multiculturalism as a critique of assimilation is a relational concept suggesting transforming the power differences between minorities and majorities in whatever context their relations become relevant.

Taking multiculturalism as a critique of the rules of the game of assimilation also leads us away from the habit of focusing rather exclu- 
sively, in debates on multiculturalism, on the context of bounded nation-states. This, for example, is the framework of debate that is central for Kymlicka, as it is in debates which take multiculturalism as a 'policy option' in competition with integration. This takes us in the direction of transnationalism, diaspora and cosmopolitanism (Bauboeck \& Faist 2010). However, it also takes us towards the multiculturalism of the more philosophical critique of assimilation that Tully (2008) developed. Tully speaks of assimilation when citizens, although they are encouraged to participate in political deliberation, are constrained to deliberate in a particular way, and with reference to particular sets of accepted forms of knowledge:

This is the unfreedom of assimilation, for one is not free to challenge the implicit and explicit rules of the dominant practice of deliberation, but must conform to them and so be shaped by them (ibid.: 117).

To counter such unfreedom, we must remedy democratic deficits rather than deficits with regard to the recognition of people's (pre-existing or constructed, and in any case rather static) identities. This requires attention to how assimilation hinders them from participating on an equal footing, on how they want to collectively organise their lives, and not (primarily) on who they are.

Creation and perpetuation of such democratic deficits conforms with the most universal form of assimilation today, which is neither national nor even identitarian. As Tully (ibid.) argues, this is the assimilation taking place all over the world. People are encouraged, or even forced, to assimilate to the liberal (and capitalist) idea of the modern citizen who strives to realise individual freedom through the private and economic spheres rather than by participating in the political sphere. This last, overarching, form of assimilation discourages collective political reflection and blocks the very processes of citizenisation that Kymlicka sees as multiculturalism's objective. Subjects are excluded from the practical basis of solidarity's continual regeneration, i.e., 'forms of life which embody the principle of democracy in different ways' (ibid.: 119). Following Tully's interpretation, assimilation towards the liberal idea of citizenship, which is assimilation in a much broader sense than from one ethnos into another or into a national culture, plays a crucial role in the formation of identitarian politics that multiculturalism is sometimes seen to embody. Such a broad critique of assimilation should be incorporated into a reflection on assimilation, secularism and multiculturalism in the current European context. 
I would like to make two last remarks for further reflection. The first deals with the relation of a critical multiculturalism to contemporary debates about secularism and religion in political philosophy. The second one addresses the question of why we should phrase my proposal for critical multiculturalism in terms of multiculturalism at all, as I tend to do, despite the criticisms of multiculturalism discussed earlier.

\section{POSTCOLONIAL DELIBERATION; FROM THE SECULAR-RELIGIOUS FRAMEWORK TO MULTICULTURALISM AGAIN}

Part of the recent debate about multiculturalism in political theory has developed in line with more general critiques of liberal interpretations of justice in terms of the just distribution of rights. Critics of justice as rights have often proposed deliberative democracy as an alternative, or at least a necessary complement, to justice. Whereas in justice as rights subjects remain relatively passive and thus also relatively powerless, deliberation enables them to act as citizens, even if organising deliberation democratically proves difficult in the context of mass democracy (Habermas 1998).

In the context of multiculturalism, Mookherjee (2010) recently developed a version of deliberative democracy which explicitly deals with multicultural questions. She calls this 'postcolonial multiculturalism'. She argues that one answer to the paradoxes of multicultural rights should be to focus more on the inclusion of minorities in political deliberation. Her argument concords in many respects with Tully's critique of assimilation, and is also akin to my proposal for multiculturalism as a critique of assimilation and assimilationist secularism.

Mookherjee's (ibid.) article, without thematising it, nicely exposes the point that there is an immediate link between debates about multiculturalism and those about secularism within political theory. She argues that public deliberation in post-imperial settings implies that deliberative democracy should be freed of the standard emphasis on the achievement of rationally motivated consensus. Although Mookherjee does not mention it, this takes her straight to today's political philosophical debates concerning the legitimacy of religious argument within public debate, in comparison to secular argumentation (see, e.g., Habermas 2008; Lafont 2009).

Mookherjee (2010) argues that multicultural deliberation involves the possibility of contesting or disputing the priority of supposedly common values, such as autonomy, to be replaced, for example, by agency. Further, largely in line with Tully (2008), she argues that multicultural deliberation has two major conditions. The first is reciprocity, 
which is the imperative to hear the other party on its own terms and in its own language (audi alterem partem). The second is to conceive of public reasons as social constructions. Mookherjee argues that we should not be focusing on whether a specific reason is philosophically true or secular, but instead take every reason as a contingent, socially constructed ideal.

A framework of multicultural democracy, along the lines of the arguments made by Mookherjee (2010) and Tully (2008), makes it much easier to address the central problem, as I see it, in today's debates about the place of religion in politics, than would be the case if we remained within the religion-secularity framework. From within this latter framework it can seem completely appropriate to question the legitimacy of religious argument within the public sphere, or even to question the legitimacy of visible religious practice. However, if we reflect on those same questions from the perspective of whether and how they tend to repeat the logic of assimilationism, they become more problematic. Wanting to establish the legitimacy of certain arguments or practices a priori is a way of fixing the rules of the game in advance, rather than reflecting on what is needed for the political inclusion of everyone on an equal footing. From within a multicultural framework we can more easily facilitate both a questioning of that logic and permit reflection upon it.

If we take the critique of assimilation centrally into account, it might also better enable us to see that deliberation is not everything, as even Tully and Mookherjee tend to suggest. From within the secularity-religion framework it has almost come to seem self-evident, over the last decade, that the greatest challenge to reasonability comes from religious neighbours outside of our secular-Christian 'civilisation'. Yet the standard of reasonability is compromised both by the structural inequalities produced within democracies themselves and by the histories of their production. Critique of those inequalities has many traditions within Europe, argumentative, deliberative ones, but also artistic ones. For example, our reading of Proust served to expose the visceral and emotional dimensions of the experience of these inequalities and gave them a rhetorical form which can certainly also be deemed political. More than including or excluding religious argument, such critique can and should also involve the formation of counter-public spaces for dealing with, parodying and narrating cultural power differences (Fraser 1992; Dryzek 2000; Bader 2007; Rosenthal 2012; Merry 2013).

Hence, more than to distinguish between religion and rationality, it seems politically crucial to realise that cultures of (secular) deliberation, and the related political practices, need to be criticised for the 
deep inequalities they produce and uphold. This is what critical social theory has always tried to do and still does. But why then critical multiculturalism?

\section{WHY RECLAIM MULTICULTURALISM - AND HOW?}

Why, again, defend multiculturalism if it is such a spongy concept and one which is moreover deeply connected to easily reifiable notions of identity and recognition and despised in many political settings throughout Europe from left to right? Why indeed - especially as recent criticisms of multiculturalism argue precisely that the concept inhibits equality by remaining assimilatory in its basic premises? This point has been forcefully made, for example, by the anthropologist Elizabeth Povinelli (2011: B3):

[L]iberal states and publics made others justify their inclusion into the new tolerant polity. How was their 'culture' different enough to afford recognition and yet not too different to be repugnant? Difference could not make too much of a difference ... Because the ethical imperative to recognise the worth of other ethical-cultural systems is contained within the condition that these different ethical-cultural systems are not repugnant to foundational liberal principles, the deep affective and cognitive normative background of liberalism is protected.

Povinelli's criticism is in accord with Žižek's (2010) recent argument that liberal multiculturalism is internally related to securisation, by keeping critical, possibly 'dangerous' otherness at a distance, even excluding it. He sees 'today's tolerant liberal multiculturalism as an experience of the Other deprived of its Otherness - the decaffeinated Other' (ibid.: 2).

My trouble with a wholesale rejection of multiculturalism is that it may lead us to overlook the dynamism between assimilationism and multiculturalism that has existed for more than forty years, and to underestimate how strongly the Other's decaffeination is rooted, traditionally, in assimilationism and integrationism. If we heap the blame on multiculturalism, it may become less rather than more clear what alternatives are at stake - and this risk is manifested in the return of assimilationism and integrationism today. Moreover, blaming multiculturalism can also lead us to overlook those resources of critique within older Euro-Atlantic traditions that have been captured in terms of multiculturalism (Bauboeck 2001a; Alexander 2006; Bader 2007; Tully 2008; Mookherjee 2010). 
Couldn't the introduction of a new, fresh concept be of more help? For example, 'interculturalism' is increasingly presented as a more dynamic notion than multiculturalism for understanding and normatively dealing with cultural diversity. Taylor (2012) recently defined a potentially influential notion of interculturalism, which he suggests as an alternative to multiculturalism in the European context. As heads of the Quebecqian 'Consultation Commission on Accommodation Practices Related to Cultural Differences (CCPARDC)', Bouchard and Taylor (2008: 287) put forward interculturalism's definition as follows:

a politics or model advocating harmonious relations between cultures, grounded in intensive interaction and built on a mode of integration which does not seek to abolish differences while favouring the formation of a shared identity [my translation].

This definition acknowledges the reciprocal dynamic existing between different groups. However, this definition crucially leaves aside the extent to which a society is served by the possibility of criticism of the presumption that harmony and integration are good for a society per se, or even attainable (see further Merry 2013; Jansen 2013a). My worry is that interculturalism is actually quite close to integration, and that it misses the crucial element of critique of the rules of the game of assimilation even more than multiculturalism has in the past. A central question is therefore if and how interculturalism can take into account the multicultural idea that the rules of the game itself and the 'us' that defines these rules can also come under discussion in a democratic polity. ${ }^{5}$

There is another, more strategic, reason for sticking to multiculturalism. Alana Lentin and Gavan Titley, John Bowen, Nacira Guénif-Souillamas, Markha Valenta and many others have argued that in the many criticisms of multiculturalism, or as in the French case, of communautarisme, there have been motives that do not just imply a critique of multiculturalism as a policy option, but also a rejection of multicultural society, or even a rejection of specific groups, such as North African Arabs in the French case (as Pierre Bourdieu argued as far back as 1989!). If that is so, then in being adaptive to a rejection of multiculturalism, one might also become complicit in the very undermining of multicultural society, especially insofar as there has yet to appear any vocabulary which has captured two of the central intuitions of multiculturalism. The first of these is that liberal democracy is currently far from enabling the participation of minorities on an equal 
footing with majorities. The second one is that, for minorities, 'without control over the rules, it is impossible to win' (Bauman 1988: 56).

For these reasons, 'multiculturalism as a project of hope' (Alexander 2006: 457) and certainly a more modest 'multicultural sensibility' (Kivisto \& Faist 2007) deserve more of a chance than they have received in Europe, and in European academia as well, in recent years. No easier alternatives are available, especially not in the European context, where liberal democracy has historically been intertwined with both explicitly particularistic nationalism and an equally particularistic assimilationist or secularist Republicanism. This book has traced the subtle and not particularly subtle deep inequalities that are produced by the idea that the focus, in dealing with cultural diversity, should be on 'them'. The progressive multicultural way is to focus on 'us' and 'them' together and to pinpoint our intricacies, conflicts and relationships, always with an eye to the equal access of all to the rules of the game, including the game of critique of self and other. 



\section{Notes}

\section{Notes Chapter 1}

1 See the debates on the website 'Open Democracy' among Kenan Malik, Klaus Leggewie, Markha Valenta, Cécile Laborde and others (accessible through Malik 2011).

2 For example, on www.signandsight.com there was a 2007 debate about Islam and 'Enlightenment fundamentalism' between Pascal Bruckner, Timothy Garton Ash and Ian Buruma. See also Buruma (2006).

3 This metaphor stemmed from the Us immigrant Israel Zangwill's 1908 theatre play titled 'The Melting Pot': 'There she lies, the great Melting-Pot-Listen! Can't you hear the roaring and the bubbling? ... Ah, what a stirring and a seething! Celt and Latin, Slav and Teuton, Greek and Syrian, black and yellow ... Jew and Gentile ... East and West, and North and South, the palm and the pine, the pole and the equator, the crescent and the cross - how the great Alchemist melts and fuses them with his purifying flame! Here shall they all unite to build the Republic of Man and the Kingdom of God' (quoted from Sahlins 1997: 1).

4 The result is that assimilation turns into 'hyphenation', an in-between form which accepts the boundaries set by assimilationism but makes them less rigid because of the gradual acceptance of the public status and visibility for claims and practices that were first considered to have to remain private. An example is the idea that one can legitimately be 'Mexican-American'. Here I follow the distinctions made by Alexander (2006), but we find these same basic distinctions in Noiriel (e.g., 1989).

5 A similar argument is captured in the title of a book by Gerd Baumann, Contesting Culture: Discourses of Identity in Multi-ethnic London (1996). According to Baumann, the claims of culture and identity are moulded by both politicians and by actors in the name of those cultures. Culture, he argued, is always a construction with political and discursive sides that needs to be analysed instead of being immediately adopted (see also Baumann 1999). A similar line of thought has been formulated by other authors. An early example is The Satanic Verses, which portrays the hybridity, flexibility and confusion of its migrant protagonists. Hanif Kureishi's novel The Black Album makes fun of, and reveals the politics and psychology behind, the 'hurt feelings' of some British Muslims at the appearance of Salman Rushdie's novel, and makes it rather implausible to ascribe these feelings to a 'different culture' or a differently structured religious experience of the protagonists.

6 See Ferrara (2009) for an analysis in which the public status of the Catholic Church in Italy is at the centre of the debates about secularism, instead of only forming a historical reference as is often the case in the French debates. The con- 
centration on Islam is also less evident in the United States, where the Christian religious right rather occupies the minds of liberal secularists such as John Rawls, Stephen Macedo, Christina Lafont, Amy Gutmann and Robert Audi.

7 State intervention in religion was perhaps even stronger in the colonial context, where the doctrine of laïcité was not always applied (see Achi 2004; Maussen 2008).

8 For an account of the early debate, see the 2004 Conseil d'État report. For a detailed account of the juridical debate from 2009 to 2011 about the burqa, see Mathieu and De Hert (2011).

9 This was especially the case in France. But similar ideas have come up elsewhere in Europe. In the Netherlands, secularism was advocated by the socialist mayor of Amsterdam Eberhard van der Laan. Left-wing intellectuals such as Dick Pels, Youri Albrecht and Eddy Terstall have referred to secularism as a specific limit to be set against religion which has been neglected by multiculturalism (see also Jansen 2011b).

10 General sociological factors may be more important here than Kymlicka indicates. Foner and Alba (2008), comparing the position of Muslims in Europe and the United States, established that the general distrust of Islam as a 'religion' is less frequent in the United States, where religion is seen as an aid to integration. They also indicate that the percentage and socio-economic position of Muslims compared to the rest of the population is very different in Europe than in the United States, where by far most migrants are Christians from Mexico. In the United States, Muslims tend to have a socio-economic status which is even above the national average (Foner and Alba 2008).

11 The commission was officially named Commission de réflexion sur l'application du principe de laïcité dans la République, but this was soon abbreviated by the name of it president, the Christian Democratic politician Bernard Stasi.

12 The expression was also used by Trigano (1985), Bellamy (1997) and Silverman (2007).

13 Perhaps the importance of the Stasi report has been overestimated in terms of its actual role in the making of the law on the headscarves. French sociologist Valéry Amiraux suggested to me in a personal comment that the actual decision to propose the law on the scarves had already been taken in political circles in June 2003, long before the Stasi Commission had issued its report. Also, the later report of the Machelon Commission (2006) has a better reputation in terms of its academic qualities. But as a resource for understanding the French culture of laicism, the widely mediated report is valuable and I am drawing out motives that have been largely overlooked.

\section{Notes Chapter 2}

1 I quote from the lemma 'assimilation' in the French dictionary Le Petit Robert. In physiology, assimilation specifically meant the process through which organised beings transform the materials they absorb into their own substance.

2 The views of these authors are reminiscent of the way life in the French banlieues was represented in the movie La Haine by Mathieu Kassovitz as far back as 1995. Geisser \& Zemouri (2007) emphasised dimensions related to colonial 
history of the specific forms that racialisation has taken, especially with regard to Muslims from North Africa, and its connections to notions of security.

3 However, Jeanne-Hélène Kaltenbach and Michèle Tribalat, who are fierce opponents of the headscarf, kept defending old style Republican assimilation, as did some public intellectuals like Emmanuel Todd and Dominique Schnapper.

4 From the 1970s, intellectuals had occupied themselves with the future of regional languages and cultures, which had also suffered from strict assimilation policies, for example, prohibiting the use of Breton and Occitan as public languages. Speaking these languages was banned altogether in the 1950 .

5 The commissariat preferred 'insertion' as a concept for understanding migration rather than integration, adaptation, or assimilation. In its view, all the other candidate concepts were too suggestive of hierarchical and organic thinking (Kaltenbach \& Tribalat 2002: 35).

6 Only to stress in the next sentence that we should not 'exalt' these differences and that a politics of integration should put the emphasis on resemblances and convergences (Kaltenbach \& Tribalat 2002: 36).

7 Sen (2006b) called a similar top-down multiculturalism in the British context 'state multiculturalism'.

8 See Laborde (2008) and Birnbaum (1998). The Front National had already hijacked Claude Lévi-Strauss' famous speech about race et histoire given at the United Nations in 1951.

9 Birnbaum (2008) explores the role that a Jewish background played for eight 2oth-century Jewish sociologists. The first among them is Durkheim.

10 Noiriel's argument is close to criticisms made in the context of British cultural studies of the essentialist aspects of multiculturalism, when it relies on a reified concept of culture. Baumann (1996) opposed the reified concept of culture. For an extensive reply, see Bader (2001).

11 Noiriel argues that the factor that determines the level of integration of the descendants of immigrants is not their ethnic background but the geographic place where their parents come to live. For example, quantitative research among French immigrants conducted by INSEE in 1986 and 1987 (published in 1990) showed that social-economic integration has proven difficult in industrial regions, whereas in Paris descendants of all ethnic backgrounds have achieved upward trajectories.

12 From a song by Dr John from the 1973 album In the Right Place.

13 Chapter 6 offers a critique of similar interpretations of the meaning of religious claims in the French political context within the framework of the debates about lä̈cité.

14 Noiriel's vision of the structural influence of the assimilation process on migrants is related to Bourdieu's habitus concept, which also carries excessive structuralist and determinist traces, although Bourdieu was critical of structuralism. For a critique on the heritage of structuralism within the habitus concept, see Bader (1991).

15 For a similar argument in the Dutch context see Saharso (1992); for analyses of the literary exploration of hybridity in contemporary France see Thomas (2007). 
16 This in contrast to national minorities, who usually try and succeed, though sometimes at great cost, to preserve their own language (for this distinction, see Kymlicka 1995). For an overview of categories 'between' those of migrants and national minorities, see Bauboeck (1996).

17 Chapter 3 turns to the concept of integration, which has been criticised for similar reasons (Bader 1997b; Favell 2001a, 2001b; Morawska \& Joppke 2003; Schinkel 2007).

\section{Notes Chapter 3}

1 Exclusion from citizenship had long been common because of the ius sanguinis definition of citizenship in the German legal tradition. This law was only changed into a ius soli notion of citizenship in 1999. It then became possible for migrants' children who had been born on German soil to acquire citizenship. The use of multiculturalism to exclude 'metics' (from the ancient Greek word for 'stranger') or denizens from citizenship has not escaped multiculturalists and transnationalists. Kymlicka (2002) asserts that multicultural rights are meant to supplement citizenship rights (and human rights), not to replace them.

2 Not only delinquents were 'sent back', but so too were refugees from the former Yugoslavia, particularly Roma who had been in Germany for years. The Dutch, since 2002, have 'returned' individuals who grew up in the Netherlands for most or all of their lives to their so-called 'countries of origin'.

3 However, Brubaker (2001) argues that in the USA, segregation and ghettoisation remained great problems in the 1990s, and at some points escalated due to the segregating effects of multiculturalism.

4 Joppke and Morawska provide a somewhat simplifying summary of Luhmann, removing the critical potential of his theory of functional differentiation. Luhmann recognises different scales of inclusion and, moreover, introduces the concept of 'negative integration', which denotes a strong integration in subsystematic zones of society which is caused by forms of radical exclusion from diverse social systems (see Luhmann 1995: 237-264, 1997: 618-634).

5 For example, a frequently repeated distinction suggests that Germany has a ius sanguinis tradition of citizenship while France has a ius soli one. The German law on citizenship has been changing gradually since the introduction of the Citizenship Act of 1999.

6 For an analysis of the interconnections between neo-liberalisation and specific forms of multiculturalism, see Lentin \& Titley (2011) and Van Reekum \& Duyvendak (2011).

7 This is the case, for example, if the existence of Islamic schools in the Netherlands is discussed merely in terms of a segregation between 'black' and 'white' schools, neglecting the complex motives of the people who want to maintain or start such schools (see Bader 2007).

8 In a problematic rhetorical gesture, Joppke and Morawska (2003) quote Carens's critique of the thinness of Kymlicka's justification for cultural rights for voluntary immigrants without mentioning that these points of criticism were a reason for Carens to embark on a more pluralist path than Kymlicka's in 1995, instead of reverting to plain liberalism (Carens 2000; see also Bauboeck 1996). 
9 For examples of multicultural reasoning in relation to the position of 'minorities within minorities', see Shachar (2001); Bader (2005a); Bowen (2010a).

10 In this sense, the relational view of multiculturalism is also connected to Levy's (2000) 'multiculturalism of fear', based on Judith Shklar's 'liberalism of fear'. A multiculturalism of fear is grounded in the reality of inter- and intra-ethnic evils and focuses on minimal goals such as trying to prevent interethnic civil wars, cruel practices within certain communities, and state violence against ethnic and religious minorities.

11 In this brief genealogy of citizenship I draw on Bader (2006).

12 Prins and Saharso (2008) have written detailed reconstructions and rhetorical analyses of these debates.

13 A similar story is told in István Szabó's movie Sunshine: Ein Hauch von Sonnenschein (1999). The film narrates the full assimilation of the Jewish-Hungarian Sonnenschein family within four generations into the Hungarian national culture. The family first, around 1900, changes its name into the Hungarian (and Latin) 'Sors'. Subsequently, one generation later, they shed the traces of their religious belonging by becoming liberal Catholics. In the lead-up to World War II, they are unable to respond to the growing threat of anti-Semitism and Nazism by departing from the land with which they identified so strongly and came to trust, notwithstanding the many confrontations with anti-Semitism that they lived through. After the war, the only surviving son identifies with assimilation once more by adhering to communism. Only after the communist deception does he start to rediscover his Jewish background. This is when he changes his name back into Sonnenschein.

14 In the Netherlands, historian Lucassen (2005) argued that the romantic projection of a homogeneous nation that existed before immigration reveals the shortterm memory of contemporary alarmist views of migration.

15 The example of this, for Brubaker (2001), is the fact that the use of language can change within a few generations without any person consciously choosing to stop speaking one language and speak only the language of the country of arrival.

\section{Notes Chapter 4}

1 I write 'protagonist' when referring to the main character at the moment of the narrated experience, and 'narrator' when alluding to the protagonist writing his memories.

2 La Juive (1835) was a popular opera at the time, composed by Jacques Fromental Halévy to a libretto of Eugène Scribe, while the line 'Israel romps ta chaîne' is from the opera Samson et Dalila (1877) by Camille Saint-Saëns (Éditions GF 1987).

3 I quote these verses from Éditions GF 1987: I, 593. The last part of the translation is quoted from Proust 1996: II, 847, where these verses reappear.

4 Hughes (2001) further explored the intertextual references to the opera, and traces them throughout the novel. For example, Proust refers to the 'hide our mysteries' phrase again when narrating the homosexual desires of Bloch's greatuncle Nissim Bernard (Proust 1996: II, 874). 
5 The opera is situated in early 15th-century Switzerland, which was then dominated by the Austrians. It narrates a struggle around intermarriage between a Jewish father, called Eléazar, his adopted daughter Rachelle, whom he saved as a baby, a Catholic King, and a Cardinal. The (married) king is in love with Rachelle and when this becomes public, severe laws threaten to punish both of them. Rachelle lets herself be convinced (by the king's wife) to declare that the king is innocent. Rachelle and her father can avoid punishment by converting, but they refuse to do so. When Rachelle is killed by being thrown into a cauldron with burning oil, Eléazar tells the Cardinal that Rachelle is his lost daughter and then follows her into the cauldron.

6 The English translation is a little inadequate here. The French original says ' $\mathrm{Oh}$, je me méfie', which also means 'Oh, I distrust that' (Proust 1996: I, 90).

7 The first verses are from the opéra comique Joseph (1807), by Étienne-Nicolas Méhul, which was performed in 1899 at the Opéra in Paris (Éditions GF 1987: I, 593).

8 In the Third Republic, free-masons, Jews and Protestants were all accused by Catholics of hidden partiality under their universalist Republicanism, and in part rightly so. Many Catholics were fired from their public offices and a large number of free-masons took their place (Baubérot 2000).

9 This term was borrowed from the movement for Catholic Emancipation in Britain (Schechter 2003: 263, following Katz 1964).

10 The most extreme examples are from Robespierre's arsenal of the instalment of a new calendar and public holidays. The teaching of the principles of the Revolution as if they were new religious, fundamental principles combined with Jacobinism was already criticised by Condorcet and other more moderate thinkers just after the Revolution.

11 The Abbé wrote this in a text with the ambitious title: 'Report on the necessity and means of destroying the regional vernaculars and universalising the use of the French language' (my translation).

12 The name 'Bloch' recalls this Ashkenazim background. 'Judeo-German' is one of the occidental versions of Yiddish (Schechter 2003: 13).

13 Though a self-confessed Revolutionary at the time he made these speeches and wrote these essays, the young Grégoire had been educated as a priest by Jansenists. More than a century before the Revolution, the Jansenists had proposed kinder treatment of the Jews in preparation for their conversion (Hertzberg 1968: 9).

14 This is a reference to Judeo-German.

15 Hertzberg thought these lawyers were basically anti-Jewish: 'The Alsatian enemies of the Jewish communal bodies were not moved by a humane regard for the masses of the Jews, who were supposedly groaning under the oppressive yoke of their leaders. The purpose of men like Hell and Jacquot was to try to destroy the community structures in order to remove the prime protector of the Jews' (Hertzberg 1968: 227). Perhaps Hertzberg's judgement was one-sided, but we might keep in mind that the distrust of minority elites in current anti-multiculturalism has one of its origins in the strong centralisation of the nation-state in Revolutionary France. 
16 The quote is very famous, but usually only its beginning is cited, which refers to refusing Jews everything as a nation and giving them everything as individual citizens. The alternative of expulsion is quoted less frequently.

17 Voltaire was the first to ascribe to the Jews a desire to form a 'state within the state' (Birnbaum 1988; Katz 1972). Later Malesherbes, when commanded to do so by Louis XVI in 1787, studied the position of the Jews in France, after having previously composed a report on the Protestants. He concluded that the Jews did not so much constitute a State within the State, but an imperium in imperiis (Poliakov 1981: 64), and that they were in that sense comparable to the Jesuits.

18 Forced distinction had been invented by King Saint-Louis (1226-1270).

19 The heritage of marranisme was overcome gradually not long before the Revolution. For example, only from 1686 onwards did Jewish people refrain from presenting their newborns for baptism, and even in 1753 some Jewish marriages were still being registered at parishes (see Hertzberg 1968: 25; Schechter 2003).

20 Asad (1993) demonstrates more generally that the concept of religion as we know it today emerged only in the 19 th century.

21 Misread by Burns (1992: 11) as 'judesco-ebraico', which misses Grégoire's association of the Alsatian Jews with Germany. One of the aspects that made Dreyfus extra suspicious in the eyes of the anti-Semites was the fact that his family stemmed from Alsace.

22 Proust himself was influenced by the neo-Kantian professor of philosophy Alphonse Darlu, whose lessons he described quite realistically in his earlier novel Jean Santeuil. M. Beulier, Jean's teacher at Lycée Henry IV, in many respects resembles Darlu. The portrait of Bloch and the protagonist as adolescent friends is partly based on Proust's own friendship, at Lycée Condorcet, with Daniel Halévy, Robert Dreyfus and Jacques Bizet. Halévy was the grandson of the composer whose arias the grandfather hums (see Tadié 1996).

23 The concept of 'race' derives from the Latin 'ratio' (order of things, category, species; hence, ironically, it has the same root as 'reason'). It appears in France from 1512 onwards. Three meanings of the concept were used at the end of the 19th century without being neatly distinguished. The first links race with family, but it does so mainly in relation to noble families whose descent determines their (high) social position. The second, biological meaning, was used from 1648 onwards: 'Ethnic group which differentiates itself from others by an ensemble of hereditary physical characteristics (skin colour, shape of the head...) representing the variations within the species'. The third meaning is derived from the biological one and started to be deployed in the 19th century. It turns the biological meaning into a cultural one: 'natural group of men that have similar characteristics (physical, psychological, social, linguistic or cultural) originating in a shared past' (summary and quotes from the article 'race' in Le Grand Robert 1985: VII, 989-991, my translations).

24 This is suggested, for example, by novelist Henci Raczymow, in his Bloom et Bloch (see Schulte Nordholt 2002). Raczymow 'extracts' Bloch from the Recherche (and Bloom from Ulysses) and places them at the end of the 2oth century. 
25 Later, in 1905, when the anti-Semitic newspaper La libre parole wrote that Proust was one among a certain group of Jews who had criticised the anti-Dreyfusard Maurice Barrès, Proust wrote to his friend Robert Dreyfus: 'To rectify, it would have been necessary to say that I am not a Jew and I did not want to do that' (Correspondance v: 180-181, quoted from Fraisse 1996: 322, my translation).

26 L'Aurore was the newspaper in which writer Émile Zola published his famous 'J'accuse', in which he publicly asserted Dreyfus's innocence. The French original of this passage can be found in Proust (1971 [1952]: 651).

27 Descombes (1987) extensively elaborates on this theme, linking Proust's perspectivism with Wittgenstein's concept of language games.

\section{Notes Chapter 5}

1 Rue d'Aboukir is a street in Ménilmontant in Paris which has housed migrants for more than two centuries.

2 Except for the important gender distinction, to which I will return.

3 Reinach's definition of assimilation occupies a somewhat mythical status in histories of the Jews in France. Usually, only the part ranging from 'the Jews, since they have ceased' to 'religious denomination' is quoted. I copied this part of the translation from Marrus (1971: 92); the rest is my own. Bauman (1988: 57) copies the phrase from Marrus, but he misreads 'dispersed' for 'despised'. Birnbaum (1988: 47) ascribed the passage to H. Prague, editor of the Archives Israélites, but this was an error.

4 A good example is Adolphe Crémieux, who was a witness at the marriage of Proust's parents. He served as minister of justice in the Second Republic and, in 1870, managed to extend the citizenship rights of Jews to those living in Algeria.

5 The question of whether the representatives of the Jews would consent to intermarriage had been the central question directed at the rabbis upon the formation of the Grand Sanhédrin (Benbassa 2000).

6 This translation is drawn from the previous English translation, since the relevant pages are missing in the 1981 edition (Remembrance of Things Past, New York: Random House, 1932, quoted from Hassine 1996: 122).

7 To mention an infamous example from the German context, we can see this in Martin Heidegger in a letter from 2 October 1929 to a high official in the ministry of education: 'The matter concerns no less than an urgent recognition that we are confronted with a choice - either we will replenish our German spiritual life with genuine native forces and educators or we will once and for all surrender it to the growing Judaisation in a broader and narrower sense' (quoted in Sieg 1989, translation quoted from Ettinger 1995: 36-37). With Verjudung 'in the broader sense', he probably targeted critical modernist thinking, and with Verjudung 'in the narrower sense', he targeted the Jews in person.

8 Markell (2003: 9) calls a similar project a 'politics of acknowledgement'. He argues 'that the source of relations of subordination lies not in the failure to recognise the identity of the other, but in the failure to acknowledge one's own basic situation and circumstances'. A politics of acknowledgment starts from this insight. 
9 For a historical analysis of the aristocracy's attitude towards Dreyfus, see Brelot (1994).

\section{Notes Transit II}

1 Much in line with Vidal and Nordmann (2004), Algerian-American sociologist Lazreg (2011) offers the opinion that postcolonial studies will not achieve much in France as long as the relationship of French universalism with racism is not discussed at a fundamental level.

2 The signatories to this letter were Elizabeth Badinter, Régis Debray, Alain Finkielkraut, Élizabeth de Fontenay and Cathérine Kintzler.

3 Many of these critical voices have been brought together in a book that would merit an English translation to get a more balanced view of French intellectual culture about secularism: Le foulard islamique en questions (2004). Secularism's links with securitisation in the colonial context, particularly the Algerian one, and its legacies in contemporary France have been analysed in Achi (2004), Deltombe (2005), Lucassen (2005), Geisser \& Zemouri (2007), and Maussen (2008). The racialisation of Arabs and Muslims in the name of feminism has been analysed by Guénif-Souillamas and Macé (2004).

4 The basic arguments made during the headscarf debates have been dealt with in many places. John Bowen reconstructed them elaborately in his Why the French don't like Headscarves (2007). A collection of essays critical of the headscarf law by French intellectuals and scholars can be found in Nordmann 2004, and there are also, e.g., good essays by sociologist Valéry Amiraux (2006, 2009, 2010a and 2010b) and philosopher Cécile Laborde (2005, 2008).

5 Benbassa sounds a critical note about the use of the concept of assimilation in discussing the history of the French Jews when she writes: 'Did this insistence on the supposed assimilation of French Jews not owe something to the vision of the Zionist ideologues and historiographers, for whom life in the diaspora inevitably led to the effacement of Jewish identity?' (Benbassa 2003: 12, my translation). I think she is being a little too severe here on those who think that assimilation is an important normative concept relevant to 19th-century French Judaism. It was relevant at an ideological level, and it determined, to a large extent, interpretations of public traces of Judaism. Benbassa also does not address the problem which Birnbaum, in the footsteps of Tocqueville, makes explicit as a critique of Franco-Judaism: 'In the United States, for example, a country with a weak State where multiple forms of the auto-organisation of collective life have always been very dense thanks to the early installation of a political democracy which, in its foundation, was essentially pluralistic, the community life specific to the Jews has never caused any problems because it is similar to that of the other communities; even better, it is also equally legitimate' (Birnbaum 1988: 18-19, my translation).

\section{Notes Chapter 6}

1 The 'écoles libres' in 1903 in France were usually religious schools, Catholic schools in practice. The 'Affair' means the Dreyfus Affair. 'The laws from Ferry' means the education laws introduced by minister Jules Ferry in 188o, which prepared the secularisation of education by constraining the influence of the 
(Jesuit) clerus. In 1903, a more stringently 'secularist' version of a law separating Church and State was proposed by Émile Combes, therefore known as the 'loi Combes'. This law implied the expulsion of religious orders from France's territory, as well as the withdrawal of all state support for the maintenance of religious buildings such as Cathedrals. The eventual law from 1905 was significantly more liberal and moderate than the original law from 1903 (for more details, see Baubérot 2000).

2 Compared with Republican France, Protestant countries in general were less radically separationist. Yet radical Protestantism (Calvinism) was more separationist than Lutheranism, so that within Protestantism, too, it is a matter of degree (Fetzer \& Soper 2005).

3 See Benbassa (2003), Roy (2005), Asad (2006) and Bowen (2007a). This was also the case in the colonial context, where the doctrine of laïcité was not always applied, and often accompanied by strong state interventions in religious matters (see Achi 2004; Maussen 2008).

4 The neo-Kantian pedagogue Buisson was director of primary education from 1879 to 1896 and edited the Dictionnaire de Pédagogie et d'Instruction primaire, which Gérard Raulet (1999: 16) calls the 'bible of republican educators at all levels in the Third Republic'.

5 The following analysis is inspired by Raulet's (1999) excellent discussion of neo-Kantian debates about morality, and of Durkheim's answer to the Kantian antinomy of morality. I quote Durkheim's lessons from Raulet (1999: 24-27). The page numbers given refer to those listed by Raulet where he quotes from Durkheim's L'éducation morale; the translations are my own.

6 I borrow the term 'une laïcité intériorisée' from Nicolet (1994).

7 Raulet (1999) suggests that the popularity of Kant may have been caused partly by the idea that the Prussian ethics of duty, which was strongly connected, at least in the French interpretation, to Kant's philosophy of transcendental morality, had led the Germans to their victory in the Franco-Prussian war.

8 I have commented upon Asad's reading of French secularism more generally as a manifestation of the modern state's integrationism in Jansen 2010 and 2011a. Here I confine myself to commenting on his reading of the headscarf as a religious sign.

9 Similar critiques of Enlightenment's universalism have been made since Romanticism, but recent critiques of secularism concentrate on problematising the status and role of practices (customs) and intensities (affects) in secularist concepts of both reason and (interiorised) religion.

10 However, it is questionable that we can say anything about the meaning of the scarf in general, even from a religious perspective. Individual persons have mixed motives for acting in complex cultural situations that invest the scarf, like all other objects in human interaction, with a polysemy that cannot be denied by official or religious interpretations. Upon Nicolas Sarkozy's question to the Al-Azhar University about the religious duty to wear a scarf, even the university replied that it was not an absolute duty (this, unsurprisingly, did not convince many wearers of headscarves). 
11 For a detailed account of the politics related to the scarf in French Algeria and during the war of independence, see Shepard 2006. This ambiguity might help to explain why only two women wearing headscarves were interviewed by the Stasi Commission (Bowen 2007a). This rather curious disinterestedness has been explained in terms of the idea that women wearing scarves were regarded as 'oppressed' and without agency. I would suggest some of them were considered without political agency, and others with too much, and not entirely trustworthy, political agency.

12 For a similar argument about the Italian context, see Ferrara 2009.

\section{Notes Chapter 7}

1 One of the signatories of the petition against the headscarf organised by the fashion magazine Elle (and published in Le Monde on 9 December 2003) was Samira Bellil, who, in L'enfer des tournantes, wrote a moving account of her escape from a ghetto where women, particularly those dressed in a Western style and non-veiled, were assaulted on a daily basis ('Elle s'engage: Notre appel à Monsieur Jacques Chirac, Président de la République’).

2 When I had the opportunity to ask Alain Touraine in summer 2008 about his vote in favour of the law on the headscarves, he put forward three more strands for his change of mind. He first mentioned that diversity is an enrichment but separationism is not and that 'a boundary had to be drawn'. However, he also said that if the Stasi Commission had advised otherwise, 'a million people would have been on the streets the day after', and suggested that the political hysteria of the moment had forced a decision upon the Commission in order to prevent grave civil unrest. Finally, he said that there had been a lot of tension between its members more generally and that he personally had had to quarrel with other members to make certain that two women actually wearing scarves were interviewed by the committee (sic!) (see also Latour 2004 and Bowen 2007a).

3 For the more complicated dimensions of the role of gender in the debates surrounding the scarf, see Balibar (2004), Göle (2005), Guénif-Souillamas \& Macé (2004), Amiraux (2009) and Laborde (2008).

4 This insight is a crucial one in the French context where fear of 'separation' is ubiquitous among secularist intellectuals. Some of the terms that were invented to discuss the threats posed by communautarisme are 'libanisation', 'tribalisation', 'cantonisation' and 'ottomanisation'. The Stasi Commission also refers to a presupposed 'tribalisation' of the Netherlands (Stasi 2003: 2.3).

5 The Stasi Commission forgets to mention that secularist and repressive centralist regimes in the Islamic world, such as, for example, in Turkey, Tunisia and Iran, prohibited the scarf (in public places or even generally) before the rise of Islamism. Under communism in the Islamic world, the state's patronising attitude towards dress sometimes became ridiculous. In Afghanistan in the early 1980 os, children were prohibited from wearing scarves and were also forced to wear red trousers when going to school. In the 1930s, there were large unveiling campaigns in Islamic parts of the UsSR. Moreover, in the Algerian context, unveiling has had tremendous political connotations from the 1950 os onwards (Shepard 2006). For the politics of the scarf in a global context, see Ahmed (2011); Elver (2012). 
6 Please note that in this sense the Commission was less secularist than much of liberal political theory. It does explicitly acknowledge the legitimacy of religiously motivated political argument.

7 Raulet (1999: 101) concludes from Kepel's analysis that what is proposed by the Islamists is 'the spectre of a collection of collectivities which, under the pretext of making their differences known, finally do not campaign for anything but their ghettoisation' (my translation). Such jumping to conclusions leads Republican argumentation astray, even in Raulet, who is such a good critic of Republican philosophical history.

8 Arguably, for example, Sayyid Qutb's work shows the traces of the modernist dichotomies we are discussing here (Calvert 2004). But most Muslim claims are more complex than Kepel suggests. For extensive research into Muslim selfconceptions and explanations of specific practices in the French context, see Bowen (2010a).

9 Touraine in Libération, 15 October 1990.

10 He obviously radically changed his opinion about what adopting a law could achieve during this struggle, because several weeks after, he voted in favour of the law.

11 This is why Roy does not use the term 'political Islam' for 'Islamisme'. 'Political Islam' was introduced as a better name for the movement which is often called Islamic fundamentalism, because the latter term is linked to Protestantism and to the reading of theological texts in purely theological and not political terms. According to some, fundamentalism is a frequently used misnomer suggesting the desire for a return to an authentic religion and neglecting the fact that Islamism and other current religiously inspired movements are modern and thus far from retrograde or reactive. Roy, by contrast, distinguishes between political Islam, which was prevalent in the 1970s and 1980s and concentrated on the creation of an Islamic state, and what he calls 'neo-fundamentalism' or 'salafisme', which is not aimed at the state but at purifying Islam from all cultural and ethnic relations in order to internationalise and even globalise it.

12 Roy's criticism of the reified use of the concept of culture within multiculturalism is familiar from the debates within multiculturalist discourse itself. Constructivists have made their critique of the reified concept of culture into their programme for multiculturalism's redefinition or even rejection (see Chapter 1). Chapter 3 analysed the links between constructivist concepts of culture and a return to classic liberalism (see, e.g., Asad 1993; Bader 2001; Modood 1998).

13 Such a critique of modernity's conceptualisations of religion has been developed by Taylor $(1995,2003)$. He deconstructs William James's subjectivist concept of religious experience.

\section{Notes Chapter 8}

1 Only Françoise, the protagonist family's long-time servant, who feels at risk of becoming identified with the city proletariat, holds fast to her rural values. She even, in a certain sense, 'fundamentalises' them (see Chapter 4 on Françoise's rejection of Saint-Loup).

2 For a reflection on the concept of 'race' in late 19th-century France, see Chapter 4. 
3 Intertextuality is used here in the sense of 'something reserved to indicate a diffuse penetration of the individual text by memories, echoes, transformations of other texts'. 'Transtextuality', on the other hand, is reserved for overt relationships between specific texts. These definitions are taken from Hawthorn (1994: 126).

4 The first meaning of the French original, which is carcan (Proust 1988: III, 61), is the iron ring that persons condemned to the pillory were made to wear around their necks. This caused a wound that looked like a red collar.

5 The French is more cruel than the English translation. 'Une fleur de sang' literally means 'a flower of blood' and a 'rubis en flammes' means 'a ruby in flames'.

6 Even when her nephew Saint-Loup dies in World War I, Mme de Guermantes does not manage to mourn for longer than a week. And this already impresses the narrator, because he considers a week relatively long for her. He had anticipated that she would mourn only briefly, because her 'Guermantes wit' might have incited her to show that she did not 'share the superstition about the ties of blood' (Proust 1996: VI, 197). The suggestion, though ironic, makes clear the extent to which at the time an affective memory of the dead, even when this concerns a family member, was associated with the Reaction.

7 Adorno realised the importance of forgetting in Proust. In Adorno's view, a dialectical step has been left out of Benjamin's interpretation of involuntary memory; namely, that of forgetting (Adorno \& Benjamin 1999 [1940]: 321). He adds that both remembrance and memory are located in forgetting, and the structure of the experience of an individual person may depend in the last instance upon 'how that person forgets' (ibid.). Adorno obviously had forgotten what Benjamin had already written about forgetting in Proust in 1929 (see above).

8 This in line with how Wittgenstein, in his Philosophical Investigations, escaped from the epistemological-modernist framework that produces its 'either-ors' and opposes habit and freedom, culture and individual, opinion and truth and the like. Wittgenstein suggests that we learn to recognise things and to understand the rules of meaning-making only in the course of social learning processes, through actual practices of meaning-making. This is a basis for the rethinking of the concept of religion in recent scholarship (Asad 1993; Bader 2001; 2007).

\section{Notes Chapter 9}

1 The phrase is (in)famous but it was not widespread during World War II (De Haan 1997). Sluiter (2005) traces its precise origins and the many ways it has been referenced in recent years.

2 This is especially the case if we refer to the most traumatic moment in the modern European history of the Jews, as we tend to do because these memories are so present. An example is the heated discussions that took place in the Netherlands after the Dutch historian Mak (2005: 69-70) compared some iconic aspects of the portrayal of Muslims in Ayaan Hirsi Ali and Theo van Gogh's film Submission Part I with that of Jews in Der ewige Jude.

3 Roy's view that today's neo-fundamentalisms, including salafisme, should not be called political because they do not strive for state power but 'only' for a reli- 
gionisation of society is not really reassuring and depends on an overly classical understanding of the relation between state and society (see Mahmood 2005).

4 Maclure and Taylor (2011) suggest that this might be easier in the case of laïcité because this word does not carry the same legacy of modernist secularisation theory as the word 'secularism'.

5 Another alternative is the 'politics of acknowledgement' that Markell (2003) offers in contrast with the politics of recognition. Or Bader's (2007) view that it is better to argue for religious pluralism than multiculturalism when thinking about the position of ethno-religious minorities in Europe. I reflect on these alternatives in Jansen (2013a). 


\section{Works cited}

Abu Zayd, Nasr (2006), Reformation of Islamic Thought: A Critical Historical Analysis. Amsterdam: Amsterdam University Press.

Achi, Raberh (2004), 'La séparation des Églises et de l'État à l'épreuve de la situation colonial: Les usages de la dérogation dans l'administration du culte musulman en Algérie (1905-1959)', Politix 17 (66): 81-106.

Adorno, Theodor W. (1994) [1954], 'Die Wunde Heine', in Noten zur Literatur. Frankfurt am Main: Suhrkamp, 95-100.

— (1990) [1966], Negative Dialektik. Frankfurt am Main: Suhrkamp.

- (1977) [1940], 'George und Hofmannsthal: Zum Briefwechsel', in Gesammelte Schriften. x (i). Frankfurt am Main: Suhrkamp, 325-330.

- (1962), 'Über Statik und Dynamik als soziologische Kategorien', in Sociologica II. Reden und Vorträge. Max Horkheimer and Theodor W. Adorno. Frankfurt am Main: Suhrkamp, 223-240.

Adorno, Theodor W. \& Walter Benjamin (1999) [1940], The Complete Correspondence 1928-1940. Henri Lonitz (ed.). Cambridge (MA): Harvard University Press.

Agulhon, Maurice (1981), Notes sur le Manuel Républicain de Charles Renouvier. Paris: Garnier.

Ahmed, Leila (2011), A Quiet Revolution: The Veil's Resurgence from the Middle East to America. New Haven: Yale University Press.

Akan, Murat (2009), 'Laïcité and multiculturalism: The Stasi report in context', The British Journal of Sociology 60 (2): 237-256.

Alba, Richard (1995), 'Assimilation's quiet tide', Public Interest 119: 3-18.

Alba, Richard \& Victor Nee (2003), Remaking the American Mainstream: Assimilation and Contemporary Immigration. Harvard: Harvard University Press.

Alexander, Jeffrey (2006), The Civil Sphere. Oxford and New York: Oxford University Press.

- (2001), 'Theorizing the "modes of incorporation": Assimilation, hyphenation and multiculturalism as varieties of civic participation', Sociological Theory 19 (3): 237249.

Alouane, Rim-Sarah (2012), 'The practice of religion in the French public and private workplace: In search of an elusive balance', in A Test of Faith: Religious Diversity and Accommodation in the European Workplace, K. Alidadi, M-Cl. Foblets \& J. Vrielink (eds). London: Ashgate, 205-224.

Amiraux, Valéry (2010a), 'Crisis and new challenges? French Republicanism featuring multiculturalism', in A. Silj (ed.), European Multiculturalism Revisited. London: Zed Books, 65-104.

- (2010b), 'From empire to republic, the French Muslim dilemma', in A. Triandafyllidou (ed.), Muslims in 21st Century Europe: Structural and Cultural Perspectives. London: Routledge, 137-159. 
- (2009), 'L'affaire du foulard' en France: Retour sur une affaire qui n'en est pas encore une', Sociologie et sociétés 41 (2): 273-298.

- (2006), 'Speaking as a Muslim: Avoiding religion in French public space', in V. Amiraux \& G. Jonker (eds), Politics of Visibility. Bielefeld: Transcript, 21-52.

Amnesty International (2012), Choice and Prejudice. Discrimination against Muslims in Europe, retrieved from http://www.amnesty.eu/content/assets/REPORT.pdf.

Amoore, Louise (2007), 'Vigilant visualities: The watchful politics of the war on terror', Security Dialogue 38: 215-232.

Andersen, Hans Christian (2005) [1845], 'The red shoes', retrieved from http://hca. gilead.org.il/red_shoe.html.

Anderson, Elizabeth (2011), The Imperative of Integration. Princeton: Princeton University Press.

Appiah, Kwame Anthony (1996), 'Race, culture, identity', in K.A. Appiah \& A. Gutman (eds), Color Conscious. Princeton: Princeton University Press, 98-99.

Arendt, Hannah (1979) [1948], The Origins of Totalitarianism. San Diego, New York and London: Harcourt Brace \& Company.

Asad, Talal (2006), 'Trying to understand French secularism', in H. De Vries \& L. Sullican (eds), Political Theologies. New York: Fordham University Press, 493-526.

- (2003), Formations of the Secular: Christianity, Islam, Modernity. Stanford: Stanford University Press.

- (2001), 'Reading a modern classic: W.C. Smith's “The Meaning and End of Religion”', in H. De Vries \& S. Weber (eds), Religion and Media. Stanford: Stanford University Press.

- (1993), Genealogies of Religion. Baltimore: The Johns Hopkins University Press.

Assmann, Jan (1999), Das kulturelle Gedächtnis. München: Beck.

Back, Les, Michael Keith, Azra Khan, Kalbir Shukra \& John Solomos (2002), 'The return of assimilationism: Race, multiculturalism and new labour', Sociological Research Online 7 (2).

Bader, Veit Michael (2010a), 'Constitutionalizing secularism, alternative secularisms or liberal-democratic constitutionalism? A critical reading of some Turkish, ECtHR and Indian supreme court cases on "Secularism"', Utrecht Law Review (6) 3: 8-35.

- (2010b), 'Religions and liberal democracy: Reflections on doctrinal, institutional, and attitudinal learning', in M. Mookherjee (ed.), Toleration and Recognition in an Age of Religious Diversity, Dordrecht: Springer, 17-46.

- (2007), Secularism or Democracy? Associational Governance of Religious Diversity. Amsterdam: Amsterdam University Press.

- (2006), '(Staats-)Bürgerschaft', in S. Gosepath, W. Hinsch \& B. Roessler (eds), Handbuch der Politischen Philosophie und Sozialphilosophie. Berlin: Walter de Gruyter.

- (2005a), 'Associative democracy and minorities within minorities', in A. Eisenberg \& J. Spinner-Halev (eds), Minorities within Minorities. Cambridge: Cambridge University Press, 319-339.

- (2005b), 'The ethics of immigration', Constellations 13 (3): 331-361.

- (2003a), 'Religious diversity and democratic institutional pluralism', Political Theory 31 (2): $265-294$.

- (2003b), 'Democratic institutional pluralism and cultural diversity', in D. Juteau \& C. Harzig (eds), The Social Construction of Diversity. New York and Oxford: Berghahn, 131-167. 
- (2001), 'Culture and identity: Contesting constructivism', Ethnicities 1 (2): 251-273.

- (1999), 'Religious pluralism: Secularism or priority for democracy?', Political Theory 27 (5): 597-633.

- (1998), 'Egalitarian multiculturalism: Institutional separation and cultural pluralism', in R. Bauboeck \& J. Rundell (eds), Blurred Boundaries. Aldershot: Ashgate, 185-220.

- (1997), Citizenship and Exclusion. London: Macmillan.

- (1991), Collectief handelen: Sociale ongelijkheid en collectief handelen. Deel 2. Groningen: Wolters-Noordhoff.

Badiou, Alain (2006), Polemics. London and New York: Verso.

Bal, Mieke (1999), 'Introduction', in M. Bal, J. Crewe \& L. Spitzer (eds), Acts of Memory: Cultural Recall in the Present. Hanover and London: University Press of New England, vii-xvii.

Balibar, Etienne (2007), 'Uprisings in the banlieues', Constellations 14: (1): 47-71.

- (2004), 'Dissonances within laïcité', Constellations 11 (3): 353-367.

- (2003), We, the People of Europe. Reflections on Transnational Citizenship. Princeton (NJ): Princeton University Press.

Bancel, Nicolas, Pascal Blanchard \& Françoise Vergès (2005), La République coloniale. Paris: Hachette.

Bangstad, Sindre (2009), 'Contesting secularism/s: Secularism and Islam in the work of Talal Asad', Anthropological Theory 9: 188-208.

Bangstad, Sindre \& Matti Bunzl (2010), 'Anthropologists are talking about Islamophobia and anti-Semitism in the new Europe', Ethnos 75 (2): 213-228.

Barkat, Sidi Mohammed (2005), Le corps d'exception: Les artifices du pouvoir colonial et la destruction de la vie. Paris: Éditions Amsterdam.

Barry, Brian (2001), Culture and Equality: An Egalitarian Critique of Multiculturalism. Cambridge (MA): Polity Press.

Barthes, Roland (1980) [1971], 'Une idée de recherche', in Recherche de Proust. G. Genette (ed.). Paris: Editions du Seuil, 34-39.

Baubérot, Jean (2010), 'The evolution of secularism in France: Between two civil religions', in Comparative Secularisms in a Global Age. Basingstoke: Palgrave Macmillan.

- (2004a), 'Voile, école, femmes, laïcité', in A. Houziaux (ed.), Le voile, que cache-t-il?, 49-79.

- (2004b), 'Proposition faite par Jean Baubérot à la Commission Stasi' in A. Houziaux (ed.), Le voile, que cache-t-il?, 111-117.

- (2000), Histoire de la laïcité en France. Paris: PUF.

- (1998), 'Two thresholds of laïcisation', in R. Bhargava (ed.), Secularism and its Critics. Delhi: Oxford University Press, 94-136.

Bauboeck, Rainer (2011), 'Citizenship and free movement', in R.M. Smith (ed.), Citizenship, Borders, and Human Needs, 343-376.

- (2009), Citizenship Policies in the New Europe. Expanded and updated edition. Amsterdam: Amsterdam University Press.

- (2006), Migration and Citizenship: Legal Status, Rights and Political Participation. Amsterdam: Amsterdam University Press.

- (2002), 'Farewell to multiculturalism? Sharing values and identities in societies of immigration', retrieved from http://international.metropolis.net/events/rotterdam/ presentation_speakers.../Bauboeck.htm. 
- (2001a), 'Minderheiten im Übergang. 20 Thesen zur Assimilation von Einwanderern. Gesellschaft für bedrohte Völker', retrieved from www.gfbv.it/dossier/eu$\mathrm{min} / 2$ oassimila.html.

- (2001b), 'Integration von Einwanderern: Reflexionen zum Begriff und seine Anwendungsmoglichkeiten', in H. Waldrauch (ed.), Die Integration von Einwanderern, Vol. 2: Ein Index rechtlicher Diskriminierung. Frankfurt am Main: Campus Verlag, 25-52.

- (1998a), 'The crossing and blurring of boundaries in international migration. Challenges for social and political theory', in R. Bauboeck \& J. Rundell (eds), Blurred Boundaries: Migration, Ethnicity, Citizenship. Ashgate: Vermont, 17-52.

- (1998b), 'Sharing history and future? Time horizons of democratic membership in an age of migration', Constellations 4 (3): 320-347.

- (1996), 'Cultural minority rights for immigrants', International Migration Review Xxx (1): 203-250.

- (1994), Transnational Citizenship. Aldershot: Edward Elgar.

Bauboeck, Rainer \& Thomas Faist (eds) (2010), Transnationalism and Diaspora: Concepts, Theories and Methods. Amsterdam: Amsterdam University Press.

Bauboeck, Rainer \& Christian Joppke (2010) (eds), How Liberal are Citizenship Tests? (EUI Working Paper RsCAS, 41) Fiesole: Robert Schuman Centre for Advanced Studies.

Bauman, Zygmunt (1998), 'Assimilation into exile: The Jew as a Polish writer', in S.R. Suleiman (ed.), Exile and Creativity: Signposts, Travellers, Outsiders, Backward Glances. Durham and London: Duke University Press, 321-353.

- (1989), Modernity and the Holocaust. Cambridge: Polity Press.

- (1988), 'Entry tickets and exit visas: Paradoxes of Jewish assimilation', Telos 77: 45-77.

Baumann, Gerd (2001), 'Culture and collectivity. Constructivism as the methodology of choice: A reply to Veit Bader', Ethnicities 1 (2): 274-282.

- (1999), The Riddle of Multiculturalism: Rethinking National, Ethnic, and Religious Identities. New York and London: Routledge.

- (1996), Contesting Culture: Discourses of Identity in Multi-ethnic London. New York and Cambridge: Cambridge University Press.

Bellamy, Elizabeth (1997), Affective Genealogies: Psychoanalysis, Postmodernism, and the 'Jewish Question' After Auschwitz. Lincoln and London: University of Nebraska Press.

Bellil, Samira (2001), L'enfer des tournantes. Paris: Gallimard.

Bem, Jeanne (1980), 'Le Juif et l'homosexuel dans À la Recherche du Temps Perdu', Littérature 37: 100-112.

Benbassa, Esther (2007), 'Xenophobia, anti-semitism and racism', in M. Bunzl (ed.), Anti-Semitism and Islamophobia: Hatreds Old and New in Europe. Chicago: Prickly Paradigm Press, 77-89.

- (2003), La République face à ses minorités. Les Juifs hier, les Musulmans aujourd'hui. Paris: Mille et une nuits.

- (2000) [1997], Histoire des Juifs de France. Paris: Le Point Seuil.

Benhabib, Seyla (1996), Democracy and Difference: Contesting the Boundaries of the Political. Princeton: Princeton University Press.

Benjamin, Walter (1997), 'Some motifs in Baudelaire', in Baudelaire, a Lyric Poet in the Era of High Capitalism. New York and London: Verso: 109-154. Translated from the German by H. Zohn. 
- (1980) [1938], 'Über einige Motive bei Baudelaire', in R. Tiedemann \& H. Schweppenhäuser (eds), Gesammelte Schriften. Band I (ii). Frankfurt am Main: Suhrkamp, 605-655.

- (1977b) [1933], 'Erfahrung und Armut', in R. Tiedemann \& H. Schweppenhäuser (eds), Literarische und ästhetische Essays. Gesammelte Schriften. Band II (1). Frankfurt am Main: Suhrkamp, 213-219.

- (1977a) [1929], 'Zum Bilde Prousts', in R. Tiedemann \& H. Schweppenhäuser (eds), Literarische und ästhetische Essays. Gesammelte Schriften. Band II (1). Frankfurt am Main: Suhrkamp, 310-324.

- (1968), 'The image of Proust', in Illuminations. New York: Shocken Books, 201-217.

Berger, Peter (ed.) (1999), The Desecularisation of the World: Resurgent Religion and World Politics. Washington, DC: Ethics and Public Policy Center.

Bergson, Henri (1990) [1880], Matière et mémoire: Essai sur la relation du corps à l'esprit. Paris: PUF.

Berkovitz, Jay R. (1989), The Shaping of Jewish Identity in Nineteenth-century France. Detroit: Wayne State University Press.

Bernet, Anne (2004). 'Vers l'obtention de la citoyenneté avec Louis XVI', retrieved from www.historia.presse.fr/data/thématique/87/08705001.html.

Bhabha, Homi (1994), The Location of Culture. New York: Routledge.

Bhargava, Rajeev (2009), 'Review symposium: Why not secular democracy?', Ethnicities 9 (4): 553-560.

Birnbaum, Pierre (2008), Geography of Hope: Exile, the Enlightenment, Disassimilation. Stanford: Stanford University Press.

- (2001) [1998], The Idea of France. New York: Hill and Wang. Translated from the French by M.B. DeBevoise.

- (1998), La France imaginée. Paris: Gallimard.

- (1996), 'Grégoire, Dreyfus, Drancy and the Rue Copernic: Jews at the heart of French history', in P. Nora (ed.), Realms of Memory. New York: Columbia University Press, 379-423.

- (1993), La France aux Français: histoire des haines nationalistes. Paris: Seuil.

- (1989), 'Sur l'étatisation révolutionnaire: l'abbé Grégoire et le destin de l'identité juive', Le Débat 53: 157-173.

- (1988), Un mythe politique: la 'république juive'. Paris: Gallimard.

Bloemraad, Irene, Anna Korteweg \& Gökçe Yurdakul (2008), 'Citizenship and immigration: Multiculturalism, assimilation, and challenges to the nation-state', Annual Review of Sociology 34: 153-179.

Bouamama, Said (2006), 'De la visibilisation à la suspicion: la fabrique Républicaine d'une politisation', in N. Guénif-Souillamas (ed.), La République mise a nue par son immigration. Paris: Editions La Fabrique.

Bouchard, Gérard \& Charles Taylor (2008), Fonder l'avenir. Le temps de la conciliation. Rapport final. Commission de consultation sur les pratiques d'accommodement reliées aux différences culturelles, retrieved from http://www.accommodementsquebec.ca/documentation/rapports/rapport-final-integral-fr.pdf.

Bourdieu, Pierre (1999) [1989], 'Un problème peut en cacher un autre', archives du Collège de France, retrieved from www.ldh-toulon.net/spip.php?article325.

- (1979), La Distinction: Critique sociale du jugement. Paris: Minuit.

Bowen, John (2011), 'Europeans against multiculturalism: Political attacks misread history, target Muslims, and may win votes', The Boston Review, July-August, 28-35. 
- (2010a), Can Islam Be French? Pluralism and Pragmatism in a Secularist State. Princeton: Princeton University Press.

- (2010b), 'Secularism: Conceptual genealogy or political dilemma?', Comparative Studies in Society and History 52 (3): 680-694.

- (2007a), Why the French don't Like Headscarves: Islam, The State and Public Space. Princeton and Oxford: Princeton University Press.

- (2007b), 'A view from France on the internal complexity of national models', Journal of Ethnic and Migration Studies 33 (6): 1003-1016.

- (2005), 'Toward a French Islam: How can a "laic" state recognise religion?', paper presented at Imiscoe Conference, Amsterdam, May 26-28.

- (2004), 'Pluralism and normativity in French Islamic reasoning', in R. Hefner (ed.), Remaking Muslim Politics: Pluralism, Contestation, Democratisation. Princeton: Princeton University Press, 326-345.

Bowie, Malcolm (1998), Proust among the Stars. New York: Columbia University Press.

Brahm Levey, Geoffrey (2009), 'Secularism and religion in a multicultural age', in G.B. Levey \& T. Modood (eds), Secularism, Religion and Multicultural Citizenship. Cambridge: Cambridge University Press, 1-24.

Brahm Levey, Geoffrey \& Tariq Modood (eds) (2009), Secularism, Religion and Multicultural Citizenship. Cambridge: Cambridge University Press.

Brelot, Claude-Isabelle (1994), 'Entre nationalisme et cosmopolitisme: les engagements multiples de la noblesse', in P. Birnbaum (ed.), La France de l'Affaire Dreyfus. Paris: Éditions Gallimard, 339-362.

Brown, Wendy (2006), Regulating Aversion: Tolerance in the Age of Identity and Empire. Princeton: Princeton University Press.

- (2004), 'Tolerance and/or equality? The "Jewish Question" and the "Woman Question”', Differences: A Journal of Feminist Cultural Studies 15 (2): 1-31.

- (2002), 'Suffering the paradoxes of rights', in W. Brown \& J. Halley (eds), Left Legalism/Left Critique. Durham: nC: Duke University Press, 420-434.

- (1995), States of Injury: Power and Freedom in Late Modernity. Princeton: Princeton University Press.

Brubaker, Rogers (2001), 'The return of assimilation? Changing perspectives on immigration and its sequels in France, Germany and the United States', Ethnic and Racial Studies 24 (4): 531-548.

- (1992), Citizenship and Nationhood in France and Germany. Cambridge (MA): Harvard University Press.

Brun, Bernard (1988), 'Brouillons et brouillages: Proust et l'antisémitisme', Littérature 70: $110-28$.

Buisson, Ferdinand (1888), 'Neutralité', in F. Buisson (ed.), Dictionnaire de pédagogie et d'instruction primaire. Paris: Librairie Hachette \& Cie.

- (1899), 'Le devoir présent de la jeunesse', in É. Boutroux (ed.), La morale sociale. Paris: Librairie Hachette \& Cie.

Bunzl, Matti (ed.) (2007) Anti-Semitism and Islamophobia: Hatreds Old and New in Europe. Chicago: Prickly Paradigm Press.

Burns, Michael (1991), Dreyfus: A Family Affair, from the French Revolution to the Holocaust. Harper Collins: New York.

Buruma, Ian (2007), 'Freedom cannot be decreed', retrieved from www.signandsight. $\mathrm{com} /$ features/1161.html. 
- (2006), Murder in Amsterdam: Liberal Europe, Islam, and the Limits of Tolerance. New York: Penguin.

Butler, Judith (1997), The Psychic Life of Power: Theories in Subjection. Stanford: Stanford University Press.

Cady, Linell \& Elizabeth Shakman Hurd (eds) (2010), Comparative Secularisms in a Global Age. Basingstoke: Palgrave Macmillan.

Calvert, John (2004), 'Sayyid Qutb and the power of political myth: Insights from sorel', Historical Reflections 3: 509-528.

Carens, Joseph (2012), 'The most liberal citizenship test is not at all', in R. Bauböck \& C. Joppke (eds), How Liberal are Citizenship Tests? (EUI Working Paper RsCAs, 41) Fiesole: Robert Schuman Centre for Advanced Studies, 19-21.

- (2010), Immigrants and the Right to Stay. Cambridge/Boston: MIT Press.

- (2000), Culture, Citizenship and Community. Oxford: Oxford University Press.

Carens, Joseph, Rainer Bauboeck \& Patrick Weil (2004), 'The French law on hijab', email exchange, via personal email contact.

Carlston, Erin (2002), 'Secret dossiers: Sexuality, race, and treason in Proust and the Dreyfus Affair', Modern Fiction Studies, 48 (4): 937-968.

Casanova, José (2007), 'The stillborn God: The great separation', review of Mark Lilla's The Stillborn God, retrieved from www.ssrc.org/blogs/immanent_frame/2007/12/07/ the-great-separation/.

- (2006), 'Secularisation revisited: A reply to Talal Asad', in D. Scott \& C.Hirschkind (eds), Powers of the Secular Modern: Talal Asad and his Interlocutors. Stanford: Stanford University Press, 12-31.

- (1994), Public Religions in the Modern World. Chicago and London: University of Chicago Press.

Césaire, Aimé (1950), Discours sur le colonialisme. Paris: Réclame.

Cesari, Jocelyne (2010), 'Securitisation of Islam in Europe', in J. Cesari (ed.), Muslims in the West after 9/11: Religion, politics and law. London and New York: Routledge, 9-27.

Chakrabarty, Dipesh (200o), Provincializing Europe: Postcolonial Thought and Historical Difference. Princeton: Princeton University Press.

Chouder, Ismahane, Malika Latrèche \& Pierre Tevanian (eds) (2008), Les Filles Voilées Parlent. Paris: Éditions La Fabrique.

Connolly, William (2008), Capitalism and Christianity, American Style. Durham and London: Duke University Press.

- (2006), 'Europe: A minor tradition', in Powers of the Secular Modern: Talal Asad and His Interlocutors. Stanford: Stanford University Press, 75-93.

- (2005), Pluralism. Durham: Duke University Press.

- (2002), Neuropolitics: Thinking, Culture, Speed. Minnesota: University of Minnesota Press.

- (1999), Why I am Not a Secularist. Minnesota: University of Minnesota Press.

Costa-Kostritsky, Valeria (2012), 'France and the veil: The dark side of the law', retrieved from www.opendemocracy.net/5050/valeria-costa-kostritsky/france-and-veil--dark-side-of-law.

De Genova, Nicholas (2007), 'The production of culprits: From deportability to detainability in the aftermath of "homeland security"', Citizenship Studies 11 (5): 421-448. 
De Genova, Nicholas \& Nathalie Peutz (2010), The Deportation Regime: Sovereignty, Space and the Freedom of Movement. Durham: Duke University Press.

De Graaf, Beatrice (2011), 'Religion bites: Religieuze orthodoxie op de nationale Veiligheidsagenda', Tijdschrift voor Religie, Recht en Beleid 2 (2): 62-80.

De Haan, Ido (1997), Na de ondergang: De herinnering aan de Jodenvervolging in Nederland 1945-1995. Den Haag: sDu Uitgevers.

De Tocqueville, Alexis (1966) [1836], Democracy in America. New York: Harper and Row.

De Vries, Hent (1999), Philosophy and the Turn to Religion. Baltimore and London: Johns Hopkins University Press.

Deleuze, Gilles (2000), Proust and Signs. Minneapolis: University of Minnesota Press.

- (1964), Proust et les signes. Paris: Presses Universitaires de France.

Deltombe, Thomas (2005), L'Islam imaginaire: La construction médiatique de l'islamophobie en France, 1975-2005. Paris: Éditions La Découverte.

Descombes, Vincent (1987), Proust: Philosophie du roman. Paris: Les éditions de Minuit.

Dressler, Markus \& Arvind Mandair (eds) (2011), Secularism and Religion-Making. Oxford: Oxford University Press.

Dryzek, John (200o), Deliberative Democracy and Beyond: Liberals, Critics, Contestations. Oxford: Oxford University Press.

Durkheim, Émile (1925), L'éducation morale. Paris: Félix Alcan.

Duyvendak, Jan-Willem, Menno Hurenkamp \& Evelien Tonkens (2010), 'Culturalisation of citizenship in the Netherlands', in A. Chebel d'Appolonia \& S. Reich (eds), Managing Ethnic Diversity after 9/11: Integration, Security and Civil Liberties in Transatlantic Perspective. New Brunswick: Rutgers University Press, 233-252.

Edmunds, June (2011), "The "new" barbarians: Governmentality, securitisation and Islam in Western Europe', Contemporary Islam, 1-18.

Elver, Hilal (2012), The Headscarf Controversy: Secularism and Freedom of Religion. Oxford: Oxford University Press.

Entzinger, Han (2009), 'Different systems, similar problems: The French urban riots from a Dutch perspective', Journal of Ethnic and Migration Studies, 35 (5): 815-834.

- (2006), 'Changing the rules while the game is on: From multiculturalism to assimilation in the Netherlands', in M. Bodemann \& G. Yurdakul (eds), Migration, Citizenship, Ethnos: Incorporation Regimes in Germany, Western Europe and North America. New York: Palgrave Macmillan, 121-144.

Ettinger, Elzbieta (1995), Hannah Arendt, Martin Heidegger. New Haven and London: Yale University Press.

Fanon, Frantz (1952), Peau noire, masques blancs. Paris: Seuil.

Farris, Sara \& Sara De Jong (2013), 'Discontinuous intersections: Second-generation immigrant girls in transition from school to work', Ethnic and Racial Studies, March, online first.

Favell, Adrian (2001a), Philosophies of Integration: Immigration and the Idea of Citizenship in France and Britain. Basingstoke and New York: Palgrave.

- (2001b), 'Integration policy and integration research: A review and a critique', in T.A. Aleinikoff \& D. Klusmeyer (eds), Citizenship Today: Global Perspectives and Practices. Washington DC: Brookings Institution Press, 349-399. 
Ferrara, Alessandro (2009), 'The separation of religion and politics in a postsecular society', Philosophy and Social Criticism 35 (1/2): 77-91.

Ferrari, Alessandro \& Sabrina Pastorelli (eds) (2013), The Burqa Affair Across Europe: Between Public and Private Space. London: Ashgate.

Fetzer, Joel S. \& J. Christopher Soper (2005), Muslims and the State in Britain, France, and Germany. Cambridge and New York (NY): Cambridge University Press.

Foblets, Claire Marie \& Jean-Yves Carlier (eds) (2010), Islam \& Europe: Crises are Challenges. Leuven: Leuven University Press.

Foucault, Michel (1997) [1979], 'What is enlightenment?', in P. Rabinow (ed.), Ethics: Subjectivity and Truth. New York: The New Press, 303-321.

- (1976), La volonté de savoir: Histoire de la sexualité I. Paris: Gallimard.

Foner, Nancy \& Alba, Richard (2008), 'Immigrant religion in the us and Western Europe: Bridge or barrier to inclusion?', International Migration Review 42: 360-392.

Fraisse, Luc (1996), Proust au miroir de sa correspondance. Paris: SEDEs.

Fraser, Nancy (2003), 'Social justice in the age of identity politics: Redistribution, recognition and participation', in N. Fraser \& A. Honneth (eds), Redistribution or Recognition? A Political-philosophical Exchange. London: Verso, 7-109.

- (2001), 'Recognition without ethics', Theory, Culture \& Society 2-3: 21-42.

- (1995), 'From redistribution to recognition? Dilemmas of justice in a post-socialist age', New Left Review 212: 68-93.

- (1992), 'Rethinking the public sphere: A contribution to the critique of actually existing democracy', in C. Calhoun (ed.), Habermas and the Public Sphere. Cambridge (мA): міт Press, 109-142.

Freedman, Jonathan (2001), 'Coming out of the Jewish closet with Marcel Proust', Journal of Lesbian and Gay Studies 7 (4): 521-551.

Gaspard, Françoise \& Farhad Khosrokhavar (1995), Le foulard et la République. Paris: La Découverte.

Gauchet, Marcel (1998), La religion dans la démocratie: Parcours de la laïcité. Paris: Gallimard.

Geisser, Vincent (2003), La nouvelle Islamophobie. Paris: La découverte.

Geisser, Vincent \& Aziz Zemouri (2007), Marianne et Allah: Les Politiques francais face à la 'question musulmane'. Paris: La découverte.

Genette, Gérard (1972), Figures III. Paris: Éditions du Seuil.

- (1966), Figures. Paris: Éditions du Seuil.

Gianni, Matteo (2003), 'Retour de l'assimilation ou affirmation de l'intégration?', Impressum 1: 18-24.

Gilroy, Paul (2006), 'Multiculturalism and post-colonial theory', in The Oxford Handbook of Political Theory, 656-677.

- (2004), After Empire: Melancholia or Convivial Culture? London: Routledge.

Glazer, Nathan (1997), We Are All Multiculturalists Now. Cambridge (MA): Harvard University Press.

Glazer, Nathan \& Patrick Moynihan (1963), Beyond the Melting Pot: The Negroes, Puerto Ricans, Jews, Italians, and Irish of New York City. Cambridge (мA): MIT Press.

Göle, Nilufer (2011), 'The new faces of the European far-right', retrieved from http:// blogs.ssrc.org/tif/2011/05/11/the-european-far-right/.

- (2005), Interpénétrations, L'Islam et l'Europe. Paris: Galaade Éditions. 
- (1996), The Forbidden Modern: Civilisation and Veiling. Ann Arbor: University of Michigan Press.

Grégoire, L’Abbé (1989) [1788], Essai sur la régénération physique, morale et politique des juifs. Paris: Flammarion.

- (1975) [1788], 'Rapport sur la nécessité et les moyens d'anéantir les patois et d'universaliser l'usage de la langue française', in M. De Certeau, D. Julia \& J. Revel (eds), Une politique de la langue: La Révolution française et les patois. Paris: Gallimard, 302-317.

Groenendijk, Kees \& Ricky van Oers (2010), 'How liberal citizenship tests are does not merely depend on their content, but also their effects', in R. Bauböck \& C. Joppke (eds), How Liberal are Citizenship Tests? (Eur Working Paper RsCAs, 41) Fiesole: Robert Schuman Centre for Advanced Studies, 9-11.

Guénif-Souillamas, Nacira (ed.) (2006), La république mise à nu par son immigration. Paris: La Fabrique.

- (2005), 'La réduction à son corps de l'indigène de la République', in La Fracture Coloniale: La société francaise au prisme de l'héritage colonial, 199-208.

Guénif-Souillamas, Nacira \& Eric Macé (2004), Les féministes et le garçon arabe. Paris: Éditions de l'aube.

Habermas, Jürgen (2008a), 'Die Dialektik der Säkularisierung', in Blätter für deutsche und internationale Politik, 33-46. Translation into English: 'Notes on a Postsecular Society', retrieved from www.signandsight.com/features/1714.html.

- (2008b), Between Naturalism and Religion: Philosophical Essays. Cambridge and Malden (USA): Polity Press.

- (1998), The Inclusion of the Other: Studies in Political Theory. Cambridge, MA and London: MIT Press.

- (1994), 'Struggles for recognition in the democratic constitutional state', in A. Gutmann (ed.), Multiculturalism. Princeton: Princeton University Press: 107-49.

Halbwachs, Maurice (1994) [1925], Les Cadres sociaux de la mémoire. Paris: Éditions Albin Michel.

Hall, Stuart (2001), 'The multicultural question' (Pavis Papers in Social and Cultural Research no. 4). Milton Keynes: Open University.

Hartmann, Douglas \& Joseph Gerteis (2005), 'Dealing with diversity: Mapping multiculturalism in sociological terms', Sociological Theory, 23 (2): 218-240.

Hassine, Juliette (1996), 'The Dreyfus Affair in the work of Marcel Proust: A critique of Hannah Arendt and Julia Kristeva', Shofar 14 (3): 107-124.

Hawthorn, Jeremy (1994), A Concise Glossary of Contemporary Literary Theory. London: Arnold Press.

Hertzberg, Arthur (1968), The French Enlightenment and the Jews. New York and London: Columbia University Press.

Hirsi Ali, Ayaan (2002), 'Integratie is een cultureel probleem', NRC-Handelsblad, 31 August-1 September.

Honig, Bonnie (1999), 'My culture made me do it', in J. Cohen, M. Howard \& M. Nussbaum (eds), Is Multiculturalism Bad for Women? Princeton: Princeton University Press, 35-41.

Honneth, Axel (2001a), 'Personal identity and disrespect', in S. Seidman \& J.C. Alexander (eds), The New Social Theory Reader. New York and London: Routledge, 39-45. 
- (2001b), 'Recognition or redistribution? Changing perspectives on the moral order of society', Theory, Culture \& Society 2/3: 43-50.

Horkheimer, Max \& Theodor W. Adorno (2002) [1947], Dialectic of Enlightenment. Philosophical Fragments. Stanford: Stanford University Press.

Hughes, Edward (2011), Proust, Class and Nation. Oxford: Oxford University Press.

- (2001), 'Textual and tribal assimilation: Representing Jewishness in À la recherche du temps perdu', in Jewish Culture and Hisotry, 6(1): 152-173. Reprinted in 2004 in The Image of the Jew in European Liberal Culture 1789-1914. Bryan Cheyette and Nadia Valman (eds). London and Portland: Vallentine Mitchell, 152-173.

Huysmans, Jef (2006), The Politics of Insecurity: Fear, Migration and Asylum in the EU. London: Routledge.

Huyssen, Andreas (2005), 'Diaspora and nation: Migration into other pasts', in M.A. Baronian, S. Besser \& Y. Jansen (eds), Diaspora and Memory: Figures of Displacement in Contemporary Art, Literature and Politics. Amsterdam and New York: Rodopi.

- (1995), Twilight Memories, Marking Time in a Culture of Amnesia. New York: Routledge.

Ivanescu, Carolina (2013), 'Regimes of secularity: Citizenship, religion and Muslimness in Rotterdam, Leicester and Marseille'. Dissertation, Erasmus University Rotterdam.

Jansen, Yolande (2013a), 'Religious pluralism, secularism, interculturalism; what these concepts make visible and invisible about the position of Jews and Muslims in Europe today', under submission Ethnicities.

- (2013b), 'Bedrieglijk prisma: Voorbij de tegenstelling tussen religie en seculariteit'. Inaugural lecture, vu Amsterdam, 28 November.

- (2011a), 'Postsecularism, piety and fanaticism: Reflections on Saba Mahmood's and Jürgen Habermas' critiques of secularism', Philosophy and Social Criticism 37 (9): 977-998.

- (2011b), 'Scheiding van kerk en staat en de bestuurlijke praktijk in Frankrijk: De relevantie van de Frans-Algerijnse geschiedenis', retrieved from www.eutopiainstitute. org/2011/o3/scheiding-van-kerk-en-staat-en-de-bestuurlijke-praktijk-in-frankrijkde-relevantie-van-de-frans-algerijnse-geschiedenis.

- (2010), 'Secularism and security: France, Islam and Europe', in L. Cady \& E. Shakman Hurd. Comparative Secularisms in a Global Age. Basingstoke: Palgrave Macmillan, 94-115.

- (2008), 'De postkoloniale context van de Islam in Frankrijk', Review of Le choc colonial et l'islam: Les politiques religieuses des puissances coloniales en terres d'islam (ed. Pierre-Jean Luizard, Paris, 2006): Le foulard islamique en questions (ed. Charlotte Nordmann, Paris, 2004), and Why the French don't like Headscarves: Islam, the State and Public Space (John Bowen, Princeton, 2007) in De Academische Boekengids.

Joppke, Christian (2009), Veil: Mirror of Identity. Cambridge and Malden: Polity Press.

- (2007a), 'State neutrality and Islamic headscarf laws in France and Germany', Theory and Society (36): 313-342.

- (2007b), 'Transformation of citizenship: Status, rights, identity', Citizenship Studies $11(1): 37-48$. 
- (1999), Immigration and the Nation-State: The United States, Germany, and Great Britain. New York: Oxford University Press.

Joppke, Christian \& Steven Lukes (1999), 'Introduction: Multicultural questions', in C. Joppke \& S. Lukes (eds), Multicultural Questions. Oxford: Oxford University Press, $1-27$.

Joppke, Christian \& Ewa Morawska (2003), 'Integrating immigrants in liberal nationstates: Policies and practices', in C. Joppke \& E. Morawska (eds), Toward Assimilation and Citizenship: Immigrants in Liberal Nation-States. New York: Macmillan, 1-37.

Jouilli, Jeanette (2009), 'Negotiating secular boundaries: Pious micro-practices of Muslim women in French and German public spheres', Social Anthropology 17 (4): 445470.

Kaltenbach, Jeanne-Hélène \& Michèle Tribalat (2002), La République et l'Islam: Entre crainte et aveuglement. Paris: Gallimard.

Kant, Immanuel (2003) [1793], Die Religion innerhalb der Grenzen der blossen Vernunft. Hamburg: Felix Meiner Verlag.

- Political Writings (1991) [1795], Cambridge: Cambridge University Press.

- (1993) [1796], 'On a newly arisen superior tone in philosophy', in P. Fenves (ed.), Raising the Tone of Philosophy: Late Essays by Immanuel Kant, Transformative Critique by Jacques Derrida. Baltimore: Johns Hopkins University Press, 51-72. Translated from the German by P. Fenves.

- (1983) [1796], 'Von einem neuerdings erhobenen vornehmen Ton in der Philosophie', in W. Weischedel (ed.), Werke in zehn Bänden. Darmstadt: Wissenschaftliche Buchgesellschaft III, 377-400.

- (1990) [1793], Die Religion innerhalb der Grenzen der blossen Vernunft. Hamburg: Felix Meiner Verlag.

- (1838) [1764], Sämtliche Werke. F. Rosenkranz \& F.W. Schubert (eds), Leipzig: Voss.

Katz, Jakob (1972), Out of the Ghetto. The Social Background of Jewish Emancipation. Cambridge (MA): Harvard University Press.

- (1964), 'The term "Jewish emancipation": Its origin and historical impact', in A. Altman (ed.), Studies in Nineteenth Century Jewish Intellectual History. Cambridge: Harvard University Press, 1-25.

- (1961), Exclusiveness and Tolerance: Studies in Jewish-Gentile Relations in Medieval and Modern Times. Cambridge: Oxford University Press.

Katz, Steven (2004), 'The impact of modernity on Jewish life', in Educating for Democracy: Paideia in an Age of Uncertainty. New York: Rowman and Littlefield.

Kepel, Gilles (1996) [1994], Allah in the West. Cambridge: Polity Press. Translated from the French by Pascale Ghazaleh.

- (1991), Les Banlieues d'Islam: Naissance d'une Religion en France. Paris: Editions du Seuil.

Kintzler, Cathérine (2003), 'La tolérance, la läicité et l'école', Le Nouvel Observateur, 17-23 July.

- (1998), Tolérance et laïcité. Paris: Pleins Feux.

Kivisto, Peter (2005), 'The revival of assimilation in a historical perspective', in Incorporating Diversity: Rethinking Assimilation in a Multicultural Age. Boulder: Paradigm Publishers, 3-29. 
Kivisto, Peter \& Thomas Faist (2007), Citizenship: Discourse, Theory and Transnational Prospects. Malden, etc.: Blackwell.

Klug, Brian (2012), 'Islamophobia: A concept comes of age', a review of Chris Allen, Islamophobia. Farnham: Ashgate Publishing, 2010; J.L. Esposito \& I. Kalin (eds), Islamophobia: The Challenge of Pluralism in the 21st Century. Oxford: Oxford University Press, 2011; M. Helbling (ed.), Islamophobia in the West: Measuring and Explaining Individual Attitudes. London: Routledge, 2012; M. Malik (ed.), AntiMuslim Prejudice: Past and Present. London: Routledge, 2010; S. Sayyid \& A. Vakil (eds), Thinking Through Islamophobia: Global Perspectives. London: Hurst and Company, A. Shryock (ed.) Islamophobia/Islamophilia: Beyond the Politics of Enemy and Friend. Bloomington, IN: Indiana University Press, Ethnicities, 12: 665-681.

- (2003), 'The collective Jew: Israel and the new antisemitism', Patterns of Prejudice 37: 1-19.

Kristeva, Julia (1994), Le temps sensible: Proust et l'expérience littéraire. Paris: Gallimard.

- (1989), Étrangers à nous-mêmes. Paris: Fayard.

Kymlicka, Will (2010), 'The rise and fall of multiculturalism? New debates on inclusion and accommodation in diverse societies', in S. Vertovec \& S. Wessendorf (eds), The Multiculturalism Backlash, European Discourses, Policies and Practices. London and New York: Routledge, 32-50.

- (2007), Multicultural Odysseys: Navigating the New International Politics of Diversity. Oxford: Oxford University Press.

- (2002), Contemporary Political Philosophy. Oxford: Oxford University Press.

- (1995), Multicultural Citizenship. Oxford: Oxford University Press.

Laborde, Cécile (2012), 'Protecting freedom of religion in the secular age', retrieved from http://blogs.ssrc.org/tif/2012/o4/23/protecting-freedom-of-religion-in-thesecular-age.

- (2011), 'Political liberalism and religion: On separation and establishment', Journal of Political Philosophy, 21 (1): 67-86.

- (2008), Critical Republicanism: The Hijab Controversy and Political Theory. Oxford: Oxford University Press.

- (2005), 'Secular philosophy and Muslim headscarves in schools', The Journal of Political Philosophy 13 (3): 305-329.

- (2002), 'On republican toleration', Constellations 9 (2): 167-183.

Lafont, Christina (2009), 'Religion and the public sphere. What are the deliberative obligations of democratic citizenship?', Philosophy \& Social Criticism, 35 (1-2): 127-150.

Langlois, Claude (1996) [1992], 'Catholics and seculars', in P. Nora (ed.), Realms of Memory. New York: Columbia University Press. Translated from the French by A. Goldhammer.

Latour, Bruno (2004), 'La République dans un foulard', Le Monde, 18 January, retrieved from www.gauches.net/articles507.html.

Lazreg, Marnia (2011), 'Mirror mirror tell me who I am: Colonial empire and French identity', Public Culture 23 (1): 177-189.

Leezenberg, Michiel (2008), Islamitische filosofie: Een geschiedenis. 2nd revised edition. Amsterdam: Bulaaq.

Lentin, Alana \& Gavan Titley (2011), The Crises of Multiculturalism: Racism in a Neoliberal Age. London: Zed Books. 
Lerner, Lawrence Scott (2001), 'Beyond Grégoire: A third discourse on Jews and the French', Modern Judaism 21: 199-215.

Levitt, Peggy \& Mary Waters (2002), The Changing Faces of Home: The Transnational Lives of the Second Generation. New York: Russell Sage Foundation.

Levy, Jacob (200o), A Multiculturalism of Fear. New York: Oxford University Press.

Lorcerie, Francoise (ed.) (2005), La politisation du voile: L'affaire en France, en Europe et dans le monde arabe. Paris: L'Harmattan.

Lucassen, Leo (2005), The Immigrant Threat: The Integration of Old and New Migrants in Western Europe since 1850. Urbana \& Chicago: University of Illinois Press.

Luhmann, Niklas (1997), Die Gesellschaft der Gesellschaft. Frankfurt am Main: Suhrkamp.

- (1995), Soziologische Aufklärung 6: Die Soziologie und der Mensch. Opladen: Westdeutscher Verlag.

Maclure, Jocelyn \& Charles Taylor (2011), Secularism and Freedom of Conscience. Harvard: Harvard University Press.

Mahmood, Saba (2005), Politics of Piety: The Islamic Revival and the Feminist Subject. Princeton: Princeton University Press.

Mak, Geert (2005), Gedoemd tot Kwetsbaarheid. Amsterdam and Antwerp: Atlas.

Malik, Kenan (2011), 'A Merkel Attack on Multiculturalism', retrieved from www.eurozine.com/articles/2011-02-21-malik-en.html.

Mamdani, Mahmood (2004), Good Muslim, Bad Muslim: America, the Cold War and the Roots of Terror. Pantheon, New York.

March, Andrew (2009), Islam and Liberal Citizenship: The Search for an Overlapping Consensus. Oxford: Oxford University Press.

Markell, Patchen (2003), Bound by Recognition. Princeton: Princeton University Press.

Marrus, Michael R. (1971), The Politics of Assimilation: A Study of the French Jewish Community at the Time of the Dreyfus Affair. Oxford: Clarendon Press.

Marsden, Magnus (2005), Living Islam: Muslim Religious Experience in Pakistan's North-West Frontier. Cambridge: Cambridge University Press.

Marshall, Thomas H. (1965), Class, Citizenship and Social Development. New York: Anchor.

Mathieu, Cécile \& Paul de Hert (2011), 'L'interdiction de la dissimulation du visage dans l'espace public mise en cause par le tribunal de police de Bruxelles. Annotation de Pol. Bruxelles, 26 janvier 2011', Vigiles: Revue du droit de police 17 (3): 92-99.

Maussen, Marcel (2008), Constructing Mosques: Negotiating Islam and Cultural Diversity in France and the Netherlands. Amsterdam: University of Amsterdam.

Maussen, Marcel, Veit Bader \& Annelies Moors (eds) (2011), Colonial and Post-Colonial Governance of Islam: Continuities and Ruptures. Amsterdam: Amsterdam University Press.

Mbembe, Achille (2010), 'Provincializing France?', Public Culture 23 (1): 85-119.

Mendelssohn, Moses (1989) [1783], Schriften über Religion und Aufklärung. Darmstadt: Wissenschaftliche Buchgesellschaft.

Merry, Michael (2013), Equality, Citizenship and Segregation. New York: Palgrave Macmillan.

Mezzadra, Sandro (2006), 'Citizen and subject: A postcolonial constitution for the European Union?', Situations 1 (2): 31-42. 
Michalowski, Inez (2011), 'Required to assimilate? The content of citizenship tests in five countries', Citizenship Studies 15 (6/7): 749-68.

Mill, John Stuart (1912) [1863], Utilitarianism, Liberty and Representative Government. London: Dent.

Modood, Tariq (2010), 'Moderate secularism, religion as identity and respect for religion', The Political Quarterly (81): 4-14.

- (2007), Multiculturalism: A Civic Idea. Oxford: Polity Press.

- (2005), 'Remaking multiculturalism after $7 / 7$ ', retrieved from www.openDemocracy. net.

- (1998), 'Anti-essentialism, multiculturalism and the "recognition" of religious groups', The Journal of Political Philosophy 6 (4): 378-399.

Modood, Tariq \& Nasar Meer (2008), 'The multicultural state we're in: Muslims, "multiculture" and the civic re-balancing of British multiculturalism'. Political Studies 57: 473-497.

Mogahed, Dalia (2007), 'Beyond multiculturalism versus assimilation, a gallup world poll', Special report on the Muslim world, retrieved from http://media.gallup.com/ muslimwestfacts/PDF/londonbrieffullo41307.pdf.

Mookherjee, Monika (2010), 'Postcolonial multiculturalism', in D. Ivison (ed.), The Ashgate Research Companion to Multiculturalism. Farnham and Burnington: Ashgate.

Moors, Annelies (2011), 'Colonial traces? The (post-)colonial governance of Islamic dress: Gender and the public presence of Islam', in M. Maussen, V. Bader \& A. Moors (eds), The Colonial and Post-colonial Governance of Islam. Amsterdam: Amsterdam University Press, 135-155.

Morey, Peter \& Amina Yaqin (2011), Framing Muslims: Stereotyping and Representation after 9/11. Cambridge (MA) \& London: Harvard University Press.

Namer, Gérard (1994), 'Épilogue', in Les cadres sociaux de la mémoire. Paris: Albin Michel.

Nederveen Pieterse, Jan (2007), Ethnicities and Global Multiculture: Pants for an Octopus. Lanham: Rowman and Littlefield.

Nicolet, Claude (1994) [1982], L'idée Républicaine en France (1789-1924). Paris: Gallimard.

Noiriel, Gérard (2007), Immigration, antisémitisme et racisme en France (xIxe-xxe siècle) : Discours publics, humiliations privées. Paris: Fayard.

- (2002), 'Petite histoire de l'intégration à la française', retrieved from www.mondediplomatique.fr/2002/01/noiriel/15983.

- (1992a), Population, immigration et identité nationale en France, XIXe-Xxe siècle. Paris: Hachette.

- (2001), Etat, nation et immigration: Vers une histoire du pouvoir. Paris: Belin.

- (1996a) [1989], The French Melting Pot: Immigration, Citizenship and National Identity. Minneapolis: University of Minnesota Press.

- (1996b) [1992], 'French and foreigners', in P. Nora (ed.), Realms of Memory. New York: Columbia University Press, 145-181. Translated from the French by A. Goldhammer.

- (1992b), 'Français et étrangers', in P. Nora (ed.), Les lieux de mémoire. Paris: Gallimard, 276-319.

Noiriel, Gérard \& Stéphane Beaud (2004), 'Les nouveaux parias de la République', Le Monde, 19 February, retrieved from www.ac-versailles.fr/PEDAGOGI/ses/themes/ equite/beaud_noiriel.html. 
- (1991), 'Penser l'intégration des immigrés', in P.A. Taguieff (ed.), Face au racisme II. Paris: Éditions de la Découverte, 261-282.

- (1989), 'L'assimilation: Un concept en panne', Revue Internationale d'action communautaire /International Review of Community 21: 63-76.

Nora, Pierre (ed.) (1996) [1992], Realms of Memory. New York: Columbia University Press. Translated from the French by A. Goldhammer.

Nordmann, Charlotte (ed.) (2004), Le Foulard Islamique en Questions. Paris: Éditions Amsterdam.

Nordmann, Charlotte and Jérôme Vidal (2004), 'La République à l'épreuve des discriminations', in Le Foulard Islamique en Questions. Paris: Éditions Amsterdam, 5-14.

Norton, Anne (2011), 'On the Muslim question', in M. Mookherjee (ed.), Democracy, Religious Pluralism and the Liberal Dilemma of Accommodation. Dordrecht: Springer, 65-77.

Okin, Susan (1999), Is Multiculturalism Bad for Women? Princeton: Princeton University Press.

Orgad, Liav (2010), 'Illiberal liberalism: Cultural restrictions on migration and access to citizenship in Europe', American Journal of Comparative Law 58 (1): 53-105.

Ozouf, Mona (1984), L'Ecole de la France: Essais sur la Révolution, l'utopie et l'enseignement. Paris: Gallimard.

Parekh, Bhiku (200o), Rethinking Multiculturalism. London: Macmillan.

- (1999,) 'A varied moral world', in J. Cohen, M. Howard \& M. Nussbaum (eds), Is Multiculturalism Bad for Women? Princeton: Princeton University Press, 69-76.

- (1994), 'Decolonizing liberalism', in A. Shtromas (ed.), The End of 'Isms'? London: Blackwell, 85-105.

Pena-Ruiz, Henri (2003), Qu'est-ce que la laïcité? Paris: Gallimard.

Pétition Elle (2003), 'Droit des femmes et voile islamique: Elle s'engage: Notre appel à Monsieur le Président Jacques Chirac, Président de la République', Le Monde, 9 December.

Phillips, Anne (2007), Multiculturalism without Culture. Princeton: Princeton University Press.

Poliakov, Léon (1981) [1955], Histoire de l'antisémitisme 2: L'âge de la science. Paris: Calmann-Lévy.

Poulat, Émile (2003), 'Les bagarres qu'on a pour le voile, on les a eues pour les filles qui venaient en pantalon', Le Monde, 13 December, retrieved from www.lemonde.fr/txt/ article/o,1-o@2-3224,36-345686,o.html.

Poulet, Georges (1964), L'espace Proustien. Paris: Gallimard.

Povinelli, Elizabeth (2011), 'Neoliberalism and multiculturalism: The deeply woven kinship between two seemingly disparate ideologies', American Academy, Der Tagesspiegel, 9 September, $\mathrm{nr} 21$ 091, page B3.

Prins, Baukje (2004), Voorbij de onschuld: Het debat over integratie in Nederland. $2^{\text {nd }}$ ed. Amsterdam: Van Gennep.

Prins, Baukje \& Sawitri Saharso (2008), 'In the spotlight: A blessing and a curse for immigrant women in the Netherlands', Ethnicities 8: 365-386.

Probst Solomon, Barbara (2000), 'Citizen Proust: On politics and race', in B. Probst Salomon (ed.), The Reading Room: Writing of the Moment. Retrieved from http:// internationalpsychoanalysis.net/wp-content/uploads/2009/11/SolomonProust.pdf. 
Prodolliet, Simone (2003), 'Assimilation. Ein fragwürdiger Rückgriff auf ein überholtes Konzept', Impressum 1: 24-26.

Proust, Marcel (1996), In Search of Lost Time. Six volumes. Revised by D.J. Enright (ed.), London: Vintage. Translated from the French by C.K. Scott-Moncrieff \& T. Kilmartin.

- (1987-1989), À la recherche du temps perdu. 4 volumes. Jean-Yves Tadié (ed.). Paris: Gallimard, Bibliothèque de la Pléiade.

- (1987b), Du côté de chez Swann. B. Brun \& A. Herschberg-Pierrot (eds), Paris: Garnier Flammarion.

- (1987c) Sodome et Gomorrhe. E. Eels-Ogée (ed.), Paris: Garnier Flammarion.

- (1985) Jean Santeuil. Middlesex and New York: Penguin Books. Translated from the French by G. Hopkins.

- (1971) [1952], Jean Santeuil. Paris: Gallimard, Bibliothèque de la Pléiade.

- (1970-1993), Correspondance, 21 volumes, édition présentée, établie et annotée par P. Kolb. Paris: Plon.

Raczymow, Henri (1993), Bloom et Bloch. Paris: Gallimard.

Rancière, Jacques (2006), 'Democracy, representation, republic', Constellations 13 (3): 297-307.

Raulet, Gérard (1999), Apologie de la citoyenneté. Paris: Cerf.

Rawls, John (1999), The Law of Peoples. Harvard: Harvard University Press.

- (1993), Political Liberalism. New York (NY): Columbia University Press.

Reinach, Théodore (1901) [1884], Histoire des Israélites: Depuis la ruine de leur indépendance jusqu'à nos jours. Paris: Hachette.

Renaut, Alain \& Alain Touraine (2005), Un débat sur la laïcité. Paris: Stock.

Renouvier, Charles (1896), Philosophie analytique de l'histoire. Tome IV, Paris.

Ricœur, Paul (1990) [1992], Soi-même comme un autre. Paris: Éditions du Seuil. Translated from the French by K. Blamey. [Oneself as another. Chicago: Chicago University Press.]

- (1985) [1984], Time and Narrative II. Chicago and London: The University of Chicago Press. Translated from the French by K. McLaughlin \& D. Pellauer.

Rodriguez-Garcia, Dan (2010), 'Beyond assimilation and multiculturalism: A critical review of the debate on managing diversity', Journal of International Migration and Integration / Revue de l'intégration et de la migration internationale 11 (3): 251-271.

Rorty, Richard (1991) [1985], 'Texts and lumps', in Objectivity, Relativism, and Truth. Philosophical Papers. Vol. 1. Cambridge: Cambridge University Press, 78-92.

Rosello, Mireille (2007), 'Laïcité', grammar, fable: Secular teaching of secularism', Postcolonial Studies, 10 (2): 153-169.

Rosen, Elisheva (1995), 'Littérature, autofiction, histoire: l'Affaire Dreyfus dans À la recherche du temps perdu', Littérature 100: 64-80.

Rosenthal, Irena (2012), Democracy and Ontology: An Agonic Encounter between Political Liberalism, Foucault and Psychoanalysis. Amsterdam: vu University.

Roy, Olivier (2005), La laïcité face à l'islam. Paris: Éditions Stock. Translated as Secularism confronts Islam, New York: Columbia University Press (2007).

- (2004) [2002], Globalised Islam: The search for a new Ummah. London: Hurst \& Co.

Rumbaut Rubén (1997), 'Paradoxes (and orthodoxies) of assimilation', Sociological Perspectives 40 (3): 483-511.

Rushdie, Salman (1989), The Satanic Verses. London: Picador. 
Saharso, Sawitri (1992), Jan en alleman: Etnische jeugd over etnische identiteit, discriminatie en vriendschap. Utrecht: Van Arkel.

Said, Edward (1995) [1978], Orientalism. London: Penguin.

Salins, Peter (1997a), 'Assimilation, American Style', retrieved from http://reason.com/ archives/1997/02/o1/assimilation-american-style.

- (1997b), Assimilation, American Style. New York: Basic Books.

Schain, Martin (1999), 'Minorities and immigrant incorporation in France', in C. Joppke \& S. Lukes (eds), Multicultural Questions. Oxford: Oxford University Press, 199224.

Schechter, Ronald (2003), Obstinate Hebrews: Representations of Jews in France, 17151815. Berkeley and Los Angeles: University of California Press.

Scheffer, Paul (2000), 'Het multiculturele drama', NRC Handelsbad, 29 January.

Schinkel, Willem (2010), 'The virtualisation of citizenship', Critical Sociology 36 (2): 265283.

- (2007), Denken in een tijd van sociale hypochondrie: Aanzet tot een theorie voorbij de maatschappij. Kampen: Klement.

Schinkel, Willem \& Friso van Houdt (2010), 'The double helix of cultural assimilationism and neo-liberalism: Citizenship in contemporary governmentality', British Journal of Sociology 61 (4): 696-715.

Schnabel, Paul (1999), De multiculturele illusie: Pleidooi voor aanpassing en assimilatie. Forum: Utrecht.

Schulte Nordholt, Annelise (2002), 'Henri Raczymov entre Proust et Flaubert', Neophilologus. 86: 363-385.

Scott, Joan Wallach (2011), 'Review of "Can Islam Be French? Pluralism and Pragmatism in a Secularist State" by John R. Bowen and "Passive Revolution: Absorbing the Islamic Challenge to Capitalism" by Cihan Tugal', American Ethnologist 38: 184-187.

- (2007), The Politics of the Veil. Princeton and Oxford: Princeton University Press.

sCP/wODC/CBs (2005), Jaarrapport Integratie. Retrieved from www.scp.nl/publicaties/ boeken/9037702376/Jaarrapport_Integratie_2005.pdf.

Seligman, Adam (2005), 'Secularism, liberalism and the problem of tolerance: The case of the USA', retrieved from http://histoire-sociale.univ-parisı.fr/Collo/Migrations/ Seligman.pdf.

Sen, Amartya (2006a), Identity and Violence: The Illusion of Destiny. New York: Norton and Company.

- (2006b), 'The uses and abuses of multiculturalism: Chili and liberty', The New Republic 27 (2), retrieved from http://www.pierretristam.com/Bobst/library/wf-58.htm.

Shachar, Ayelet (2001), Multicultural Jurisdictions. Cambridge: Cambridge University Press.

Shepard, Todd (2006), The Invention of Decolonisation: The Algerian War and the Remaking of France. Ithaca and London: Cornell University Press.

Shoohan, Yasemin \& Riem Spielhaus (2010), 'The concept of the Muslim enemy in the public discourse', in J. Cesari (ed.), Muslims in the West after 9/11: Religion, Politics and Law. London and New York: Routledge, 198-228.

Sieg, Ulrich (1989), 'Die Verjudung des deutschen Geistes, ein unbekannter Brief Martin Heideggers (2 October 1929)', Die Zeit, 29 December.

Silberman, Roxane, Richard Alba, \& Irène Fournier (2007), 'Segmented assimilation in France? Discrimination in the labor market against the second generation', Ethnic and Racial Studies 30: 1-27. 
Silverman, Max (2007), 'The French republic unveiled', Ethnic and Racial Studies 30: 4, 628-642.

Simon, Patrick \& Valéry Sala Pala (2010), 'We're not all multiculturalists yet: France swings between hard integration and soft anti-discrimination', in S. Vertovec \& S. Wessendorf (eds), The Multiculturalism Backlash, European Discourses, Policies and Practices. London and New York: Routledge, 92-111.

Sluiter, Ineke (2005), Maken en Breken: Over taal, identiteit en minderheden. Leiden: Diesrede. Retrieved from www.nieuws.leidenuniv.nl/contents_docs/diesrede_sluiter.pdf.

Soloveitchik, Haym (1994,) 'Rupture and reconstruction: The Transformation of contemporary orthodoxy', Tradition 28 (4). Retrieved from www.opensourcejudaism. com/transformationoforthodoxy.htm.

Soysal, Yasemin (1994), Limits to Citizenship. Chicago: University of Chicago Press.

Spijkerboer, Thomas, (2007), Zeker weten: Inburgering en de fundamenten van het Nederlandse politieke bestel. Den Haag: SDU.

Stasi, Bernard (Commission de réflexion sur l'application du principe de laïcité dans la République) (2003), 'Rapport au Président de la République', retrieved from http:// lesrapports.ladocumentationfrancaise.fr/BRP/034000725/oooo.pdf.

Stendhal (1964) [1831], Le rouge et le noir. Paris: Garnier Flammarion.

Strik, Tineke, Marcia Luiten \& Ricky van Oers (2010), Country report The Netherlands. (Report published in the framework of the INTEC project. Integration and Naturalisation Tests: The New Way to European Citizenship). Nijmegen: Centre for Migration Law.

Swamy Vinay \& Sylvie Durmelat (eds) (2012), Screening Integration: Recasting Maghrebi Immigration in Contemporary France. Lincoln: Nebraska University Press.

Tadié, Jean-Yves (1996), Marcel Proust: Biographie. Vol. I and II. Paris: Gallimard.

Taguieff, Pierre-André (1987), La force du préjugé: Essai sur le racisme et ses doubles. Paris: Gallimard.

Taylor, Charles (2012), 'Interculturalism or multiculturalism?', Philosophy and Social Criticism 38 (4-5): 413-423.

- (2009), 'What is secularism?', in G. Brahm Levey \& T. Modood (eds), Secularism, Religion and Multicultural Citizenship. Cambridge: Cambridge University Press, xixxii.

- (2007), A Secular Age. Cambridge and London: Harvard University Press

- (2003) [2002], Wat betekent religie vandaag? Kapellen: Pelckmans. Translated from the English and introduced by G. Vanheeswijck.

- (1995), 'Lichtung or Lebensform. Parallels between Heidegger and Wittgenstein', in Philosophical Arguments. Harvard: Harvard University Press, 61-78.

- (1994), 'The politics of recognition', in A. Gutmann (ed.), Multiculturalism: Examining the politics of recognition. Princeton: Princeton University Press, 25-75.

Tévanian, Pierre (2004), 'Une loi antilaïque, antiféministe et antisociale', Le Monde Diplomatique, 8 February.

Thomas, Dominic (2007), Black France: Colonialism, Immigration, and Transnationalism. Bloomington: Indiana University Press.

Tissot, Sylvie (2011), 'Excluding Muslim women: From hijab to niqaab, from school to public place', Public Culture 23 (1): 39-46. 
Todd, Emmanuel (1994), Le Destin des Immigrés: Assimilation et Ségrégation dans les Démocraties Occidentales. Paris: Seuil.

Todorov, Tzvetan (1998) [1995], Les abus de la mémoire. Paris: Arléa, 28-41.

Touraine, Alain (2003), 'Membre de la commission Stasi, Alain Touraine raconte sa conversion au principe d'une loi', Le Monde, 18 December.

- (1990), 'Pour une société multiculturelle', Libération, 15 October.

Trigano, Shmuel (2003), La démission de la République: Juifs et Musulmans en France. Paris: Presses Universitaires de France.

- (1982), La République et les juifs. Paris: Presses d'aujourd'hui.

Tully, James (2008), Public Philosophy in a New Key. Volume II, Cambridge: Cambridge University Press.

- (2002), 'The unfreedom of the moderns in comparison to their ideals of constitutional democracy', The Modern Law Review 65 (2): 204-228.

Valenta, Markha (2011), 'Multiculturalism and the politics of bad memories', retrieved from www.opendemocracy.net/markha-valenta/multiculturalism-and-politics-ofbad-memories.

Van Oers, Ricky \& Inez Michalowski (2012), 'How can we categorise and interpret civic integration policies?', Journal of Ethnic and Migration Studies 38 (1): 163-171.

Van Reekum, Rogier \& Jan-Willem Duyvendak (2011), 'Running from our shadows: The performative impact of policy diagnoses in Dutch debates on immigrant integration'. Unpublished research paper.

Vasta, Ellie (2007), 'From ethnic minorities to ethnic majority policy: Multiculturalism and the shift to assimilationism in the Netherlands', Ethnic and Racial Studies 30 (5): 713-740.

Vatter, Miguel (ed.) (2011), Crediting God: Sovereignty and Religion in the Age of Global Capitalism. Oxford: Oxford University Press.

Vertovec, Steven \& Susanne Wessendorf (2010), 'Introduction: Assessing the backlash against multiculturalism in Europe', in S. Vertovec \& S. Wessendorf (eds), The Multiculturalism Backlash: European Discourses, Policies and Practices. London and New York: Routledge, 1-31.

Vertovec, Steven \& Susanne Wessendorf (eds) (2010), The Multiculturalism Backlash: European discourses, policies and practices. London and New York: Routledge.

Vidal, Jerôme (2007), 'Gérard Noiriel et la République des Intellectuels'. Retrieved from http://jeromevidal.blogspot.com/2007/11/grard-noiriel-et-la-rpublique-des.html.

Vink, Maarten (2007), 'Dutch “multiculturalism” beyond the pillarisation myth', Political Studies Review 5: 337-350.

Waldron, Jeremy (1995) [1992], 'Minority cultures and the cosmopolitan alternative', in W. Kymlicka (ed.), The Rights of Minority Cultures. Oxford: Oxford University Press, 93-121.

Weil, Patrick (2009), 'Why the French laïcité is liberal', Cardozo Law Review 2699-2714.

Williams, Melissa (200o), Voice, Trust and Memory: Marginalized Groups and the Failings of Liberal Representation. Princeton: Princeton University Press.

Williams, Raymond (1961), The Long Revolution. London: Chatto and Windus.

Winter, Elke (2011), 'Immigrants don't ask for self-government: How multiculturalism is (de)legitimized in multi-national societies', Ethnopolitics 10 (2): 187-204. 
Wittgenstein, Ludwig (1984) [1952], Philosophische Untersuchungen. Frankfurt am Main: Suhrkamp.

— (1967), Philosophical Investigations. Oxford: Basil Blackwell.

Young, Iris Marion (2000), Inclusion and Democracy. Oxford: Oxford University Press.

- (1990), Justice and the Politics of Difference. Princeton (NJ): Princeton University Press.

- (1989), 'Polity and group difference: A critique of the ideal of universal citizenship', Ethics 99 (2): 250-274.

Yovel, Yirmiyahu (1998), Dark Riddle: Hegel, Nietzsche, and the Jews. University Park: Pennsylvania State University Press.

Žižek, Slavoj (2010), 'Liberal multiculturalism masks an old barbarism with a human face', retrieved from www.guardian.co.uk/commentisfree/2010/oct/o3/immigration-policy-roma-rightwing-europe.

Zolberg, Aristide (1997), 'Modes of incorporation: Towards a comparative framework', in V. Bader (ed.), Citizenship and Exclusion. London: Macmillan, 139-155.

Zolberg, Aristide \& Long Litt Woon (1999), 'Why Islam is like Spanish: Cultural incorporation in Europe and the United States', Politics and Society 27 (1): 5-38.

\section{Films, songs and television programmes}

Submission Part 1 (2004) Dir. Ayaan Hirsi Ali and Theo van Gogh. Broadcast on 29 August 2004.

Sunshine: Ein Hauch von Sonnenschein (1999) Dir. István Szabó.

La Haine (1995) Dir. Mathieu Kassovitz.

I been in the right place, but it must have been the wrong time. Song by Dr. John from the album In the Right Place (1973).

\section{Remark with regard to quotations from Proust}

In the quotes from In Search of Lost Time, I always also refer to the Pléiade edition of $\grave{A}$ la recherche du temps perdu (after the semi-colon, by simply noting, for example, I, 210). Please find a document with all the French originals referred to in this volume at http://uva.academia.edu/YolandeJansen. 



\section{Index}

Adorno, Theodor W. 117-118, 255, 261, 263-264, 309

Alexander, Jeffrey 21, 23-25, 53, 81, 99$100,109,113,123,184,288-293,297$

Algeria 64, 221-23, 251, 304-305, 307

Amnesty International 229, 280, 284

Anti-Semitism

- Arendt's understanding of 176-181

- in earlier editions of In Search of Lost Time 160-163

- in In Search of Lost Time 137-140, 155-171, 179, 193

- Klug's understanding of 130

Arendt, Hannah 47-48, 105, 117, 131, 176-177, 179, 181, 199

Asad, Talal 16, 27, 35, 44, 54, 98, 203204, 219-223, 234, 239, 248, 276, 281, 286, 303, 306, 308

Assimilation

- and integration 34-38

- and multiculturalism in the Netherlands 36-38, 111

- and the Emancipation of the French Jews 143-150, 170-171

- critical concept of 112-116

- in contemporary French sociohistoire $33,59-83$

- in contemporary sociology and political theory 83-115

- its logic 81-82, 133, 292

- its paradoxes see paradoxes of assimilation

- its precariousness according to Benjamin 255

- Proustian critique of 137-165, 167194, 253-273

- Reinach's definition of 171-173, 176

Autonomy 28, 52, 93, 214-216, 231-232,

$241,249,271,281,289,291$
Bader, Veit 9, 16, 20, 22, 40-42, 44, 5455, 80, 82, 97, 99, 103, 105-106, 108, 197, 218-219, 225, 233-235, 248, 254, 271-272, 286-288, 292-293, 299, 300-301, 308310

Bal, Mieke 57, 132, 268

Balibar, Etienne 6o-61, 72, 82, 126, 197, 238, 307

Banlieues, suburbs 64, 72, 228, 238-239, 240, 242, 264

Barrès, Maurice 63, 153-154, 262, 304

Barthes, Roland 166

Battle of Algiers 223

Baubérot, Jean 41, 140, 196-199, 201, 205, 207, 210, 217, 222, 241-242, 282, 284, 302, 306

Bauboeck, Rainer 9, 22, 28, 37, 78, 95, 99, 101, 105-107, 111, 113, 229, 251, 273274, 282, 289, 293, 300

Bauman, Zygmunt 38, 47, 60, 83, 169, $179,181-182,184,295,304$

Benbassa, Esther 48-49, 72, 117-118, 126, 128, 146, 149-150, 171, 173-175, 191, 201, 227, 304-306

Benign neglect 42

- and difference-blindness see difference-blindness

Benjamin, Walter 11, 49, 55, 117-118, 254-255, 257, 260-264, 270, 309

Bergson, Henri 260, 262-263, 270

Birnbaum, Pierre 39, 48-49, 75, 101, 113, 115, 117, 125-126, 140, 142-145, 147-148, 150, 153-154, 204, 217, 227, 250, 299, 303-305

Bloch (character in Proust) 132, 137, 150-152, 154-155, 157, 160, 162-163, 165, 167-169, 170, 175, 179-181, 184-187, 189, $248,249,259,302,303$ 
Bourdieu, Pierre 34, 60, 73, 238, 250, 255, 294, 299

Bowen, John 9, 27, 40, 44, 77, 197-198, 201, 207, 238, 244, 250, 285, 294, 301, 305-308

Brahm Levey, Geoffrey 41, 42, 44, 129, 218, 225, 234, 286-287

Brown, Wendy 20, 27, 29, 48, 154, 176, 288

Brubaker, Rogers 33, 35, 51-52, 83-84, 88-93, 104, 111, 114-116, 300-301

Ferdinand Buisson 203, 207, 212-213, 215-216, 221-222, 306

Bunzl, Matti 42, 119, 121, 125, 127-128, 280,286

Carens, Joseph 20-21, 37, 87, 103, 229, 288, 300

Catholä̈cité 209

Catholicism 15, 138, 141-140, 144, 146, 153, 156, 160-161, 171-172, 205-206, 208, $210,217,219,221-222,234,256,282$, 301,302

Citizenship

- and denizenship 85

- and postnationalism $84,85,89$

- and the Emancipation of the French Jews 141, 146, 150, 169, 199

- and transnationalism 105-107

- de-ethnicised form of 52, 94-95, 106, 108, 114

- dual 52, 90, 94-95, 105, 107, 112, 114

Class 34, 61, 72, 75, 141, 170, 177, 179, 181, $183-84,186-87,191-92,196,249$

Clermont-Tonnerre $145,148,173$

Communautarisme 15, 63-64, 73, 81, 104, 228-230, 241, 244, 246, 283, 294, 307

- and communitarian multiculturalism 28, 45, 104, 195, 240,245

Connolly, William 55, 128-129, 219-220, 254, 271-272, 286-287

Cruelty 67, 120, 264 - and culture 138, 309

Cultural analysis 57
Cultural memory 17, 120, 127, 165, 175, 185, 191-192, 223, 251, 263, 268

- and assimilation 17, 52, 74-75, 112, $114-116,121,127,132,165,170,253-$ 254, 260-261, 278-279, 289

- and forgetting 114, 254, 266, 268271, 273-274, 309

- Proust's narrative of 165, 185, 251, 253-254, 258, 260-261, 264, 266-275, 278

- role in producing cultural difference $75,121,127,165,175,190$, 192, 274, 277-279, 289

Culture

- as defined by Bonnie Honig 249251

- reified concepts of $26,30,87,299$

Culturalisation 50, 81, 98, 122

- and de-culturalisation 53,173, 247$249,264,283$

De-ethnicised citizenship see citizenship

Deleuze, Gilles 55, 166, 253, 269

Deliberation, deliberative democracy 237, 291-292

Democratic memory 2, 18, 224, 259-260

Democracy

- and memory 185, 262

- and secularism 54

- as demos 205

- or secularism 233, 283

Difference-blindness 20, 42-46, 81, 124, 195, 287, 288

Differentiated citizenship 21, 102, 105

Disassimilation 49, 113, 274

- and the paradoxes of assimilation see paradoxes

Discursive effects of assimilationism 59, 77, 80, 89, 108, 111, 117-118, 122, 130, 206

Dreyfus Affair

- history of 15, 87, 94

- in In Search of Lost Time 92-95, 122-126, 157-160

- in Proust's Jean Santeuil 122-125 
Durkheim, Émile 19, 45, 241, 279

- and Kant 117, 186

- on assimilation 30-33, 64

- on religion in the context of laïcité 177, 193, 217, 224, 234-235, 259

Elias, Norbert 11, 65-67, 79

Emancipation 15, 47, 49, 53, 71, 88, 117$118,124,132,140-142,144,146-147$, 150-169, 171-172, 182-183, 199, 201, 302

Enlightenment 47, 50, 51, 117, 121-122, $165,176,197-198,201,210-211,213,227$, 236, 290, 308

- and enlightened citizens 198, 208

Evenhandedness 103, 287

Experience

- modern experience in Adorno and Benjamin 261-263

Franco-Judaism 46, 121, 124, 142, 199, 227, 305

Foucault, Michel 57, 143, 219

Forgetting 113-114, 121, 254, 258, 265266, 268-274, 278, 283, 309

Framing (and reframing) of cultural diversity $15,17,43-44,50,112,126$, 128, 174, 199, 211, 226-227, 242, 245

Fraser, Nancy 96, 109, 292

Freedom 30, 32-34, 39, 45, 47, 49, 71, 75, $81,85,96,101,136,151,162,198-199$, 202, 204-205, 208, 214, 221-222, 224, 227-228, 230, 232, 237-238, 240, 242$243,280,283,302,309$

- of conscience $37,40,78,92,206$, $228,231,235,237,287$

- of the citizen 52-53, 209

Fundamentalism 33, 39, 235, 297, 308

Gallicanisme as support-and-control of religion 70,191

Gauchet, Marcel 54, 206, 208, 225, 233, 242-243

Gestion of religion 40, 79, 227

Grégoire, Abbé Henri-Baptiste 143-146, $148,150,302$
Guénif-Souillamas, Nacira 23, 64, 305, 307

Habermas, Jürgen 16, 91, 93-94, 214, 235-236, 291

Habit(s) 23, 25, 31, 37, 52, 64, 74, 80, 93, 149, 154-155, 160, 185, 220, 249, 253, 259, 264, 269, 271, 289, 309

Halbwachs, Maurice 262-263

Halévy family, the (Fromental, Généviève, Daniel) 156, 301, 303

Headscarf affairs 10, 15, 16, 38, 40, 45, 54, 64-65, 72, 128, 148, 195-196, 198, 212, 215, 219-223, 228-229, 236-237, 239, 241, 249-251, 280-281, 299, 305-307

Headscarves

- as part of religious practice 198 , 221, 284

- as religious signs 148-150, 281-284

- in relation to beards and wigs in Pre-Revolutionary France 148, 149

Heine, Heinrich 38, 141

Hertzberg, Arthur 147, 276, 302-303

Historical analogies 118

- between the position of Jews and Muslims as minorities in France 118-125, 276

Hodgepodge 87, 98, 283

Honig, Bonnie 249

- her definition of culture 249

Hughes, Edward 9, 118, 131, 133, 301

Hybdridity, 44-45, 76, 87, 110, 131, 229, 297, 299

Huyssen, Andreas 120, 274

Identity politics $27,38-39,64,87,101$, 201, 236, 239, 242-244, 249, 264, 271$272,289,293-294,297,304$ Inassimilability $63-66,73,78,80,276$ Incorporation 5, 15, 22-24, 32-33, 48-49, $52,59,61-63,65,67,69,71-77,79,81$, 92, 98-100, 108, 110, 113, 128, 200, 283 Indigènes de la République 74

Inequality 14, 19, 23, 26-27, 33, 37-38, 54, $72,76,90,96,102-104,107-109,114$, $123,177,183,193,210,234,278,283$, 292-293, 295 
Integration $8,11-12,17,24,26-31,38-39$, $43-44,46,52,55-58,62,64-66,70$, $77-79,82-84,86,89,102-104,115,130$, $132,134,136,138,140,142,144,146$, $148,150,152,154,156,177,194,199,213$, 220, 222, 238, 251, 270, 282-283, 287, 291-293, 305, 307

- as civic integration $13,18,34,37$, 84,277

- integration test(s) 53, 73, 137, 139, $141,143,145,147,149,151,153,155$, $157,159,161,163$

Interculturalism 294

Irony as a response to paradoxes of assimilation in In Search of Lost Time 132-33, 150, 167, 170, 191

Islam 15-18, 30-34, 39-46, 63, 72, 78, 98, 128, 199, 204, 236-239, 245-250, 280, 285,297

- and globalization 245, 249

- and identity politics 36, 45, 244

- its securitisation $43,54,225,239$ 245, 284-286

Islamophobia 118, 119, 123, 126, 129, 130

Jacobinism 91, 142-143, 148-150, 197, $205,207,226,284$

Jewishness $6,47,117,126,130-31,133$, $138,154,169,175-177,199,201,222$

Joppke, Christian 14, 32-35, 37, 51-52, $83-96,101-115,197,229,289,300$

Judaism 47-48, 53, 117, 126, 131, 150, 154, $162-163,171-177,199,201,217-218,234$, 278-279, 305

Kant, Immanuel 106, 172, 204, 212-214, 216-220, 231, 234, 306

Kintzler, Cathérine 215, 305

Klug, Brian 42, 128, 130, 132, 189, 280

Kymlicka, Will 20-21, 28-29, 42-43, 76, 86-88, 99, 102-103, 109, 234-235, 287$288,290,298,300$

Laborde, Cécile 33, 79, 153, 197-199, 206, 208, 230, 234, 282, 286-287, 297, 299, 305,307

\section{Läicité}

- and the 'gestion' of religion, 40, 79

- and the headscarf affairs 40, 148, 195-196, 198, 215-228, 249, 280

- and the production of religion 210-212, 286-287

- as cacophonous concept 197

- as in lä̈cité interiorisée 213

- in the Third Republic 15, 195, 203204, 207, 217, 221, 247, 253, 277

- de combat 197, 201, 207, 227

- Durkheim's view 203, 212-215, 221, 247

- redefined by the Stasi Commission 46, 79, 196, 215, 226230, 237, 250, 298

- Proust on 201, 203, 253

Laicism 15, 54, 140, 198-204, 210-228

- as culture 198, 238

Liberalism 9, 21, 34-35, 79, 86-88, 101, $107,192,197,225-226,228,286,293$,

294, 301

- and multiculturalism 86, 293, 301

- and secularism 41-42, 199

- without secularism 233

Maclure, Jocelyn 54, 198-199, 207-208, $212,231,282,286,310$

Madame de Guermantes (character in Proust) 156, 254-259, 264-267, 273274, 309

Markell, Patchen 47, 184, 279, 304, 310 Marrus, Michael 156, 171, 199, 304

Meer, Nasar 42, 45, 97-98, 288

Melting Pot 24, 32, 46-47, 227-28, 297 - and Franco-Judaism 46-47, 227

Majorities

- as hosts 91,183

- in relation to minorities $15,21-23$, $25,29-30,32-33,45,74-76,88,91,97-$ $99,113,130,149,182,184,276,283$, $287,289,295$

Memory see cultural memory, see democratic memory

Mendelssohn, Moses 172, 204, 217-218, 234 
Metaphor

- and assimilation 134-187, 190-93

- Barthes on metaphor in Proust 132-133

- Deleuze and Benjamin on metaphor and memory 207, 270272, 275, 277

Mill, John Stuart 232, 235

Modernism 18, 46, 50, 53-54, 84, 107, 199, 203, 215-233, 238, 240-251, 253, $261,271,278,283,286,288,304,308$, 310

Modernist dichotomies, binary oppositions 18, 53-54, 82, 152, 199, 201-202, 210, 225, 231-232, 238, 240$241,245,247,251,254,263,286,308$

Modood, Tariq 22, 28, 40-42, 45, 97$98,129,197,206,287-288,308$

Mookherjee, Monika 27, 29, 30, 80, 109, 233, 288, 291-293

Morawska, Ewa 32-35, 51-52, 83-97, 102, $105,109-15,289,300$

Multiculturalism as a project of hope $19,25,53,184$, 281, 195

- bifurcation within $38,43,287-288$

- communitarian see communitarian multiculturalism

- critiques of $24,26,28,30,34,84$, 87,90

- democratic 229

- from above/as a state project 32, 61

- liberal 26-28, 42, 86, 240, 293

- relational 19, 22, 28, 29, 80, 98, 102$105,230,250,289,301$

Neo-Kantianism

- in French intellectual culture today $54,204,208,216$

- in the Third Republic 54, 153, 203204, 277, 306

Neutrality 20, 27, 39, 78,82, 85, 95-115

- as semi-neutrality 182

- cultural 99-100,102

- religious 39, 103, 207-208, 221, 282
Noiriel, Gérard 33, 51, 52, 59-76, 78-79, $80,82,84,88,99,101,104,107,111-116$, $123,126,148,183,197,229,277,297,299$

Nordmann, Charlotte 81, 195, 238, 305

Other, Otherness $37,73,79,122,126$ $127,139,165,176,179,250,278,283$ decaffeinated 293

Ozouf, Mona 143, 153, 217, 284

Paradoxes

- of assimilation, $17-25,31,38,45-50$, $53,55,57,81,113-118,123-125,127$, $132-135,152,154,165,176-177,179$, 201, 253, 255, 278-279

- of the Republican model 38, 50, 123-125

Parekh, Bhiku 28, 94, 104, 232, 235

Perspectivism 155, 159, 160, 162, 274

Philosophy as critical activity, critical theory 55-56, 288-295

Postnationalism 84-85, 89-90, 105, 107

Postcolonial theory 26, 40, 225

Power

- history of 61

- its presence and absence in the secular-religious framework 206, $213,235,245-246,256$

Private-public distinctions 49, 52-53, $86,101,128-129,143,155,177,193,202$, 206, 221, 249, 286

- in relation to problematisation of secular-religious framework, 20 , 129, 155, 286

- problematisation in Proust 125, $155,157-158,163,278$

Protestantism 172-173, 214, 216-218, 247, 282, 283, 306, 308

- and secularism 214-218, 247-250, 282

Proust, Marcel

- and the Dreyfus Affair, 10, 47, 50, $55,57,117,131,133-34,156,158,162$, 174, 176-78, 253-55, 260, 265-66, 273, 280 
- and the paradoxes of assimilation 125, 131-133, 141, 156, $161-162,168,174,180-181,189$

- his narrative of tense pasts and the role of cultural memory and forgetting 254, 265-266, 269-270, $270,273-274$

- on laïcité see Laïcité

Public order/ordre public 54, 205, 221, 237-239, 284-285

Racialisation 46-48, 50, 61, 72, 81, 97, $124,133,154-155,212,299,305$

Racism 14, 15, 18, 24, 27, 32, 38, 40-41, $42,45,71-72,80-81,96,122,126,129$, $176,238,276-278,280,285,305$

Raulet, Gérard 213-214, 217, 222, 306, 308

Reciprocity 291, 294

Reinach, Théodore 53, 171-174, 199, 200, 201, 218

Religion 8-16, 23-27, 31-35, 37-38, 42-43, 46-48, 50-51, 57, 64, 68-72, 75, 85, 96, 104, 111, 119, 135, 139, 142-146, 149, 158, 165-169, 175, 185, 188, 190-220, 222-229, 231-232, 235, 237-244, 246, 248, 264, $267,270,274-281,284,285,291,296$, 299, 301-305, 308-310

- in Proust 156, 165, 168, 170, 176, 203, 253, 278

- governance of 41, 77, 79, 201

- produced by laïcité see laïcité

- support and control of 40, 77, 198

Renouvier, Charles 153, 207-208, 211212

Republic 15, 25, 46, 48, 54, 59, 91, 106, 117-118, 120-125, 140, 143-144, 153-157, 163, 171, 187, 192, 195-198, 200-205, 207, $210,215,217,221,228,245,248,253$, 262, 277, 297, 302, 304, 306

Republicanism 18, 64, 103, 123-125, 141, $152,185,207,278-279,282,295,302$

Revolution 39, 46, 48, 64, 123-124, 138, 140, 142-145, 147-149, 171, 191, 196, 204-205, 211, 243, 262, 302

Revolving doors 10, 165-177, 179, 181-191, $193,277,280-281$
Roy, Olivier 30, 39, 40, 54, 60, 77, 126, 148, 195, 198, 211, 225-227, 245-49, 251, 283, 306, 308

Rules of the game

- in assimiliationism 36, 51, 288-289, 292, 294-295

- in multiculturalism $36,184,289$, 292, 294-295

Rushdie, Salman 15, 16, 27, 59, 60, 70, $76,87,98,195,276,297$

Saint-Loup (character in Proust) 165, 167-168, 177, 180-181, 184-192, 308, 309

Schechter, Ronald 120-121, 125, 142, 145, 276, 302-303

Schinkel, Willem 22-23, 29, 35, 108

Schnabel, Paul 111

Scott, Joan 229, 238

Secular-religious framework, also laïcité-religion framework 54, 64, 125, 165, 198, 203-223, 225-251, 282-287, 292-294

Security 40, 43, 51, 54, 76, 148, 225, 227, 229, 231, 233, 235-239, 241, 243, 245, $247,249,251,253,284,299$

- and securitisation 43, 46, 51, 54, 81, 95, 98, 112, 225, 238, 245, 280, 285, 287,305

Segregation 14, 19, 24, 32, 55, 71-72, 81, 83, 88-90, 96-97, 108-109, 113, 179, 181, $182,240,300$

- of the Jews in the 19th century 179-182

Shachar, Ayelet 44, 82, 99, 104, 105, 230, 301

Silverman, Max 38, 48, 118, 123-125, 298 Stasi Commission 46, 54, 79, 196, 215, 220-242, 250, 258, 284, 307

Swann (character in Proust) 55, 132, 137, 141, 160-163, 177, 254-259, 264-268, 273-274

\section{Taqiyya 285}

Taylor, Charles 10, 20, 28, 41, 54, 198199, 207-208, 216, 231, 235-236, 242, $282,294,308,310$ 
Tense pasts 253

Third Republic 15, 46, 54, 117-118, 120, $121,125,140,153,156,171,192,195,200$, 203-204, 207, 210, 212, 217, 221-222, $233,247,253,277,302,306$

Treason

- fear of treason produced by paradoxes of assimilation 179 - in Proust 47, 48, 131, 150

Trigano, Shmuel 48, 123-125, 298

Tradition 26, 38-39, 45, 66, 140, 144, 152-153, 169, 174, 190, 192, 200, 206, 209, 211, 230, 236, 245, 262-263

Todorov, Tzvetan 120-121

Touraine, Alain 10, 30, 54, 196, 228-229, 240-243, 307

Transnationalism 19, 22, 29, 30, 77, 8385, 91-92, 96, 105-107, 200, 288-290

Tully, James 99, 233, 290, 292
Uprootedness 60, 70, 146, 153-155, 246, $248-249,262$

Vidal, Jérôme 73, 81, 101, 195, 238, 305

Waldron, Jeremy 78, 87

Wilders, Geert 285

Wittgenstein, Ludwig 119, 219, 248, 304, 309

Young, Iris Marion 21, 55, 99, 102 Yovel, Yirmiyahu 127

Žižek, Slavoj 29, 286, 293

Zolberg, Aristide 78, 100 



\section{Other IMISCOE Research titles}

Marlou Schrover and Deidre M. Moloney (eds)

Gender, Migration and Categorisation: Making Distinctions between Migrants in Western Countries, 1945-2010

2013 ISBN 9789089645739

Birgit Glorius, Izabela Grabowska-Lusinska and Aimee Kuvik (eds)

Mobility in Transition: Migration Patterns after EU Enlargement

2013 ISBN 9789089643926

Joan Font and Mónica Méndez (eds)

Surveying Ethnic Minorities and Immigrant Populations: Methodological

Challenges and Research Strategies

2013 ISBN 9789089645432

Marek Okólski (ed.)

European Immigrations: Trends, Structures and Policy Implications

2012 ISBN 9789089644572

Ulbe Bosma (ed.)

Post-Colonial Immigrants and Identity Formations in the Netherlands 2012 ISBN 9789089644541

Christina Boswell and Gianni D’Amato (eds)

Immigration and Social Systems: Collected Essays of Michael Bommes

2012 ISBN 9789089644534

Maurice Crul, Jens Schneider and Frans Lelie (eds)

The European Second Generation Compared: Does the Integration Context Matter? 2012 ISBN 9789089644435

Bram Lancee

Immigrant Performance in the Labour Market: Bonding and Bridging Social Capital

2012 ISBN 9789089643575

Julie Vullnetari

Albania on the Move: Links between Internal and International Migration

2012 ISBN 9789089643551

Blanca Garcés-Mascareñas

State Regulation of Labour Migration in Malaysia and Spain: Markets, Citizenship and Rights

2012 ISBN 9789089642868 
Albert Kraler, Eleonore Kofman, Martin Kohli and Camille Schmoll (eds)

Gender, Generations and the Family in International Migration

2012 ISBN 9789089642851

Giovanna Zincone, Rinus Penninx and Maren Borkert (eds)

Migration Policymaking in Europe: The Dynamics of Actors and Contexts in Past and Present

2011 ISBN 9789089643704

Michael Bommes and Giuseppe Sciortino (eds)

Foggy Social Structures: Irregular Migration, European Labour Markets and the Welfare State

2011 ISBN 9789089643414

Peter Scholten

Framing Immigrant Integration: Dutch Research-Policy Dialogues in Comparative Perspective

2011 ISBN 9789089642844

Liza Mügge

Beyond Dutch Borders: Transnational Politics among Colonial Migrants, Guest Workers and the Second Generation

2O10 ISBN 9789089642448

Rainer Bauböck and Thomas Faist (eds)

Diaspora and Transnationalism: Concepts, Theories and Methods

2O1O ISBN 9789089642387

Cédric Audebert and Mohamed Kamel Dorai (eds)

Migration in a Globalised World: New Research Issues and Prospects

2010 ISBN 9789089641571

Richard Black, Godfried Engbersen, Marek Okólski and Cristina Pantîru (eds) A Continent Moving West? EU Enlargement and Labour Migration from Central and Eastern Europe

2O1O ISBN 9789089641564

Charles Westin, José Bastos, Janine Dahinden and Pedro Góis (eds)

Identity Processes and Dynamics in Multi-Ethnic Europe

2010 ISBN 9789089640468

Rainer Bauböck, Bernhard Perchinig and Wiebke Sievers (eds)

Citizenship Policies in the New Europe: Expanded and Updated Edition

2009 ISBN 9789089641083 
Gianluca P. Parolin

Citizenship in the Arab World: Kin, Religion and Nation-State

2009 ISBN 9789089640451

Maurice Crul and Liesbeth Heering (eds)

The Position of the Turkish and Moroccan Second Generation in Amsterdam and

Rotterdam: The TIES Study in the Netherlands

2008 ISBN 9789089640611

Marlou Schrover, Joanne van der Leun, Leo Lucassen and Chris Quispel (eds)

Illegal Migration and Gender in a Global and Historical Perspective

2008 ISBN 9789089640475

Corrado Bonifazi, Marek Okólski, Jeannette Schoorl and Patrick Simon (eds)

International Migration in Europe: New Trends and New Methods of Analysis

2008 ISBN 9789053568941

Ralph Grillo (ed.)

The Family in Question: Immigrant and Ethnic Minorities in Multicultural Europe 2008 ISBN 9789053568699

Holger Kolb and Henrik Egbert (eds)

Migrants and Markets: Perspectives from Economics and the Other Social Sciences 2008 ISBN 9789053566848

Veit Bader

Secularism or Democracy? Associational Governance of Religious Diversity 2007 ISBN 9789053569993

Rainer Bauböck, Bernhard Perchinig and Wiebke Sievers (eds)

Citizenship Policies in the New Europe

2007 ISBN 9789053569221

Rainer Bauböck, Eva Ersbøll, Kees Groenendijk and Harald Waldrauch (eds)

Acquisition and Loss of Nationality: Policies and Trends in 15 European Countries

Volume 1: Comparative Analyses

2006 ISBN 9789053569207

Volume 2: Country Analyses

2006 ISBN 9789053569214

Leo Lucassen, David Feldman and Jochen Oltmer (eds)

Paths of Integration: Migrants in Western Europe (1880-2004)

2006 ISBN 9789053568835 
Rinus Penninx, Maria Berger and Karen Kraal (eds)

The Dynamics of International Migration and Settlement in Europe: A State of the Art

2006 ISBN 9789053568668

\section{IMISCOE Textbooks}

Marco Martiniello and Jan Rath (eds)

An Introduction to International Migration Studies: European Perspectives (Vol. 2) 2012 ISBN 9789089644565

Marco Martiniello and Jan Rath (eds)

Selected Studies in International Migration and Immigrant Incorporation (Vol. 1) 2O10 ISBN 9789089641601 